\title{
Innovation in commercial real estate
}

Citation for published version (APA):

Chegut, A. M. (2013). Innovation in commercial real estate. [Doctoral Thesis, Maastricht University]. Datawyse / Universitaire Pers Maastricht. https://doi.org/10.26481/dis.20131212ac

Document status and date:

Published: 01/01/2013

DOI:

10.26481/dis.20131212ac

Document Version:

Publisher's PDF, also known as Version of record

\section{Please check the document version of this publication:}

- A submitted manuscript is the version of the article upon submission and before peer-review. There can be important differences between the submitted version and the official published version of record.

People interested in the research are advised to contact the author for the final version of the publication, or visit the DOI to the publisher's website.

- The final author version and the galley proof are versions of the publication after peer review.

- The final published version features the final layout of the paper including the volume, issue and page numbers.

Link to publication

\footnotetext{
General rights rights.

- You may freely distribute the URL identifying the publication in the public portal. please follow below link for the End User Agreement:

www.umlib.nl/taverne-license

Take down policy

If you believe that this document breaches copyright please contact us at:

repository@maastrichtuniversity.nl

providing details and we will investigate your claim.
}

Copyright and moral rights for the publications made accessible in the public portal are retained by the authors and/or other copyright owners and it is a condition of accessing publications that users recognise and abide by the legal requirements associated with these

- Users may download and print one copy of any publication from the public portal for the purpose of private study or research.

- You may not further distribute the material or use it for any profit-making activity or commercial gain

If the publication is distributed under the terms of Article $25 \mathrm{fa}$ of the Dutch Copyright Act, indicated by the "Taverne" license above, 


\title{
Innovation \\ in \\ Commercial Real Estate
}

\author{
Andrea Chegut \\ Maastricht University School of Business and Economics \\ Maastricht
}

A thesis submitted for the degree of

Doctor of Philosophy at Maastricht University

December 12, 2013 
All rights reserved. No part of this publication may be reproduced, stored in a retrieval system, or transmitted, in any form, or by any means, electronic, mechanical, photocopying, recording or otherwise, without the prior permission in writing from the author.

ISBN 9789461592842

Printed by Datawyse / Universitaire Pers Maastricht

\section{About the Cover Artist}

Amy Casey is the artist for the artwork on the front and back covers. The image is of a painting, acrylic on panel, entitled 'Steadfast Bunch' and is a part of her 2011 exhibition Boomtown at Zg Gallery. Amy earned her BFA in painting from the Cleveland Institute of Art in 1999, she has shown her work regionally and nationally with solo shows in Cleveland, Chicago, San Francisco and Los Angeles. Her work has been published in the New York Times, New American Paintings, Juxtapoz, Hi Fructose and Elephant Magazine. She enjoyed a fellowship at the Vermont Studio Center and a summer residency at the Fine Arts Work Center in Provincetown, MA- the latter in conjunction with the Ohio Arts Council. She was artist in residence at Zygote Press in 2006 and is currently working there as a Resident Artist. Amy has been awarded two Ohio Arts Council Individual Excellence Awards, the Cleveland Arts Prize as an emerging artist and a grant through CPAC's Creative Workforce Fellowship program. She is represented by Zg Gallery in Chicago. Amy Casey resides in a little blue house in Cleveland.

For more on her work and to view earlier and later collections, please go to: http://www . amycaseypainting.com/index.html

This book was typeset using LTEX. 


\section{Innovation \\ in \\ Commercial Real Estate}

(met een samenvatting in het Nederlands)

\section{DISSERTATION}

to obtain the degree of Doctor at Maastricht University, by the authority of Prof. dr. L.L.G. Soete, Rector Magnificus, in accordance with the decision of the Board of Deans, to be defended in public

on Thursday, December 12th 2013, at 12:00 pm

by

\section{Andrea Chegut}


Promotor:

Prof. dr. Piet M.A. Eichholtz

Co-promotor:

Dr. Nils Kok

Evaluation committee:

Prof. dr. Rob Bauer, Chairman

Prof. dr. David M. Geltner

Prof. dr. Pierre Mohnen 
-To Andre and Marie 



\section{Acknowledgements}

I am so lucky. My PhD has enabled me to live globally, travel internationally, and learn something new everyday. I am very grateful for and humbled by this experience and for all that it has given to me. However, I did not get where I am alone. I was joined in these experiences by many. To which, I am happy and proud to acknowledge an amazing group of people who have contributed to my research and development as an academic, but who have also made this journey enjoyable.

This thesis would not be possible without the guidance and support of my promoter and co-promoter, Piet Eichholtz and Nils Kok. Piet, I feel very fortunate to have had you as a supervisor. Your strategy for supervision and development of $\mathrm{PhDs}$ is so innovative; it is patentable. You are a tough supervisor, but I believe this greatly enhanced the quality and precision of the work. Thank you for this wonderful opportunity. Nils, thank you for setting the tone. You set the bar high in work and in life. It is amazing to be coached and developed by someone as talented as yourself. However, Piet and Nils, I would not have come to you, if it were not for one man, Rob Bauer. Sir, without you this thesis would not have happened. Thank you for recognizing my passion and putting me with the right people to get it done. It has been a great joy being a part of ECCE. What a wonderful institute it is and I am so happy that I could contribute. It is serendipitous that Maastricht University has provided me with two other mentors, Pierre Mohnen and Dennis Bams. Pierre, thank you for our conversations on innovation and technical change in physical capital, it meant a great deal to the conceptual development of this thesis. Dennis, thank you for all our talks on personal development. I greatly appreciate your wisdom, tough questions and coaching moments.

I have continuing gratitude and appreciation for David Geltner. Thank you for hosting me at MIT. In addition, thank you for believing in my ideas, giving extensive feedback and asking numerous questions to refine and enhance them. My time at MIT was incredibly productive and beneficial for research development. I especially enjoyed our weekly mini-think tank sessions with Leighton and Schery, which certainly expanded and enhanced my knowledge of indices and commercial real estate. My time with you has offered me opportunities to meet many new people at MIT, to whom I also owe gratitude for their feedback on the last two chapters of this thesis, namely: Albert Saiz, Bill Wheaton, Schery Bokhari, Thies Lindenthal and Walter Torous. How- 
ever, my time at MIT and ability to seize opportunities would not have been possible without Dennis Yeskey, Lisa Thoma, Karen Kelsey, Maria Vieira and Tricia Nesti. Thank you!

Three chapters of this thesis would not be possible without Bob White of Real Capital Analytics and his amazing Analyst Yi. Thank you so much for providing me with your unconditional support and data since 2009. Also, thank you for joining me on this research journey to explore how innovation is a part of the built environment with your data. Dave and Paul of Geotel, thank you for providing me with amazing data. I really enjoyed learning about telecommunications and networks through your hearts and minds.

I would also like to thank the members (and invited members) of my Corona, who have all, in some way along this path, contributed to my research and development as an academic. Hans Schenk and Bert Scholtens thank you for your early mentorship on my thesis, first paper publication and getting my foot in the door towards a PhD. Dirk Brounen thank you for always doing an excellent job at discussing my papers. You offer interesting insights that others just do not see! Stefanie Kleimeier and Rachel Pownall thank you for your insights on developing as a female academic and interesting research discussions along the way. Peter Schotman thank you for your guidance on the simplest but most important economic questions.

I would also like to thank the past and present colleagues of the Finance Department: George, Jeroen, Oana, Nadja, Arvid, Rogier, Thomas, Sally, Paul, David, Stefan, Pomme, Mukul, Carl and Michael, and certainly our fun newer additions, Judy, Gaby, Wiebke, Omar, Clarissa, Iman, Rogier and Hang. There have been many great discussions and debates at lunch and at coffee over the years, but almost just as important, great food. Thank you for joining in the annual Thanksgiving celebration. You all learned and perfected many traditional American dishes by putting your personal style into them. Every year was better than the previous. I greatly appreciate you all joining along.

Literally, much of my every day would not be possible without the four lovely ladies of the secretariat: Carina, Cecile, Els and Francien. You kept me going everywhere that I needed to go! Thank you for taking care of me, when I am far from home. Thank you to my office mates, Katie, Erkan and Gildas our time together in the office was short, but epic. Great research talks that pushed this work forward. Matteo, simply great research talks, great development talks and 'Austrian' moments. I can't wait to see your name in The Economist. Leonard you are a great friend, but also a great thinker. I love our talks on any subject. They open my mind and change my perspective. Aleks we have had great talks, great conference moments and many laughs about this journey. Anna, girl you are great, what an inspiration. Simone, miss you already, it has been great sharing our office and PhD moments together. Thank you so much for exposing me to the wonders of Köln. 
Although, I have made some new mentors, colleagues and friends in the PhD. I am lucky to have kept some old friends, mentors and colleagues close throughout the years who have been shining lights of encouragement.

I am grateful to everyone at Sherman. Danette, Kevin, Les, Ben, Dave, Brian and Robert, Sherman was an amazing experience, which also enabled this one. Dennis and Hong, thank you for helping me make the right choice about school, you were right.

I started this journey in Amsterdam and many of these people were very supportive of this endeavor who deserve mentioning: Florence de Favitski, Lennart Kleinen, Jill Pisters, Alan van Ramshorst, Mieke Woestenburg, Sem Assink, Aard Bakker, Jephta Dullaart, Ralf Pisters, Olivier Blanson Henkemans and the Blanson Henkemans' clan. Thank you for your support during a great period of this journey.

I am also lucky to have a team of ladies that offer girl power in times of thick and thin. Jessica, our friendship is old school. I love that no matter where I go and what I do you have my back. Thanks for being positive and supportive all the way through and thanks for getting on that plane to share this experience with me. Kelly Petrik, I love how you always keep us together. You are the glue that keeps everyone in place. Thank you for being an ever present friend and supporting me in this process. Yes, I am finally done with school. My dearest "Pal", Nadia, thank you so much for the support over the past years. You are just a great friend, ever supportive and ever present in all of the things that I do. Thank you for coming to see me in the Netherlands and in Boston and thank you for standing by through thick ' $n$ ' thin. Kitten, Courtney, that goes for you too. Thank you for always believing in me, the great talks and epic laughs over the past four years and not to mention your journey to see me here and in Boston. Katie, our friendship is a treasure to me. Thanks for sharing all the doctor moments with me. We started this journey together in Amsterdam and we ended in very similar places. Thank you for always keeping me grounded and healthy! Some other ladies also deserve gratitude for laughs, talks, long distance support and mentoring: Lauren Mulkey, Lisa Waldron, Lindsay Greenwood, Trivette Hatcher and Cathy Woods. Without y'all Charleston (and Boston) would not have been the same. Thank you so much.

Claudio, it was so great to spend our time together here in Maastricht. I think the PhD would not have been the same without you. Thanks for all the supportive moments and keeping my chin up. Melissa, you are my sage, thank you for being so amazing, it brings me excitement for what 'we' will do next. Paulo, you are a great friend and co-author, but more importantly the person that I go to for a great laugh. Thanks for being a P-Nymph and an ever supportive colleague. Lauren, you are my everyday, my family. Thank you for your love and unconditional support even from afar. You are always on my team. I am so very very luck to have you. Also, thank you Nathan and Lauren for always getting on that plane to see me and thanks Deedles for being such a great Mom and taking care of these two. 
My family has been a great sense of joy and recharging when I have returned to Florida. Sam, Kose, Ryan, Sara, Amy, Franny, Joyce and all the kids. Thanks for allowing me to work, even though I was at home. Thanks for understanding the process, being a never ending source of laughs and feeding me the best food ever. Yabo-4-Ever! I love you all. Also, a special thanks to the Bos/Vos family!

I cannot be thankful enough for four women in my life, Grace, Nora, Cousin Kate and Cousin Pat. In my opinion, you all came from strong stock, survivor stock. Your stories and your life have contributed endlessly to mine. Throughout my childhood, it was pointed out to me that I should be as smart as Cousin Kate, as worldly as Cousin Pat, a leader like Aunt Nora, and as gracious and funny as Grace. In many ways, I have been lucky enough to have four mothers. To this day, you pick me up when I am down, remind me of who I am, where I come from and certainly what my potential is. Thank you, thank you, thank you for living your lives so that I could learn from them and live mine.

JWBBVII, the professor and the man. You are a brilliant economist, a tremendous econometrician and an amazing teacher. Thank you for all of our amazing intellectual discussions over the years. However, more importantly, thank you for being a strong partner, companion and friend.

And last, but not least, my father. You are the first economist I ever met. For more reasons than one, I would not be working in this field, if it were not for you. Thank you for all our talks for as long as I can remember about gold, interest rates, mortgages and real estate, it has truly served me well in my development as an economist. I am truly grateful for your support and mentorship throughout my life.

Thank you. 


\section{Contents}

Propositions $\quad$ i

Acknowledgements $\quad$ v

List of Figures $\quad$ xi

List of Tables $\quad$ xiii

1 Introduction $\quad \mathbf{1}$

1.1 London and New York City . . . . . . . . . . . . . . . . 1

1.2 Innovation in the Built Environment . . . . . . . . . . . . . . 4

1.3 Urban Economics Foundations . . . . . . . . . . . 6

1.4 The Economics of Innovation . . . . . . . . . . . . . . . . 7

1.4 .1 Meeting Demand . . . . . . . . . . . . . . 8

1.4 .2 Demand Momentum . . . . . . . . . . . . . 8

1.4 .3 Supply Constraints . . . . . . . . . . . . . . 8

1.4.4 Effort Costs for Product and Process Innovations . . . . . . . . . 9

1.4.5 Short- vs. Long-Run Dynamics . . . . . . . . . . . . . . . 9

1.5 The Value Components of Commercial Real Estate Innovations . . . . . 9

1.5.1 Benchmarking Property Value . . . . . . . . . . . . . . 9

1.5.2 The Value of Green Innovation . . . . . . . . . . . . . . . . . . . . . . . . . . . . . . . .

1.5.3 The Cost of Green Innovation . . . . . . . . . . . . . . . . . 11

1.5.4 The Value of Information Technology Innovation . . . . . . . . . 13

1.6 Innovation in Commercial Real Estate . . . . . . . . . . . . . . . . . 14

2 The London Commercial Property Price Index 15

2.1 Introduction . . . . . . . . . . . . . . . . . . . 15

2.2 Repeat Sales Indices for Commercial Properties . . . . . . . . . . . . . . 17

2.3 Methodology . . . . . . . . . . . . . . . . . 20

2.4 London Data . . . . . . . . . . . . . . . . . . . . 23

2.4 .1 Summary Statistics . . . . . . . . . . . . . . . 26

2.5 Repeat Sales Index Estimation and Performance . . . . . . . . . . . . 28

2.6 London and New York City . . . . . . . . . . . . . . . . 34 
2.7 Conclusion . . . . . . . . . . . . . . . . . . . . . . . . . 39

3 Supply, Demand and the Value of Green Buildings 43

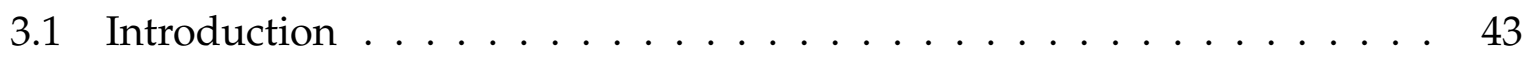

3.2 The UK Market for Green Office Space . . . . . . . . . . . . . . . . . 46

3.2.1 Environmental Certification for Commercial Buildings . . . . . 46

3.2.2 Supply of Green Office Space . . . . . . . . . . . . . . . . 46

3.2.3 Demand for Green Office Space . . . . . . . . . . . . . . . . . 47

3.3 UK Property Market Data . . . . . . . . . . . . . . . . . . . . . . 49

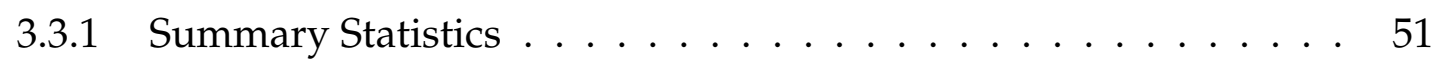

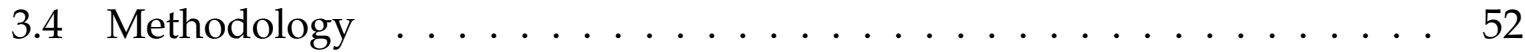

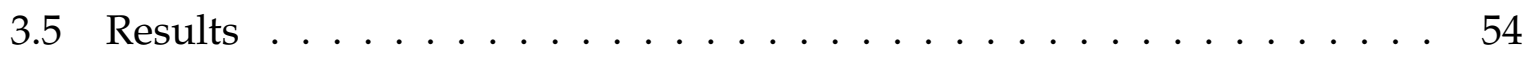

3.5.1 Green Buildings and Rental Rates . . . . . . . . . . . . 54

3.5.2 Green Buildings and Transaction Prices . . . . . . . . . . . 57

3.5 .3 Additional Analysis . . . . . . . . . . . . . . . 60

3.6 Discussion and Conclusion . . . . . . . . . . . . . . . . . . . . 61

4 The Marginal Cost of Green Buildings $\quad 65$

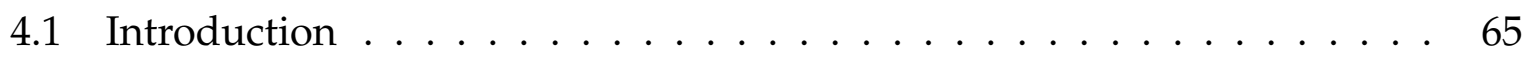

4.2 Green Building Innovation Costs . . . . . . . . . . . . . . . . . 68

4.2 .1 Identifying Green Construction . . . . . . . . . . . . . . . . 69

4.2.2 Cost Expectations of Green Innovation … . . . . . . . 72

4.2.3 The Magnitude of Green Innovation Costs _ . . . . . . . . . 73

4.2.4 Green Development Stage . . . . . . . . . . . . . . . . . . 74

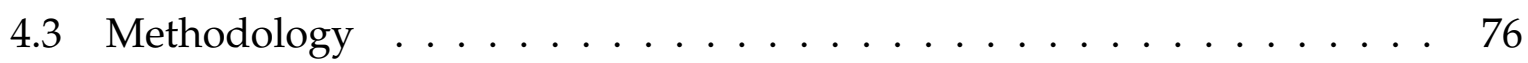

4.4 Construction Cost Data . . . . . . . . . . . . . . . . . . . . . 78

4.4 .1 Summary Statistics $\ldots \ldots \ldots \ldots$

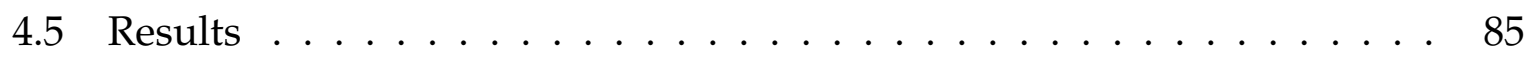

4.5 .1 Green Innovation Costs . . . . . . . . . . . . . . . . . 85

4.5.2 The Magnitude of Green Innovation Costs _ . . . . . . . . . . . 91

4.5.3 The Dynamics of Green Innovation Costs . . . . . . . . . . . . 94

4.6 Discussion and Conclusion . . . . . . . . . . . . . . . . . 98

5 The Value of Real Estate Capital in the Digital Economy 103

5.1 Introduction . . . . . . . . . . . . . . . . . . . . . 103

5.2 Information Technology and Commercial Real Estate . . . . . . . . 108

5.2.1 Getting Connected to the Information Superhighway . . . . . . . 108

5.2.2 Reconfiguring the Commercial Real Estate Stock . . . . . . . . 111

5.2.3 Architectural Innovations . . . . . . . . . . . . . . . . . . . . . 114

5.3 Telecommunications Data . . . . . . . . . . . . . . . . . 117

5.3 .1 Summary Statistics . . . . . . . . . . . . . . . . . . . . . 121 
5.4 Methodology . . . . . . . . . . . . . . . . . . . . . . 124

5.5 Results . . . . . . . . . . . . . . . . . . . . 125

5.5.1 Innovation Value . . . . . . . . . . . . . . . . . . . 125

5.5.2 Telecommunications Competition and Neutral Carrier Facilities . 129

5.6 Discussion and Conclusion . . . . . . . . . . . . . . . . 132

6 Conclusion 135

6.1 Investigating Innovation in Commercial Real Estate . . . . . . . . . 136

6.1 .1 Measurement Matters . . . . . . . . . . . . . . . . . . . . . 136

6.1 .2 Supply Matters . . . . . . . . . . . . . . . . . . . . . . . 137

6.1 .3 Dynamics Matter . . . . . . . . . . . . . . . . . . . . . 137

6.1 .4 Meeting Demand Matters . . . . . . . . . . . . . . . . . . . 138

6.1 .5 Costs Matter . . . . . . . . . . . . . . . . . . . . . . . . . . 139

6.2 Future Research . . . . . . . . . . . . . . . . . . . . . . . . 140

$\begin{array}{ll}\text { References } & 141\end{array}$

$\begin{array}{lr}\text { English summary } & 149\end{array}$

$\begin{array}{ll}\text { Nederlandse samenvatting } & 153\end{array}$

$\begin{array}{ll}\text { Curriculum Vitae } & 155\end{array}$ 



\section{List of Figures}

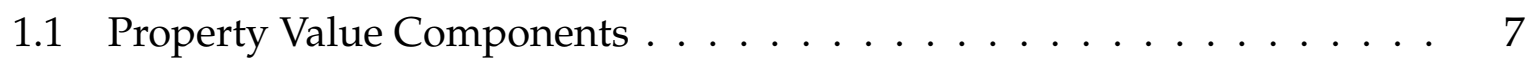

2.1 Market Activity 1996 to $2011 \ldots \ldots \ldots$. . . . . . . . . . . . . . . . . . 24

2.2 Transaction and Repeat Sales Activity for London Commercial Property 1996 to $2011 \ldots \ldots \ldots$

2.3 The London Commercial Property Price Index - Annual Frequency . . . 30

2.4 The London Commercial Property Price Index - Quarterly Frequency . . 31

2.5 The London Commercial Property Price Index - Annual \& IPD London Commercial Property Annual Capital Growth Index _ . . . . . . . . 35

2.6 London and New York City Repeat Sales Indices . . . . . . . . . . . . 39

3.1 Geography of Green Buildings in the UK and London by BREEAM Rating 48

3.2 Marginal Effects of BREEAM-Certified Building Supply . . . . . . . . . 57

4.1 Ecobuild Participants and Exhibitors . . . . . . . . . . . . . . 75

4.2 Mean Construction Costs by BREEAM Certified . . . . . . . . . . . . 82

4.3 Distribution of BREEAM-certified and Non-certified Dependent Variables 83

4.4 Propensity Score Distribution and Area of Common Support . . . . . . 85

4.5 Market Ability for BREEAM-certified Construction . . . . . . . . . . 94

4.6 Green Construction Cost Index . . . . . . . . . . . . . . . . . . . 97

5.1 United States and New York CBSA Land and Sea Fiber-Optic Routes . . 110

5.2 United States and New York CBSA Fiber-Lit Buildings . . . . . . . . . 112

5.3 Google Data Centers: Redevelopment and New Construction . . . . . 116

5.4 United States and New York CBSA Data Centers . . . . . . . . . . . 118 



\section{List of Tables}

2.1 London Repeat Sales Descriptive Statistics _ . . . . . . . . . . . . 27

2.2 Repeat Sales Estimation . . . . . . . . . . . . . . . . . . . . . . . . . 29

2.3 The London Commercial Property Price Indices - Annual \& IPD London Commercial Property Annual Capital Growth Index . . . . . . . . . . 33

2.4 London and New York City Transaction Turnover and Cross-Border Capital Flows . . . . . . . . . . . . . . . 36

2.5 London and New York City Index Descriptives . . . . . . . . . . . 37

2.6 London Quarterly Repeat Sales Index . . . . . . . . . . . . . . . . 42

3.1 Comparison of BREEAM-certified and Non-certified Samples _ . . . . 53

3.2 Office Rents for BREEAM-certified Buildings . . . . . . . . . . . 56

3.3 Office Sales for BREEAM-certified Buildings . . . . . . . . . . . . . . 59

3.4 The Value of Green Certification in US Cities . . . . . . . . . . . . 63

4.1 BREEAM 2008 Offices Scorecard . . . . . . . . . . . . . . . . . . . 69

4.2 Comparison of BREEAM-certified and Non-certified Construction Sam-

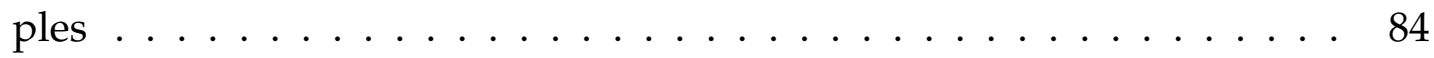

4.3 Construction Costs for BREEAM-certified and Non-certified Buildings . 86

4.4 Marginal Construction Costs for BREEAM-certified and Non-certified

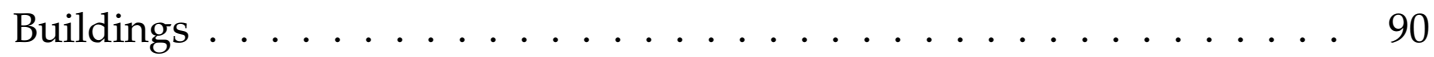

4.5 Construction Costs for BREEAM-certified Projects . . . . . . . . . . . 92

4.6 Construction Costs for BREEAM-certified and Non-certified Buildings:

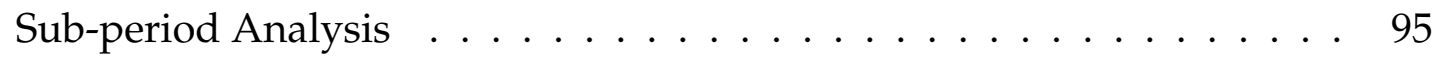

5.1 New York Transaction Prices and Building Characteristics _. . . . . 122

5.2 New York Telecommunications Environment . . . . . . . . . . . . . 123

5.3 New York Buyers and Sellers . . . . . . . . . . . . . . . . . . . . . 123

5.4 New York Data Center Location Risks . . . . . . . . . . . . . . . . . . . 124

5.5 Transaction Prices for Fiber-lit Buildings and Data Centers . . . . . . . 126

5.6 Carrier Competition and Neutrality Impacts on Transaction Prices . . . 130 



\section{Chapter 1}

\section{Introduction}

\subsection{London and New York City: A Brief History of Trade, Innovation and Real Estate}

London owes its birth to its strategic location along the River Thames. Unlike locations further southeast on the Thames Estuary, the width of the river here enabled the construction of a bridge and was just deep enough to allow for the entry of ships. With the estuary's proximity to the North Sea, this resulted in an ideal location for a port to be used by ancient Roman Liburnian rowing ships. Although the port was founded by the Celts, it was expanded and further developed by the Romans. When excavated in the 21st century, archaeologists found the remnants of an early 'world trade center,' which consisted of buildings used for trading and exporting lead, tin and wool. Thus, it was from the turn of the first millennium and for the next 400 years that Londonium would establish itself as a Roman trade center and, indeed, it is in this early Roman real estate, known today as 'The City,' that London would become once again a central place to serve global trade.

New York City, like London, owes its birthplace to its unique geography. In 1609, when Henry Hudson sailed the 'Halve Maen' up the once Mauritis River (Hudson River), he could not have foreseen the significance of exploring the Hudson River Valley and what would one day become New York City. However, his enterprising Dutch employers saw the great potential of Hudson's discovery to meet the demand for mercantile trade (Shorto, 2005). New York City sits at the head of two waterways and as a naturally fortified location, the city is sheltered by two large islands, Long and Staten, and two small islands, Governor and Liberty. And yet, it is still accessible to the Atlantic Ocean. The trading port of New Amsterdam, started in 1624 by the Dutch West India Company, was purchased to establish an incorporated colony that would serve the company's growing trade routes. For the 41 year holding period, the Dutch fleet of approximately 48 ships sailed along the trade routes carrying slaves from the Dutch Caribbean colonies to New Amsterdam and, in turn, otter, beaver, mink and rat 
furs were taken back to Amsterdam proper for trade. The real estate transaction necessary for this endeavor is the now infamous transaction between Peter Minuit and the Lenapes tribe for 60 guilders worth of goods. This transaction would lay the foundation for a trading port stretching from 'Waal Straat' (Wall Street) to the Fort of Amsterdam (Battery Park). In this way, similar to early Roman traders, the Dutch laid the real estate foundation for the future global trade center in New York City (Burrows and Wallace, 1999).

The Dutch tenure of New Amsterdam was relatively long for a financial investment, but ended in a 17th century-style hostile takeover when in 1674 the British seized the colony to unite New York to London. For the next one hundred years, Caribbean sugar, African slaves and Southern tobacco were the main imports and exports of trade. During this period, both London and New York City would develop a vast mercantile economy in the original Roman and Dutch colonies, including ports, warehouses, distribution facilities, refineries, shipyards, insurance houses, and weigh stations (Burrows and Wallace, 1999; Zahedieh, 2010). One example of prime commercial real estate is The Pool of London. From 1700 until 1800, 'The Pool' would increasingly serve as a central place in the global mercantile markets. In the 18th century, it was the largest port in the world, accommodating about 1,335 vessels in 1705, about 1,682 vessels in 1751 and about 3,663 vessels in 1794 (Hobhouse, 1994). Just behind it on Thames Street were sugar, wool, and tin refineries and distribution facilities. Every building met the demand of 18 th century trade.

In London's Georgian Era, the concentration of mercantile and port lands was held in the hands of the aristocracy and the growing mercantile class slowly gained lands through estate acts. When the Industrial Revolution began, London really started to thrive. The change in transportation possibilities and connectivity immediately advanced London's dominance as a global trading post and along with it created large warehouses and factories to support the burgeoning commercial trade. From the steam locomotive to steamboats, London was dubbed a mega-city for its leadership in technical change and commercial adoption of innovations. At this time, real estate for trade started opening up further and from 1800 to 1830 the Docklands were established. These engineered and technically advanced docks were established by Parliament, but given as monopolies to Robert Milligan and Joseph Cotton, who were in charge of the West India Docks and East India Docks, respectively. In the 1840s, the first railroad linked the cities of England and Scotland to the Docklands. The London and Blackwall Railway would travel from the Docks to the Great Western Railway to deliver goods to the rest of England and Whales. In time, every major dock from Blackwall, the Isle of Dogs and The Pool would be served by rail and sea, which served to diffuse more of these refineries and distribution facilties needed for trade.

In the New World Era from the late 1660s to early 1770s, New York City ports serviced far fewer vessels than London, averaging 200 per year over the period (Burrows 
and Wallace, 1999). However, there was notable growth in the port from its early Dutch founding, which was physically concentrated on the Hudson River shores on Manhattan and New Jersey. Notable mercantile estates developed from the service of the ports: the Livingstons, the Morrises, Roosevelts, Van Cortlands, Rhinelanders and the Astors, who combined would grow to own 80 percent of the real estate in the boroughs of New York and in New Jersey. The addition of more commercial activity came with the steamboat. In New York City, the steamboat linked the country side to the harbors on the coast and with the opening of the Erie Canal in 1825, goods could move from The Great Lakes down the Hudson River to New York City. The vast change in navigable waterways would result in New York City taking up more market share of Atlantic trade, which had a large impact on the port of New Orleans in bringing cotton and tobacco from the South. Steamships would chug along, but when the railroads started entering the fray neighborhoods like the Highline and Chelsea on Manhattan's west side would become the bedrock of industrial trade.

However, as the automobile and telephone made their entrance in the 1920s and 1930s, London and New York City went through a period of industrial diversification. Highways moved people and jobs out of the city and to the suburbs, which made central places for commercial activity like ports and harbors less unique. In turn, the production, distribution and service of goods took place in more places with the rise of other commercial centers. Moreover, after World War II, New York City took over London's role as a financial center, and it was not until the mid 1970s and early 1980s that London would rise again. ${ }^{1}$ During this period, it was the continued development of London's financial services sector that led to the rebirth of London, where the largest geographic presence for over-the-counter foreign exchange (FX) trades exists today, in addition to the London Stock Exchange, Lloyds of London Insurance, The Bank of England and over 500 banks. This agglomeration of financial services landed once again in a very central part of London, 'The City,' a prime location for the global financial network. New York City, like London, shifted its trade from serving mercantile and industrial trade to meeting the demands of the financial sector. New York City is home to the New York Stock Exchange and NASDAQ, the two largest stock exchanges by market capitalization. However, the city also has large concentrations of firms in the financial services sector, accountancy, banking, management consultancy, insurance and real estate.

What is clear from the history of London and New York City is that new innovation enables transportation to reach further into the landscape where there is a potential for a new city and commercial real estate venture. Importantly, it is the node- like nature of harbors and railroad stations that supported earlier forms of transportation like ships, steamboats and railroads and contributed to the importance of central places. With

\footnotetext{
${ }^{1}$ http://www.pbs.org/wgbh/americanexperience/features/general-article/ newyork-postwar/.
} 
each subsequent technological advance in transportation more central places would be created within and across cities. The concentration of commercial activity at these nodes meant revenue for their real estate holders and increased value for the lands that could meet the demands of mercantile or industrial trade. This cycle of commercial innovation would repeat until a new technical change in transportation would lead to a new central place for commerce. Over time, in places like London and New York City, this would lead to an ever larger and more diversified commercial stock of buildings.

In the present day, London and New York City have large stocks of commercial real estate. Most of it caters to the demand for offices and retail space, but there are significant stockpiles of industrial stock to serve the ports further down the Thames Estuary and the ports shifted to the five boroughs of New York and New Jersey. There are approximately 88 thousand commercial buildings ${ }^{2}$ in Greater London covering an area of approximately 5,206 $\mathrm{mi}^{2}\left(13,480 \mathrm{~km}^{2}\right)$ and in New York City, including the five boroughs, there are 19,338 commercial buildings that cover an area of $309 \mathrm{mi}^{2}$ (800 $\left.\mathrm{km}^{2}\right){ }^{3}$ Conditional that new land is not made, the commercial real estate stocks of central London and New York City are competing with existing structures and the addition of new commercial developments is not frictionless.

This is important for the future growth of London and New York City. Land supply constraints coupled with a maturation and physical depreciation of the existing stock will require growth from means other than new development. Consequently, future growth and productivity gains for the Greater London and New York City areas should come not from 'more' of what is already in place, but from enhancing the efficiency of the existing commercial real estate products, from improving the quality of redevelopment in the existing stock, or innovating to create new building products to meet a new demand.

\subsection{Innovation in the Built Environment}

London and New York City's history demonstrates that commercial real estate as a form of physical capital is an important component in the production of real goods and services in an economy. It is clear that buildings serve a need, but what is also clear from London and New York's path is that these needs change over time. In turn, commercial real estate's own growth, demand, price dynamics and ownership structure play a significant role in the real economy.

One aspect of economic growth is the development and commercial diffusion of innovations. From the history of London and New York City it becomes clear that with

\footnotetext{
${ }^{2}$ This statistic was compiled using the National Statistics Office Hereditaments Counts Statistics for the 1998 to 2008 period. There were 84,200 commercial properties in 2008. Extrapolating a little less than average growth rate during the financial crisis would lead to roughly 88 thousand hereditaments.

${ }^{3}$ http://www.nyc.gov/html/dof/downloads/pdf/12pdf/nyc_property_tax_fy12.pdf, accessed July 25, 2013
} 
each innovation a new real estate venture is to be had. Unfortunately, there is limited data on the financial performance of adopting new building products and processes and what still remains unclear is how 21st century innovations impact the value of the built environment itself. This is important as society has not stopped innovating in transportation or information technology. However, knowledge on the uptake, valuation, diffusion and decay of modern innovations is needed to decrease the uncertainty around innovative investments. In that way, uncertainty can be transformed into risk and priced more efficiently in the commercial real estate market.

This thesis contributes to our understanding of the creation and valuation of innovations in the built environment, by focusing on the financial performance of innovations in commercial real estate. As properties go through a natural cycle of value and move through the stages of economic, functional and physical obsolescence, there are opportunities for innovators in commercial real estate to capitalize on a site's economic potential. From the brief history of London and New York City, it becomes clear that neighborhoods or cities undergo phases of growth and decline in the long run, and properties within those cities have their own lifecycle too. Some of those dynamics of growth and decline may be explained by the supply and demand of innovative new products, the improvement of building quality and efficiency enhancements of the existing stock. After all, the pecuniary rewards to innovation serve as the carrots to investors. Moreover, the key to development may lie in the incentive for diffusion for innovators. Thus, by looking at the trends and value developments of innovative properties in the modern era, the understanding of value dynamics over the property cycle may be enhanced.

In his 2013 address to the American Economics Association, Edward Glaeser cites numerous booms and busts in land values and new commercial real estate products over more than 200 years of history of the US. In total, he attributed nine booms and busts to uncertainty around the growth of innovative investments. In contrast to previous booms and busts, today a large part of these assets are owned by corporate, private and institutional investors. This is mainly because in the 1970s and 1980s, commercial real estate was seen as a hedging instrument for inflation and a diversification instrument for investors, given its relatively lower risk profile and stable returns. More recently, it has become collateral in securitization and in the wake of the Financial Crisis, real estate serves as collateral in the eyes of the world's central banks. As a result, commercial real estate plays an important role not only as a capital input in real production, but also as an investment asset for the financial sector, the key to hedging inflation risk, perhaps some of the return in a pension fund's portfolio and even as a financing mechanism for carbon abatement. Thus, in contrast to the past 300 years, at present the financial performance of commercial real estate is important not just to a few titans of industry, but to the population at large.

To explore the value dynamics of innovative products in commercial real estate, 
this thesis looks at the economic value of two types of innovations in commercial real estate from the perspective of the innovator. I investigate green and telecommunications services buildings in the contemporary economies of London and New York City. Within multiple chapters the main objective is to assess value through the ex-post financial performance of green building innovations, via their transaction values, rents and costs, and fiber-lit and data center building innovations through their transaction values. In the next sections, I highlight the urban economic framework that many of these chapters are working in and accompany a conceptual framework on innovation. Subsequently, I highlight the main results of each chapter in the thesis and briefly discuss the main contribution of this body of work.

\subsection{Urban Economics Foundations}

Neighborhood succession theory suggests that the real usage value of a property goes through five potential phases over time (Hoover and Vernon, 1962). The first phase is growth. Growth stems mainly from three sources: from economies of scale, from economies of agglomeration as a result of linkages and synergies in an area, and from positive locational externalities as a result of shared demand in the raw inputs of production. The second phase is maturity. As time passes, the maturity of the area sets in, leading to the establishment of the economic base, which can be drawn from the export base and service sectors of the economy. The third phase is binomial: a neighborhood can begin to decline or surge ahead towards more intensive development. In the fourth phase there is potential for decline from the physical, functional or economic obsolescence of a neighborhood's structure. However, in the fifth phase the neighborhood may rise again to rejuvenate and serve a new usage.

Just like each neighborhood has its own economic cycle, so too does each individual property. As properties undergo a common cycle of construction/reconstruction, it is the changes in these components of property value that we are interested in. Figure 1.1, adapted from Geltner, Miller, Clayton, and Eichholtz (2013), depicts the components of property value over time. On the vertical axis are the property value components, where $U$ represents the usage value of the property, $K$ represents the development/redevelopment costs of a building at the time $R, P$ represents the property's price or value as it evolves through time between major reconstructions (Value drift also reflects depreciation from physical, functional and economic factors), $L$ represents the appraisal value of the land and $C$ represents the land redevelopment option value.

The theoretical explanation for what drives $U$ is the property value, comprised of the underlying land and structure value. Property value that serves its highest and best use meets its economic demand. Investors, owners, developers, urban planners and policy makers are interested in what drives the highest and best use of a property 
Figure 1.1: Property Value Components

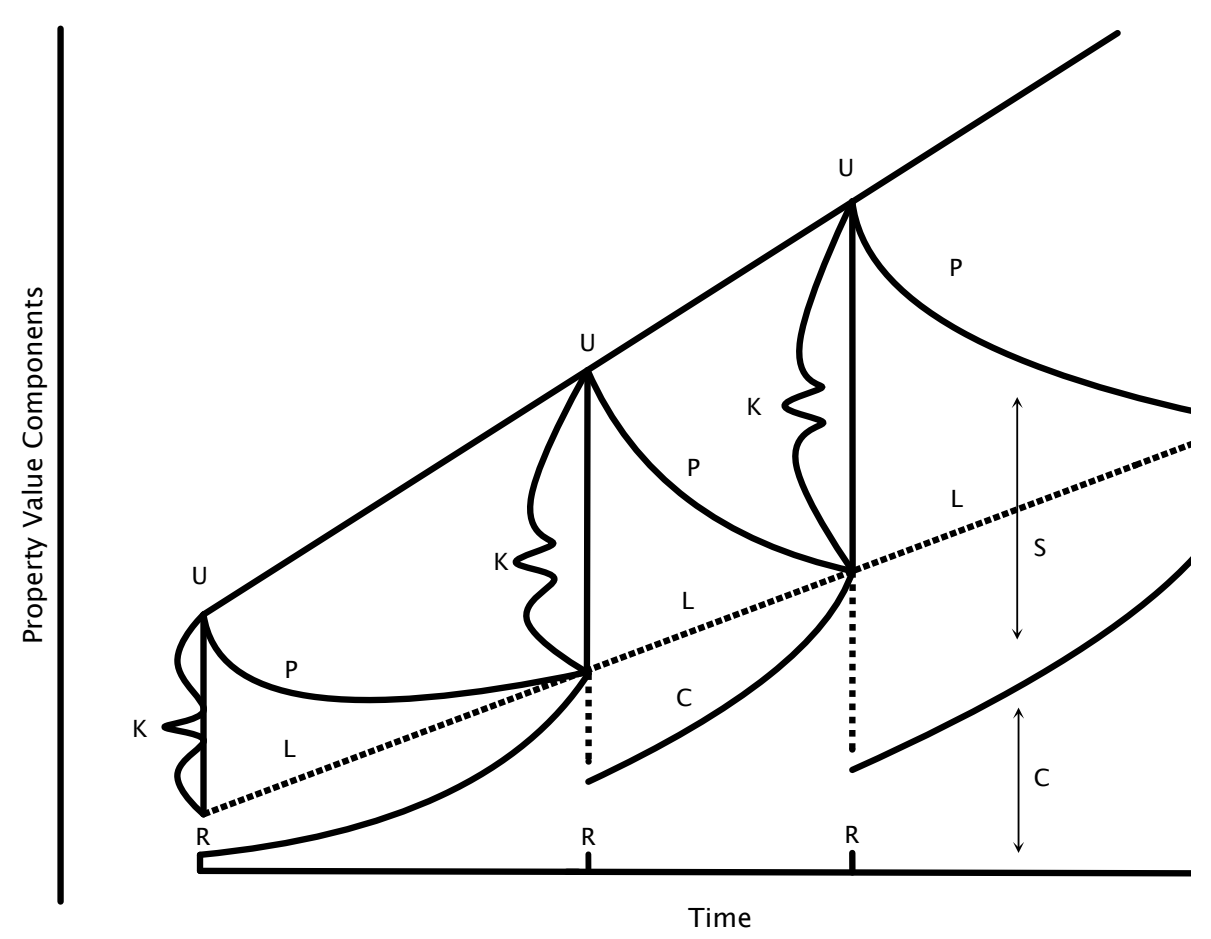

at any given time. Within Figure 1.1, the structure value is not static. Just like in the history of London and New York, the commercial real estate that served harbors and ports went on later to serve other demands. Although the structure value of the commercial properties may have increased over time, the cost of redeveloping the property as well as investing in a property that meets the demand of the current period can be sizeable.

Combined, the neighborhood succession theory and the components of property value depict the the long run economic outcomes of a property. In general, the growth in the property stock takes up available land, which increasingly becomes scarce and leads to a general increase in land values. Over time, this is also true of the structures. As the building stock increases, it becomes more difficult to take the land and develop seamlessly. Theoretically, this is due to land supply constraints where the value of land and the building stock have a slight positive trend. ${ }^{4}$

\subsection{The Economics of Innovation}

It is the formation of cities and geographic concentration that fertilizes the seeds of innovation, nurtures its uptake, finances its growth and provides the landscape for its diffusion. What is less understood is the dynamic process of the built environment

\footnotetext{
${ }^{4}$ Empirically, this has been shown to not be the case in 'real' economic value. Wheaton, Baranski, and Templeton (2009) demonstrates for 86 properties in Manhattan over a 100 year period real estate in the late 200s is worth what it was at the turn of the 19th century. Eichholtz (1997) depicts similar results for properties on the Herengracht canal in Amsterdam for the period between 1628 and 1940.
} 
that steadily changes to provide new building products and construction processes to serve these new demands. To understand this dynamic process of commercial real estate valuation, this thesis links the concepts found in the innovation literature to neighborhood succession theory and the components of property value theory outlined in the previous section. The primary link between these concepts and innovation theory is the idea of usage value $U$. The usage value of a commercial building is a relative value. It is based on a properties ability to serve its highest and best use, the demand for the property and the supply of competing resources. However, at the same time the property value is subject to other factors, such as the competition between 'sites' that are able to serve the same cohort of demand and seek to capitalize on the highest and best use. Here the concept of innovation is useful, since by innovating, the site's owners are able to differentiate supply and better serve (heterogenous) demand.

\subsubsection{Meeting Demand}

Identifying and developing/redeveloping the physical, functional and economic use of a site serves as an important driver for innovation in commercial real estate. A structure can become obsolescent if it fails to remain physically maintained. Physical depreciation stems from a lack of maintenance of the infrastructure of the building. A structure can also become functionally unsound as a result of a lack of technological development. Moreover, the economic use of the structure can go amiss over time, when the demand that it served before is in decline or non-existent. Restoring the physical, functional and economic use of a site to meet new demand creates value.

In many ways this serves as a model for conventional real estate. However, it could also serve as a model to understand general quality improvements and technical change within the built environment. Many of these improvements could be thought of as quality enhancements. Importantly, in the absence of competitors this brief time could serve as a period to garner innovation value.

\subsubsection{Demand Momentum}

The demand for innovative building products is not necessarily instantaneous. The first building may have been built out of necessity or the presence of the innovation embedded within the project may lay latent until enough tenants or capital market participants recognize that the require the innovation. Thus, the demand may not necessarily be linear in time and may possess jumps, which make it difficult (uncertain) for expanding building development. In this way, the first building developers of an innovation may stumble upon innovation value. 


\subsubsection{Supply Constraints}

Innovation thrives on scarcity. Innovators that can supply a scarce product, resource or commodity are rewarded with monopoly rents. There are various methods for protecting these rents in the real economy, including patents and licenses. However, in commercial real estate innovators cannot patent or license building products. Thus, in commercial real estate innovators secure these rents in two ways. First, through the scarcity of suitable sites that can meet the commercial demand of the period. Second, the value of real estate is also driven by the stickiness of supply. Development of sites is not instantaneous. In fact, the development and construction of future sites is a long-run process, which serves as a way to protect rents in commercial real estate.

\subsubsection{Effort Costs for Product and Process Innovations}

Innovation requires effort: research, planning and development. Effort is not costless. Thus, a fundamental change in the process of construction or the redefinition of the construction process to serve a new type of need is likely to be costly. Construction is likely to go through a process innovation by advancing the quality of the materials, labor and capital for construction. In turn, process innovations may result in making the development of commercial real estate buildings more efficient, less wasteful and hopefully less costly. However, construction can also reconfigure to develop new building products. Advances in construction technology can change the type of buildings that are used for commercial activity and develop a more tailored building product for the user.

\subsubsection{Short- vs. Long-Run Dynamics}

The usage value of a property is not static. There are short- and long-run dynamics in meeting demand. However, it is in the short run that the property values within a neighborhood can increase as a result of innovation. Competition to develop useful structures that can also meet demand will likely ensue over time. However, in the short run, supply constraints from suitable real estate and construction periods can protect innovation value in the short run.

\subsection{The Value Components of Commercial Real Estate Innovations}

\subsubsection{Benchmarking Property Value}

Chapter 2 assesses the short-run price dynamics of the general office stock by constructing a repeat-sales index for the London office market and compares it to the New 
York Office market index from the Moody's/RCA CPPI developed at the MIT Center for Real Estate. Getting at a general measure of the value dynamics of the existing commercial real estate stock is paramount for understanding the value dynamics of the new and innovative stock. Thus, the development of commercial property indices is important for the industry to understand trends in value, but also for an academic assessment of structure value dynamics.

This chapter contributes to the real estate literature by documenting the results of a repeat-sales index application for the London office market. Most of the literature on valuing real estate relies on a hedonic model, originally applied to commercial real estate by Fisher, Geltner, and Webb (1994). However, it is often difficult to obtain hedonic data for commercial properties of sufficient quality. This among other considerations has favored the development of repeat-sales indices as the first regularly published "production" indices of CRE. The continued development of larger and better CRE transaction databases (for both repeat-sales and hedonic data) is, however, affording greater opportunities for price indexing, which this thesis seeks to demonstrate. Moreover, these types of indices have been yet applied commercially or in the academic literature to markets in Europe.

By combing two data sets on office transactions, this chapter demonstrates that it is possible to generate an index for one of the world's largest commercial real estate markets. And by following the methods for construction espoused by Bokhari and Geltner (2011), this chapter demonstrates that robust and commercially viable methods are available for the construction of an index. In addition, this chapter shows that the use of a transaction-based index rather than an appraisal-based index of property value leads to a more timely measure of office value, where the quarterly and annual indexes demonstrate peaks and troughs approximately three to four quarters earlier than the existing appraisal based London office property index.

Index construction is important. The economic insights from these trends are significant for understanding the economic conditions in the commercial property markets. Central bankers, regulators and investors that are highly invested in a global property portfolio are interested in the correlations and trends between major commercial real estate markets. According to Real Capital Analytics Data, New York and London are the two largest commercial real estate office markets in the world, by volume and number of transactions per annum. This chapter documents the trends between these two markets, where surprisingly the rise and fall of the office market in London preceded that of the New York office market over the course of the economic rise in the early 2000s and subsequent, Financial Crisis. This is important for an increasing number of investors and bankers who hold the office markets of these two cities as collateral in their loan portfolios. 


\subsubsection{The Value of Green Innovation}

Chapter 3 looks at the value of green buildings in the London office market. On the one hand, these green buildings represent a process innovation in construction. On the other hand, green buildings represent a new commercial real estate product, which meet a new demand by addressing the physical and functional obsolescence of the existing and new building stock.

Importantly, the existing building stock represents 40 percent of global carbon emissions and 75 percent of current electricity consumption (Enkvist, Naucler, and Rosander, 2007). Economically, green buildings therefore present a real opportunity to decrease waste in raw materials and energy.

This chapter contributes to the growing literature on the value of these buildings by documenting the value of certified green commercial real estate in the UK. Using a hedonic model, the chapter documents the ex-post value of transactions and rents for the London office market, in general, and explicitly looks at the value of green buildings as measured by the BREEAM green building label. Indeed, the value premium for BREEAM-certified buildings is 24.6 and 18.0 for rents and transactions, respectively.

The main economic contribution from this chapter is an assessment of green value dynamics as a result of changes in competition. In an additional analysis, this chapter assesses the localized competition for BREEAM labeled buildings at the time of rent or sale. Importantly, even whilst controlling for numerous neighborhood characteristics, competition has an economically and statistically significant impact on the value premium of BREEAM-certified buildings, where each additional BREEAM-certified building competes away 1.6 and 4.7 percent in BREEAM-certified rents and transaction prices, respectively.

Finally, this chapter also highlights the positive impact that the expanding supply of green buildings within a given London neighborhood has on the average rents and prices for properties. The results in this chapter suggest that overall there is a gentrification effect from green buildings, where each additional BREEAM-certified building in general adds 1.6 and 5.0 percent for all buildings on their rents and transaction prices, respectively.

\subsubsection{The Cost of Green Innovation}

Chapter 4 documents the cost of green construction. In the nascent literature that addresses the value of green real estate, this value has mainly been attributed to the increased demand for energy-efficient buildings. Eichholtz, Kok, and Quigley (2013) documents that a $\$ 1$ decrease in the energy bill for an ENERGY STAR labeled building, results in a $\$ 0.95$ increase in the rents. The evident decrease in operational costs for buildings has a real economic impact for tenants that face year-over-year increases in energy costs. 
Of course, the value enhancement provided by green building is only one side of the equation. Building green may cost more, as well as providing more value. To gauge the profitability of building green, and to draw some insight about any possible innovation value in early green developments, we need to know more about the cost of building green, not in theory, simulations, designs or prototypes, but the ex-post empirical reality.

This chapter contributes to the literature on green value by documenting the results of a large-scale analysis of the cost of green construction as measured by BREEAM labeled certified construction in the UK. The results suggest that BREEAM-certified construction is on average not statistically or economically more costly than non-certified contemporary buildings. However, there is some evidence that within the BREEAMrating spectrum, those buildings that are at the highest quality BREEAM-rating cost approximately 16.7 percent more.

In line with the notion that the BREEAM label represents a commercial venture in diffusing an innovative approach to green building techniques, the differences in cost of building green and non-green buildings vary over the period 2003-2012.

Thus, in addition to the average costs, this chapter also documents the drivers and dynamics of BREEAM construction costs. The main drivers of BREEAM construction costs over the period are two elements in the so-called elemental construction cost nomenclature: superstructure and services. These represent the building costs for the walls, roof, electrical, heating and boiler equipment for a building. Given the extensive attention to energy-efficiency insulation and the addition of renewable energy sources in new and refurbished construction, it is no surprise that this is also the empirical source of a large portion of green construction costs. Moreover, the design fees for BREEAM-certified construction are on a year-over-year basis economically and statistically more costly than for contemporary construction. However, design fees are such a small fraction of total construction costs that the figures do not drive vast economic differences in construction costs between green and traditional construction.

In addition, the cost of BREEAM-certified construction itself is not static. In 2008 and 2011, when BREEAM standards became more rigorous and required more technical innovation on behalf of contractors, costs increased. However, the difference with the cost of non-certified real estate is only significant in 2008, not in 2011.

Summing up, this chapter represents an advancement in our understanding of how much it costs to build green. Reducing the uncertainty that exists about the true costs of building green can facilitate the commercial diffusion of the process behind green real estate, which in the end is paramount for the reduction in waste in materials and energy consumption. Importantly, if we pause for a moment and take the outcomes of Chapters 3 and 4, then there is some empirical grounding in finding innovation value in the green building commercial real estate market. Green buildings transact and rent for more, but they do not necessarily cost more. This may be the opportunity that 
innovators are seeing when investing in green. However, it is also clear these costs are falling, but at the same time there is evidence of increased competition within the markets. Future research should attempt to disentangle these two effects.

\subsubsection{The Value of Information Technology Innovation}

Chapter 5 looks at the value of data centers in the New York commercial office market. Data centers exist where and when an increasing number of fiber-optic cables agglomerate, to store, route and network bytes of digital information. Data centers represent a building product innovation to serve the growing digital demand for physical space, because unlike office or warehouse space that serves human demands, these spaces cater to servers, routers, fiber-optic cables and mission critical equipment like generators and fuel tanks. Importantly, for some of the existing building stock data centers serve to restore the economic relevance of their structures and in the case of new buildings demonstrate some of the most technologically advanced structures ever conceived.

There is very little evidence on the value of data centers and the impact of innovations in telecommunications infrastructure on commercial real estate values. Anecdotally, fiber-lit buildings - buildings that are connected to very high-speed fiber-optic cables - and data centers are known to have entered the portfolios of institutional and public real estate investors in the early part of the 2000s decade. The commercialization of the Internet in 1991 and the growth in telecommunications technology implied that there would be great demand for these types of facilities to serve all of the data coming 'soon'. Unfortunately, 'soon' did not arrive early enough to support the necessary rents for the infrastructure of the buildings. In turn, accompanying the dot-com bust was the crash of the market for data centers and fiber-lit buildings. Today, however, there is an average of 1 zetabyte per year of data being added to the digital universe. ${ }^{5}$ This increased demand for data storage, routing and networking is increasingly demanding more and more space.

This chapter is the first look at the value of fiber-lit buildings and data centers. The chapter documents the ex-post value of transactions for the New York commercial real estate market, by pricing the building characteristics, investor and seller types, and extensive neighborhood characteristics. The results documented in this chapter suggest that fiber-lit buildings transact for 21.6 percent more and that data centers transact for 23.5 percent more than the rest of the commercial real estate stock. Again this may be an indication of innovation value in commercial real estate, but it is difficult to disentangle development and redevelopment costs for these facilities as their construction

\footnotetext{
${ }^{5}$ Cisco provides a scalable metaphor to make this figure more tangible. Suggesting that, "[I]f the 11 ounce coffee on your desk is one gigabyte, then one zetabyte is the Great Wall of China" (http://blogs . cisco.com/news/the-dawn-of-the-zettabyte-era-infographic/, accessed August 28, 2013).
} 
is kept very secret. ${ }^{6}$ However, anecdotal evidence suggests that even for brand new data centers this marginal increase in value would not be costed away.

In addition to investigating commercial real estate value, this chapter looks at the drivers of that value. The analysis in this chapter shows that as the number of telecommunications carriers increases within a fiber-lit building, the value of that building increases. The same is the case for data centers, where data centers that enable free access to all telecommunications carriers have a greater value in the fiber-lit building market.

Finally, an important driver of the valuation of data centers and fiber-lit buildings is of course risk. Data centers are mission critical commercial spaces. Consequently, they begin to operate in a so-called 'Central Digital District', where hazard risks are minimized and energy and fiber connectivity are optimized to prevent downtime. Indeed, the chapter shows that the distance to risk drivers has a statistical and economic impact on the value of fiber-lit buildings and data centers.

\subsection{Innovation in Commercial Real Estate}

The economic outcomes of innovation value seen in Chapters 3 and 4 are also resurfacing in Chapter 5. Although the impetus for the innovation process is different for green and data center building products, there is some empirical grounding for innovation value as these building innovations transact and rent for more than their conventional commercial real estate peers. Moreover, this value is not necessarily compensating the innovator for the development costs of innovation. Thus, the main conclusion of this work suggests that there is evidence of innovation value from building product innovations in commercial real estate. The remainder of this thesis takes a more in-depth look at these empirical chapters. In addition, it also deals with some of the potential explanations for why innovation value is not immediately competed away. The thesis concludes with future research suggestions on how to develop these ideas further.

\footnotetext{
${ }^{6}$ The number of patents on data center building designs and products has tripled over the last decade
} 


\section{Chapter 2}

\section{The London Commercial Property Price Index}

\subsection{Introduction}

The financial and credit crisis of 2008/09 has illustrated once again that the value of real estate assets can have a direct impact on national wealth and investments. Its ubiquitous role as collateral makes it pivotal for the health of the banking sector, and central banks all over the world are looking at real estate prices as a pillar for their policy-making on macro-prudential stability and bank solvency.

This illustrates the importance of reliable yardsticks of property value and underscores that transaction-based indices are very practical and useful tools, and not just for central bankers. They can be used for visualizing price changes and for depicting the capital valuation that real investors in the property markets face (Fisher, Geltner, and Webb, 1994; Geltner and Bokhari, 2008). For institutional investors, transactionbased metrics are important for risk management and for valuing commercial mortgage backed securities (Fabozzi, Shiller, and Tunaru, 2010). For private investors, these metrics are important as they represent an independent benchmark of financial performance. For banks, they can be an invaluable barometer of the market performance of collateral and signals of distress in their own loan portfolios. In aggregate, transactionbased indices provide, at a minimum, an invaluable resource of timely macro-level periodic returns.

Unfortunately, transaction-based property indices, which would be vital up-to-date yardsticks to measure the health of property markets, are only available in a very limited number of countries and when they are available, they usually incorporate house prices rather than the transactions of commercial real estate. Even for a market as important as London, a transaction-based index does not exist. The London commercial property sector is among the most significant property markets globally in terms of

*This chapter is co-authored with Piet Eichholtz (Maastricht University) and Paulo Rodrigues (Maastricht University) and is forthcoming in The Journal of Real Estate Finance and Economics. 
aggregate value, attractiveness to cross-border capital flows, and significance for the global financial industry.

London's commercial property sector is no stranger to price indices. However, they are mainly appraisal-based due to two features of the UK real estate industry. First, robust aggregate transaction data was absent until the early 2000s. The search costs within London's commercial property sector are significant, even from the national public record, and markets can be closed to those that are not deal stakeholders. Second, the 'appraisal' is the foundation of real estate valuation and decision -making. It is a trusted part of the transaction process, can be frequently updated and is an alternative when transaction or data environments are dry. In the former case, data is becoming less of an impediment as independent agencies are increasingly collecting transaction information from the market and public records, but at a price. For the latter, appraisals are an instrumental tool for valuation and transactions themselves, but may not be the best tools for detecting aggregate volatility and market dynamics in a timely manner.

Given that new data providers have come on the market and competition for capturing market information has increased since 1990, sufficient transaction-based data is now available to create a transaction-based index for London commercial property. Fisher, Geltner, and Webb (1994) examine alternative price indices in the US commercial property markets. After an empirical look at un-smoothed appraisal based indices, ex-post transaction based indices and un-levered REIT share indices, they conclude that each index method can provide different insights and uses for investors and academics alike. More recent developments in the US transaction-based indices suggest that transaction-based indices can be complementary to appraisal-based indices and can indeed offer more timely information to investors on market turning points (Geltner and Fisher, 2007). Finally, four transaction-based indices, based on repeatsales and hedonic techniques, are in existence for commercial real estate in the US (see MIT's Center for Commercial Real Estate ${ }^{2}$, the NCRIEF Transaction Based Index, Moody's/Real Capital Analytics Commercial, FTSE/NAREIT Pure Property Indices). We aim to utilize the strengthening data collection process within the UK commercial property sector coupled with recent advances in the real estate literature on commercial property index analysis to gain insight into London's commercial property sector with a transaction-based index.

However, a periodic index at the metro level poses a significant challenge for index construction. Primarily, is there consistent market liquidity to support an index? Without consistent liquidity, the random error will signal spuriously higher volatility to markets, which outweighs any benefits from a transaction-based index itself. Thus, we will assess a metro level transaction-based index for London. Then, we will in-

\footnotetext{
${ }^{2}$ MIT Center for Commercial Real Estate repeat sales index construction is the basis for the first edition of the Moody's/Real Capital Analytics Commercial Real Estate Indices, http: //web.mit .edu/cre/ research/credl/rca/MIT-wp-r2.pdf.
} 
vestigate whether a transaction-based index outperforms an appraisal-based index on the basis of delivering more timely information. Finally, in line with the most recent literature in residential real estate we will assess the relationship between the commercial real estate markets in two of the most prominent financial centers, New York City and London (Holly, Hashem Pesaran, and Yamagata, 2011). Given the two cities auspicious growth in the financial services and real estate sector over the last decades, it is pertinent to assess the timing of trends between the two city's commercial real estate markets.

For our analysis, we combine two proprietary databases of commercial real estate transactions provided by data providers in the London market: Estates Gazette Interactive (EGi) and Real Capital Analytics (RCA). Combined, their London commercial property databases have transactions stretching from 1976 to date. Coverage of transactions and building specific characteristics enhanced over the last decade, and is sufficient for creating an index from the late 1990s. The data has strong coverage in London City, Midtown and the West End.

We find that there is sufficient liquidity for a repeat sales transaction-based index at the metro level even if we have to discard speculative transactions and portfolio sales. In addition, we find that the transaction-based index is more timely than the appraisalbased index in showing the market turnaround of the first financial crisis, and also reflects the fundamental underlying volatility that the market has experienced since then. Interestingly, London's office market seems to have suffered the adverse consequences of the financial crisis quite a lot earlier than New York City's market, where the London transaction-based index starts falling from 2007 and that of New York City continues to rise until 2008. The operationalization of a repeat sales transaction-based index in European markets is mainly a data issue and nothing further.

The remainder of the chapter continues as follows. In Section 2.2, we present a review of the literature on commercial property index construction methods, including repeat-sales and hedonic techniques. In Section 2.3, we present our estimation strategy for our transaction-based index, strategies for noise reduction and high frequency conversion. In Section 4.4, we introduce our data for the London market. In Section 2.5, we report results for the repeat-sales estimation and contextualize our results with a comparison with other yardsticks of commercial property performance. In Section 2.6, we provide a discussion of the relationship between the London and New York City property markets on the basis of our new index, and in Section 2.7 we conclude.

\subsection{Repeat Sales Indices for Commercial Properties}

Due to data limitations, the construction of indices for commercial real estate has been cumbersome (Miles, Hartzell, Guilkey, and Shears, 1991). That is why the early advances in the use of repeated measures regression for property indices all happened in 
housing. Bailey, Muth, and Nourse (1963) were the first to propose repeated measures techniques for housing indices, and Case and Shiller $(1987,1989)$ famously followed in their footsteps, and further developed these techniques. Since then, the literature in this field has developed very strongly, see Case and Quigley (1991), Goetzmann (1992), Clapp and Giaccotto (1992), and Quigley (1995) for some early examples.

Initially, these methodological advances were not implemented in commercial real estate construction, as the data was simply not available. Instead, the industry has relied upon appraisal-based indices, for example based on data owned by Jones Lang LaSalle (JLL), CB Richard Ellis (CBRE), and by independent data providers such as the Investment Property Databank (IPD). The first transaction based indices are currently under development at IPD using the appraisal based transaction index method, where the transaction price is regressed on the appraisal valuation in the most recent period (Devaney and Diaz, 2011).

From an index construction standpoint, the extant literature on indices has shown that appraisal-based capital valuation indices may have some drawbacks. First, a valuation is a property's price, given that the real estate markets are in equilibrium. This assumption does not always hold. Second, individual appraisals can introduce measurement error into an index through potentially subjective evaluations on behalf of appraisers. Third, when the appraisal is used for an index, index smoothing can arise from the valuation updating process, i.e., updated appraisals are based on a mixture of previous appraisals, 'new' comparable property information and current market conditions. Lee, Lizieri, and Ward (2000) find that the IPD and Jones Lang LaSalle annual and categorical appraisal based indices display consistent and statistically significant autocorrelation for lags up to 13 months. For an index this indicates that the relationship in values from one period to the next contains marginally new information, which can have the drawback of drowning out market volatility. Lastly, Chau, Wong, Yiu, and Leung (2005) find that the frequency of appraisal updates can further compound the index smoothing problem, i.e., updates every three months or daily are not likely to possess 'new' information, which causes temporal aggregation effects at the index level.

However, information markets are changing. Since the early 1990s, there has been an increased effort by the markets to track and capture pertinent real estate information at the transaction level. Concurrently, transaction based indices have started being developed in the real estate literature, based on various techniques aimed at coping with scarce and illiquid data environments.

These developments opened the door for the application of repeat sales technology in the commercial real estate market. Gatzlaff and Geltner (1998) construct a repeat sales analysis of Florida commercial properties from 1975 to 1997 . They find that the repeat sales index registers more price movements than the NCREIF appraisal based index. Chau, Wong, Yiu, and Leung (2005) constructed a repeat sales analysis for Hong 
Kong over the 1992 to 2001 period. The index takes advantage of the substantial data available for repeat sales analysis in Hong Kong due to transaction transparency in the city. More recently, in an effort to create a commercial property index for tradable property derivatives in the US, Geltner and Fisher (2007) and Geltner and Bokhari (2008) create a national index for the US and 15 sub-regions, estimated from 2001 to the present. Wheaton, Baranski, and Templeton (2009) construct a repeat sales index of 86 properties in Manhattan over a 100 year period. Their study finds that for any given decade properties appreciated by as much as 20 to 50 percent, but then faced the same decline. Ultimately, in real terms, real estate in the late 2000s is worth what it was at the turn of the 19th century.

The hedonic model, originally employed by Rosen (1974), was created for the purpose of creating a constant-quality price index for products. The method relates the price of a product to the product's individual components. As it applies to real estate, the price of a transacted building relates to the individual building characteristics, the building's neighborhood characteristics and time. In its first application to commercial real estate, Fisher, Geltner, and Webb (1994) compare commercial property index construction methods by: unsmoothing the US Russell-NCREIF Index, generating an ex-post transaction-based cap rates hedonic index and an index based on unlevered REIT shares. Results indicated that the ex-post transaction-based indices lag behind the other series in time, and are consistent with the idea that institutional investors attempt to hold onto properties until they can sell them for a price at least equal to the current appraised value, in effect trading off liquidity for reduced volatility. Colwell, Munneke, and Trefzger (1998) apply a hedonic model to Chicago office property utilizing 427 observations over the 1986 to 1993 period. The index includes building characteristics, e.g., age, lot area, size and height, and many aspects of neighborhood characteristics, e.g. distances to airport, rail and road facilities, parks and golf course access, as explanatory variables. The results depict a contrary result to general market belief that there was a nominal expansion in Chicago office transaction prices over the course of the 1980s. In an additional study on commercial property markets, Fisher, Geltner, and Pollakowski (2007) construct a quarterly transactions based index of property level investment performance for US institutional real estate investors. The main contribution of these results are the investment periodic returns, capital appreciation or price changes for the major property types included in the NCRIEF Property Index (NPI). However, it represents a hedonic based index methodology where the appraisal is used as the representative body of building hedonic characteristics, especially when recent, to explain transaction prices.

Each model has been shown to display relative strengths and weaknesses. For a metro level transaction-based index, the primary strength of the repeat sales index is the reflection of capital gains or depreciation in the market. Essentially, this type of index is a reflection of the market conditions in any given period (Geltner and Fisher, 
2007). Given that a key metric of financial performance today is marking currently held assets to market, this type of index can go a long way in measuring macro-level capital gains and losses. However, the repeat sales index method has several drawbacks. First, repeat sales only capture the set of properties that are transacting in multiple since the beginning of index construction. Thus, for repeat sales there is a significant amount of time required for indexes to mature in data scarce environments. Second, there is an inefficient use of data. Chau, Wong, Yiu, and Leung (2005) compare 11 studies using the repeat sales method and found that at most 32 percent of total transactions available in the population were used. Third, there are periods of higher turnover that can influence the index. Dorsey, Hu, Mayer, and Wang (2010) find that 20 percent of transactions in Los Angeles County between 2003 and 2006 were repeat sales and in this case the sample was catching mostly 'flips.' Lastly, indices based on repeat sales can have long lags between transactions, which may reflect new capital expenditures or changes in building techniques. If this is expansive, it may introduce a bias into the index regardless of any weighting correction (Quigley, 1995).

As an alternative, hedonic methods offer a different pricing mechanism that can enhance a metro-level transaction-based index. The primary strength of the hedonic technique when markets may be subject to illiquidity is that it utilizes the full cross section of data, thus combating noise in the index. However, just like in other techniques, the hedonic method has some drawbacks. To capture the economically significant components for explaining price, data must be flush, robust and extensive in measuring the heterogeneity between and within a building. Moreover, within the context of a dynamic built environment, where commercial real estate is shifting in terms of building quality, sustainability and usage (See Chapter 3 of this thesis), the market price of different building quality attributes are in flux, and some databases may struggle to maintain timely measures of hedonics. In housing data sets, hedonic characteristics are numerous and measured periodically and this enables a true measure of product differentiation. However, in the commercial real estate literature, at best basic hedonic characteristics on the most recent transaction are available.

In summary, each method has its advantages and drawbacks for a metro-level transaction-based index. Clearly from a data perspective, repeat sales methodologies are highly contingent upon the existence of multiple transaction events, quantity and flushness of basic data, including some building characteristics, and the number of transactions across all time cohorts. Within the context of London, where transaction volume is at its highest within Europe, an estimation may be possible. Thus, the remainder of this Chapter proceeds with the repeat sales methodology to assess the commercial property returns for the London real estate market. 


\subsection{Methodology}

From our review of the academic literature on commercial property indices, we can start by applying a repeat sales estimation strategy. The method does not use multivariate controls for hedonic, location or neighborhood characteristics in a transaction event. Instead, a repeat sale measure specifies the periodic returns. The periodic return captures the capital gain or loss between two transaction events, given the criteria that the hedonic, location or neighborhood characteristics remain constant from one transaction to the next. Otherwise, the model is misspecified and can result in upward bias (Case and Quigley, 1991).

Following Geltner and Bokhari (2008), we employ an ex-post transaction based repeat sales model to estimate our periodic returns. The original repeat sales model by Bailey, Muth, and Nourse (1963) forms the basis of the analysis. The empirical model is specified as follows:

$$
\log \left(\frac{P_{i,(t+\tau)}}{P_{i, t}}\right)=\sum_{t=1}^{T} d_{i, t} \beta_{t}+\epsilon_{i}
$$

where $P_{i,(t+\tau)}$ and $P_{i, t}$, are transaction prices for the same object observed at $t+\tau$ and $t$, respectively. The parameter estimates $\left(\beta_{t}\right)$ give the average periodic return. $d_{i, t}$ is a dummy variable taking on values of unity during the investor holding period, but the holding period's first and last year of ownership in $d_{i, t}$ is the fraction of time owned within that year (Bryan and Colwell, 1982). $\epsilon_{i}$ denotes a stochastic error term. We denote by $y$ the $N \times 1$ vector that collects all observed repeat sales transactions' returns, $X$ denotes a $N \times T$ matrix that collects all dummies $d_{i, t}$ and the $T \times 1$ vector $\beta$ collects all parameter estimates. We denote by $N$ the number of observed repeat sales and by $T$ the number of years. Given the above variable definitions, we can rewrite equation (2.1) as follows:

$$
y=X \beta+\epsilon .
$$

Different estimation procedures have been proposed in the literature. These procedures take into account different assumptions concerning the distribution of the error term or the ability to incorporate prior information. For the base case, we assume that the error term is independently and identically distributed, which results in an error covariance matrix given by $\Omega=\sigma^{2} I_{N}$, where $I_{N}$ denotes the identity matrix of dimension $N$. The resulting OLS estimator is given by:

$$
\beta_{O L S}=\left(X^{\prime} X\right)^{-1} X^{\prime} y
$$

However, the error term, $\epsilon_{i}$ is generally found to be heteroskedastic. Heteroskedasticity in this context arises because of the varying holding periods for investors, which can have the effect of over or under weighting the return series. In the case of het- 
eroskedastic errors, the error covariance matrix is given by $\Omega=\operatorname{diag}\left\{\omega_{i}\right\}$, i.e., a diagonal matrix with elements $\omega_{i}$ on the main diagonal. The resulting optimal estimator is given by the weighted least squares estimator:

$$
\beta_{W L S}=\left(X^{\prime} \Omega^{-1} X\right)^{-1} X^{\prime} \Omega^{-1} y
$$

In order to make this estimator feasible, two assumptions have been proposed in the literature. First, the variance of each observation is proportional to the holding period, and second, the variance grows linearly with the holding period but contains an unrelated constant term. For the first case, we set the $\omega_{i}$ equal to the holding period of the observation $I_{i}$. In the second case, we employ a three stage estimation procedure. First, the errors are estimated from an OLS regression, i.e., $\widehat{\epsilon}=Y-X \widehat{\beta}$. Second, the squared errors are regressed on a constant and the holding period, i.e., $\widehat{\epsilon}_{i}^{2}=\alpha+I_{i} \gamma+$ $\eta_{i}$, where $\eta_{i}$ is the i.i.d. error term for this regression. Third, the estimated squared errors $\left(\widehat{\hat{\epsilon}}_{i}^{2}=\widehat{\alpha}+I_{i} \widehat{\gamma}\right)$ are used as weight $\omega_{i}$.

The impact of transaction price noise on the estimation of the price trend is potentially high. Moreover, this noise may vary over the course of the price trend as turnover and volume fluctuate. To minimize transaction price noise, Goetzmann (1992) proposes to incorporate prior information concerning the distribution of the vector $\beta$ into the estimation. Since this parameter vector represents a time series of asset returns, it should be uncorrelated if the market efficiency hypothesis holds. In order to incorporate this prior belief into the estimation, Goetzmann (1992) augments the likelihood function by a prior distribution concerning the $\beta$ vector, specifically this prior distribution is a product of univariate normals for each $\beta_{i}$. The resulting maximization of this likelihood function gives (in case the prior is centered at zero):

$$
\beta_{\text {GOETZ }}=\left\{I+k\left(X^{\prime} \Omega^{-1} X\right)^{-1}\right\}^{-1} \beta_{W L S}
$$

where $\kappa=\sigma^{2} / \sigma_{\beta}^{2}$, i.e., the ratio of the prior and posterior variances. The estimation of the parameter $\kappa$ employed in this Chapter follows the two stage procedure proposed in Section 2.6.1 in Goetzmann (1992), i.e., we estimate $\sigma^{2}$ and $\sigma_{\beta}^{2}$ from a first stage WLS regression.

In a second strategy, Bokhari and Geltner (2012) employ a generalized inverse estimator to a series of staggered yearly returns to estimate a quarterly index. The yearly returns are constructed via index estimations where the year is measured using a calendar and a fiscal year approach, where the fiscal years start in April, July and October. In the first stage, yearly indices are estimated for the calendar and fiscal years. In the second stage regression, these individual indices are staggered, leaving the first three quarters of the fiscal year indices blank and the system of equations is under identified. However, utilizing the Moore-Penrose pseudo-inverse matrix the generalized inverse 
estimator is achieved, where:

$$
\beta_{M I T}=X^{T}\left(X X^{T}\right)^{-1} y,
$$

and $X^{T}\left(X X^{T}\right)^{-1}$ gives the Moore-Penrose inverse and the parameter vector $\beta$ gives us an estimator of quarterly returns. This means that the index methodology is comparable with the current MIT Center for Real Estate's Repeat Sales Methodology.

Finally, to generate the index we calculate the exponential value of the return series. 1996 is used as the base period and the index is estimated as:

$$
I_{t}=I_{t-1} * e^{\beta_{t}}
$$

where $I$ is the index value in period $t$ and $t-1$.

\subsection{London Data}

At the metro level, data scarcity in some periods may become an issue. Thus, we utilize two data providers for a comprehensive collection of ex-post transactions. We first collect data from Estates Gazette interactive (EGi). EGi is a commercial property database covering news, building reports, deal information, auctions, availability and occupier data, and ratable value analysis. For our analysis, we accessed the London Building Reports database to collect detailed building information. EGi began covering market information in 1976, but their coverage of transactions substantially increased in the last decade. ${ }^{3}$ Second, we incorporate the Real Capital Analytics (RCA) transaction data for the London market. RCA is a relatively recent provider for the UK market, but they are a part of the growing group of independent transaction data providers. Their London data set covers transactions from 2000 to the present with a coverage rate of about 90 percent. $^{4}$

After aggregating the datasets, the total cross-section of observations available over the 1996 to 2011 period with information on price and a transaction date amounts to 4,760 transactions for 2,701 buildings, with an average of 320 transactions in every year. One interesting aspect of both datasets is that they provide knowledge of the buyer at the time of sale. This allows us to see the type of investors that are buying in the market in any given period. Within the market, there are four significant buyers to monitor: real estate, institutional and private investors and developers. Real

\footnotetext{
${ }^{3}$ EGi covers all transactions and has a coverage rate of approximately 50 percent. In addition to transaction price and date, they capture the yield, transacting parties (buyer, seller, and agent), portfolio sales, and basic hedonic characteristics where available.Foreclosures are reported as transactions but flagged and therefore removed from our data set.

${ }^{4}$ The RCA dataset has a very high capture rate on the yields and true identity of buyers and their plans for occupancy, renovation and redevelopment. Moreover, the data includes mortgage data that indicates whether the property is in foreclosure. Consequently, foreclosures are not included as valid sales.
} 
estate investors primarily invest in diversified portfolio of commercial and residential real estate. This category also includes the newly formed UK-REIT regime structure for the UK property markets. Institutional investors, like pension funds or asset managers, focus on multiple asset classes, like equities and bonds. For these investors, real estate is another asset class for diversification. Private investors are generally owner occupied purchasers in the market or foreign direct investment from non-institutional investors. Lastly, developers are buyers of land or a building that will undergo construction or redevelopment for resale. Overall, these investors have varying shareholders and earnings targets that make their real estate selections unique in any given market. However, in London with a sampling of investments ranging from institutional grade trophy properties to speculative grade industrial parks in the outer rim, there is something for all investor types.

Figure 2.1: Market Activity 1996 to 2011

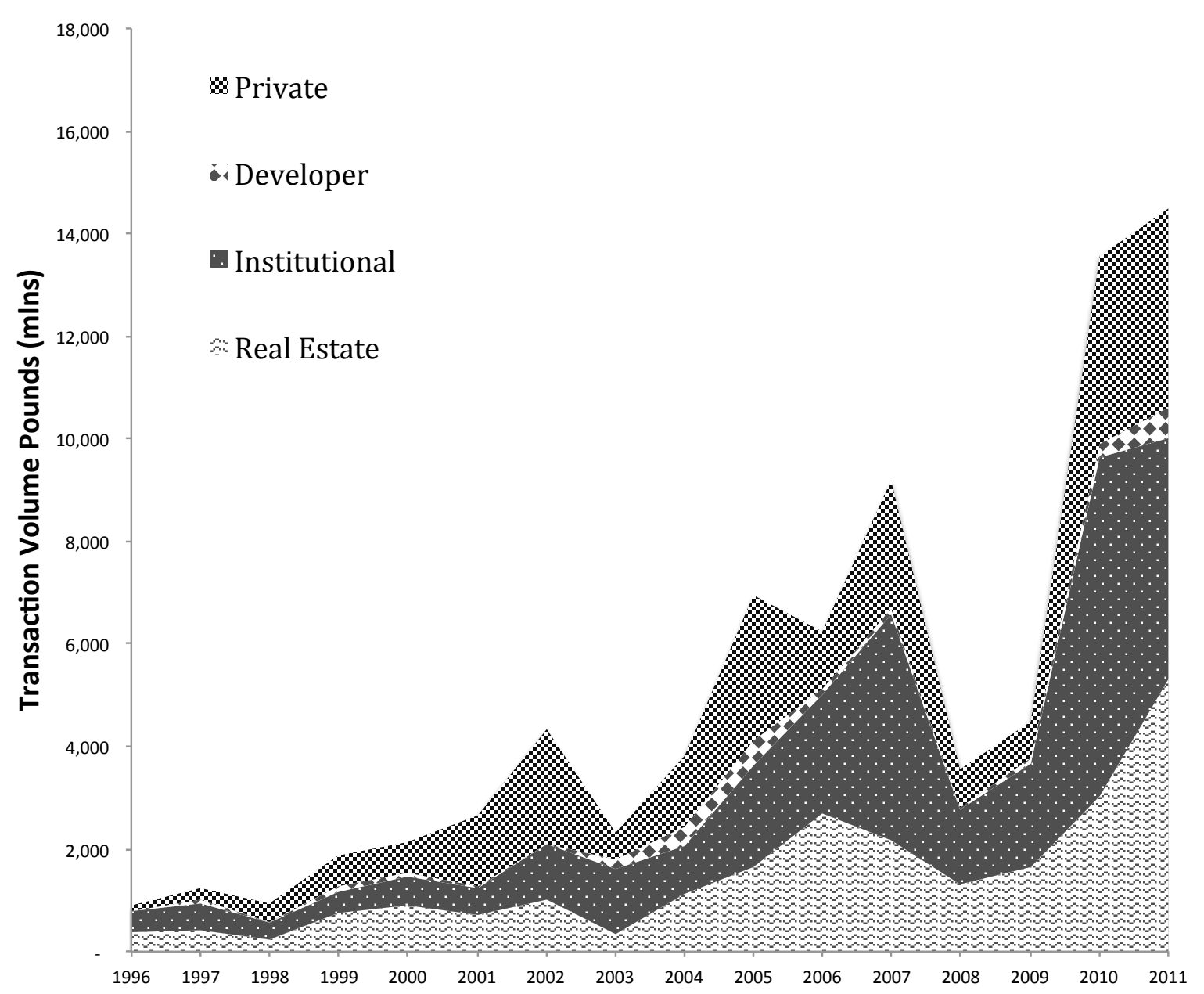

Notes: Figure 2.1 displays overall the transaction activity for London commercial property over the 1996 to 2011 period, excluding sales in which the buyer type is unknown.

Figure 2.1 depicts the investor activity over the 1996 to 2011 period. Real estate and institutional investors have the most dominant presence in the transaction sample over 
the whole period. Private investors and developers enter the market more periodically. In aggregate, the core of the market is dominated by specialized real estate investors within the UK and by domestic and international pension funds. Regardless of market period, their activity is crucial in supplying liquidity. Within the sample, mainly domestic developers are present. From the figure, we can see that their presence is sporadic, which may be evidence of a cyclical pattern as suggested by Wheaton, Torto, and Evans (1997). Private investors are mainly local owner occupiers and sovereign wealth investors. These investments are also not dominant and consistent across all investment periods.

Subsequent reductions to the full sample must be made separately before we can estimate a repeat sales index. Geltner and Fisher (2007) outline and motivate the removal of certain transaction events for a repeat sales analysis. However, our technique deviates from Geltner and Fisher (2007) in two respects, but is in line with the first Moody's/RCA Commercial Property Price Indices (Philipp, Fagan, and Levidy, 2012).

First, flips, buildings that transact within 6 quarters are removed in the US indices so as not to bias the sample with speculative activity. We also remove flips, but we only regard transactions that took place within 4 quarters as flips. Francke (2010) motivates this more limited exclusion in a sample of Dutch housing transactions by adding an investor period dummy for index estimation. Results do not significantly differ and more transaction events are viably added. For sample comparability and transparency, we employ the same filters across all estimation strategies.

Second, in the Geltner and Fisher (2007) and Geltner and Bokhari (2008) estimations, average yearly returns greater than 20 percent for investor periods greater than four years are removed, but, given the nature of the market, we take 50 percent. The average returns of the London market are in the mid-thirties and the addition of the higher threshold only removes 6 observations. Appendix A outlines all filters to the data. Although our dataset does not have measures of capital expenditure and receipts (other than sales), our method reflects the realized gains for properties that have not undergone large capital expenditures: we remove properties that have changed in size.

Figure 2.2 displays the aggregate transaction activity in the London market over the 1996 to 2011 period and illustrates how we go from the full transaction sample to a 'clean' repeat sales sample, i.e., transaction pairs. The graph illustrates observations of five different sub-samples. The first line highlights the number of observations for the full sample and the subsequent reductions necessary for repeat-sales estimation. Transactions (Full Sample) indicates that the number of transactions reached local maximums in 2001, 2006, and 2011. This is similar across all sub-samples. In addition, the transaction levels clearly indicate the extent of portfolio sales, property flipping and building redevelopment during the 2005 to 2007 period. The peak of transaction activity occurred in 2006, where 98 observations are attributed to portfolio sales and 40 are flips, where as 2007 comes in second in portfolio and flip activity. Moreover, the 
number of flips dramatically decreases after 2009. Finally, we see that the remarkable increase in transaction activity in 2010 and 2011 does not result in significant amounts of repeat sales. This is due to the fact that many of the properties sold in 2010 and 2011 had not previously sold in our sample period, and if they were, they were often part of a portfolio sale, which we discard from the dataset.

Figure 2.2: Transaction and Repeat Sales Activity for London Commercial Property 1996 to 2011

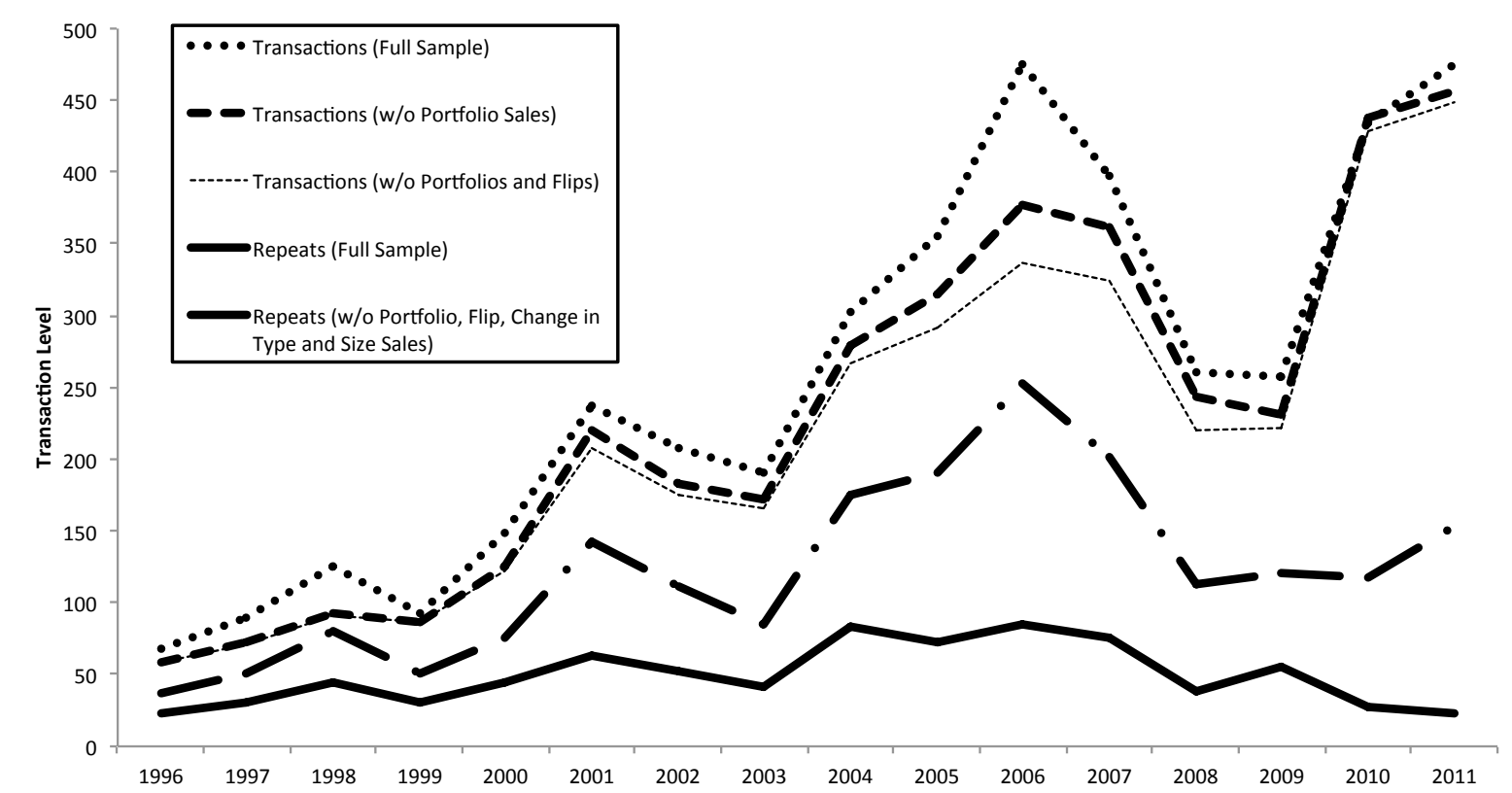

Notes: Figure 2.2 displays the transaction activity for London commercial property over the 1996 to 2011 period, including samples that exclude portfolio sales, flips (repeat transactions that occur within 12 months) and buildings that have changed in property type or size.

The resulting repeat sales sample is 797 multiple observations, culminating in 428 returns or transaction pairs over the 1996 to 2011 period. The transaction pairs specified in Figure 2.2 are a measure of the second transaction in the transaction pair, which is the unit of observation for the index. On average, there are 30 observations in any given year, with at most 63 and as little as 3 observations (in the first year). As is expected of any repeat sales index, there is evidence here of a period of adolescence in the first years of index construction. ${ }^{5}$

\subsubsection{Summary Statistics}

Table 2.1 highlights the descriptive statistics of the repeat sales sample. For the sample, the average return is about 37 percent with a standard deviation of approximately 61 percent, but the average yearly return is about 11 percent with a standard deviation of

\footnotetext{
${ }^{5}$ There is a loss of significant observations prior to the start of the index. Future research should delve into capturing these transactions for estimations.
} 
Table 2.1: London Repeat Sales Descriptive Statistics

(a) Return Characteristics

\begin{tabular}{lrcr}
\hline \multicolumn{1}{c}{ Variable } & Mean (Std. Dev.) & N \\
\hline Return and Transaction Characteristics & & & \\
\hline Cumulative Return (percent) & 37.1 & $(0.61)$ & 428 \\
Yearly Return (percent) & 11.1 & $(0.18)$ & 428 \\
Investor Period (quarters) & 17.5 & $(10.35)$ & 428 \\
Price Achieved (Emln) & 49.3 & $(86.9)$ & 428 \\
Size (Net Square M) & 5,766 & $(10,206)$ & 428 \\
Building Age (years) & 34.4 & $(38.0)$ & 428 \\
Stories & 7.90 & $(4.76)$ & 428 \\
Amenities Present* & 66.0 & - & 428 \\
Buyer** Holding Period (quarters) & & & \\
\hline Real Estate Investor & 17.6 & $(10.5)$ & 106 \\
Institutional Investor & 18.9 & $(10.3)$ & 103 \\
Developer & 16.2 & $(9.62)$ & 17 \\
Private Investor & 18.3 & $(11.2)$ & 113 \\
Unknown & 15.1 & $(8.62)$ & 88 \\
Buyer** Breakdown (percentage) & & $\mathrm{n}$ & $\mathrm{N}$ \\
\hline Real Estate Investor & 25.23 & 106 & 428 \\
Institutional Investor & 24.31 & 103 & 428 \\
Developer & 4.21 & 17 & 428 \\
Private Investor & 26.21 & 113 & 428 \\
Unknown & 21.13 & 88 & 428 \\
\hline
\end{tabular}

(b) Markets and Time Distribution

\begin{tabular}{lcc}
\hline \multicolumn{1}{c}{ Variable } & Percentage & N \\
\hline Market (percentage) & & \\
\hline City Core & 29.0 & 428 \\
City Fringe & 8.00 & 428 \\
Docklands & 1.00 & 428 \\
Midtown & 16.00 & 428 \\
North Central & 1.00 & 428 \\
South Central & 2.00 & 428 \\
Southern Fringe & 2.00 & 428 \\
West Central & 3.00 & 428 \\
West End & 37.0 & 428 \\
Transaction (percentage) & & \\
\hline Quarter 1 & 70.0 & 428 \\
Quarter 2 & 11.0 & 428 \\
Quarter 3 & 11.0 & 428 \\
Quarter 4 & 8.00 & 428 \\
1996 & 0.03 & 428 \\
1997 & 0.02 & 428 \\
1998 & 1.00 & 428 \\
1999 & 1.00 & 428 \\
2000 & 3.00 & 428 \\
2001 & 3.00 & 428 \\
2002 & 5.00 & 428 \\
2003 & 4.00 & 428 \\
2004 & 11.0 & 428 \\
2005 & 11.0 & 428 \\
2006 & 13.0 & 428 \\
2007 & 15.0 & 428 \\
2008 & 7.00 & 428 \\
2009 & 12.0 & 428 \\
2010 & 6.00 & 428 \\
2011 & 5.00 & 428 \\
\hline & & \\
& &
\end{tabular}

Notes: Table 2.1 highlights the return characteristics of the repeat-sales sample over the 1996 to 2011 period by buyer type, market and transaction period. *Amenities range from 24 hour building access to parking, elevators and air-conditioning. ${ }^{* *}$ Buyer is divided into five categories, where Real Estate Investors are solely dedicated to institutional real estate investment and Institutional Investors have a portfolio of assets and real estate is just one of them. Developers, include large development companies and local community organizations. Private Investors include local small investors as well as non-institutional foreign investors and sovereign wealth entities. Buyer's are broken down by holding period and percentage in the sample. $n$ refers to the number of observations of each type and $N$ refers to the total observations.

18 percent. The average investor period is approximately 17.5 quarters. Even across investors types variation across holding periods is rather stable, with the exception of developers. This observation in the data is important as it suggests that a majority of multiple investments, despite the removal of flips, is held for on average more than four years, with a standard deviation of about 2 years. Thus, the consistent operationalization of a repeat sales index will become more feasible as time passes. Note that the statistics presented in Table 2.1 refer either to the transaction pair, i.e., in the case of returns or to the second transaction within the transaction pair, i.e., in the case 
of building age.

The average price of the properties is approximately $£ 49.3 \mathrm{mln}$ with high variation. The average building size is 6,336 square meters, also with high variation; average building age is 34 years; the average building height is 8 stories; and more than 60 percent of buildings have amenities present. The repeats sample is largest in London City, approximately 37 percent and in the West End an additional 40 percent of the sample. With the exception of Midtown, the other London boroughs do not play a very important role in the dataset. The original intention of this Chapter was to estimate submarket indices for the London metro area as there may be some differences between each sub-market. Namely, the London market is spatially heterogeneous, which may impact returns in the market. However, due to the limited number of repeat transactions per sub-market this is not yet possible at this level. Future research should work towards these types of results.

In addition, the Docklands as a primary district for office demand is marginally reflected in the dataset. This may be attributed to the control of the Docklands investment via a trust, where transactions are not published publicly. In addition, there are very few properties that undergo repeat transactions within this area. Finally, there is a higher percentage of transactions occurring in the years from 2004 to 2009, with the highest returns accruing in 2006 and 2007, and a sudden drop in transaction activity in 2008.

\subsection{Repeat Sales Index Estimation and Performance}

Table 2.2 presents the results for the repeat sales empirical model in equation (2.1), relating the logarithmic returns of commercial property to weighted time dummies. Results are presented for ordinary least squares, weighted least squares, three stage weighted least squares and Goetzmann estimation procedures. We test for heteroskedasticity using the Breusch-Pagan test, results indicate that we can reject the null hypothesis, where the null is homoskedastic, with $p$ values of approximately zero. The time weighted dummies explain 12 to 15 percent of the variation in logarithmic returns. The mean absolute error (MAE) is on average 24 percent and the sum of squared errors (SSE) is highest with the Goetzmann procedure, but the difference with the other procedures' SSE is not substantial.

Figure 2.3 depicts the yearly index values for the The London Commercial Property Price Indices over the 1996 to 2011 period. On the left axis, index levels are reported with 2001 as the base year. We can observe the following from the graph. First, the four index estimation methods show very similar levels. Second, the market turning points are well synchronized. Third, the main difference is in the magnitude of the turning points, i.e., the Goetzmann index seems less volatile than the others and, in aggregate, 
Table 2.2: Repeat Sales Estimation

\begin{tabular}{crrrr}
\hline & R-OLS & R-WLS & R-WLS2 & R-Goet. \\
\hline 1996 & -0.15 & 0.02 & 0.02 & -0.00 \\
& $(0.20)$ & $(0.21)$ & $(0.21)$ & $(0.10)$ \\
1997 & -0.26 & -0.12 & -0.18 & -0.05 \\
& $(0.16)$ & $(0.14)$ & $(0.15)$ & $(0.09)$ \\
1998 & $0.46^{* * *}$ & $0.34^{* *}$ & $0.37^{* *}$ & $0.19^{* *}$ \\
& $(0.17)$ & $(0.16)$ & $(0.16)$ & $(0.09)$ \\
1999 & -0.22 & $-0.28^{*}$ & $-0.27^{*}$ & -0.10 \\
& $(0.17)$ & $(0.15)$ & $(0.16)$ & $(0.09)$ \\
2000 & $0.28^{*}$ & $0.44^{* * *}$ & $0.40^{* * *}$ & $0.32^{* * *}$ \\
& $(0.15)$ & $(0.14)$ & $(0.14)$ & $(0.08)$ \\
2001 & 0.20 & 0.17 & 0.18 & $0.19^{* *}$ \\
& $(0.14)$ & $(0.13)$ & $(0.13)$ & $(0.08)$ \\
2002 & -0.18 & -0.19 & -0.18 & $-0.14^{*}$ \\
& $(0.13)$ & $(0.11)$ & $(0.12)$ & $(0.08)$ \\
2003 & 0.09 & 0.12 & 0.11 & 0.08 \\
& $(0.12)$ & $(0.09)$ & $(0.10)$ & $(0.07)$ \\
2004 & 0.16 & 0.12 & 0.13 & $0.13^{*}$ \\
& $(0.11)$ & $(0.08)$ & $(0.09)$ & $(0.07)$ \\
2005 & 0.06 & $0.16^{* *}$ & 0.12 & $0.16^{* *}$ \\
& $(0.10)$ & $(0.08)$ & $(0.09)$ & $(0.06)$ \\
2006 & $0.45^{* * *}$ & $0.33^{* * *}$ & $0.36^{* * *}$ & $0.30^{* * *}$ \\
& $(0.10)$ & $(0.07)$ & $(0.08)$ & $(0.06)$ \\
2007 & -0.17 & -0.08 & -0.11 & -0.09 \\
& $(0.13)$ & $(0.10)$ & $(0.11)$ & $(0.07)$ \\
2008 & $-0.38^{* *}$ & $-0.30^{* *}$ & $-0.31^{* *}$ & $-0.24^{* * *}$ \\
& $(0.15)$ & $(0.12)$ & $(0.13)$ & $(0.08)$ \\
2009 & 0.29 & 0.13 & 0.17 & 0.10 \\
& $(0.18)$ & $(0.15)$ & $(0.16)$ & $(0.09)$ \\
2010 & 0.03 & 0.18 & 0.13 & $0.17^{*}$ \\
& $(0.22)$ & $(0.19)$ & $(0.20)$ & $(0.09)$ \\
2011 & 0.13 & 0.16 & 0.16 & 0.12 \\
& $(0.23)$ & $(0.20)$ & $(0.21)$ & $(0.10)$ \\
\hline$R^{2}$ & 0.15 & 0.13 & 0.14 & 0.12 \\
MAE & 0.25 & 0.26 & 0.26 & 0.24 \\
SSE & 133.18 & 136.66 & 135.15 & 137.30 \\
No. of Obs. & 428 & 428 & 428 & 428 \\
\hline & & & & \\
& & & & \\
& & &
\end{tabular}

Notes: This table reports the estimates of equation (2.1) for time weighted dummies over the period 1996 to 2011. This table also reports the $R^{2}$, median absolute error (MAE) and sum of squared error (SSE). The dependent variable is the logarithmic returns. ${ }^{*} p$ value is $10 \%$; ${ }^{* *} p$ value is $5 \%$; and ${ }^{* * *} p$ value is $1 \%$. 
the OLS index's movements look most pronounced.

Index levels in general over the 1996 to 2011 period have substantially risen. The index falls in 2001, coinciding with the dotcom crash, which strongly affected London's financial industry. After that, it resumed its upward trend until 2006. From 2001 to 2005 , there is a distinct undulation in the index levels, which coincides with the dot com recession. Subsequently, from 2002 to 2006, index values increased by 179 percent, clearly reflecting the long property boom. However, that boom ended abruptly after the peak of 2006. In 2007 and 2008, there is a sharp decline in index values but, despite the fact that the financial crisis is far from over, the London market has shown a very remarkable recovery, with the 2011 index level that has reached levels of 2006. This is in line with market reports indicating strong take-up and recovery in 2011 (CBRE, 2011).

Figure 2.3: The London Commercial Property Price Index - Annual Frequency

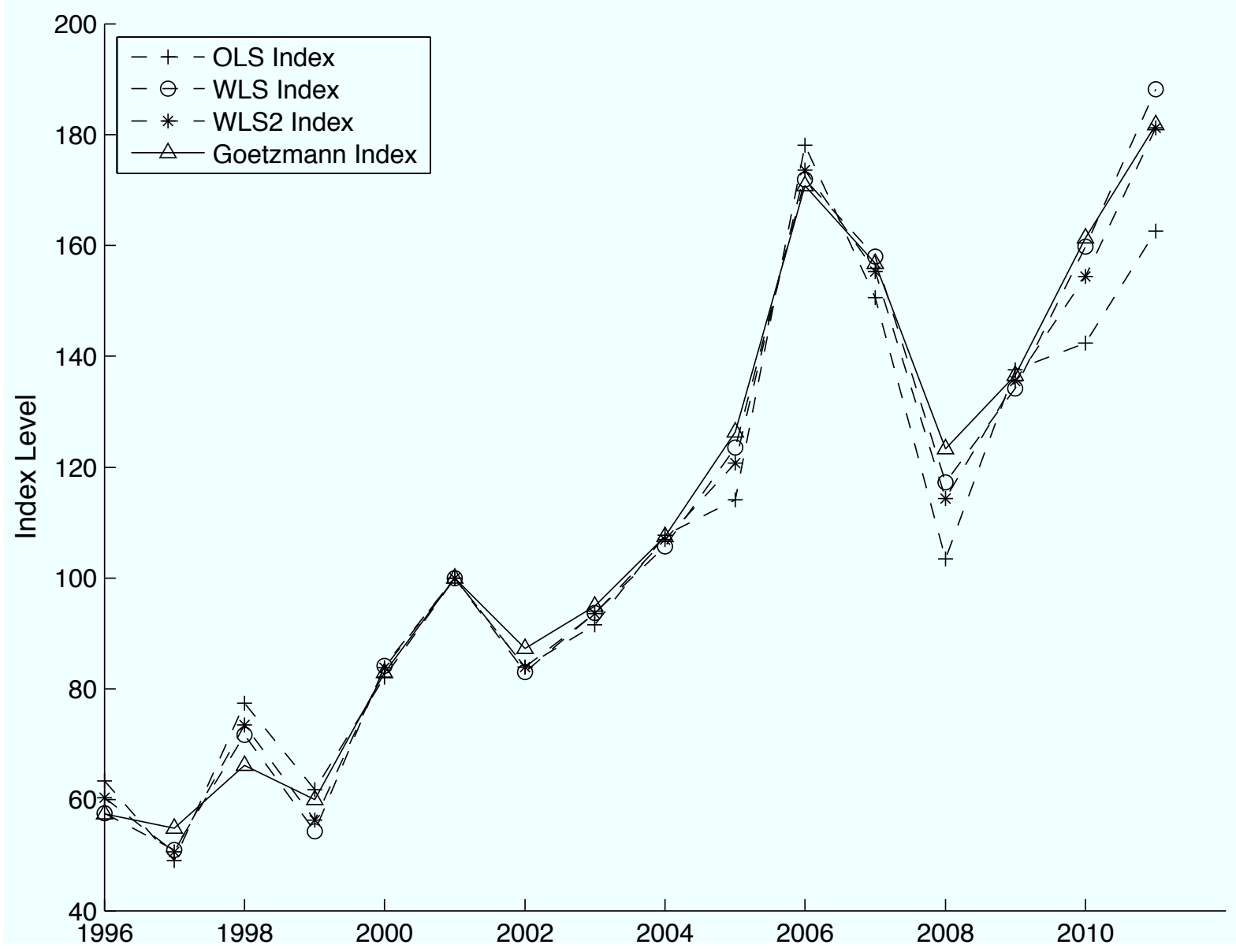

Notes: Figure 2.3 displays the annual index values for The London Commercial Property Price Index over the 1996 to 2011 period. The left vertical axis is the index level. 2001 is the base index period for all indices. The horizontal axis is the time period measured in years.

Figure 2.4 displays the quarterly index for the The London Commercial Property Price Index over the 1996 to 2011 period. These indices are constructed by using all annual estimation methods and then applying the method proposed in Bokhari and 
Geltner (2012) in order to increase the frequency to quarterly. Here also the four estimation techniques display a similar performance in terms of the timing of the index movements, but there are differences in magnitude. Again, the Goetzmann index creates a more stable specification and we use this methodology in order to construct our London Quarterly Repeat Sales Index. Moreover, this method results in an index which is constructed in the same fashion as the MIT Center for Real Estate's Repeat Sales Index. This index reflects the full estimation strategy, incorporating bayesian smoothing and generalized inverse techniques.

Return levels increased over the 2002 to 2006 period with a slight trough over the year of 2006 to 2007, an additional peak in 2007 and then a steep decline into 2008 and 2009. The latter portion of the index depicts a remarkable rebound in markets. Again, there is significant market activity as seen in Figures 2.1 and 2.2. Figure 2.2 documents that there was substantial transaction activity in 2010 and 2011. Figure 2.1 indicates that private, developer, institutional and real estate investor types returned to the market. Unfortunately, the data set is limited for estimating indices based on investor types at this time.

Over the sample period there is a significant institutional change in commercial property ownership: the UK-REIT structure. The introduction of the company structure could explain the fact that the markets rebounded in the first two quarters of 2007. However, the ownership vehicle is not yet mature in the UK market, but can yield interesting insights into investor activity. As of January 1, 2007, the UK-REIT operational vehicle has been in effect. Since that time, approximately 31 property companies have undergone this regime formation, with the highest proportion in 2007. Within the total sample, 45 percent of UK-REITs appear in both the RCA and EGi data sets as of their start dates, and are responsible for $£ 3.9$ bln in purchases and 63 transactions overall. Theoretically, these investors may have been taking advantage of the tax shield inherent in the REIT structure. However, within the repeat sample, the UK-REIT companies do not play a significant role in buying or selling their properties. Seven properties were sold, i.e., the second transaction in a pair, by UK-REITS.

In the following paragraphs, we argue that the cycle in real rents and vacancy rates that the previous literature on London property cycles finds are in line with the index results in this chapter. Mainly, we turn to the earlier empirical literature concerning London office real estate cycles, which suggests that our index is in line with overall trends that influence the London commercial property market.

First, Wheaton, Torto, and Evans (1997) find that the primary driver of office demand in London's office sector is financial and business services employment, which grew by one third over the 1998-2007 period and declined over the 2007-2010 period by 10 percent (National Office of Statistics). Targeted employment shifts over the 2000 to 2011 period correspond with the turning points estimated in the Quarterly London Commercial Property Index. Volatility in business services employment affects rental 
Figure 2.4: The London Commercial Property Price Index - Quarterly Frequency

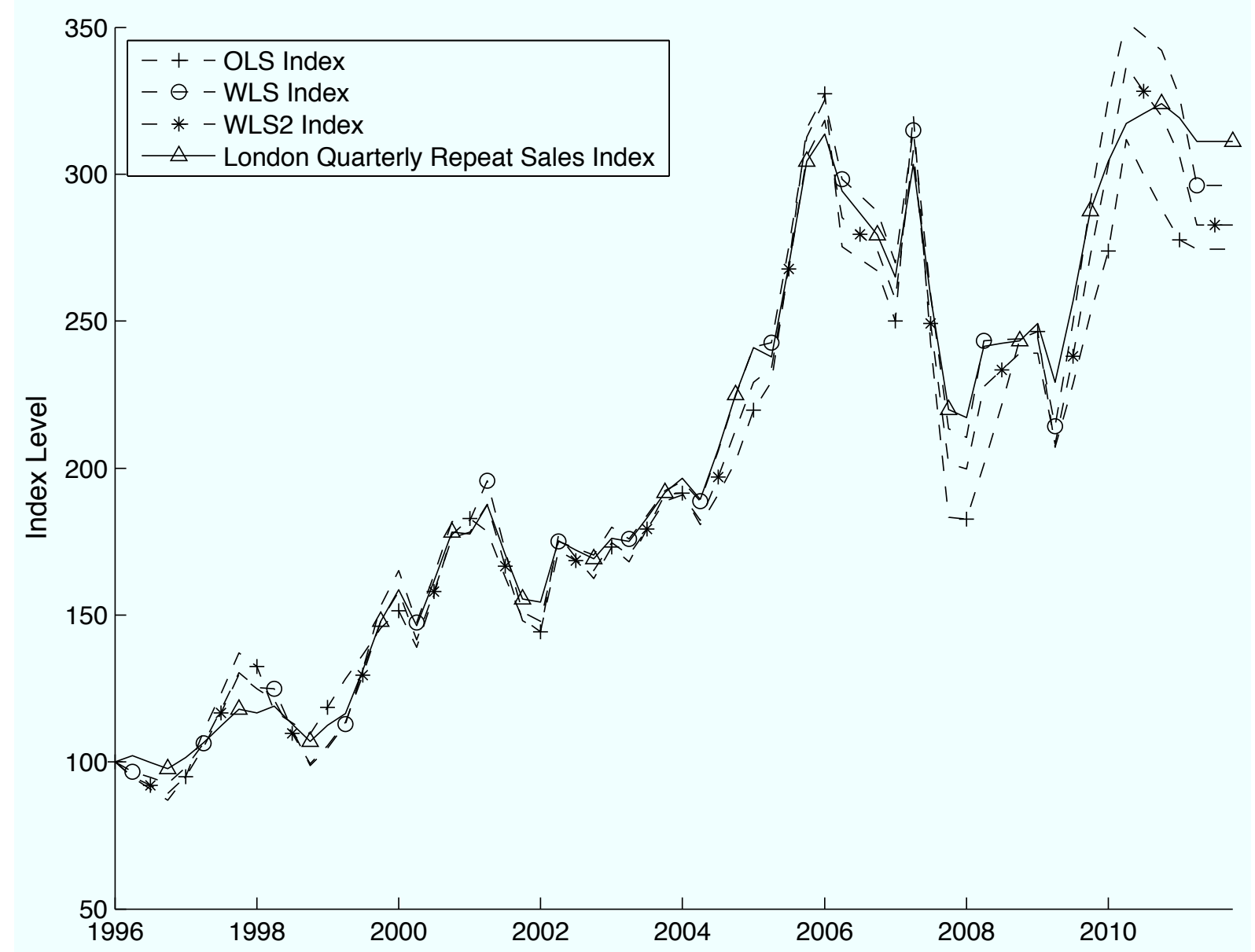

Notes: Figure 2.4 displays the quarterly index values for The London Commercial Property Price Index over the 1996 to 2011 period. The left vertical axis is the index level. 2001 is the base index period for all indices. The horizontal axis is the time period measured in years.

demand for the office space in the short run, but prices can be sticky and dependent upon rental contracts. Even so, expectations and signals from rental demand can still affect capital market demand for real estate assets. In turn, these short run dynamics in employment and real rents can influence the supply of new and redeveloped stock in the long run.

In addition, prior literature has empirically tested the property cycle for the real rental and space markets in London City. Hendershott, Lizieri, and Matysiak (1999) and Hendershott, Lizieri, and MacGregor (2010) find that real rents in London City reach low levels in 2003 and 2004, but expand again until 2006. In addition, they find that market vacancy rates peak in 2003 to 2004 and decrease until 2006. Results remain consistent and capital market returns for real estate assets are driven by employmentdriven demand for space, rental rates and supply. Ex-ante we expect that demand would increase until approximately 2002 and then subsequently decrease until 2003 to 2004 and in the long run lead to a potential expansion of the building supply and redevelopment. According to CBRE, peaks and troughs in prime rents in the City of 
London should correspond with turning points in the annual series in 2006 and 2010 (CBRE, 2011). In line with the academic literature and market reports, our index reflects an initial trough in capital returns followed by an expansionary period in investment over the same periods.

Second, literature on the performance of transaction-based index techniques suggests that a primary point of comparison is with an appraisal based index. Fisher, Geltner, and Webb (1994) find that the levels produced by the appraisal-based indices are smoothed and may be lagged, but should generally reflect the trends in the market. In general, we should understand when peaks and troughs should arise in market. Exante we can turn to IPD's Yearly London Property Capital Growth Index to get an idea of market movements over the 1997 to 2011 period. The index averages the appraisal values of approximately 1,700 properties in any given year over this time period with high proportions of the sample coming from London City, West End and Midtown.

Geltner and Fisher (2007) suggest that index noise is signaled by short-run volatility and negative autocorrelation, whereas a lag is generally denoted by low volatility and positive autocorrelation. Fisher, Geltner, and Pollakowski (2007) do not find substantial noise or lag in their hedonic index of US commercial property over the 19842007 period, while the index has autocorrelation in the returns of about 35 percent and advances the appraisal-based index by 1 to 3 years. However, their index differs substantially from ours in regional aggregation and data use: it covers the whole US rather than one city and it utilizes appraisals (just prior to transactions) as the primary independent variables in the specifications, rather than previous transactions.

Lastly, Table 2.3 and Figure 2.5 compare the Annual London Commercial Property Price indices to IPD's London Commercial Property Annual Capital Growth Index for the 1997 to 2011 period. We can visualize price trends and turning points. In line with Fisher, Geltner, and Webb (1994) and Fisher, Geltner, and Pollakowski (2007), we compare indices on the basis of appreciation returns ( geometric mean, standard deviation and first order autocorrelation) and contemporaneous cross correlation with other index methods and other financial price indices, and on the basis of Nominal Property Value Levels (percent rise trough to peak, fall to peak, year of first and second troughs and peaks).

In general, all repeat sales indices display higher geometric mean returns than the appraisal-based index. This is mainly due to the fact that the transaction-based indices show strong value growth after the market low of 2008, while the IPD index's value had not yet recovered from its 2008-2011 fall by the end of 2011. Ex-Ante we anticipated that the transaction indices would be noisier and more timely than the appraisal-based index. Aggregate results suggest that variation for indices estimated without proper care for 'prior' volatility are indeed more varying. However, noise filtering decreases index volatility and increases autocorrelation. All transaction-based indices display greater volatility than the appraisal-based index, but not substantially. First-order au- 
Table 2.3: The London Commercial Property Price Indices - Annual \& IPD London Commercial Property Annual Capital Growth Index

\begin{tabular}{lrrrrr}
\hline \multicolumn{7}{c}{ R-OLS R-WLS R-WLS2 R-Goet. } & IPD \\
\hline Return Characteristics: & & & & & \\
Mean Return & 8.56 & 9.33 & 9.11 & 8.56 & 2.33 \\
Std. Deviation & 24.98 & 22.59 & 22.68 & 16.60 & 12.36 \\
Autocorrelation (1st lag) & -37.81 & -29.90 & -32.74 & -7.03 & 29.54 \\
Nominal Property Value Levels: & & & & \\
\% Fall 1st Peak to Trough & -17.51 & -18.61 & -17.52 & -13.65 & -11.61 \\
\% Rise 1st Trough to Peak & 75.21 & 72.77 & 72.65 & 67.18 & 38.91 \\
Year of penultimate Peak & 2001 & 2001 & 2001 & 2001 & 2002 \\
Year of last Peak & 2006 & 2006 & 2006 & 2006 & 2007 \\
Year of penultimate Trough & 2002 & 2002 & 2002 & 2002 & 2004 \\
Year of last Trough & 2008 & 2008 & 2008 & 2008 & 2010 \\
Correlations: & & & & & \\
R-OLS & - & - & - & - & - \\
R-WLS & 92.16 & - & - & - & - \\
R-WLS2 & 96.03 & 99.29 & - & - & - \\
R-Goet. & 89.92 & 96.63 & 95.96 & - & - \\
IPD & -2.65 & 8.14 & 5.49 & 8.99 & - \\
\hline
\end{tabular}

Notes: Table 2.3 provides the descriptive statistics for The London Commercial Property Price Indices - Annual and the IPD London Capital Growth Index over the 1997 to 2011 period. Included are return statistics, index turning points and correlations.

tocorrelation is highest for the IPD Index, approximately 30 percent. This contrasts sharply with the transaction-based indices: the Goetzmann specification results in the highest autocorrelation, but it is only -7 percent. The other repeat sales also indices have negative autocorrelation. However, due to the limited number of time periods, the statistical significance of autocorrelations are insignificant.

Furthermore, the returns stemming from the IPD Index are not contemporaneously correlated with the returns given by the repeat sales indices over the 1997 to 2011 period. The bottom of Table 2.3 presents correlations. Clearly, the repeat-sales index returns are highly correlated over the period. However, the IPD series are not: the Goetzmann Index represents approximately 9 percent correlation with the IPD series.

Figure 2.5 depicts the transaction and appraisal based annual indices over the 1998 to 2010 period. The two indices share a similar long-run pattern, but are distinctly different in highlighting peaks and troughs over the period. Both indices suggest that index values were rising over the 2002 to 2006 period. However, there is significant variation in when the rise began. The repeat-sales index suggests that the local trough occurred in 2002, but the IPD index suggests that the trough occurred in 2004. Afterwards, there is expansion in both indices and index levels, until 2006 and 2007, respectively. In 2006, the repeat-sale indices indicate a local maximum, but the IPD index realizes the local maximum a year later. In general, the annual repeat-sales index consistently leads the IPD index by one year. 
Figure 2.5: The London Commercial Property Price Index - Annual \& IPD London Commercial Property Annual Capital Growth Index

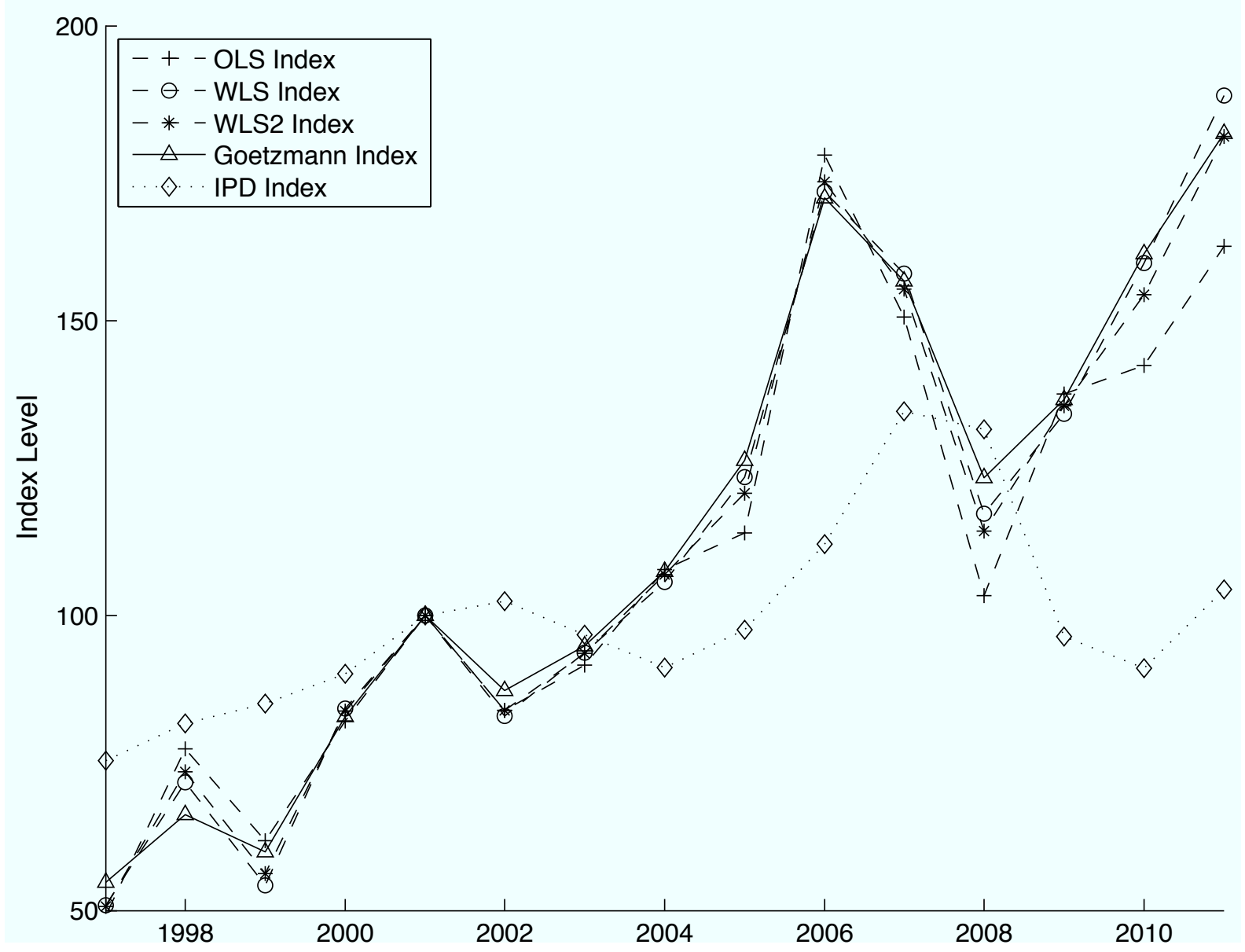

Notes: Figure 2.5 displays the index values for The London Commercial Property Price Indices - Annual and IPD London Commercial Property Annual Capital Growth Index over the 1997 to 2011 period. The left vertical axis is the index level. 2001 is the base index period for the ordinary least squares, weighted least squares, three stage weighted least squares and Goetzmann indices.

\subsection{London and New York City}

The London commercial property sector is one of the most significant real estate markets globally in terms of capital market wealth, cross-border capital movement and global financial stability. London's main competitor for talent, financial market power and business service placement is New York City. Previous literature has looked at general comparisons of transaction levels, capital growth and employment growth in the cities (Sassen, 2001), which suggests that the same dynamic trends in financial market growth and financial services labor participation are impacting both. Coe and Jones (2010) summarize that the highest number of banking/financial services companies and investments and securities companies is located in London and New York City. Moreover, globally the highest number of equities trading and commodities contracts is executed in London and New York City. Lizieri, Baum, and Scott (2000) find that there is a strong link between financial service sector firms, owner-occupation and for- 
eign ownership in the City of London office sector. Based on the previous findings, it would have been logical to assume that the commercial property markets of London and New York City are strongly related.

Table 2.4: London and New York City Transaction Turnover and Cross-Border Capital Flows

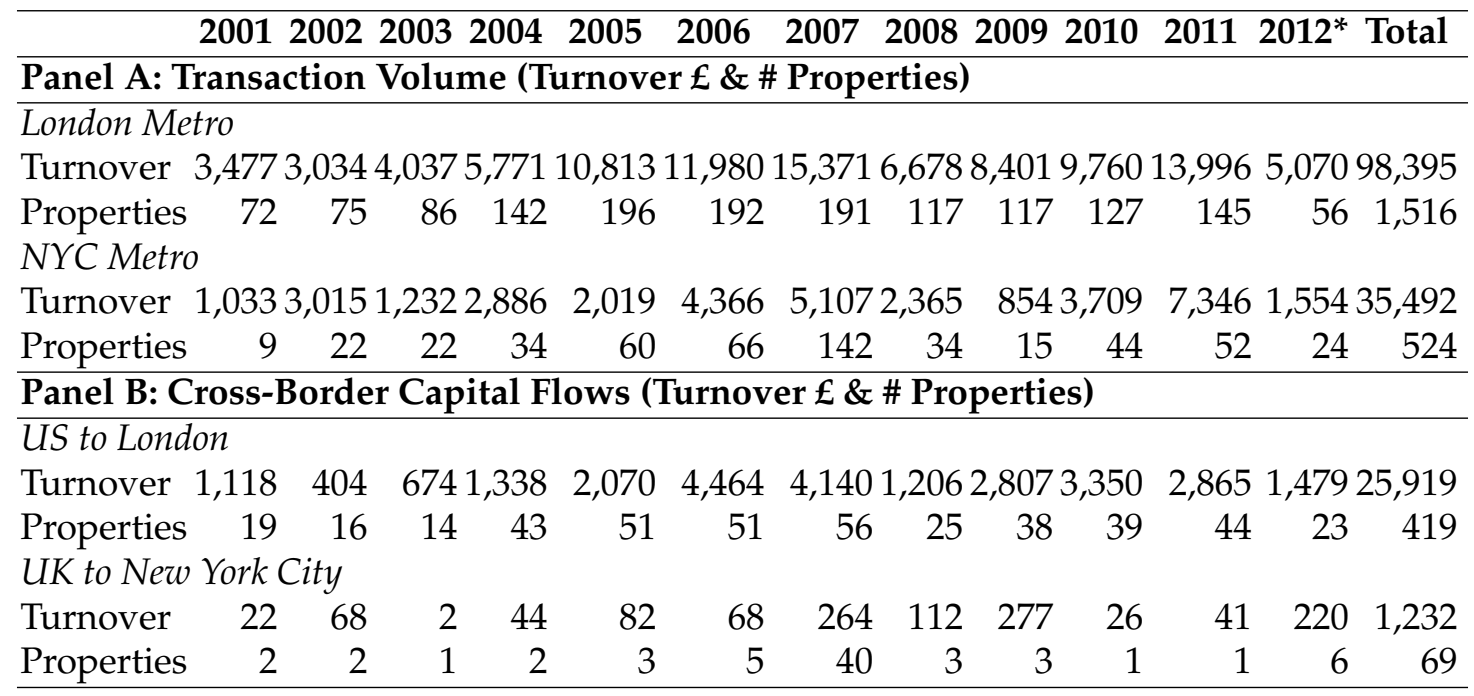

Notes: Table 2.4 presents, using data from the RCA cross-boarder capital dataset, the transaction volume and cross border capital flows in money terms $(£)$ and in number of properties for the London and New York City markets over the 2001 to June $2012^{*}$ period. Turnover is in Emillions.

Along these lines, Holly, Hashem Pesaran, and Yamagata (2011) find that exogenous shocks to New York City housing prices had a lagged impact on London house prices, and thereby the remainder of the UK housing market, over the 1976 to 2008 period. The basis for this result is that prices for London and New York City over this period were not contemporaneously correlated, but correlated with a lag. Be that as it may, the result does not say anything directly about the relationship between the two commercial property markets of London and New York City. In fact, that relationship has not been investigated with the aid of transaction-based indices. Using our quarterly London Commercial Property Price Index and MIT Center for Real Estate New York City Office Quarterly Repeat Sales Index, we are the first to examine the relationship between the return series for both markets.

Holly, Hashem Pesaran, and Yamagata (2011) estimate their model based on an impulse response function. In other words, using a spatial vector autoregressive estimator. Our series is not sufficiently long enough to estimate a meaningful impulse response function in the commercial markets, but there are other comparisons to be made in light of the new availability of a quarterly index for both markets.

Before we turn to the comparison of the two series' return characteristics we first look at transaction volumes and capital flows for London and New York City. Table 
2.4, Panel A outlines the transaction and turnover volume of London and New York City from 2001 to $2012(\mathrm{Q} 2)$ as reflected by deals greater than $\$ 2.5 \mathrm{mln}$ in the RCA transaction database. Over that full time period, aggregate transaction volume in London was almost three times that of New York City. In fact, in these 11.5 years, there has not been a single year in which New York City had higher commercial transaction volume than London.

However, volumes have been far from stable in both markets. Focusing primarily on the period around the financial crisis, London has had high transaction turnover volume since 2001. The maximum yearly turnover occurred in 2007 at $£ 15.3$ bln and just under $£ 11.9$ bln in 2006 with more than a fifty percent decline in 2008. Transaction volume peaked earlier in 2005, declined marginally until 2007 and then decreased by 39 percent in 2008. New York City's turnover underwent a similar path during the 2000s. In 2006 and 2007, transaction turnover reached its highest levels on record at $£ 4.3$ and $£ 5.1 \mathrm{bln}$, respectively. Similarly, physical transaction volume peaked in 2007 and dropped by 76 percent in 2008. In summary, transaction activity is distinctly different in each year for both markets and have distinctly different turnover patterns.

In the capital flows information in Panel B, we see a very big difference between those going West and those going East: flows from the UK into New York City's commercial property market have been very small: only $£ 1.2$ bln over the 11.5 years covered here. This suggests that capital from the UK has had at most a very marginal effect on New York City's market. Although New York City is the highest target for US capital, it is not the whole of foreign direct investment. RCA's cross border capital tracker indicates that since 2007 approximately $£ 4.0$ bln has been invested in all of the US markets. The aggregate capital flow from the US into the London market, on the other hand, has been much bigger, both in absolute terms and in relation to the total transaction volume in London's commercial property market. Just over 25 percent of all transactions are US-originated, so this could have a big influence on London's market.

We now turn to the comparison of our Quarterly London Commercial Property Price Index and MIT Center for Real Estate Quarterly New York City Index based on the same index methodologies. ${ }^{6}$ Table 2.5 highlights the return characteristics of the London and New York City series over the 2001 to 2011 period. Using the Goetzmann specification for London, returns for London and New York City are on average 6.7 and 6.0 percent, respectively. The continuously compounded returns from 2001 to the 2006 for the London series are 57.4 percent, with a subsequent decline of about 11.1 percent. New York City's cumulative returns were 88.9 percent from 2001 to 2008, after which the market subsequently saw a cumulative loss in returns of 22.1 percent. In addition, the London quarterly return series exhibits more volatility than the New

\footnotetext{
${ }^{6}$ The computation of the MIT Center for Real Estate Indices is the basis of the Moody's/RCA New York City Office Repeat Sales Index.
} 
Table 2.5: London and New York City Index Descriptives

\begin{tabular}{lrr}
\hline & London & New York City \\
\hline Return Characteristics: & & \\
Mean Return & 5.98 & 6.68 \\
Std. Deviation & 29.73 & 23.04 \\
Nominal Property Value Levels: & \\
Year of ultimate Peak & $2006 \mathrm{Q} 1$ & $2007 \mathrm{Q} 4$ \\
Year of penultimate Peak & $2007 \mathrm{Q} 2$ & $2008 \mathrm{Q} 1$ \\
Year of last Peak & $2009 \mathrm{Q} 1$ & $2008 \mathrm{Q} 3$ \\
Year of ultimate Trough & $2008 \mathrm{Q} 1$ & $2009 \mathrm{Q} 4$ \\
Year of penultimate Trough & $2008 \mathrm{Q} 1$ & $2008 \mathrm{Q} 2$ \\
Year of last Trough & $2009 \mathrm{Q} 2$ & $2009 \mathrm{Q} 4$ \\
Correlations: & & \\
New York City & -1.46 & - \\
Correlation $N Y_{2001-2005}$ & 5.25 & - \\
Correlation $N Y_{2006-2011}$ & -8.06 & - \\
Correlation $N Y_{t-1}$ & -25.98 & - \\
Correlation $N Y_{t-2}$ & -12.93 & 54.03 \\
Autocorrelation & 14.25 & \\
\hline
\end{tabular}

Notes: Table 2.5 provides the descriptive statistics for The London Commercial Property Index Quarterly and the MIT Center for Real Estate New York City office repeat sales index over the 2001 to 2011 period. Included are return statistics, index turning points and correlations and covariances.

York City series. The standard deviation for the quarterly series is approximately 30 percent, while the New York City series' standard deviation lies at 23 percent.

Nominal property value levels indicate that the ultimate peak over the 2001 to 2011 period occurred in 2006 Q1 for London, and in 2007 Q4 for the New York City series. Subsequently, both return series depict a brief rebound in 2008 with an ultimate trough in 2008 and 2009, respectively. Property value levels suggest that on the surface, the two indices appear correlated. However, we are more interested in the underlying return characteristics.

In addition, the contemporaneous correlation between the two quarterly series is statistically insignificant overall and by sub-period. However, the series appear to comove until 2006 and then diverge. This is an important and surprising result, as prior literature on international diversification in property markets would suggest that these markets are more correlated. We expected to find significantly correlated return series based on the anecdotal evidence in the literature. The New York City index exhibits higher autocorrelation than the London Index.

Figure 2.6 depicts both transaction-based indices for London and New York City. Returns ultimately peaked in 2006 for London and in late 2007 for New York City, and then fell sharply. Although it is also obvious that both markets have experienced a strong rebound, starting in 2009 and 2010, respectively. This recovery is still underway in both markets, despite the fact that financial markets are once again in deep turmoil, and the fact that the health of the financial industry occupying the commercial properties we study here is far from perfect. 
Figure 2.6: London and New York City Repeat Sales Indices

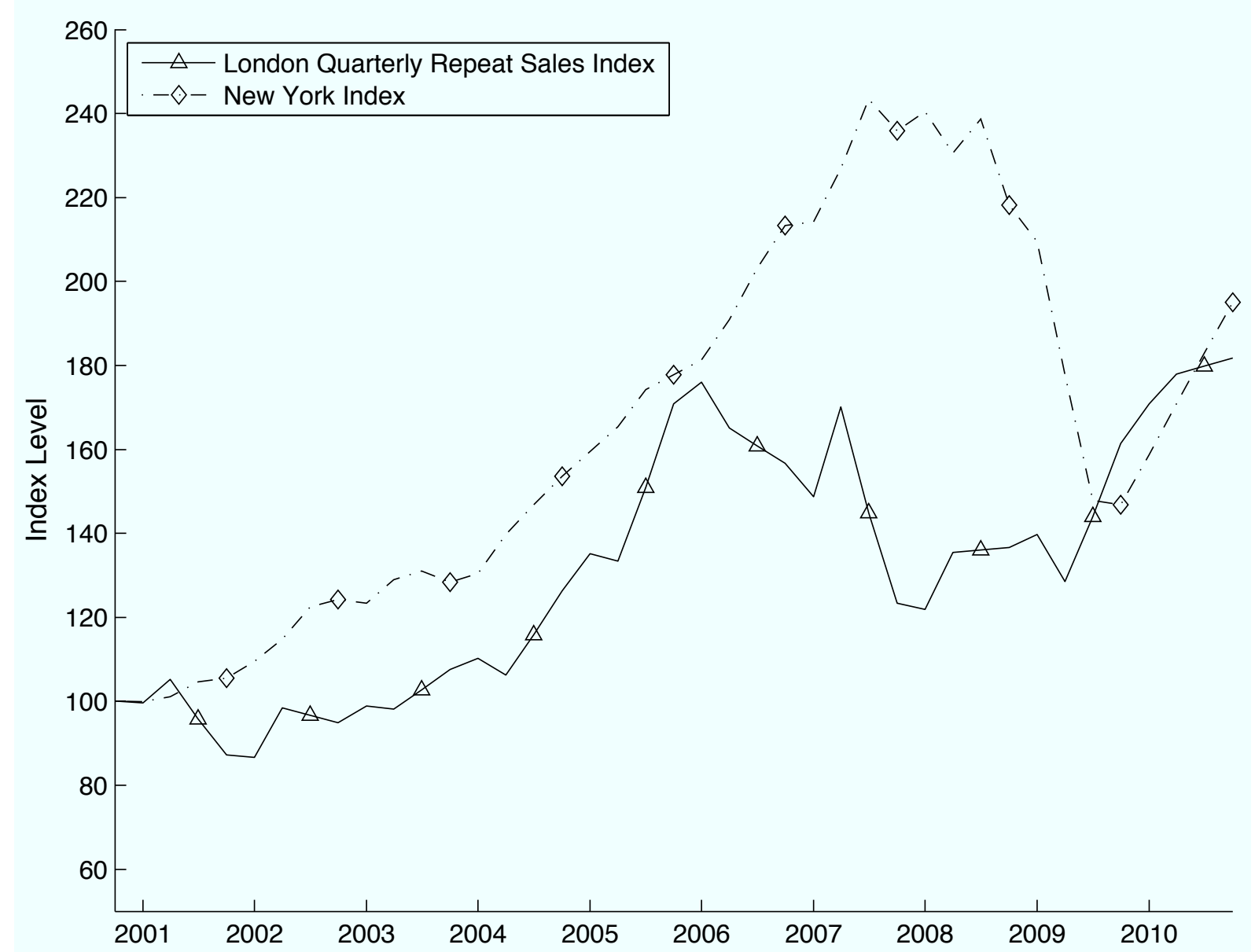

Notes: Figure 2.6 displays the index values for the London Commercial Property Index - Quarterly and MIT Center for Real Estate Quarterly New York City Office Index over the 1998 to 2011 period. The left vertical axis is the index level.

Overall, we find two primary differences between the two markets. First, for the 2001 to 2011 period, turning points in commercial real estate in New York City do not lead London's markets. On the contrary, the 2006/2007 turn in London's property cycle occurred almost one full year ahead of New York City's cycle. This is even corroborated by the IPD valuation series, where the turning point for the London market was seen in 2007 and for that of New York City in 2008. Secondly, the two return series are not correlated contemporaneously, nor correlated with a one or even two quarter lag, which suggests strong diversification effects from a combination of London and New York City commercial properties.

In contrast, there are two main similarities between the markets. Both New York City and London markets share remarkably in the boom period until the collapse in the markets in 2006/2007. Moreover, both markets share in the same recovery in 2010 and 2011, despite the fact that the global financial markets are still in turmoil in 2012. 


\subsection{Conclusion}

We examine the realized returns for investors in London commercial real estate between 1997 and 2011. We estimate a repeat sales transaction-based index at the metro level, combining two transaction datasets, noise filtering techniques and high frequency conversion to produce a quarterly frequency index. The estimation strategy incorporates the most recent techniques in repeat sales index construction techniques and applies them to the most liquid commercial-property market in the world. Results suggest that their is sufficient liquidity across all market periods for a metro level index. However, returning to the extant literature on index construction, we have provided another empirical outcome to test the trade-off between noise and lag in index construction. Overall, there was a decrease in noise and lag, but future techniques should concentrate on sufficiently ridding indices of 'noise.'

The resulting index differs markedly from IPD's London Commercial Property Annual Capital Growth Index. It has higher volatility and lower autocorrelation, while it leads the IPD Index in the timing of troughs and peaks by approximately 1 year. These differences are in line with the previous US based index literature (Fisher, Gatzlaff, Geltner, and Haurin, 2003) and (Geltner and Fisher, 2007).

The results of the index are comparable to the MIT Center for Real Estate Repeat Sales New York City Office Index on the grounds of capital return and volatility. However, the results presented here suggests that London's market and that of New York City's are not consistently related. Correlations are low and not significant, even when using lags.

Repeat sales indices are absent in the commercial real estate sector in Europe (Financial Stability Board and International Monetary Fund, 2010). This leads to a lack in timely yardsticks for the commercial property markets, while these are strongly needed by Central Bankers, policy makers, and property researchers. For London, a global real estate investment center, a repeat sales index is a contribution to the suite of ex-post analysis tools for investors, regulators and academics alike. 


\section{Appendix A. Data Restrictions}

Following Geltner and Fisher (2007) and Geltner and Bokhari (2008) and adapted for our data set, we employ specific controls for data inclusion in the repeat sales or spatialtemporal index. The rules mainly restrict spurious data or speculation in the markets. In addition, employing the rules ensures that the same cross-section of data is comparable to MIT Center for Real Estate's transaction price index. The exact filtering process is difficult to report as a transaction event may belong to one or many of the exclusion criteria. However, we report the exclusion criteria along with the number of observations that were excluded on those grounds.

1. "Flips" filter. All properties in the index are held for 1 year or more. This filter prevents "flipped" properties from entering the index. The flips filter removed 186 transactions.

2. Portfolio transactions. All properties that are a part of portfolio (multiple-property) transactions, 546 in the sample, are discarded.

3. Excessively old data. All properties with first transactions prior to 1996 are dropped due to data sparsity. Data collection began for EGi's electronic database in 1973. Transactions were sparse over the 1973-1996 period, for a total deletion of 627 transactions with on average 6.5 transactions per quarter. Our data does not have time-series information from RCA prior to 2000.

4. Incomplete information. Properties without transaction price or date are dropped for the repeat sales analysis, 164 observations.

5. Consistent Usage. Properties must be comparable in terms of use and size from the first sale to the second. Thus, they cannot change property types, i.e., become residential, or if they have been renovated a flag must be included. There was no filtering necessary on the sample due to changes in property type.

6. No major change in size. The rentable area must not change between transactions. If so, then the change is discarded. There are 490 observations that undergo a change in size.

7. Extreme yearly returns or losses are also filtered from the analysis. Transactions that had a higher yearly return than 50 percent within the first 16 quarters, i.e., 4 years were removed. As well as those that had a yearly loss greater than 50 percent. 


\section{Appendix B. The Quarterly London Index}

Table 2.6: London Quarterly Repeat Sales Index

\begin{tabular}{crcc}
\hline \multicolumn{1}{c}{ Date } & \multicolumn{1}{c}{ Value } & Date & Value \\
\hline 1996-Q1 & 100.00 & 2004-Q1 & 196.55 \\
1996-Q2 & 102.07 & $2004-\mathrm{Q} 2$ & 189.27 \\
1996-Q3 & 99.87 & $2004-\mathrm{Q} 3$ & 206.39 \\
1996-Q4 & 97.72 & 2004-Q4 & 225.06 \\
1997-Q1 & 101.53 & $2005-\mathrm{Q} 1$ & 240.89 \\
1997-Q2 & 106.57 & $2005-\mathrm{Q} 2$ & 237.82 \\
1997-Q3 & 112.16 & $2005-\mathrm{Q} 3$ & 269.05 \\
1997-Q4 & 118.04 & $2005-\mathrm{Q} 4$ & 304.38 \\
1998-Q1 & 116.63 & $2006-\mathrm{Q} 1$ & 313.66 \\
1998-Q2 & 119.09 & $2006-\mathrm{Q} 2$ & 294.25 \\
1998-Q3 & 112.83 & $2006-\mathrm{Q} 3$ & 286.70 \\
1998-Q4 & 106.89 & $2006-\mathrm{Q} 4$ & 279.34 \\
1999-Q1 & 112.36 & $2007-\mathrm{Q} 1$ & 265.00 \\
1999-Q2 & 116.50 & $2007-\mathrm{Q} 2$ & 303.25 \\
1999-Q3 & 131.21 & $2007-\mathrm{Q} 3$ & 258.20 \\
1999-Q4 & 147.77 & $2007-\mathrm{Q} 4$ & 219.84 \\
2000-Q1 & 158.71 & $2008-\mathrm{Q} 1$ & 217.17 \\
2000-Q2 & 146.46 & $2008-\mathrm{Q} 2$ & 241.35 \\
2000-Q3 & 161.56 & $2008-\mathrm{Q} 3$ & 242.37 \\
2000-Q4 & 178.21 & $2008-\mathrm{Q} 4$ & 243.39 \\
2001-Q1 & 177.65 & $2009-\mathrm{Q} 1$ & 249.11 \\
2001-Q2 & 187.42 & $2009-\mathrm{Q} 2$ & 229.10 \\
2001-Q3 & 170.70 & $2009-\mathrm{Q} 3$ & 256.68 \\
2001-Q4 & 155.48 & $2009-\mathrm{Q} 4$ & 287.59 \\
2002-Q1 & 154.33 & $2010-\mathrm{Q} 1$ & 304.40 \\
2002-Q2 & 175.33 & $2010-\mathrm{Q} 2$ & 317.18 \\
2002-Q3 & 172.17 & $2010-\mathrm{Q} 3$ & 320.55 \\
2002-Q4 & 169.07 & $2010-\mathrm{Q} 4$ & 323.97 \\
2003-Q1 & 176.19 & $2011-\mathrm{Q} 1$ & 319.14 \\
2003-Q2 & 175.02 & $2011-\mathrm{Q} 2$ & 311.05 \\
2003-Q3 & 183.14 & $2011-\mathrm{Q} 3$ & 311.05 \\
2003-Q4 & 191.63 & $2011-\mathrm{Q} 4$ & 311.05 \\
\hline
\end{tabular}

Notes: This table reports the index values for the London Quarterly Repeat Sales Index for each quarter. The index construction follows the methodology put forward in Bokhari and Geltner (2012). 


\section{Chapter 3}

\section{Supply, Demand and the Value of Green Buildings*}

\subsection{Introduction}

In the current debate on global climate change, buildings are increasingly considered by policy makers, corporations and institutional investors to represent vehicles for achieving energy efficiency, carbon abatement and corporate social responsibility. This shift in the perception and use of buildings is gradually moving commercial property markets towards increased levels of energy efficiency and 'sustainability.'

Anecdotally, London's 2015 skyline provides testimony to this development. For example, The Shard, towering 72 stories and 306 meters into the London sky, is expected to consume 30 percent less energy than an otherwise similar building; Bishopsgate Tower generates electricity through 2,000 square meters of photovoltaic cells; and Broadgate Tower, through its extensive heat recovery system and efficient cooling plant, aims to reduce carbon emissions by 40 percent. In general, for most of the new or renovated commercial real estate coming to market in London, energy efficiency and sustainability features are primary building characteristics.

Part of the focus on energy efficiency is driven by the UK's regulatory framework regarding the carbon abatement and energy efficiency potential of the built environment. This framework is embedded in EU legislation, where buildings represent a strategic cornerstone of the recently recast Energy Performance and Buildings Directive and the Energy Efficiency Plan of 2011. To comply, the UK has enforced building energy efficiency regulations through two initiatives. First, it has implemented the mandatory display of Energy Performance Certificates, Declaration of Energy Certificates and zero carbon building initiatives. Second, the UK has instituted a carbon market, solely aimed at building energy consumption, with the Carbon Reduction Commitment of 2010. This legislation is among the first to price the negative exter-

\footnotetext{
${ }^{*}$ This chapter is co-authored with Piet Eichholtz (Maastricht University) and Nils Kok (Maastricht University, University of California - Berkeley) and is forthcoming in Urban Studies.
} 
nalities from energy consumption in buildings and ranks landlords through carbon performance league tables. Besides regulation, private sector involvement in the energy efficiency of buildings is growing. In 1990, the UK commercial real estate market was the first to introduce a private third-party assessment tool to measure a building's environmental impact - the BRE Environmental Assessment Method (BREEAM). Moreover, London's largest commercial landlords, including British Land, Grosvenor, Hammerson, Hermes and Land Securities, have taken action through the formation of the Better Buildings Partnership, with the aim to cut carbon emissions and to improve the 'sustainability' of London's commercial buildings.

Despite these initiatives, the financial implications of the transition to a more efficient building stock are not yet clear. This information becomes more important as the supply of commercial buildings certified to be 'green' increases, demand for such buildings is affected by more private sector attention to energy-efficient buildings, and regulations surrounding the energy efficiency and carbon abatement potential of buildings are tightened. Importantly, there is a notable degree of uncertainty and skepticism surrounding the economics of green building in the UK.

Prior published literature on the financial implications of green certification mostly focuses on the US, and results generally indicate a positive relationship between environmental certification and financial outcomes in the marketplace. Eichholtz, Kok, and Quigley (2010) document significant and positive effects on market rents and selling prices following environmental certification of office buildings. Relative to a noncertified sample of conventional office buildings, LEED or ENERGY STAR labeled office buildings achieve rents that are about two percent higher, effective rents that are about six percent higher, and premiums to selling prices as high as 16 percent. Other studies confirm these findings (Fuerst and McAllister, 2011a; Miller, Spivey, and Florance, 2008) and importantly, these results appear robust over the course of the financial crisis - the effect is not dented by the recent downturn in property markets (Eichholtz, Kok, and Quigley, 2013).

For investors, it is important to understand the value and risk implications of the increased focus on green building in the commercial real estate sector. In the UK, green buildings have expanded over the past decade, accounting for about ten percent of the current stock. However, market performance analysis of green certified commercial real estate is scant within the UK. ${ }^{1}$ This is surprising, as London represents one of the largest commercial real estate markets in the world. ${ }^{2}$ Moreover, London is a dominant

\footnotetext{
${ }^{1}$ Fuerst and McAllister (2011b) document for 24 BREEAM-rated properties in a sample of UK office buildings that there is no significant impact on appraised capital values and rental values. Estimated equivalent yields have a very small and negative coefficient. In addition, there is one marketbased initiative on this topic: the Investment Property Databank (IPD) and Hermes publish quarterly their IPD/IPF Sustainable Property Index for UK 'sustainable' properties. The 'sustainable' commercial properties are retrieved from the IPD database, using a questionnaire covering building quality, energy efficiency, waste management, building accessibility, water efficiency and flood risk.

${ }^{2}$ Using the Real Capital Analytics Transaction tool, the ranking for London's transaction turnover
} 
player in the global financial system, hosting a myriad of international financial and service sector firms (Clark, 2002). London is capitalizing on the nascent green economy, creating 'complementary' legal and financial instruments to support new markets, e.g., carbon markets and energy efficiency policy reforms (Knox-Hayes, 2009).

This chapter investigates the dynamics behind the financial performance of London's environmentally certified commercial building stock within the context of a changing supply and demand framework, measured ex-post by sales transactions and achieved rents over the 2000 to 2009 period. Addressing the economic fundamentals driving the value of green (i.e., supply and demand), this chapter makes two contributions to the nascent literature on commercial building energy efficiency. First, we investigate the role of green building supply on market dynamics by assessing the impact of growing competition of environmentally certified real estate on the prices of 'BREEAMcertified' and 'non-certified' office buildings. Second, we analyze in more detail the demand for environmentally certified real estate, by including rental contract features and identifying the buyers of commercial properties, exploring their impact on real estate rents and prices, respectively.

To identify London's stock of certified buildings, we utilize BRE's database on green building certification - BREEAM. We match BREEAM-labeled buildings to a rental database over the 2005 to 2010 period. We then construct a database using information from four data sources, and complement these with manual collection of information on building quality. This results in a final sample of 1,149 rental transactions, of which 64 rental transactions are in commercial properties certified by BREEAM. In addition, we match the BREEAM address files to sales transactions over the period 2000 to 2009. Following the same data collection procedure, we obtain a sample of 2,103 observations, including 68 BREEAM-certified transactions.

At the point of means, we document premiums for certified buildings of 19.7 percent for rental transactions and 14.7 percent for sales transactions, relative to noncertified buildings in the same locational cluster. A comparable analysis for Chicago, New York City and Washington DC depicts a similar premium for transactions of certified buildings in the US. Importantly, we document that growth and concentration in the green building supply has a negative effect on the marginal rents and prices paid for green buildings as compared to non-certified buildings in the same neighborhood, but a positive impact on the average level of rents and prices of all commercial buildings in that neighborhood - 'green gentrification.' The diffusion of certified real estate over the past decade has contributed to the gentrification of London's commercial districts. However, the growth in environmentally certified buildings has led these properties to become the standard rather than the exception, which has an impact on their pricing in the marketplace. Finally, investor type and contract features have a modifying impact on prices of certified buildings, and it is therefore imperative for

remains consistently in the global top five. 
these factors to be included in future research on this topic.

The remainder of this chapter is organized as follows. Section 3.2.1 introduces and discusses the UK market for green real estate. In Section 3.3, we discuss BREEAM and financial data obtained for commercial buildings in London. In Section 3.4, we outline the methodology for our analysis. In Section 3.5, we present the results of the formal analysis. Section 3.6 provides a discussion and some conclusions.

\subsection{The UK Market for Green Office Space}

\subsubsection{Environmental Certification for Commercial Buildings}

Building certification facilitates the intermediation process between building developers, investors and tenants in the context of what constitutes 'quality' or 'efficiency' in a building. This intermediation process may reduce investment in 'lemons' (Akerlof, 1970). For 'green' real estate, rating agencies may reduce adverse selection by acting as accredited and recognized assessors of environmental information. Thus, building performance disclosure may lead to reduced investment in environmentally underperforming buildings.

Within the UK, there are two private intermediaries of environmental information on buildings, BREEAM and LEED. In 1990, the UK's Building Research Establishment (BRE) began the independent certification of the environmental performance of buildings in the UK. The first commercial office space was certified in 1999. Under the 2008 scheme, a commercial office can receive BREEAM certification if it meets the minimum standards set by BRE in eight core dimensions: building management, health and well being, energy efficiency, transportation efficiency, water efficiency, material usage, pollution and land use ecology.

Competition for third-party environmental certification in the UK market is mainly with LEED, the Leadership in Energy and Environmental Design rating system designed by the US Green Building Council. The purpose of LEED is similar to that of BREEAM: increasing the energy efficiency and sustainability of the built environment through the certification of exemplary buildings. ${ }^{3}$

\subsubsection{Supply of Green Office Space}

Green buildings are considered different from conventional buildings because they command a different set of technological and human capital requirements. Green building supply is most likely driven by construction costs, other certified buildings'

\footnotetext{
${ }^{3}$ LEED also operates using a point system with the main focus on the following elements: sustainable sites, water efficiency, energy and atmosphere, materials and resources and indoor environmental quality.
} 
price signals, the prices and availability of raw materials and human capital to construct green buildings, advances in green technology, and government policies mandating energy efficiency (See Kok, McGraw, and Quigley, 2011). Thus, growth in the green building supply may have a dynamic impact on equilibrium prices over the 2000 to 2009 period.

Figure 3.1 displays the geography of UK office buildings labeled by BREEAM by level of certification, which corresponds to a label ranging from 'Pass' to 'Outstanding.' The map displays the dispersion of green office buildings across the UK, with a significant cluster of buildings located in London (368 buildings, or 23 percent of the BREEAM office population). Bristol, Manchester, Newcastle-Upon-Tyne and Glasgow are other cities with relatively high concentrations of green buildings (a total of 171 buildings, or 10 percent of the BREEAM office population). Highly rated buildings are mainly in London, with the number of Excellent and Very Good rated buildings far surpassing other markets (181 buildings).

\subsubsection{Demand for Green Office Space}

Improving the bottom line through building energy efficiency is often reported as one of the direct economic benefits for real estate investors when considering the energy efficiency and sustainability of a portfolio. For example, Jones Lang Lasalle (2011) reports for 115 office properties in their portfolio for which the energy efficiency was improved, the average realized savings for 2007 and 2008 were $1.4 \mathrm{mln}$ and $1.9 \mathrm{mln}$, respectively. British Land reported a 12 percent decrease in energy use in 2009 (some 11.1 GW of electricity), amounting to 700,000 in annual energy savings. ${ }^{4}$

In addition, institutional investors may have different investment beliefs than private investors, introducing corporate social responsibility criteria into their real estate investment strategy. A recent sustainability benchmark, commissioned by 35 of the largest institutional investors around the globe, documents institutional investor engagement in the building sector's sustainability. The property sector, by being mindful of management and implementation of energy efficiency and sustainability within their own portfolios, reduced 1.8 percent in carbon emissions and $\$ 1$ bln in energy savings over the 2010-2011 period (Kok, Bauer, and Eichholtz, 2011).

The most important factor determining demand for rental space is employment in the legal and financial service sectors (Wheaton, Torto, and Evans, 1997). In the US, the financial service sector (i.e., legal services, national commercial banks, executive legislative and general office) began occupying LEED and ENERGY STAR certified space over the 2004-2009 period (Eichholtz, Kok, and Quigley, 2011). Data from London is indicating a similar trend, where financial services firms, advertising and insurance sectors are dominant users of green space. For example, CBRE reports that 58 percent

\footnotetext{
${ }^{4}$ British Land. Achieving More Together: Corporate Responsibility Summary Report 2010.
} 
Figure 3.1: Geography of Green Buildings in the UK and London by BREEAM Rating

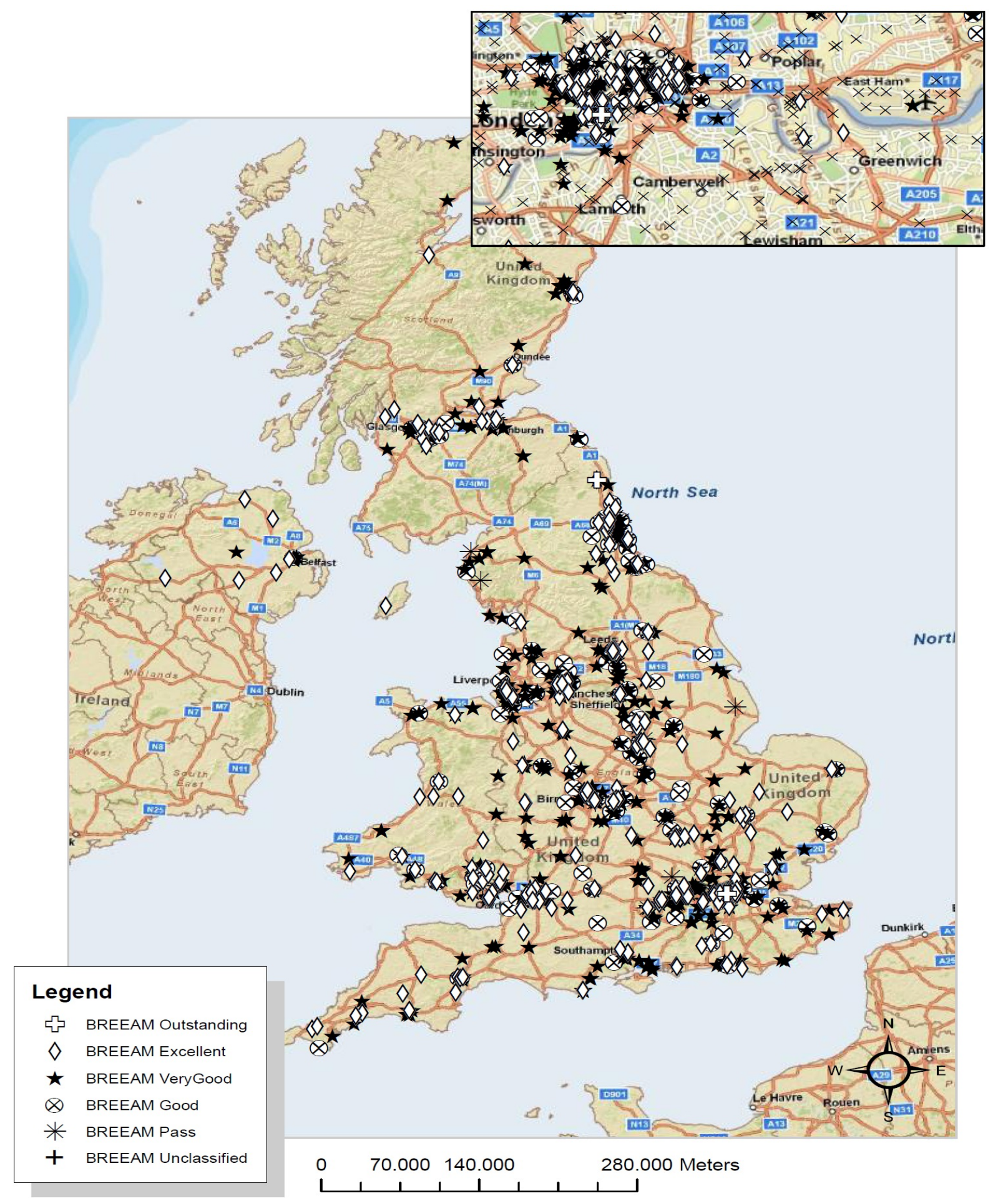


of tenants find energy efficiency 'essential' and 50 percent find other green attributes 'essential' (CBRE, 2010).

Anecdotally, the move of tenants towards green real estate is due to enhanced reputation benefits, corporate social responsibility mandates and employee productivity (Nelson and Rakau, 2010). Shifting tenant preferences suggests tenants are using the buildings they occupy to communicate their corporate vision to shareholders and employees. The literature on corporate social responsibility (CSR) has investigated this link between corporate social performance, reputation benefits and employer attractiveness (Margolis and Walsh, 2003; Turban and Greening, 1997) although claims are mostly based on case studies.

\subsection{UK Property Market Data}

The UK's primary commercial real estate market is the London metropolitan market. London is currently the most active commercial real estate market in the world (See Chapter 2 of this thesis). Any UK study will be biased towards London, leading to the following concerns: first, in hedonic models at the national level, the 'Londoneffect' creates inconsistent estimates in pricing common building characteristics, such as age, story, renovations and amenities, as these features are specific to London and its history. Second, a sample combining the commercial property markets of London, Manchester, Bristol and Leeds is geographically clustered in London, which is a concern when location is a principal factor in modeling rental and transaction prices. Third, UK databases overwhelmingly report rental and transaction observations in London, as transaction and building characteristic knowledge is more abundant for the London metro area than for any other region in the country. Given these three concerns, we focus on the London metropolitan area in this chapter.

To analyze the economic implications of environmentally certified commercial real estate in London, we match BREEAM address files to a combined dataset of rents and property transactions maintained by CoStar FOCUS ${ }^{5}$ and Estates Gazette Interactive (EGi) $^{6}$ over the periods 2005 to 2009 and 1999 to 2009, respectively. Over these periods, CoStar covered a sample of some 5,028 commercial leasing transactions and EGi and CoStar covered 4,500 sales transactions across London. However, CoStar data does not include basic building characteristics, such as age, stories, amenities, third-party assessment of building quality, etc. To collect these missing hedonic features, we consult three databases: Emporis, a global building design database, EGi, and Real Capital Analytics. In addition, we hand-collect building features from building prospec-

\footnotetext{
${ }^{5}$ CoStar FOCUS is a commercial property information platform covering deals, building reports, town reports, and values. For this analysis we used the CoStar FOCUS Deals Database.

${ }^{6} \mathrm{EGi}$ is a comprehensive commercial property database covering news, building reports, deals, auction, availability and occupier data and values analysis. For this analysis we utilized the Building Reports database to collect detailed building information.
} 
tus and advertisements, and went on physical site visits in London. Approximately 2,500 rental transactions are collected for London utilizing this manual effort. For sales data, a similar data collection procedure was conducted. This extensive data collection procedure, coupled with removal of erroneous data and portfolio sales, resulted in a sample of 1,149 lease transactions, including 64 BREEAM-certified leases, and a sales transaction sample of 2,103 observations, including 68 BREEAM-certified transactions.

Our dataset contains information on a building's environmental characteristics, i.e., the BREEAM certification status, quality characteristics, address, distance to local transportation networks, transaction date, investor types and contract features. Ex ante, we have the following expectations concerning quality characteristics, contract features, market competition, investor types and location:

Quality Characteristics: Rental unit size will play a significant and positive role in price determination. In addition, standard hedonic features, like age, stories, amenities and renovation are expected to have a significant and positive impact, where younger, taller and renovated buildings with amenities will have higher rental prices. Moreover, differences between the green and non-certified sample may manifest from differences in building quality variables. In the UK, building quality is rated on a per floor basis. Thus, a building represents a collection of different building qualities. We expect that building quality will have a positive impact on prices and modifying impact on the value of certification.

Contract Features: Longer lease lengths signal longer durations in cash flows, which implies less fluctuation in tenants and more rental stability, conditional upon tenants' credit quality. This suggests a positive impact on price. However, longer rent-free periods can signal larger discounts in rental cash flows, thus reducing prices. ${ }^{7}$ Moreover, contract features potentially have a moderating effect on certification. Furthermore, prices may also be discounted when buildings are on the market for a longer period.

Market Competition and Gentrification: Market competition may substantially influence rental prices in certified buildings. Literature on development suggests that competition plays a role in development decisions (see Grenadier, 2002, and Bulan et al., 2009, for the role of competition in influencing commercial real estate investments). We create a 'Certified Building Supply' variable, which is a numerical measure of all BREEAM-certified buildings within a 500-meter radius at the time of renting or sale. The value of this variable is similar for the green building and all non-green buildings in a given cluster. Ex ante, as the number of certified buildings in a micro-location increases, we anticipate moderating effects on the marginal rents and prices commanded by certified buildings. However, the literature on neighborhood gentrification suggests that potential increases in social and middle class environmental improvements can lead to positive new build 'gentrification' for neighborhoods or 'super-gentrification'

\footnotetext{
${ }^{7} \mathrm{~A}$ rent-free period is a time frame of one month or greater in a rental contract, during which no rental payments are required. It is generally a concession to tenants signing lease contracts in commercial real estate.
} 
(Butler and Lees, 2006). Thus, we suspect that increasing the number of renovated or new certified buildings in central London will add to the average locational value of a neighborhood.

Investor Types: Theoretically, there should be no anticipated price difference for different investor types. However, principals and agents of financial capital may have different investment criteria and mandates. Principals, like private developers and investors manage their own financial capital, whereas agents, such as real estate investment managers (e.g., $\operatorname{REITs}^{8}$ ), institutional investors, and municipal government investors manage financial capital on behalf of shareholders, trustees and communities. Thus, the type of investor may have an impact on prices.

Location: Following standard methodology, we control for building location using post- codes and transportation networks in London. London is broken down into 'London sub post-codes' the 1-3 letter prefix, which corresponds to its compass location. Transportation stations (i.e., UK's National Rail System, London Tube Stations and Docklands Light Rail) are geocoded using latitude and longitude, and station distances (within one kilometer) to buildings are then calculated. To control for accessibility for drivers and cyclists, we use Ordinance Survey road networks to calculate metric unit distances to the buildings. The physical distances for tube stations, local roads and motorways have in the past had inconsistent impacts on commercial rents and prices (Debrezion, Pels, and Rietveld, 2007), but may have an economically significant impact on prices for London.

\subsubsection{Summary Statistics}

Table 3.1 shows the dependent and independent variables used in the analysis, comparing the average characteristics of green buildings in the sample with buildings in the non-certified sample. BREEAM-certified buildings have higher achieved rents, on average, than control buildings, but the variability of rents is higher in green buildings. The size of leases in green buildings is larger, on average, than rental transactions in the non-certified sample, by about 1,100 square meters. More than half the certified sample is renovated, about double compared to the non-certified sample. Amenities are available in 51 percent of certified rentals and 68 percent of the non-certified rental samples. ${ }^{9}$ Building quality variables suggest that more than 75 percent of the BREEAM-certified sample is new or renovated, which is comparable to the non-certified sample. The distance to the nearest train stations within 500 meters from BREEAM-certified rentals is

\footnotetext{
${ }^{8}$ Real Estate Investment Trusts are tax-exempt real estate companies whose tax designation requires a 90 percent redistribution of taxable income to their investors.

${ }^{9}$ One or more of the following amenities are in the transacted building or rented space: 24-hour access, 24-hour security, air conditioning, atrium, bicycle facilities, building reception, central heating, commissionaire, concierge, dockside, double glazing, electric heating, entry phone, gas central heating, gym, information point, lift(s), loading bay(s), marble ceilings, metal ceilings, natural light, parking spaces, raised floors, roof terrace, separate entrance, suspended ceilings.
} 
greater by 50 meters. It is interesting to note that green buildings are further from A roads and $\mathrm{B}$ roads on average, with comparable variability.

The average lease length in green properties is longer by almost three years and with comparable variability to the non-certified sample, but the rent-free period is longer by about three months, with greater variation than the non-certified rental samples. The average number of days that BREEAM-certified buildings are on the market is longer. The 'Certified Building Supply' variable shows that, on average, BREEAMcertified properties have seven other certified buildings in their immediate area at the time of the rental transaction, whereas the non-certified rental samples have, on average, four green buildings in their immediate neighborhood.

In our sample, 52 percent of BREEAM-certified buildings are owned by a real estate or institutional investor, as compared to 48 percent of control buildings. Moreover, the municipal and government sector owns just seven percent of the buildings in the sample.

Non-parametric comparisons between the sample of BREEAM-certified transactions and the sample of non-certified transactions yield similar results. The variable approximating competition in the sales transaction market is noteworthy. For BREEAMcertified buildings there are on average five green buildings in a given 500 square meter radius at the time of transaction, while the non-certified sample has only three such buildings, on average.

\subsection{Methodology}

We investigate the economic implications of environmental certification for London commercial office buildings through an ex-post transaction-based hedonic model (Rosen, 1974). We use the sample of BREEAM-rated office buildings and a non-certified sample of conventional office buildings to estimate a semi-log equation relating the office rents per net square meter (or the selling price per net square meter) to the hedonic characteristics of a building:

$$
\log P_{i}=\alpha+\beta X_{i}+\delta g_{i}+\varepsilon_{i}
$$

where the dependent variable is the logarithm of the rental price (selling price) per net square meter $P_{i}$ in commercial office building $i . X_{i}$ is a vector of hedonic characteristics (e.g., age, stories, size, public transportation accessibility etc.), rental contract features (e.g., lease length and rent-free period), market signals (days on market), investor types, and macro-economic conditions (e.g., quarterly time dummies) of building $i$, and $g_{i}$ is a dummy variable with a value of 1 if building $i$ is rated by BREEAM and zero otherwise. $\alpha, \beta$ and $\delta$ are estimated coefficients and $\varepsilon_{i}$ is an error term.

We estimate equation (3.1) using OLS corrected for heteroskedasticity with clus- 
Table 3.1: Comparison of BREEAM-certified and Non-certified Samples

\begin{tabular}{|c|c|c|c|c|c|}
\hline & \multirow{2}{*}{\multicolumn{2}{|c|}{$\begin{array}{c}\text { Rental Sample } \\
\text { BREEAM-certified Non-certified }\end{array}$}} & \multicolumn{2}{|c|}{ Sales Sample } \\
\hline & & & & BREEAM-certified & n-certified \\
\hline & Observations & 64 & 1,085 & 68 & 2,035 \\
\hline & Achieved Rent/Sales Price & 1,270 & 591 & 119,767 & 84,873 \\
\hline & (GBP in thousands) & $(2,470)$ & $(1,640)$ & $(90,413)$ & $(178,063)$ \\
\hline & Achieved Rent/Sales Price & 521 & 429 & 7,433 & 16,175 \\
\hline & (GBP/net sq.meter) & $(137)$ & (177) & $(5,269)$ & $(55,962)$ \\
\hline & Certified Building Supply** & 7.21 & 4.21 & 4.64 & 2.53 \\
\hline & (building count) & $(4.21)$ & $(4.79)$ & $(5.21)$ & $(3.41)$ \\
\hline & Unit Size/ Building Size & 2,232 & 1,149 & 20,672 & 15,720 \\
\hline & (net square meters) & $(3,821)$ & $(3,031)$ & $(16,483)$ & $(26,146)$ \\
\hline & Stories & 18 & 10 & 11 & 10 \\
\hline & (number) & (15) & (9) & (7) & (9) \\
\hline E. & Age & 26 & 29 & 33 & 22 \\
\hline & (number) & $(25)$ & $(27)$ & $(36)$ & (25) \\
\hline$\stackrel{50}{0}$ & Amenity & 0.51 & 0.68 & 0.58 & 0.67 \\
\hline & (percent) & $(0.50)$ & $(0.47)$ & $(0.50)$ & $(0.47)$ \\
\hline 承 & Building Renovated & 0.69 & 0.56 & 0.68 & 0.47 \\
\hline$\stackrel{3}{\dddot{2}}$ & (percent) & $(0.47)$ & $(0.50)$ & $(0.47)$ & $(0.50)$ \\
\hline$\stackrel{\overparen{3}}{3}$ & New or renovated & 0.76 & 0.69 & 0.97 & 0.80 \\
\hline 点. & & $(0.43)$ & $(0.46)$ & $(0.14)$ & $(0.37)$ \\
\hline & Second hand & 0.24 & 0.29 & & \\
\hline & & $(0.43)$ & $(0.45)$ & & \\
\hline & Being Built & 0.00 & 0.02 & & \\
\hline & & $(0.06)$ & $(0.13)$ & & \\
\hline & Distance to Nearest Train Stations* & 423 & 457 & 408 & 378 \\
\hline تُ & (meters) & $(169)$ & $(220)$ & $(201)$ & $(200)$ \\
\hline$\frac{\pi}{0}$ & Distance to Nearest A Roads & 267 & 150 & 147 & 162 \\
\hline$\stackrel{0}{\rightleftarrows}$ & (meters) & $(182)$ & $(179)$ & $(162)$ & $(162)$ \\
\hline$\stackrel{0}{\Xi}$ & Distance to Nearest B Roads & 844 & 495 & 725 & 644 \\
\hline 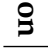 & (meters) & $(432)$ & $(421)$ & $(453)$ & $(475)$ \\
\hline & Real Estate & & & 0.33 & 0.28 \\
\hline $\bar{F}$ & & & & $(0.47)$ & $(0.45)$ \\
\hline కై & Institutional & & & 0.19 & 0.20 \\
\hline$\frac{\infty}{0}$ & & & & $(0.39)$ & $(0.40)$ \\
\hline 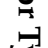 & Developer & & & 0.17 & 0.02 \\
\hline 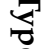 & & & & $(0.38)$ & $(0.13)$ \\
\hline$\stackrel{0}{=}$ & Municipal/ Government & & & 0.07 & 0.03 \\
\hline 胥 & & & & $(0.25)$ & $(0.18)$ \\
\hline$\hat{0}$ & Private & & & 0.11 & 0.30 \\
\hline$\stackrel{\Xi}{\Xi}$ & & & & $(0.32)$ & $(0.46)$ \\
\hline & Unknown & & & 0.13 & 0.17 \\
\hline & & & & $(0.34)$ & $(0.38)$ \\
\hline & Days on Market & 868 & 440 & & \\
\hline & & $(644)$ & $(403)$ & & \\
\hline 0 & Lease term & 10 & 7 & & \\
\hline$\underset{2}{2}$ & (years) & (4) & (4) & & \\
\hline$\stackrel{2}{2}$ & Rent-Free Period & 6 & 5 & & \\
\hline & (months) & (10) & (8) & & \\
\hline
\end{tabular}

Notes: standard deviations in parentheses; ${ }^{*}$ Straight-line distance calculation to the nearest train station within a 1000-meter radius; ${ }^{* *}$ The number of green buildings within a 500-meter radius surrounding a rental or sales transaction; ${ }^{* *}$ Investor Type is broken into five major categories of buyers: Institutional Investors, Developers, Municipal/Government Developers, Private Institutions and Unknown. 
tered standard errors (White, 1980), but employ propensity score weighting techniques to minimize bias between the BREEAM-certified and non-certified buildings. In our application, propensity score weighting aims to minimize the selection bias between certified and non-certified buildings by differentiating based on individual building characteristics. Conditional upon observable characteristics, we eliminate differences between 'treated' green buildings and 'non-treated' control buildings by estimating the propensity of receiving a BREEAM-rating for all buildings in the sales and rental samples, using a logit model (Black and Smith, 2004). The propensity score specification includes all hedonic characteristics available for each sample, and the resulting propensity score is subsequently applied as a weight in the regression of equation (3.1) (see also Eichholtz, Kok, and Quigley, 2013).

In the second part of our analysis, we document the impact of the supply of BREEAMrated buildings on transactions prices. We investigate how local certified building competition acts as a moderator to rental and transaction prices in general, and how this may moderate BREEAM-certified rented and transacted properties in particular. Following Brambor, Clark, and Golder (2006), we examine the interaction effects between certification and the market competition for certified buildings:

$$
\log P_{i}=\alpha+\beta X_{i}+\delta g_{i}+\theta C_{i}+\sigma g_{i} C_{i}+\varepsilon_{i}
$$

where equation (3.2) introduces $C_{i}$, a 'Certified Building Supply' variable, into equation (3.1) to allow the average price or rent in a neighborhood to be moderated by the level of green building competition in the marketplace. In addition, we interact certification status, $g_{i}$, with the 'Certified Building Supply', $C_{i}$, to isolate the moderating effect of geographic clustering of certified buildings on the marginal effect of certification on the price or rent of individual green buildings.

To assess the impact of a larger existing supply of green buildings on the effect of certified prices, we calculate:

$$
\frac{\partial \log P_{i}}{\partial g_{i}}=\delta+\sigma C_{i}
$$

where equation (3.3) is the marginal effect of certified rents or prices conditional upon the existing green building supply. To support the robustness of the conditional marginal effect analysis, we introduce confidence interval bands for statistical significance and use kernel density estimators to show the density of the green building supply. 


\subsection{Results}

\subsubsection{Green Buildings and Rental Rates}

Table 3.2 presents the regression results for the rental sample, relating the logarithm of rent per net square meter of commercial office space to a set of hedonic characteristics, neighborhood controls and contract features. These specifications explain almost sixty percent of the variation in the logarithm of rents per net square meter with an adjusted R-squared ranging from 59 to 62 percent.

Column (1) reports the propensity-weighted results for the hedonic specification relating office rents to the hedonic characteristics, i.e., rental size, age, stories, amenities, renovation, unit quality, transportation networks, time-fixed effects and post-code fixed effects. The coefficient on rental size is positive and significant: larger spaces command higher rental rates per net square meter. Buildings greater than ten stories or 20 stories transact for 24 to 36 percent more than those less than ten stories, respectively. For buildings less than ten years old, rents are 27 percent higher relative to buildings more than forty years old. The amenities dummy is negative, but insignificant. Regarding building quality, there is a 9.6 percent premium for new or refurbished units compared to second-hand units.

Importantly, keeping constant the observable characteristics, the green certification dummy is positive and significant. BREEAM-certified properties command a 28 percent premium over non-certified properties.

In column (2), we add control variables for rental contract features to the hedonic specification. The term structure of leases has an impact on rent levels: the rent per net square meter increases at a rate of 4.3 percent per additional year of lease, but the term structure is non-linear. Thus, the maximum achieved rent is realized at lease duration of about 12 years and the marginal increase in rent becomes zero once lease lengths surpass 11.5 years. The number of days that a unit is on the market has no significant impact on achieved rents, whereas rent-free periods have a statistically significant and positive impact on rents. Rental contract features have a moderating effect on the certification coefficient, decreasing the green rental premium by almost four percentage points.

In column (3), the specification is reported with further controls for the local supply of BREEAM-certified buildings. The variables for 'BREEAM-certified' and 'Certified Building Supply' are jointly significant at the 1 percent level. The 'Certified Building Supply' does not have a substantial impact on the hedonic parameters. However, as the number of observed certified buildings within the transacted building's microlocation increases, average rents per net square meter increase by 1.4 percent in the neighborhood, which provides some evidence on a 'green gentrification' effect.

In column (4), the specification is reported with an interaction term for 'BREEAM- 
Table 3.2: Office Rents for BREEAM-certified Buildings

\begin{tabular}{|c|c|c|c|c|}
\hline & $\begin{array}{l}\text { (PSW) } \\
(1)\end{array}$ & $\begin{array}{l}\text { (PSW) } \\
(2)\end{array}$ & $\begin{array}{l}\text { (PSW) } \\
\text { (3) }\end{array}$ & $\begin{array}{l}\text { (PSW) } \\
\text { (4) }\end{array}$ \\
\hline \multirow[t]{2}{*}{ BREEAM-certified } & $0.280^{* * *}$ & $0.246^{* * *}$ & $0.215^{* * *}$ & $0.312^{* * *}$ \\
\hline & [0.039] & {$[0.042]$} & {$[0.042]$} & {$[0.053]$} \\
\hline \multirow[t]{2}{*}{ Certified Building Supply } & & & $0.014^{* * *}$ & $0.016^{* * *}$ \\
\hline & & & {$[0.004]$} & {$[0.004]$} \\
\hline \multicolumn{2}{|l|}{ BREEAM-certified ${ }^{*}$ Certified Building Supply } & & & $-0.016^{* *}$ \\
\hline \multicolumn{5}{|l|}{ Rent Contract Features } \\
\hline \multirow[t]{2}{*}{ Lease Term } & & $0.043^{* * *}$ & $0.041^{* * *}$ & $0.043^{* * *}$ \\
\hline & & {$[0.009]$} & {$[0.009]$} & {$[0.009]$} \\
\hline \multirow[t]{2}{*}{ Lease Term ${ }^{2}$} & & $-0.002^{* * *}$ & $-0.002^{* * *}$ & $-0.002 * * *$ \\
\hline & & {$[0.000]$} & {$[0.000]$} & {$[0.000]$} \\
\hline \multirow[t]{2}{*}{ Days on Market } & & -0.000 & $-0.000^{*}$ & -0.000 \\
\hline & & {$[0.000]$} & {$[0.000]$} & {$[0.000]$} \\
\hline \multirow[t]{2}{*}{ Rent-free Period } & & $0.004^{*}$ & $0.003^{*}$ & 0.003 \\
\hline & & [0.002] & [0.002] & [0.002] \\
\hline \multicolumn{5}{|l|}{ Quality Characteristics } \\
\hline Rental Unit Size & $0.014^{* * *}$ & $0.012^{* *}$ & $0.013^{* *}$ & $0.012^{* *}$ \\
\hline (Net sq. meter in thousands) & {$[0.004]$} & {$[0.006]$} & [0.006] & [0.006] \\
\hline Story Medium & $0.241^{* * *}$ & $0.233^{* * *}$ & $0.236^{* * *}$ & $0.232^{* * *}$ \\
\hline$(1=$ yes $)$ & {$[0.039]$} & {$[0.039]$} & {$[0.039]$} & [0.039] \\
\hline Story High & $0.364^{* * *}$ & $0.347^{* * *}$ & $0.335^{* * *}$ & $0.339 * * *$ \\
\hline$(1=\text { yes })^{0}$ & {$[0.060]$} & {$[0.058]$} & [0.057] & {$[0.056]$} \\
\hline Age 1 to 10 years & $0.271^{* * *}$ & $0.239 * * *$ & $0.223^{* * *}$ & $0.229 * * *$ \\
\hline$(1=$ yes $)$ & {$[0.035]$} & {$[0.035]$} & [0.035] & {$[0.036]$} \\
\hline Age 11 to 20 years & 0.072 & 0.070 & 0.071 & 0.071 \\
\hline$(1=$ yes $)$ & [0.047] & [0.046] & [0.046] & [0.045] \\
\hline Age 21 to 30 years & $0.111^{* *}$ & $0.103^{* *}$ & $0.101^{* *}$ & $0.105^{* *}$ \\
\hline$(1=$ yes $)$ & [0.049] & [0.049] & {$[0.050]$} & {$[0.050]$} \\
\hline Age 31 to 40 years & 0.076 & 0.080 & 0.058 & 0.081 \\
\hline$(1=$ yes $)$ & [0.056] & [0.053] & {$[0.054]$} & [0.053] \\
\hline Amenities & -0.003 & -0.015 & -0.022 & -0.025 \\
\hline$(1=$ yes $)$ & [0.027] & {$[0.028]$} & [0.028] & {$[0.028]$} \\
\hline Renovated & 0.007 & 0.010 & 0.016 & 0.016 \\
\hline$(1=$ yes $)$ & [0.027] & {$[0.026]$} & [0.027] & [0.027] \\
\hline New or Renovated & $0.096^{* * *}$ & $0.062^{* *}$ & $0.055^{* *}$ & $0.055^{* *}$ \\
\hline$(1=$ yes $)$ & {$[0.028]$} & {$[0.028]$} & {$[0.028]$} & [0.027] \\
\hline Under Build Out & $0.214^{* * *}$ & $0.185^{* * *}$ & $0.164^{* * *}$ & $0.169^{* * *}$ \\
\hline$(1=$ yes $)$ & {$[0.049]$} & {$[0.050]$} & {$[0.051]$} & {$[0.052]$} \\
\hline \multicolumn{5}{|l|}{ Transportation Networks } \\
\hline Train Distance & -5.219 & -5.800 & -7.506 & -7.794 \\
\hline (1/metric distance) & [5.433] & [5.485] & [6.196] & [6.271] \\
\hline A Road Distance & -0.073 & -0.052 & -0.042 & -0.042 \\
\hline (1/metric distance) & [0.052] & [0.052] & {$[0.054]$} & {$[0.054]$} \\
\hline B Road Distance & -0.002 & 0.013 & -0.028 & -0.033 \\
\hline (1/metric distance) & {$[0.074]$} & {$[0.073]$} & {$[0.076]$} & {$[0.075]$} \\
\hline \multirow[t]{2}{*}{ Constant } & $4.809^{* * *}$ & $4.731^{* * *}$ & $4.784^{* * *}$ & $4.780^{* * *}$ \\
\hline & {$[0.083]$} & {$[0.091]$} & {$[0.090]$} & {$[0.091]$} \\
\hline Observations & 1,149 & 1,149 & 1,149 & 1,149 \\
\hline R-squared & 0.596 & 0.615 & 0.626 & 0.628 \\
\hline Adj R2 & 0.57 & 0.59 & 0.60 & 0.61 \\
\hline
\end{tabular}

Notes: The dependent variable is logarithm of rental price per net square meter. Standard deviations in parentheses. All models include post-code fixed effects to control for location, and time-fixed effects to control for time-variation in rental prices. Stories medium and high are relative to low story buildings and the age factors are relative to buildings older than 40 years in age. New or renovated and under build out units are relative to second hand units. Lastly, certified supply demarks the number of certified buildings within 500 meters of the rented unit and BREEAM-certified ${ }^{*}$ Certified Building Supply is the same measure, but for BREEAM-certified rental units. ${ }^{*}, * *, * *$ denotes significance at the ten, five and one percent level, respectively. 
Certified' and 'Certified Building Supply.' Isolating the effect of green building competition in the specification shows that each additional green building in a cluster decreases the marginal effect of certification by some 1.6 percent, ceteris paribus. At the average number of certified buildings (7.21), the marginal rent commanded by a green building, relative to non-green buildings in the same neighborhood, is 19.7 percent.

Figure 3.2: Marginal Effects of BREEAM-Certified Building Supply

(a) Rental Sample (2005 - 2009 Period)

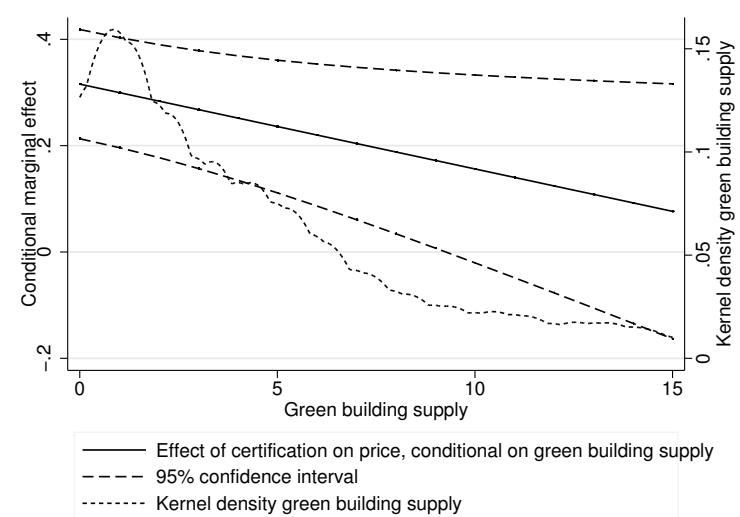

(b) Transaction Sample (2000 - 2009 Period)

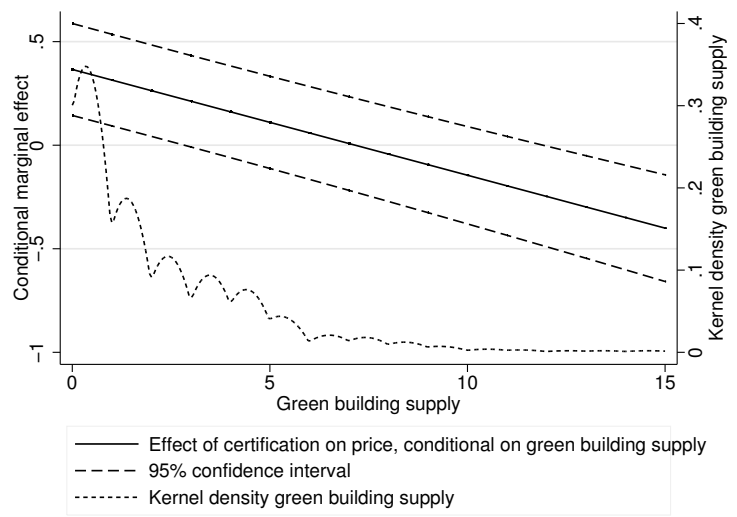

Notes: Green building supply is the number of green buildings within a 500-meter radius. Figure 3.2 shows the conditional marginal effects of the green building supply on rental, transaction and transaction prices with respect to investor type. The thick dashed line depicts the kernel density of the certified building supply. The solid line is the marginal effect of rents (sales) per net square meter, given that the unit is certified, with the certified building supply. The two thick dashed lines denote confidence intervals.

Figure 3.2a shows the results of the conditional marginal effects analysis. There are three axes: the left vertical axis depicts the beta coefficient of the conditional marginal effect; the horizontal axis is the 'Certified Building Supply' (the number of BREEAMcertified buildings within 500 meters at the time of renting); and the right vertical axis represents the 'Certified Building Supply"s univariate kernel density estimate. The kernel density estimate is a non-parametric estimation of the probability density function.

In the figure, the bold dashed line depicts the kernel density of the certified building supply. From left to right, about 15 percent of units have at least two certified buildings within 500 meters and less than five percent of the sample has more than six certified buildings surrounding them. The solid line shows the change in rents per net square meter for certified units when the 'Certified Building Supply' increases. Thus, when the number of certified buildings in a cluster increases, the green premium decreases by 1.6 percent, on average. ${ }^{10}$ From confidence interval bounds, the interaction term (BREEAM-certified ${ }^{*}$ Certified Building Supply) is statistically significant until approximately 9 buildings, where the premium is still positive, but substantially lower.

\footnotetext{
${ }^{10}$ Green building supply and competition have a linear relationship with price, the estimations of non-linear parameters are very small and insignificant.
} 


\subsubsection{Green Buildings and Transaction Prices}

Table 3.3 presents the results for the sales sample, relating the logarithm of sales price per net square meter of office buildings to a set of hedonic characteristics, investor types and neighborhood controls. These specifications explain about 22 percent of the variation in the sales price per net square meter.

Column (1) reports the propensity-weighted hedonic specification relating sales prices to hedonic qualities, i.e., size, age, stories, amenities, renovation, building quality, transportation networks, post-code fixed effects and time-fixed effects.

Building size has a negative and significant impact on transaction price, with transaction prices decreasing by 1.4 percent as building size increases by 1,000 square meters. Relative to buildings more than 40 years old, buildings constructed after 2000 transact at a premium and buildings from the 1980s transact at a discount. The variable for new and renovated buildings (as a percentage of floor space) is significantly negative, suggesting that as new and renovated floor space increases, there is a negative relationship with price, but other (unreported) specifications indicate that this is mostly due to second-hand space. Lastly, transportation networks (i.e., the proximity of buildings to a station) have a positive impact on prices, but road networks, while modifying other parameters, are insignificant. In central London, public transport matters more than accessibility by car. Comparable results have been documented for the Dutch office market (Kok and Jennen, 2012).

Most importantly, the BREEAM-certified coefficient is positive and significant, suggesting that BREEAM-certified buildings transact at a 24 percent premium during the sample period, after controlling for observable differences in building quality and location.

In column (2), investor types are added to the specification. Relative to private investors, real estate investors and institutional investors paid more for commercial real estate during the sample period. In addition, when adding investor types, the premium for BREEAM-certified real estate decreases to 18 percent. Controlling for the identity of the buyer is an important moderating factor in determining the economic value of green buildings in the marketplace.

In column (3), the 'Certified Building Supply' measure is added to the specification. Controlling for 'Certified Building Supply' has a positive and significant impact on the average transaction price in the cluster, resulting in a 3.8 percent increase in transaction price per net square meter. This reinforces the gentrification effect of green buildings previously documented for the rental results. Including 'Certified Building Supply' has a moderating effect on the green premium, decreasing the coefficient by one percentage point. The 'BREEAM-certified' and 'Certified Building Supply' parameters are jointly significant at the 1 percent level.

In column (4), the interaction term is added to the transaction price specification. The green gentrification effects remain, but the results show that the marginal effect of 


\subsection{Results}

green building certification decreases when more green buildings come on the market at a given location. At the average number of certified buildings (4.64), the marginal effect of green building certification is 14.7 percent, relative to non-green buildings in the same neighborhood.

Figure $3.2 \mathrm{~b}$ presents the results of the conditional marginal effects analysis. In the figure, the marginal effect of the sales price per net square meter and the 'Certified Building Supply' are shown. In the figure, the bold dashed line depicts the kernel density of the 'Certified Building Supply.' From left to right, about 30 percent of observations have at least two certified buildings within 500 meters and less than five percent of the sample has more than six certified buildings surrounding them. The solid line shows the marginal effect of the sales price per net square meter, given that the building is certified, with the certified building supply. As certified buildings in a cluster increase, the green premium decreases, by 4.7 percent, on average. The certified green building supply result is statistically significant until approximately 8 buildings, where the premium is still positive, but reduced substantially.

\subsubsection{Additional Analysis}

The marginal effects documented for environmentally certified real estate in the UK are generally in line with the literature investigating the economic outcomes of LEED and ENERGY STAR certification in US commercial markets. However, Eichholtz, Kok, and Quigley (2010) specifically control for building quality using the Building Owners and Managers Association (BOMA) building class definitions and document significant reductions in the marginal effects of green building certification when including these quality controls. In the Tokyo residential real estate market, Yoshida and Sugiura (2011) control for residential building quality, and show that this building quality variable accounts for a large part of the green premium. Their results find bias and inconsistency in the event of exclusion of such quality indicators.

In the dataset at hand, building quality measures, such as independently assessed building structural features and building management quality are measured by building quality proxies other than the definitions of the US BOMA. In Europe and in the UK, the existing quality proxies are not independent, third-party measures and are not applied consistently across all databases and buildings.

Controls for building quality are critical to filter out quality differences in hedonic specifications, since it would not be surprising for a BREEAM 'Excellent' or 'Very Good' rated buildings to be classified as 'Institutional Grade' or 'Class A' office space. Given the extensive attention to finishes, lighting, and other measures in BREEAM 'Very Good' and 'Excellent' buildings, these ratings may in fact be proxies for building quality controls and synonyms for 'institutional' grade real estate.

To analyze further the effect of lacking quality characteristics on the magnitude of 
Table 3.3: Office Sales for BREEAM-certified Buildings

\begin{tabular}{|c|c|c|c|c|}
\hline & $\begin{array}{l}\text { (PSW) } \\
(1)\end{array}$ & $\begin{array}{l}\text { (PSW) } \\
(2)\end{array}$ & $\begin{array}{l}\text { (PSW) } \\
\text { (3) }\end{array}$ & $\begin{array}{l}\text { (PSW) } \\
(4)\end{array}$ \\
\hline BREEAM-certified & $\begin{array}{l}0.235^{\text {*** }} \\
{[0.076]}\end{array}$ & $\begin{array}{l}0.180^{* *} \\
{[0.079]}\end{array}$ & $\begin{array}{l}0.170^{* *} \\
{[0.079]}\end{array}$ & $\begin{array}{l}0.365^{* * *} \\
{[0.102]}\end{array}$ \\
\hline Certified Building Supply & & & $\begin{array}{l}0.038^{* * *} \\
{[0.008]}\end{array}$ & $\begin{array}{l}0.050^{* * *} \\
{[0.009]}\end{array}$ \\
\hline BREEAM-certified ${ }^{*}$ Certified Building Supply & & & & $\begin{array}{l}-0.047^{* * *} \\
{[0.016]}\end{array}$ \\
\hline Investor Type & & & & \\
\hline $\begin{array}{l}\text { Real Estate Investor } \\
(1=\text { yes }) \\
\text { Institutional Investor } \\
(1=\text { yes }) \\
\text { Developer } \\
\text { (1= yes) } \\
\text { Municipal Developer } \\
\text { (1= yes) }\end{array}$ & & $\begin{array}{l}0.177^{* * *} \\
{[0.054]} \\
0.269^{* * *} \\
{[0.062]} \\
0.194 \\
{[0.126]} \\
0.198 \\
{[0.136]}\end{array}$ & $\begin{array}{l}0.155^{* * *} \\
{[0.054]} \\
0.238^{* * *} \\
{[0.062]} \\
0.157 \\
{[0.125]} \\
0.156 \\
{[0.135]}\end{array}$ & $\begin{array}{l}0.157^{* * *} \\
{[0.054]} \\
0.258^{* * *} \\
{[0.062]} \\
0.144 \\
{[0.125]} \\
0.156 \\
{[0.135]}\end{array}$ \\
\hline Quality Characteristics & & & & \\
\hline $\begin{array}{l}\text { Building Size } \\
\text { (Net sq. meter in thousands) } \\
\text { Story Medium } \\
\text { (1= yes) } \\
\text { Story High } \\
\text { (1= yes) } \\
\text { Age } 1 \text { to } 10 \text { years } \\
\text { (1= yes) } \\
\text { Age } 1 \text { to } 20 \text { years } \\
\text { (1= yes) } \\
\text { Age } 20 \text { to } 30 \text { years } \\
(1=\text { yes) } \\
\text { Age } 30 \text { to } 40 \text { years } \\
\text { (1= yes) } \\
\text { Amenities } \\
\text { (Yes=1) } \\
\text { Renovated } \\
\text { (Yes=1) } \\
\text { New or Renovated } \\
\text { (Fraction of floors space) } \\
\text { New or renovated } 2 \\
\text { (Fraction of floors space) }\end{array}$ & $\begin{array}{l}-0.014^{* * *} \\
{[0.001]} \\
0.094 \\
{[0.077]} \\
0.383^{* * *} \\
{[0.106]} \\
0.337^{* * *} \\
{[0.064]} \\
0.162^{* *} \\
{[0.077]} \\
-0.179^{* *} \\
{[0.088]} \\
0.015 \\
{[0.139]} \\
-0.144^{* * *} \\
{[0.049]} \\
0.076 \\
{[0.050]} \\
-1.486^{* * *} \\
{[0.390]} \\
1.674^{* * *} \\
{[0.370]}\end{array}$ & $\begin{array}{l}-0.014^{* * *} \\
{[0.001]} \\
0.050 \\
{[0.078]} \\
0.324^{* * *} \\
{[0.108]} \\
0.326^{* * *} \\
{[0.064]} \\
0.140^{*} \\
{[0.077]} \\
-0.179^{* *} \\
{[0.088]} \\
-0.014 \\
{[0.142]} \\
-0.181^{* * *} \\
{[0.050]} \\
0.092^{*} \\
{[0.050]} \\
-1.348^{* * *} \\
{[0.389]} \\
1.566^{* * *} \\
{[0.369]}\end{array}$ & $\begin{array}{l}-0.015^{* * *} \\
{[0.001]} \\
0.057 \\
{[0.078]} \\
0.332^{* * *} \\
{[0.108]} \\
0.336^{* * *} \\
{[0.063]} \\
0.173^{* *} \\
{[0.077]} \\
-0.162^{*} \\
{[0.088]} \\
0.019 \\
{[0.141]} \\
-0.180^{* * *} \\
{[0.050]} \\
0.095^{*} \\
{[0.050]} \\
-1.371^{* * *} \\
{[0.387]} \\
1.606^{* * *} \\
{[0.367]}\end{array}$ & $\begin{array}{l}-0.015^{* * *} \\
{[0.001]} \\
0.032 \\
{[0.078]} \\
0.301^{* * *} \\
{[0.108]} \\
0.321^{* * *} \\
{[0.064]} \\
0.164^{* *} \\
{[0.077]} \\
-0.166^{*} \\
{[0.088]} \\
0.010 \\
{[0.141]} \\
-0.177^{* * *} \\
{[0.050]} \\
0.102^{* *} \\
{[0.050]} \\
-1.362^{* * *} \\
{[0.386]} \\
1.602^{* * *} \\
{[0.367]}\end{array}$ \\
\hline Transportation Networks & & & & \\
\hline $\begin{array}{l}\text { Train Distance } \\
(1 / \text { metric distance }) \\
\text { A Road Distance } \\
(1 / \text { metric distance) } \\
\text { B Road Distance } \\
(1 / \text { metric distance }) \\
\text { Constant }\end{array}$ & $\begin{array}{l}33.592^{* * *} \\
{[8.805]} \\
-0.109 \\
{[0.102]} \\
-0.081 \\
{[0.270]} \\
8.906^{* * *} \\
{[2.458]}\end{array}$ & $\begin{array}{l}31.678^{* * *} \\
{[8.786]} \\
-0.146 \\
{[0.103]} \\
-0.043 \\
{[0.270]} \\
8.785^{* * *} \\
{[2.448]}\end{array}$ & $\begin{array}{l}31.228^{* * *} \\
{[8.744]} \\
-0.126 \\
{[0.102]} \\
-0.045 \\
{[0.269]} \\
8.890^{* * *} \\
{[2.436]}\end{array}$ & $\begin{array}{l}31.876^{* * *} \\
{[8.730]} \\
-0.121 \\
{[0.102]} \\
-0.094 \\
{[0.269]} \\
8.918^{* * *} \\
{[2.431]}\end{array}$ \\
\hline $\begin{array}{l}\text { Observations } \\
\text { R-squared } \\
\text { Adj R2 }\end{array}$ & $\begin{array}{l}2,103 \\
0.226 \\
0.210 \\
\end{array}$ & $\begin{array}{l}2,103 \\
0.234 \\
0.210 \\
\end{array}$ & $\begin{array}{l}2,103 \\
0.242 \\
0.220 \\
\end{array}$ & $\begin{array}{l}2,103 \\
0.245 \\
0.220 \\
\end{array}$ \\
\hline
\end{tabular}

Notes: The dependent variable is the logarithm of sales price per net square meter. Standard deviations in parentheses. All models include post-code fixed effects to control for location, and time-fixed effects to control for time-variation in rental prices. Stories medium and high are relative to low story buildings and the age factors are relative to buildings older than 40 years in age. New or renovated and under build out units are relative to second hand units. Lastly, certified supply demarks the number of certified buildings within 500 meters of the rented unit and certified competition is the same measure, but for BREEAM-certified rental units. ${ }^{*},{ }^{* *},{ }^{* *}$ denotes significance at the ten, five and one percent level, respectively. 
premiums documented in this chapter, we test how certification premiums for US cities would be affected by the removal of building quality controls, and compare our results with those for New York City, Chicago and Washington DC, using data from Eichholtz, Kok, and Quigley (2013). ${ }^{11}$ Results of the propensity score weighted hedonic specification for LEED and ENERGY STAR buildings are reported in Appendix Table 3.4. Summarizing, when third party building quality controls are excluded from the hedonic specification, the certified premiums for LEED and ENERGY STAR are substantially larger. The results for these three main US cities indicate that when we do not control for building quality, results are comparable to the London specifications. Thus, future studies that acquire a more standardized documentation of building quality measures may find substantially lower marginal effects for green office buildings in the London commercial property market.

\subsection{Discussion and Conclusion}

Intervention from governments and special interest groups to achieve higher levels of energy efficiency for the property sector in general, and the UK in particular, has increased substantially over the past decade. New construction or retrofits by the UK government are required to be BREEAM-certified, and should have both EPC and DEC labels. New building codes incorporate stricter energy-efficiency mandates and by 2018, all new construction must adhere to zero-carbon standards. Ultimately, this will have a substantial impact on the supply of 'green' buildings and the competition within that market. The advent of the Carbon Reduction Commitment in 2012, in which capital market investors and tenants are responsible for buildings' CO2 emissions, represents another nudge towards increased demand for energy-efficient real estate, and can only increase the salience of sustainability for the commercial property sector.

This chapter investigates the financial performance of London's rapidly evolving environmentally-certified commercial building stock, within the context of a dynamic supply and demand framework as measured by ex-post sales transactions and achieved rents over the 2000 to 2009 period. We document that, at the point of means, BREEAM certification in the London office market results in a premium of 19.7 percent for rents and 14.7 percent for sales transactions, relative to non-certified buildings in the same neighborhood. Importantly, this marginal effect is conditional upon the lease conditions and the identity of the acquirer. We show that growth in green building supply has an economically significant impact on London's commercial real estate prices in general and on certified real estate in particular. From 2000 to 2009, stand-alone green building rents and transaction prices are higher relative to non-green buildings in the

\footnotetext{
${ }^{11}$ Holly, Hashem Pesaran, and Yamagata (2011) document that there is high correlation between the real estate markets of London and New York City.
} 
same neighborhood. However, non-green buildings that are a part of those neighborhoods have been able to capture some of the gentrification benefits, through higher average location rents and prices. Importantly, buildings increasingly feature green credentials, but late entrants do not realize the same rental and price premiums as compared to early adopters, as the marginal effect of certification relative to non-green buildings in the neighborhood decreases as the number of certified buildings increases.

Over the sample period, the supply of green buildings expanded by 1.8 percent, resulting in some 1,600 green office buildings in 2010. Within the UK, London had the highest growth in certified real estate where the supply expanded to 368 buildings as of 2010, with an average of seven (five) certified buildings for a given neighborhood, at the time of a certified rental (sales) transaction. Within the context of London, where buildings transact with an increasing supply of green buildings surrounding them, it is thus important to take into consideration the diffusion of environmentally-certified real estate. However, real estate supply in the UK is highly regulated, with British regulatory policies that limit development creating considerable supply side restrictions in the commercial real estate market (Cheshire and Hilber, 2008). The geographical spread of green building in the UK confirms the theory of slow diffusion, and in the absence of market equilibrium, there may still be profitable investment opportunities for green buildings in local UK markets.

Of course, green premiums may reflect increased construction or renovation costs, i.e., demand-side responses to changes in supply. To date, there is limited systematic evidence reporting on the marginal construction costs of environmentally certified real estate in the UK and US commercial real estate sector. ${ }^{12}$ Furthermore, the transaction costs associated with certification, consulting, design fees, contingencies and development are largely unavailable (Fisher and Bradshaw, 2010). Unfortunately, current transaction cost data is insufficient for meaningful statistical inferences. Thus, future research incorporating construction and redevelopment cost may provide a better understanding of the ROI related to investments in green building.

The results of this chapter provide the first evidence on the economic outcomes from investments in energy-efficiency and sustainability in the UK marketplace. There is currently a measurable premium for developers and investors that take their green buildings to market, but future outcomes are contingent upon new development, existing building regulations and the drive for energy-efficiency by the UK government. Importantly, communities gain from the advance of green buildings in their surroundings on three fronts. First, green buildings in London are designed for reduced energy consumption, carbon-emissions and waste. Second, green buildings have a positive

\footnotetext{
${ }^{12}$ For a specific case study focusing on BREEAM, BRE Center for Sustainable Construction and Cyril Sweett (2005) estimated the incremental construction costs for a single building in case it would have been rated by BREEAM as Good, Very Good and Excellent, distinguishing between natural ventilation air conditioning. For the naturally ventilated space (493 m2), a Good Rating cost a maximum of 0.4 percent more and an Excellent Rating about 3.4 percent. For an air-conditioned space $(10,098 \mathrm{~m} 2)$, maximum additional costs for a Good rating were 0.2 percent and for an Excellent rating 7.0 percent.
} 
price impact (i.e., gentrification) on their peers, which can increasingly improve neighborhoods. Finally, as green buildings increasingly diffuse and cluster, more and more buildings will need to compete on energy-efficiency and sustainability metrics, where premiums for green will become discounts for non-green, 'brown' buildings. In combination, these positive economic externalities from green buildings in the commercial property sector can help to mitigate the substantial negative externalities that buildings impose on the environment. 
Table 3.4: The Value of Green Certification in US Cities: Based on (Eichholtz, Kok, and Quigley, 2013)

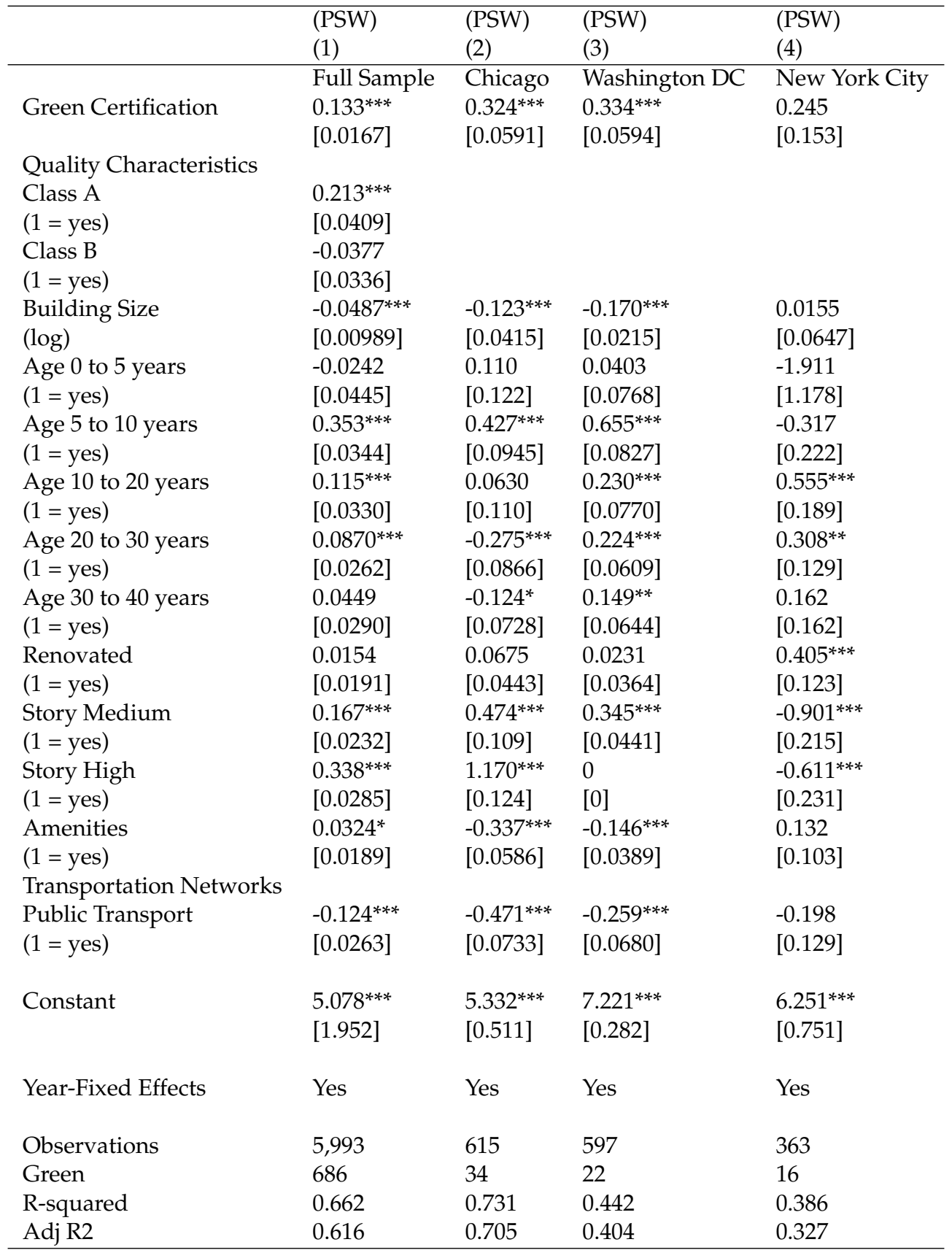

Notes: The dependent variable is the logarithm of sales price per square foot; Standard deviations in parentheses. All models include post-code fixed effects to control for location, and time-fixed effects to control for time-variation in rental prices. Stories medium and high are relative to low story buildings and the age factors are relative to buildings older than 40 years in age. New or Renovated and Under Build Out units are relative to Second hand units. Lastly, certified supply demarks the number of certified buildings within 500 meters of the rented unit and certified competition is the same measure, but for BREEAM-certified rental units. ${ }^{*}, * *$, *** denotes significance at the ten, five and one percent level, respectively. 


\section{Chapter 4}

\section{The Price of Innovation: An Analysis of the Marginal Cost of Green Buildings ${ }^{*}$}

\subsection{Introduction}

Green building is now an inseparable part of the construction industry. This is reinforced by legislative goals in Europe for zero-energy buildings by 2020 (Directive $2012 / 27 / E U, 2012)$ and the growth of green building certification schemes globally (Chegut and Kok, 2011; Eichholtz, Kok, and Quigley, 2010). Indeed, a recent report from McGraw-Hill documents that green building construction in the US alone is expected to be worth $\$ 122$ billion by 2015 , representing about 45 percent of all commercial real estate construction. ${ }^{1}$ This new form of construction has also caused a shift in employment: the US green construction sector created 101,792 jobs in 2010, which for that year is four percent of the total jobs created. ${ }^{2}$

Much of the literature on green buildings documents that investors pay premiums for green buildings that undergo a certification process. Eichholtz, Kok, and Quigley (2010) document that ENERGY STAR and LEED-certified real estate transacts for 16 percent more than non-certified buildings, a finding that is corroborated by other US studies, (Eichholtz, Kok, and Quigley, 2013; Fuerst and McAllister, 2011a; Miller, Spivey, and Florance, 2008). In Europe, BREEAM-certified commercial buildings in London transact at a 14 percent premium (Chegut, Eichholtz, and Kok, 2013) and a study for the Netherlands shows that energy-inefficient commercial buildings (measured by the EU's Energy Performance Certificates) rent at a 6.5 percent discount

\footnotetext{
${ }^{*}$ This chapter is co-authored with Piet Eichholtz (Maastricht University) and Nils Kok (Maastricht University, University of California - Berkeley).

${ }^{1}$ http://www. carpetrecovery.org/pdf/annual_conference/2012_conference_pdfs/ Presentations/USGreenMarketTrends .pdf, accessed June 14, 2013.

${ }^{2}$ http://www.bls.gov/news.release/ggqcew.t01.htm and http://www.bls.gov/news.release/ ggqcew.nrO.htm, accessed March 21, 2013. McGraw-Hill indicates a higher number of green jobs as of 2011, approximately 611,000. However, this includes designers, engineers and architects. http://www. carpetrecovery.org/pdf/annual_conference/2012_conference_pdfs/ Presentations/USGreenMarketTrends . pdf, accessed June 14, 2013.
} 
(Kok and Jennen, 2012).

Similar evidence exists for non-commercial real estate. In a study for the Netherlands, Brounen and Kok (2011) find a 3.8 percent premium for houses with A, B and C class Energy Performance Certificates, compared to their energy-inefficient peers. Similar premiums have been found for residential property by others (Bonde and Song, 2013; Cerin, Hassel, and Semenova, 2012; Deng, Li, and Quigley, 2012; Hyland, Lyons, and Lyons, 2012). ${ }^{3}$

However, less is known about the drivers of the green premium. Eichholtz, Kok, and Quigley (2013) focus on the operating costs of buildings, and find that within a sample of ENERGY STAR rated buildings, a one dollar saving in energy costs of a building is, on average, associated with a $\$ 0.95$ greater rent. Chegut, Eichholtz, and Kok (2013) focus on supply-side effects, and find that with more localized competition from other green buildings, green building rents and transaction prices decrease by a small margin with each additional competitor.

Another open question is whether the green premiums found in the literature are also present on a net basis, after subtracting input costs. To shed light on that question, we analyze the construction costs of green commercial real estate. We focus on the largest commercial real estate market in Europe, the United Kingdom, and match two proprietary data sets, the Building Research Establishments (BRE), BREEAM-certified properties database, and the Royal Institute of Chartered Surveyors' Building Cost Information Services (BCIS) elemental construction cost data set. After the match, we obtain a complete construction cost database for 107 BREEAM-certified buildings and 242 similar non-certified construction projects over the 2003 to 2012 period. This database allows us to assess the additional costs involved in building green, the important cost drivers, and their development over time.

In our analysis, we deviate from previous studies in three distinct ways. First, we have a sample size that allows us to match BREEAM-certified and non-certified buildings on the basis of observable characteristics. As a result, we can measure the additional cost of green buildings, which tend to be larger, built in distinct areas and have other 'treatment' characteristics. By matching building and location characteristics, the analysis differentiates from existing studies, which are more case study in nature and are unable to do. Second, we assess the importance of institutional aspects in driving up building costs. We study the importance of the contracting of green buildings measured by the number of tenders that bid on a project, the contract lengths, the type of building contract, and how the bidding process is established. Third, by exploring the relatively long sample period, we can examine the potential dynamics of green building costs by generating an index for the 2003 to 2012 period.

Green real estate is still a relatively novel phenomenon, and it is unclear how large

\footnotetext{
${ }^{3}$ However, there is one exception: Yoshida and Sugiura (2010) report insignificant financial impacts for Tokyo condominium units after controlling for building quality and management.
} 
the cost premium for green construction should be, and where it originates. The differences in marginal costs for green construction could stem from incorporating green products, processes and organizational innovations into a building. Modular innovations like triple glazed windows, building monitoring systems and embodied carbonfree insulation may increase material and labor costs in construction. In addition, architectural innovations like photovoltaics and wind energy, which in addition to the material and labor costs require a reconfiguration of a building and may increase construction costs. A new sustainability department or supply chain management strategy for materials may also lead to organizational innovations, which also increase construction costs. In line with innovation theory, these three types of innovations combined may require an entire systems innovation in construction (Slaughter, 1998). Most of these costs are expected to change over time. As more specialized materials, labor and capital for green construction become available, unit costs may decrease (Katz and Shapiro, 1985). And as more green buildings are built, soft costs may decrease as a result of learning.

A univariate comparison of the BREEAM-certified and non-certified means suggests that there is not an economically or statistically significant difference in construction costs. For the cross-sectional regression analysis, the average total cost of BREEAM-certified construction is not statistically higher than for an otherwise similar sample of conventional construction projects. In addition, the conditional marginal effects analysis suggests that at the BREEAM-certified mean, construction costs for these projects are on average an additional zero to three percent more. However, as a BREEAM-certified construction projects move up the quality ladder, there is evidence that Outstanding buildings cost on average 16.7 percent more than non-certified projects. The drivers of BREEAM-certified construction costs stem from the superstructure and services components of a building, as well as from the contracting method. More efficient methods like the 'Design and Build' method drive costs down. Yet, design fees and contingencies previously thought to be the main drivers of green construction costs are economically insignificant relative to the total projects costs. Moreover, the institutional characteristics including tendering, contract types and contract lengths do not appear to significantly affect the construction cost differences between green and conventional real estate. Lastly, the 'UK Green Construction Cost Index', suggests that BREEAM-certified construction costs increased from 2004 to 2008, but subsequently decreased in the period of 2009 to 2012.

Our results complement and deepen the findings in the previous literature. The importance of our sampling and matching procedure becomes clear when we compare to other studies, which often report significantly higher cost premiums. Kats (2003) compares 33 LEED-certified buildings against their peers and documents an average cost premium for Certified, Silver, Gold and Platinum buildings of 1.84 percent. ${ }^{4}$ In

\footnotetext{
${ }^{4}$ Moreover, the average cost for the Silver building sample is consistently two percent in each sub-
} 
a larger study, Langdon (2004) find for 45 LEED- seeking and 93 non-LEED buildings that most projects achieve LEED certification for zero to three percent over their initial budget. Finally, Crawford et al. (2009), in a study of 67 LEED-certified and registered projects and 44 non-certified buildings, document averages for the two samples and find no difference between LEED-certified and non-certified buildings from a construction cost perspective.

European case study results suggest that green construction is costly. The BRE Center for Sustainable Construction and Cyril Sweett (2005) estimate the incremental construction costs for a single BREEAM-certified building rated from Good, Very Good to Excellent and distinguish between natural ventilation and air conditioning. For the naturally ventilated space, a Good Rating costs a maximum of 0.4 percent more and an Excellent Rating about 3.4 percent. For an air-conditioned space, maximum additional costs for a Good rating are 0.2 percent and for an Excellent rating 7.0 percent. In a later study, Atkinson (2010) looks at three building sites that seek BREEAM Excellent, Outstanding and Zero Carbon status in new construction. Results suggest that going toward an Outstanding and Zero Carbon BREEAM 2008 certification costs between 15.4 and 37.4 percent more, respectively.

Our analysis suggests that some of these earlier findings may have been the result of small samples, a lack of controls for contract and client differences, and/or the lack of an appropriate comparable control group. This lack of data and dearth of systematic analysis is problematic for investors and policy makers in the commercial real estate sector, as uncertainty about the ex-post returns to innovation will lead to a slow uptake of more efficient building practices. Moreover, these results also contribute to understanding the innovation process of green buildings in commercial real estate. In general, assessing green buildings within the commercial real estate construction sector suggests that a more efficient construction process in innovation is taking place. Future research should take into consideration the dynamic cost patterns documented in this chapter.

The remainder of this chapter is structured as follows. In section 2, we outline the theoretical expectations for green construction cost drivers and hypotheses. Section 3 follows with a detailed analysis of data collection and descriptive statistics. Section 4 covers our estimation methodology and model expectations. Section 5 highlights our propensity score weighted regression results. Section 6 provides a discussion on the relationship between green construction costs and green premiums in a dynamic framework. Finally, section 7 provides a conclusion.

period since 1996. 


\subsection{Green Building Innovation Costs}

In this section, we develop a framework for the analysis of green construction cost. We start with embedding green buildings into a broader literature on innovation and explain what this literature can tell us about the existence of a green construction cost premium. Next, we continue on this path and explore implications for the size of that premium. Finally, we make use of the analogy with other innovation diffusions to derive expectations for the development of the cost premium over time.

\subsubsection{Identifying Green Construction}

In real estate, there are numerous green labels, such as LEED, Energy Star, Green Star and BREEAM, but within the UK, our market of interest, there are two private intermediaries of environmental information: BREEAM and LEED. BREEAM certification is the dominant rating scheme in the UK (See Chapter 3 of this thesis). ${ }^{5}$ These sustainability labels have two important roles. On the one hand, they are a signal to the market that 'this is not a lemon' (Akerlof, 1970). On the other hand, the organizations handing out these labels may be thought of as 'committees' which propose a market mechanism towards a process of 'standardization' as originally proposed by Farrell and Saloner (1985). In either case, both concepts build on the idea of a common standard, which is important for a market aiming at the commercial diffusion of an innovation like green construction.

What then is the impact of green labeling on the process of building commercial real estate? Table 4.1 provides a comprehensive breakdown of weightings, minimum standards and points for the BREEAM 2008 scheme. There are points awarded on various issues corresponding to the environmental performance of the building, from the 'Reduction of CO2' emissions to Building Use Guides and Green Leases. Each issue is supported with evidence to support the issuance of points. For example, for the Management 4 - Building User Guide credit to be received, a Building User Guide must be shown with documentation for proof of the point. After each issue has been assessed, all claims and supporting documentation are compiled into a report. At BREEAM headquarters, the reports receive a grade on the quality of their report, which includes assessment of items such as documentation, evidence and even language and style. Then, BREEAM itself confirms or denies the decision. Lastly, BREEAM conveys the rating to the building owners. ${ }^{6}$

\footnotetext{
${ }^{5}$ BRE was originally founded in 1917 by the Department of Scientific and Industrial Research as a research and development program to investigate construction materials and methods for use in housing after World War I. For a look at the 90 year history of BRE (see: http://www. bre.co.uk/page.j.sp?id= 1712). The agency has grown and become a global certification scheme for the design and procurement of sustainable and energy-efficient commercial and residential real estate projects.

${ }^{6}$ Details are in the BREEAM Offices 2008 Assessor Manual.
} 
Table 4.1: BREEAM 2008 Offices Scorecard

\begin{tabular}{|c|c|c|c|c|c|c|c|c|c|}
\hline 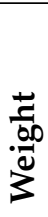 & \multicolumn{2}{|r|}{ BREEAM Issue and Title } & 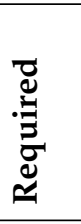 & 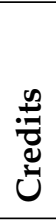 & 离 & \multicolumn{2}{|c|}{ 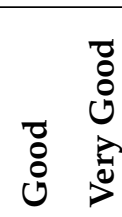 } & 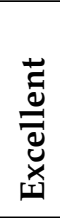 & 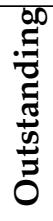 \\
\hline \multirow[t]{10}{*}{12} & \multirow{10}{*}{ 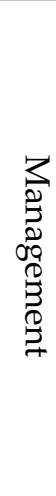 } & 1 - Commissioning & Yes & 2 & 1 & 1 & 1 & 1 & 2 \\
\hline & & 2 - Considerate Constructors & Yes & 2 & & & & 1 & 2 \\
\hline & & 3 - Construction Site Impacts & No & 4 & & & & & \\
\hline & & 4 - Building User Guide & Yes & 1 & & & & 1 & 1 \\
\hline & & 5 - Site Investigation & No & 0 & & & & & \\
\hline & & 6 - Consultation & No & 0 & & & & & \\
\hline & & 7 - Shared Facilities & No & 0 & & & & & \\
\hline & & 8 - Security & No & 1 & & & & & \\
\hline & & 9 - Publication Of Building Information & Yes & 1 & & & & & 1 \\
\hline & & 10 - Development As A Learning Resource & Yes & 1 & & & & & 1 \\
\hline \multirow[t]{12}{*}{15} & \multirow{12}{*}{ 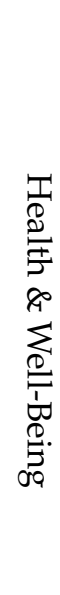 } & 1 - Daylighting & No & 1 & & & & & \\
\hline & & 2 - View Out & No & 1 & & & & & \\
\hline & & 3 - Glare Control & No & 1 & & & & & \\
\hline & & 4 - High Frequency Lighting & Yes & 1 & 1 & 1 & 1 & 1 & 1 \\
\hline & & 5 - Daylighting & No & 1 & & & & & \\
\hline & & 6 - Lighting Zones And Controls & No & 1 & & & & & \\
\hline & & 8 - Indoor Air Quality & No & 1 & & & & & \\
\hline & & 9 - Volatile Organic Compounds & No & 1 & & & & & \\
\hline & & 10 - Thermal Comfort & No & 1 & & & & & \\
\hline & & 11 - Thermal Zoning & No & 1 & & & & & \\
\hline & & 12 - Microbial Contamination & Yes & 1 & 1 & 1 & 1 & 1 & 1 \\
\hline & & 13 - Acoustic Performance & No & 1 & & & & & \\
\hline \multirow[t]{9}{*}{19} & \multirow{9}{*}{ 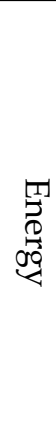 } & 1 - Reduction Of CO2 Emissions & Yes & 15 & & & & 6 & 10 \\
\hline & & 2 - Sub-Metering Of Substantial Energy Uses & Yes & 1 & & & 1 & 1 & 1 \\
\hline & & 3 - Sub-Metering Of High Energy Load & No & 1 & & & & & \\
\hline & & 4 - External Lighting & No & 1 & & & & & \\
\hline & & 5 - Low Or Zero Carbon Energy Uses & Yes & 3 & & & & 1 & 1 \\
\hline & & 6 - Building Fabric Performance & No & 0 & & & & & \\
\hline & & 7 - Cold Storage & No & 0 & & & & & \\
\hline & & 8 - Lifts & No & 2 & & & & & \\
\hline & & 9 - Escalators And Travelling Walkways & No & 1 & & & & & \\
\hline \multirow[t]{6}{*}{8} & \multirow{6}{*}{ 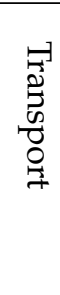 } & 1 - Provision Of Public Transport & No & 3 & & & & & \\
\hline & & 2 - Proximity To Amenities & No & 1 & & & & & \\
\hline & & 3 - Cyclist Facilities & No & 2 & & & & & \\
\hline & & 4 - Pedestrian And Cyclist Safety & No & 1 & & & & & \\
\hline & & 5 - Travel Plan & No & 1 & & & & & \\
\hline & & 6 - Maximum Car Parking Capacity & No & 2 & & & & & \\
\hline
\end{tabular}


Table 4.1 - continued from previous page

\begin{tabular}{|c|c|c|c|c|c|c|c|c|c|}
\hline $\begin{array}{l}\frac{\pi}{\pi} \\
.000 \\
3 \\
3\end{array}$ & & BREEAM Issue and Title & 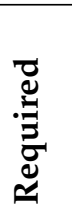 & 茪 & 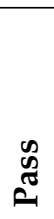 & $\begin{array}{l}0 \\
0 \\
0 \\
0\end{array}$ & $\begin{array}{l}\overline{0} \\
0 \\
0 \\
0 \\
i \\
>\end{array}$ & 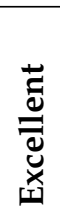 & 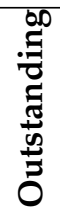 \\
\hline \multirow[t]{4}{*}{6} & \multirow{4}{*}{$\sum_{\substack{0 \\
\mathbb{D}}}$} & 1 - Water Consumption & Yes & 3 & & 1 & 1 & 1 & 2 \\
\hline & & 2 - Water Meter & Yes & 1 & & 1 & 1 & 1 & 1 \\
\hline & & 3 - Major Leak Detection & No & 1 & & & & & \\
\hline & & 4 - Sanitary Supply Shut Off & No & 1 & & & & & \\
\hline \multirow[t]{7}{*}{12.5} & \multirow{7}{*}{ 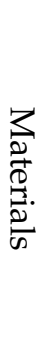 } & 1 - Materials Specification & No & 4 & & & & & \\
\hline & & 2 - Hard Landscaping And Boundary Protection & No & 1 & & & & & \\
\hline & & 3 - Re-Use Of Facade & No & 1 & & & & & \\
\hline & & 4 - Re-Use Of Structure & No & 1 & & & & & \\
\hline & & 5 - Responsible Sourcing Of Materials & No & 3 & & & & & \\
\hline & & 6 - Insulation & No & 2 & & & & & \\
\hline & & 7 - Designing For Robustness & No & 1 & & & & & \\
\hline \multirow[t]{6}{*}{7.5} & \multirow{6}{*}{ 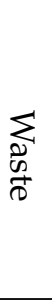 } & 1 - Construction Site Waste Management & No & 4 & & & & & \\
\hline & & 2 - Recycled Aggregates & No & 1 & & & & & \\
\hline & & 3 - Storage Of Recyclable Waste & Yes & 1 & & & & 1 & 1 \\
\hline & & 4 - Compactor & No & 1 & & & & & \\
\hline & & 5 - Composting & No & 1 & & & & & \\
\hline & & 6 - Floor Finishes & No & 1 & & & & & \\
\hline \multirow[t]{6}{*}{10} & \multirow{6}{*}{$\begin{array}{l}1 \\
0 \\
0 \\
0 \\
\& \\
10 \\
11 \\
0 \\
0 \\
0 \\
0 \\
0 \\
4\end{array}$} & 1 - Reuse Of Land & No & 1 & & & & & \\
\hline & & 2 - Contaminated Land & No & 1 & & & & & \\
\hline & & 3 - Ecological Value Of Site & No & 1 & & & & & \\
\hline & & 4 - Mitigating Ecological Impact & Yes & 2 & & & 1 & 1 & 1 \\
\hline & & 5 - Enhancing Site Ecology & No & 3 & & & & & \\
\hline & & 6 - Long Term Impact On Biodiversity & No & 2 & & & & & \\
\hline \multirow[t]{8}{*}{10} & \multirow{8}{*}{ 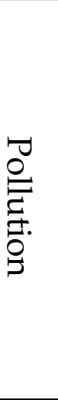 } & 1 - Refrigerent Building Services & No & 1 & & & & & \\
\hline & & 2 - Preventing Refrigerant Leaks & No & 2 & & & & & \\
\hline & & 3 - Refrigerant Cold Storage & No & 1 & & & & & \\
\hline & & 4 - No Emissions From Heating Source & No & 3 & & & & & \\
\hline & & 5 - Flood Risk & No & 3 & & & & & \\
\hline & & 6 - Minimising Watercourse Pollution & No & 1 & & & & & \\
\hline & & 7 - Reduction Of Night Time Light Pollution & No & 1 & & & & & \\
\hline & & 8 - Noise Attenuation & No & 1 & & & & & \\
\hline 10 & & 1- Innovation & No & 1 & & & & & \\
\hline
\end{tabular}

Notes: Table 4.1 breaks down the BREEAM rating standards by weight, issue, title and indicates if the issue is considered required for BREEAM ratings. The BREEAM process is as follows. Each BREEAM Issue is give a weight and each sub-issue is given their corresponding weight. There are points awarded on various issues corresponding to the environmental performance of the building, from Reduction of $\mathrm{CO} 2$ emissions to Building Use Guides and Green Leases. Each issue is given a decision by the assessor and is supported with evidence to support the issuance of points. For example, for the Management 4 - Building User Guide credit to be received then, the a Building User Guide must be shown with proof of documentation for proof of the point. After each issue has been assessed, all claims and supporting documentation are compiled into a report. At BREEAM headquarters, the reports receive a grade on the quality of the report, which includes assessment of items such as documentation, evidence and even lan- 
guage and style. Then,BREEAM itself confirms or denies the decision. This is based on the report conducted by the assessor or in some cases BREEAM repeats the assessment to have a robust confirmation of the report. Lastly, BREEAM conveys the rating to the building. Should there have been problems or exceptions to be cleared from construction or renovation, then those must be cleared beforehand as the rating is denied until all requirements are satisfied. (BREEAM Offices 2008 Assessor Manual, BREEAM, 2009)

Importantly, buildings assessed by BREEAM are provided an absolute and not a relative score, ranging from Unclassified with a score of less than 30, to Outstanding with a score greater than 85 . This means that standards are set ex-ante by a committee and revisited periodically, which is distinct from a process that is continuously benchmarked by the most recent standards. Summing up, in order to receive a high rating, developers need to reconsider every (cost) element of the building they construct.

\subsubsection{Cost Expectations of Green Innovation}

The cost of innovation is an important signal in the marginal cost of green construction. However, to answer how much it costs to build green, it is important to establish basic cost expectations. From the vast theoretical literature on innovation, it is suggested that the cost of innovation is positive (Aghion and Griffith, 2005). Indeed, as early as Schumpeter, innovation in any sector results in augmenting the existing quality of a product or process, which requires research or effort, a so-called 'effort cost' incurred by an innovator. Moreover, the quality of the product in the previous period forms the basis of learning and development and the amount of research or effort the individ$\mathrm{ual} /$ innovator is willing to perform determines the foundation of the cost. The change to the existing quality is not necessarily linear, as the cost of innovating is not strictly increasing or decreasing in time, but instead the cost of innovating has a learning function. Tirole (1988) suggests that the key aspect of innovation for a firm is the realization of scale economies, in order to operate at the lowest average cost point. In the early stage of a new construction project's life cycle, a firm minimizes costs, but still faces many uncertainties and is likely to operate below a minimum efficient scale and at an increased cost level.

For the construction industry, a firm can potentially incur a cost for adopting a new process in construction. Construction innovation is more unique as projects are large, complex, long-lasting and are created and built by a temporary alliance of organizations (Slaughter, 1998). In addition, commercial real estate is a heterogeneous product, with unique inputs of capital, labor and materials for every project. Innovative real estate may require non-standard, more expensive inputs, which may suggest that it costs more to construct. As a result, making the effort to innovate increases the cost of producing the building and the effort cost is effectively the marginal cost of innovation. Thus, our first hypothesis is as follows: 
$H_{1}$ : The effort cost for green construction projects is positive.

\subsubsection{The Magnitude of Green Innovation Costs}

The literature on innovation can help us understand the magnitude of the innovation costs or effort the innovator must undergo, but this will depend on the type of innovation, as well as on the stage of innovation.

Slaughter (1998) maps the innovation typology outlined by Abernathy and Clark (1985) to the construction sector. Within this typology, innovations can take on one of five forms; incremental, modular, architectural, systems and radical. In fact, the BREEAM certification process largely captures the increase in effort costs as we go from incremental to radical innovations. Alternatively, we can view the innovation typology of Slaughter (1998) as capturing a so-called systems innovation in construction, which is a combination of architectural, modular and organizational changes in the construction process that may impact the magnitude of costs. Considering Table 4.1 again, we can then identify the sources of architectural, modular and organizational change to the construction process for BREEAM labeled buildings.

Consider for example Energy credits, possibly leading to the incorporation of photovoltaics (PV) or wind energy. This technology may lead to a building reconfiguration in a non-conventional way, and requires distinct human and physical capital in construction. Tatari and Kucukvar (2011) document in a neural network analysis of predicted construction costs for LEED-certified buildings that there is a 'high sensitivity for increased costs from Energy Assessment points when implementing new technologies for renewable energy systems. Within Slaughter's (1998) framework, the result is likely an architectural innovation requiring a reconfiguration of the building's service systems to adopt renewable energies. Moreover, site selection can be reconfigured to meet different ecological standards. Tatari and Kucukvar (2011) find that for the LEED certification, high community connectivity can lead to more points for 'Sustainable Sites'. However, the magnitude of hard construction costs can increase when choosing more land-constricted areas like highly connected, walkable and bikable communities.

In addition, organizational innovations may influence the soft costs of construction. Mapp, Nobe, and Dunbar (2011) document soft costs for 33 LEED-certified bank buildings including, design fees, which accounted for roughly 73 percent of the costs of attaining a LEED certification, but only two to three percent of the total construction costs. ${ }^{7}$ Fisher and Bradshaw (2010) survey green developers to investigate how firms change their structure or contracts to accommodate green construction. Out of 102 responses, firms' experiences with their first and subsequent green projects indicate that there are substantial changes that firms make to develop green buildings.

\footnotetext{
${ }^{7}$ The largest cost was for an in-house, LEED project administrator. However, Mapp et al. price outside contractors and claims that they may cost three to four times as much. Also, the cost of contracting may increase in uncertain use cases.
} 
Thus, the magnitude of the cost differences is likely driven by differences in the hard and soft construction costs for the project. Hard construction costs may be higher due to the materials, capital and labor for this new type of construction. In addition, soft costs like the design and procurement of a certified green construction project are not a part of conventional construction. Moreover, other stakeholders and participants in the real estate and construction industry may not possess the human capital necessary for assessing this innovation process. Hence, the innovation costs are a function of the type of innovation and can be further decomposed into hard, soft, search and transaction costs in construction. Therefore, we can formulate the second hypothesis:

$\mathrm{H}_{2}$ : The magnitude of innovation costs of green buildings stems from differences in hard costs in green materials, labor and capital, from higher soft costs in green design, and from larger procurement costs in green contracting.

\subsubsection{Green Development Stage}

Now that we have explored the existence of a green construction cost premium and its determinants, we discuss how a premium might develop over time. The dissemination of the BREEAM label and the green materials, capital and labor to support it have undergone a dynamic process, which may influence the cost of green construction over time. ${ }^{8}$

Tirole (1988) identifies three stages in the research and development process for an innovative product; the development of fundamental knowledge, conducting applied research, and dissemination for commercial use.

For BREEAM, elements of the first two stages continue to play a role, as the standards prescribed for green buildings have certainly changed. The first commercial office space was certified in 1998 and at that time a building could earn 87 credits under eight categories. Since that time, the process has undergone eight upgrades and today the number of credits has increased to 150 with ten categories in Version 2011. This suggests that research and development for the BREEAM standard undergoes a periodic review, which may be important in understanding the level of costs in any given period.

However, the commercial dissemination phase may also play a role. The BREEAM certification process itself suggests that diffusion may rely on the cooperation of the market and where the extent of commercial dissemination may influence the magnitude of the costs for other green builders. Katz and Shapiro (1985) outline the theo-

\footnotetext{
${ }^{8}$ Historically, BRE was a research and development initiative for identifying efficient building and construction techniques for the UK market. Over time, the agency established a BREEAM method for energy-efficient and sustainable construction. To apply this technique within the UK market, they established a certification scheme, the so-called BREEAM rating. The BREEAM label is disseminated to the commercial market through a fee paid to the BREEAM assessor to learn how to undergo this new design and procurement process, which is signified by a standardized label (http: //www.bre.co.uk/page.jsp?id=1712, accessed June 14, 2013.)
} 
retical cost and adoption expectations for innovations that possess a positive network externality. Essentially, a product, in this case a certification, becomes more valuable when more users adopt the same goods or compatible goods. The realized construction cost for BREEAM-certified innovators depends on the extent to which a sufficient share of the market is able to undergo the BREEAM process. Tentative evidence on the willingness to adopt the process is from attendance and participation at Ecobuild, the largest UK trade show for green building products, which has been growing since 2005. Figure 4.1 highlights the growth in the number of participants and exhibitors over the 2003 to 2012 period. Ecobuild began in 2005 with 50 exhibitors and 1500 participants, and has grown to 1500 exhibitors and 57,000 participants in 2012.

Figure 4.1: Ecobuild Participants and Exhibitors

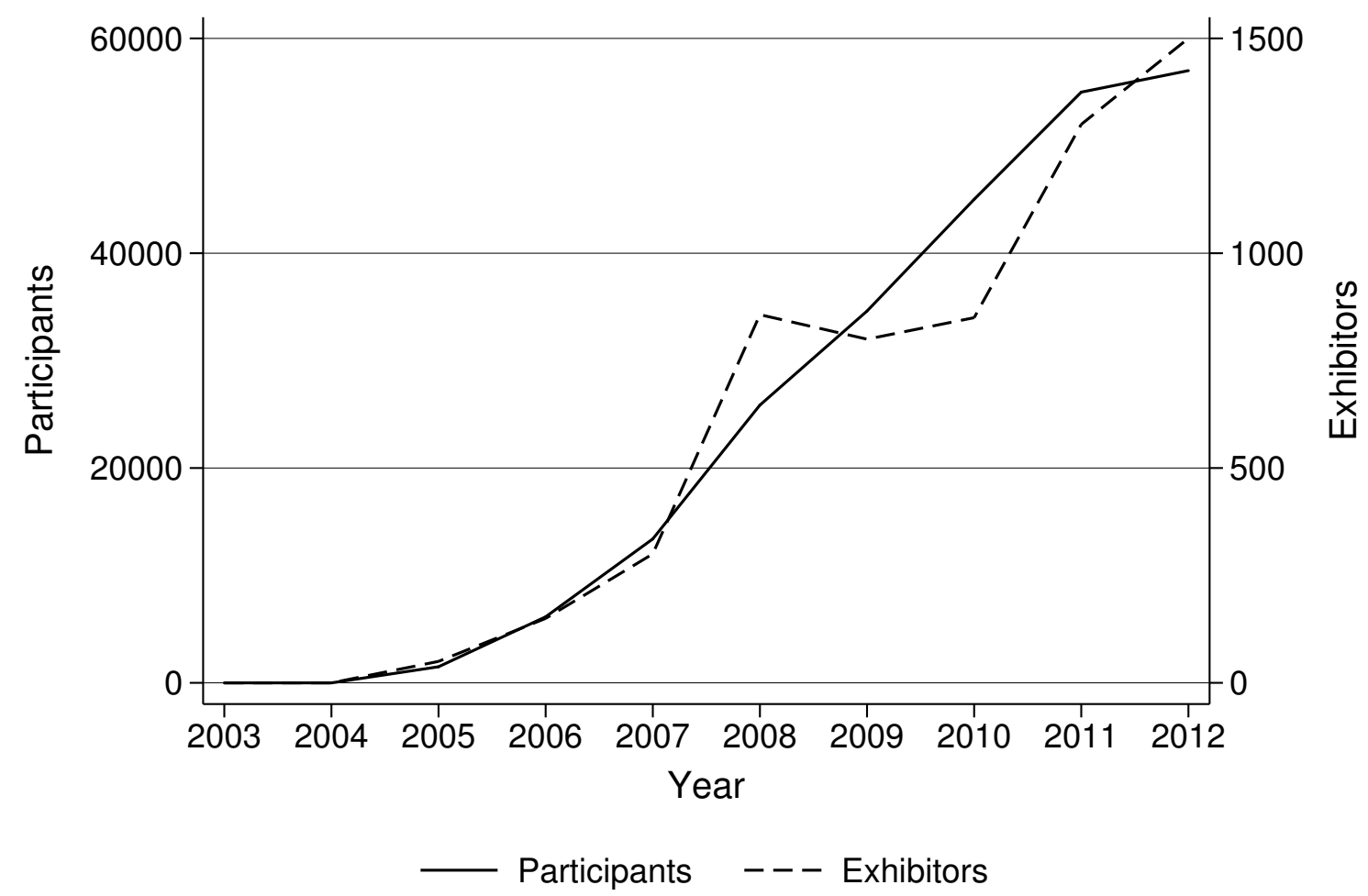

Notes: Figure 4.1 displays for the 2003 to 2012 period Ecobuild annual participation by attendees and the number of exhibitors displaying green goods and services year over year. Ecobuild began in 2005 with just 1500 participants and 50 exhibitors and grew in 8 years to 57,000 participants and 1500 exhibitors.

The green building network established by Ecobuild may play a role is the diffusion of these green certification schemes, as costs are transformed over time in two ways. First, as firms learn about the implementation of the certification process, they can handle that process more cost effectively for subsequent projects, which may decrease soft costs in the long-run. Second, firms can benefit from economies of scale in production, as they add to their existing stock of certified buildings. In the case of early innovation adoption, new products or materials may not be available in large quantities to reach 
scale economies, requiring some added costs in the hard costs of the building. However, these indirect positive externalities will increase as more of the product diffuses (Katz and Shapiro, 1985). ${ }^{9}$

Summing up, the magnitude of innovation costs is a function of the phase of innovation. Thus, our third hypothesis is as follows:

$\mathrm{H}_{3}$ : The cost of BREEAM construction decreases as the certification process expands.

\subsection{Methodology}

Assessing the marginal construction cost of green buildings is impossible without comparing green buildings with conventional real estate. However, this comparison is far from trivial. Many conventional buildings are incomparable to modern green real estate, which is built in different locations and is often larger, younger and of higher general quality (Chegut, Eichholtz, and Kok, 2013; Eichholtz, Kok, and Quigley, 2010, 2013). To address this issue, we first select our sample on the basis of vintage and location. Then, we employ a matching model to construct a control group of conventional buildings on the basis of observable characteristics such as the number of stories, its age, the number of tenders and the building contract length. Next, we accommodate possible non-linear cost developments over time with a so-called general index of technical change consisting of a series of time dummies (Baltagi and Griffin, 1988). Moreover, in our analysis of construction cost elements, we closely follow the nascent literature on modern construction economics (Runeson, 2010) and in particular the expost construction measures documented by Wheaton and Simonton (2007).

Our first step consists of the construction of a benchmark cost model. In general, cost functions relate the mix of inputs to input prices in order to minimize costs. In the case of construction, firms take multiple inputs to produce a single output a building. We adapt the assumptions made by Rao, O'Donnell, Battese, and Coelli (2005) for the construction of a building and assume that a construction firm does not possess enough power to affect the prices of inputs and must take the prices of goods and services as given, especially in the short-run. Moreover, construction costs can never be negative, an increase in the input prices of labor and materials will not decrease costs, it costs more to produce more buildings, doubling the price of inputs will double the price of outputs and the demand function for inputs cannot be upward sloping, meaning increasing prices do not increase demand. In line with these assumptions, the basic

\footnotetext{
${ }^{9}$ Thus, in the more formal theoretical expectations derived by Tirole (1988), it is likely that first order condition is still negative, but the second order condition may be less than in the first case, i.e. $C^{\prime \prime}\left(t_{c}\right)>C^{\prime \prime}\left(t_{n c}\right)$, where $c$ is the case of the developer experiencing positive externalities, undergoing a certification process and $n c$ is where there is no certification process and each developer must learn to innovative independently.
} 
cost model is as follows:

$$
C(w, q)=\min _{x}\left(w^{\prime} x\right)
$$

where firms combine given input prices $w=\left(w_{1}, w_{2}, \ldots, w_{n}\right)$ and output (building) quantities $q$ such that the construction $\operatorname{cost} C$ is minimized and input prices $w$ and input quantities $x$ produce a building quantity $q$ at minimal cost and zero waste. However, it is unlikely that there is zero waste in the construction process. Thus, when operationalized there should be the addition of filters that control for potential search and transaction costs in the construction process.

Empirically, we operationalize equation (4.1) using a multi-variate cost regression model following Emsley, Lowe, Duff, Harding, and Hickson (2002); Lowe, Emsley, and Harding (2006); McCaffer, McCaffrey, and Thorpe (1984):

$$
\log C_{i}=\alpha+\phi Z_{i}+\beta X_{i}+\gamma Z_{i} \cdot X_{i}+\theta K_{i}+\delta T_{i}+\lambda R_{i}+\epsilon_{i}
$$

where $C$ is construction cost per square meter and $\alpha$ is a constant. ${ }^{10}$ As our principal variable of interest, we employ a dummy variable for green certification $Z$, where building $i$ certified by BREEAM is one, and zero otherwise. $X$ is a vector of (exogenous) construction characteristics capturing input prices $w$ and input quantities $x$. It includes the substructure, superstructure, finishes, fittings and furnishings, services, contingencies and design fees of building $i$. We account for the possibility that BREEAM-certification and construction characteristics are related by including an interaction term $Z_{i} \cdot X_{i}$. K captures the likely waste in the construction process and can be represented by a vector of control variables including the contract style, procurement strategy, tendering strategy, duration of contract, contract features, cost rendering and contractual ability to shift costs and building purpose, and the building hedonic characteristics significant for construction, like the main construction type, stories and age in the case of building refurbishments and new construction/refurbishment status. $T$ is a vector of of time dummies, representing the year of construction for building $i$ and $R$ is a vector of county dummies, representing the region of construction for building $i$. The estimated parameter vectors are $\phi, \beta, \gamma, \theta, \lambda$ and $\delta$ and $\epsilon$ is a vector of regression disturbances. 11

We employ propensity score weighting techniques to minimize bias between the BREEAM-certified and non-certified buildings (Rosenbaum and Rubin, 1983) and more

\footnotetext{
${ }^{10}$ We use the cost per square meter to control for size differences. Results are qualitatively similar if we include the log of construction cost and control for the size of a building on the right-hand side.

${ }^{11}$ The functional form of the operationalized equation is in log-log form (for non-discrete variables). This form assumes that there are diminishing marginal increases to the construction cost of a building and that any given increase in an element of construction is a constant fraction of total cost. Our estimation procedure for equation (4.2) is OLS corrected for heteroskedasticity with robust standard errors (White, 1980).
} 
recently (Black and Smith, 2004). Applying this method to the construction cost literature, propensity score weighting aims to minimize the selection bias between BREEAMcertified and non-certified buildings by differentiating based on individual construction characteristics. Conditional upon observable characteristics, we eliminate differences between "innovative" green buildings and "non-innovative" control buildings by estimating the propensity of undergoing the design and procurement process for BREEAM certification for all buildings in the construction cost sample. The propensity scores are estimated via a logit model, based on the building and contract characteristics significant for construction, e.g., the elemental costs of construction (available for the subject and non-certified sample). Using the buildings with a common propensity for undergoing the certification treatment, we apply the resulting propensity score as a weight in the regression of equation (4.2) (See for an application of the propensity score in commercial real estate Eichholtz, Kok, and Quigley (2013); and Chegut, Eichholtz, and Kok (2013)).

\subsection{Construction Cost Data}

Our dataset contains a sample of 564 UK construction projects, 121 BREEAM-certified and 443 non-certified. To create this sample, we merge two data sources. First, we use the Royal Institute of Chartered Surveyor's BCIS database, a comprehensive construction cost database. ${ }^{12}$ Second, to identify BREEAM-certified buildings in the BCIS database we use the Green Book Live Public certification database. ${ }^{13}$

After cleaning the data, we obtain a cross-section of 351 construction projects, 107 BREEAM-certified and 244 non-certified projects. The dataset includes information on BREEAM-rating, elemental costs, building, client, and contract characteristics, tender and procurement strategy, construction location and the year of construction. ${ }^{14}$

Ex ante, we have the following expectations about the magnitude of BREEAMcertified costs stemming from the types of innovation and the stage of innovation:

BREEAM-rating: The extent of innovation can be measured in two ways. One by

\footnotetext{
${ }^{12}$ For the analysis, we use the BCIS Online tool, which includes over 18,000 projects spanning the last 50 years. The database includes cost breakdowns for projects, indices and location-adjustment factors. Subscribers to the database are also the source of the data, providing data on realized construction cost as experienced in the marketplace. According to the BCIS website, the data includes construction projects from public and private investors. However, the extent that this a fifty-fifty split across the full sample period is not the case. However, for the cross-section, the public and private controls are roughly equally split, where the public data represents 58 and 52 present for the BREEAM-certified and non-certified sample, respectively.

${ }^{13} \mathrm{http}$ ://www.greenbooklive.com/search/scheme.jsp?id=202 To eliminate erroneous labeling of buildings as BREEAM-certified, we conducted a manual verification of all buildings from the BCIS dataset to confirm that indeed they are BREEAM-certified.

${ }^{14}$ We dropped a total of 213 observations: 2 because of invalid construction years, 1 because of a missing story variable, 1 because of a missing new or renovated construction status, 105 observations were not in BREEAM-certified counties, 62 had incomplete elemental costs and 42 had missing contract lengths.
} 
BREEAM-certification itself, representing a process change in construction. However, there is attention to more advanced technology, fittings and finishes as construction moves up the quality ladder. For BREEAM-certified construction, this is measured by achieving higher BREEAM-ratings, where Outstanding and Excellent buildings are likely to cost more than non-certified construction projects.

Elemental Costs: Given the functional form of the specification, these variables measure the cost elasticity of increased elemental inputs for a total building. The elemental cost is representative of the materials, capital and labor to produce that element of a building, which is in turn scaled by the gross internal floor area and then the logarithim is taken. The elemental costs of the building itself are broken down into seven categories: substructure, superstructure, finishes, fittings, services, contingencies and design fees. ${ }^{15}$ Concerning general cost expectations, superstructure, which represents the walls and roof of the structure are likely to be the most expensive element of any building. However, the quality of these elements will be reflected in the finishes, fittings or services for the building.

Regarding the magnitude of costs, the hard costs for BREEAM-certified buildings are likely to have higher costs in the superstructure and services elements of the building. It is suspected that substructure costs will have a zero or negative impact on variation as they are a normal part of any construction process. Regarding soft costs, BREEAM-certified buildings likely have higher design fees as they undergo a more elaborate design process as measured by the BREEAM certification or contingencies costs as they have longer construction periods. ${ }^{16}$

Building Characteristics: We expect that the size of buildings will play a significant and positive role in construction costs, both hard and soft. Buildings with larger gross internal floor areas and more stories will be more costly in total, but due to increasing economies of scale, increase at a decreasing rate. Moreover, new buildings will be less costly than refurbished buildings as new buildings can start from scratch in the design process and do not need building "cohort" specific materials. The main construction materials are brick, concrete, timber and steel. Steel is the dominant form of construction and is likely to be the least expensive material for construction for both the certified and non-certified buildings.

Client Characteristics: Developers, private builders and public entities may have different functional requirements increasing or decreasing capital requirements for con-

\footnotetext{
${ }^{15}$ Some buildings, like refurbishments or renovations do not undergo substructure costs. Within the analysis, these observations are controlled for and in place of log zero which is undefined a zero is put into place.

${ }^{16}$ Brief definitions of elemental costs: substructure is construction below the lowest floor together with the foundation; superstructure is the frame, floors, roof, stairs, external walls, windows and doors; finishes are for the wall, floor, and ceiling enhancements; fittings are items like installed furniture, flooring and equipment; services are the sanitary, kitchen, plumbing, disposal, water, heat sources, air treatment, electrical wiring, lifts and protective systems costs; contingencies are for cost overages; and design fees are the costs for designing the building.
} 
struction. Within the sample, buildings can be for the purpose of 'Administration', 'Office', 'Retail', 'School', 'Residential' and 'University' use. The anticipated impacts on certification are economically significant as the functionality and end-user of the building may independently cause the price of certification to increase. Buildings that require more elaborate finishes as well as lengthy life-cycles are likely to cost more.

Contract Characteristics: Generally, as the number of tenders on a project increases, it is expected that the marginal cost of construction decreases, resulting in a negative impact on construction prices in general. However, longer contract lengths, i.e., construction periods, can lead to prolonged use of construction equipment and labor. Thus, longer contract lengths will likely have a positive cost impact. It is expected that due to the innovative nature of BREEAM-certified buildings they will have fewer tenders and longer contract periods, at first (Katz and Shapiro, 1985). Fewer contractors will have the human and physical capital to implement the 'innovative' construction initiatives that a BREEAM-certified building would require. Moreover, given the R\&D intensiveness of these construction projects, they may take longer to construct, due to learning, unexpected outcomes and more intensive monitoring of projects. As controls, specific aspects of the contract have also been added, like fixed vs. firm contracting costs and a specification of the costs of materials ex-ante via a bill of quantities. ${ }^{17}$

Year of Construction and Regional Effects: The BCIS constructs construction cost indices on a quarterly basis for the whole of the UK. Since 1985, construction costs measured by the BCIS General Building Cost Index have tripled, meaning that the cost of construction for an "average" building in 1985 has increased by two hundred percent, not inflation adjusted. Thus, we expect a positive trend in the year dummies year over year. Moreover, there are 52 counties represented in the sample, with one-third of the sample in the more expensive London and Manchester markets.

\subsubsection{Summary Statistics}

We first compare the BREEAM-certified and non-certified sample using a univariate analysis. Overall, a two sample $t$-test with equal variances documents that there is not a statistically significant difference between BREEAM-certified and non-certified construction costs per square meter. The mean difference is $£ 142$, but statistically insignificant $(\mathrm{t}=1.28, \mathrm{p}=0.20)$. Figure 4.2 reports the mean construction and elemental costs per gross square meter for the BREEAM-certified and non-certified samples over the 2003 to 2012 period. The light gray bars depict the non-certified samples' mean costs and the dark grey bars depict the BREEAM-certified samples' additional costs. First, the largest drivers of construction costs overall are super-structure and services

\footnotetext{
${ }^{17} \mathrm{BCIS}$ captures the contract price documentation, which details the contractual pricing documents used to develop the tender bid. The main classifications are Employer's requirements, Contract Sum Analysis, Bill of Quantities, Bill of Approximate Quantities, Schedule of Rates, Target Cost, Specification and Drawings, Schedule of Works, etc. (BCIS, 2012).
} 
costs. Finishes, fittings, contingencies and design fees are a smaller proportion of total construction costs. Secondly, a t-test suggests that the statistically and economically largest differences between BREEAM-certified and non-certified construction projects come in 2003 and 2008. The elemental costs suggests that the difference for 2003 and 2008 are driven primarily by outliers. Within the data, there are two significant buildings that drive those costs. In 2003, a Very Good office building was constructed for $£ 2972$ per square meter, which is far more costly than all other BREEAM-certified and non-certified buildings. In 2008, two BREEAM-certified University buildings were constructed, which are on average more expensive across both the BREEAM-certified and non-certified samples. Importantly, in line with anecdotal evidence, design fees are higher for BREEAM-certified buildings, but in contrast to anecdotal evidence, represent a minor fraction of a building's total cost. ${ }^{18}$

Table 4.2 further documents the dependent and independent variables used in the analysis, comparing the average characteristics of green buildings in the sample with buildings in the non-certified sample.

The BREEAM status indicates that the majority of projects in the construction sample are BREEAM-certified as 'Very Good' and 'Excellent' buildings, with the remaining projects scattered across the 'Outstanding', 'Good' and 'Pass' categories. This corresponds with the population of BREEAM-certified buildings within the UK (Chegut, Eichholtz, and Kok, 2013) and represents a further breakdown along the BREEAM quality ladder. Construction cost characteristics for the BREEAM-certified and noncertified sample differ widely in absolute terms for BREEAM-certified projects, but once adjusted for the size of the buildings costs are comparable in terms of mean cost and variance. In absolute costs, all elemental costs are higher for green buildings than for the non-certified group and have higher variation, with particular attention to superstructure costs per gross square meter, which is in line with Figure 4.2. Furthermore, Figure 4.3 depicts that the distribution of the dependent variable for the BREEAMcertified and non-certified sample are normally distributed, although the non-certified sample is slightly positively skewed.

BREEAM-certified projects have a larger mean gross internal floor area and are more variable in size than the non-certified sample. The number of stories is, on average, greater by about one story. However, the variation for the BREEAM-certified sample is almost twice that of the non-certified sample. Eighty nine percent of the BREEAM-certified sample is new construction, as compared to 80 percent of the noncertified sample. The main construction type for BREEAM-certified buildings and the non-certified sample is steel.

\footnotetext{
${ }^{18}$ This is confirmed by a correlation test on BREEAM-certified and elemental costs, for BREEAMcertified and the other elements correlation is on average less than 10 percent. However, for design fees the correlation is 33 percent.
} 
Figure 4.2: Mean Construction Costs by BREEAM Certified
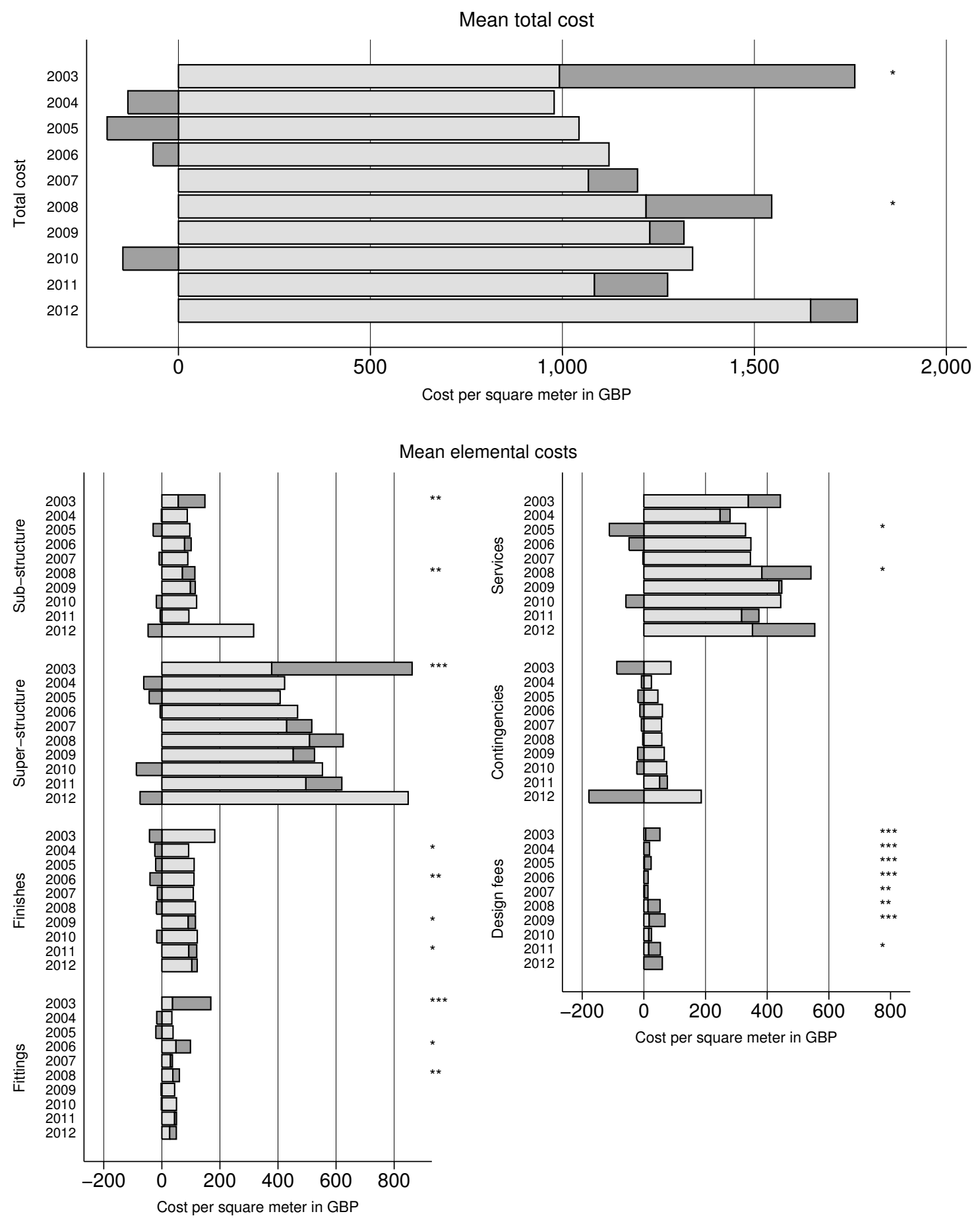

\section{$\square$ Cost non-certified $\square$ Additional cost certified}

$* / * * / * * *$ indicates differences in mean significant at the $1 / 5 / 10 \%$ level, respectively.

Notes: Figure 4.2 reports the mean construction and elemental costs per gross square meter for the BREEAM-certified and noncertified samples over the 2003 to 2012 period. The light gray bars depict the non-certified samples' mean costs and the dark grey bars depict the BREEAM-certified samples' additional mean costs. First, the largest drivers of construction costs overall are superstructure and services costs, which represent the infrastructure of a building. Secondly, a t-test suggests that the statistically and economically largest differences between BREEAM-certified and non-certified come in 2003 and 2008. Turning to the elemental costs suggests that the difference for 2003 and 2008 are driven primarily by differences in the super-structure and services costs, respectively. Within the data, there are two significant buildings that drive those costs. In 2003, a Very Good office building was constructed for $£ 2972$ per square meter, far greater than all other BREEAM-certified and non-certified buildings. In 2008, two BREEAM-certified University buildings were constructed, which are on average more expensive across both the BREEAMcertified and non-certified samples. 
Figure 4.3: Distribution of Log of Construction Cost per Square Meter

(a) BREEAM-certified Sample Building Cost

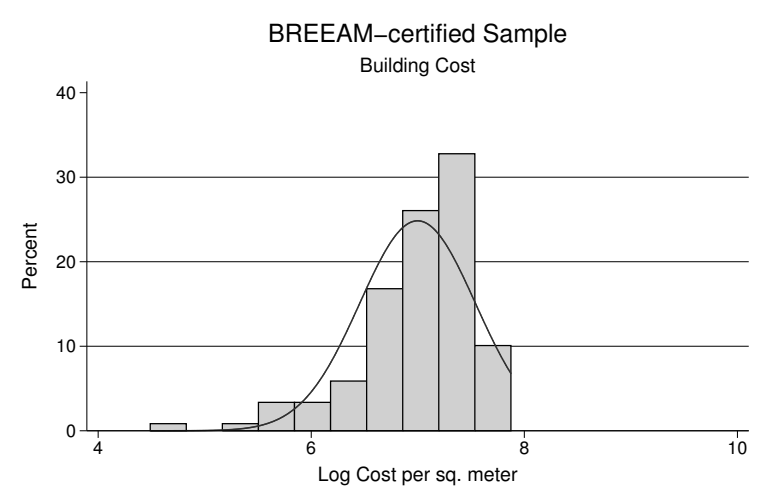

(b) Non-certified Sample Building Cost

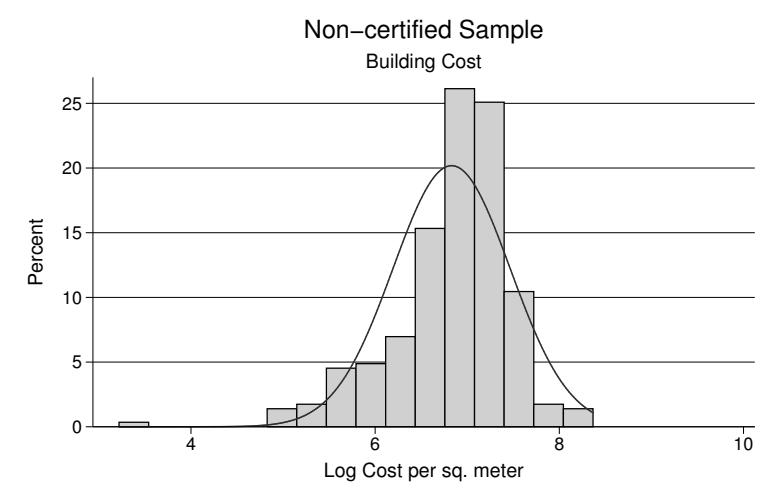

Notes: Figure 4.3 depicts the histograms of the dependent variable for the BREEAM-certified and noncertified samples, the logarithim of final construction cost per gross internal floor area (sq. meters). Panel 4.3a depicts the BREEAM-certified dependent variable, which slightly right skewed. Panel $4.3 \mathrm{~b}$ depicts the non-certified dependent variable, which is slightly positively skewed. However, both samples cover similar densities and logarithimic spans.

Both the certified and the non-certified sample have the same distribution of property types. The main building project types are 'Offices' and 'Schools' for both the BREEAM-certified and non-certified samples, with the largest representation for both samples coming from the 'Public' sector with 58 and 52 percent, respectively.

Interestingly, BREEAM-certified projects have, on average, one less tender than non-certified projects, with similar variation. A caveat of the UK construction market is that it is dominated by a few large contractors and this may be showing up in this sample as well. Contract lengths for BREEAM-certified projects are longer by about 2.5 months, but with comparable variation. Costs are mainly fixed for the BREEAM-certified sample, indicating little ex-post contracting changes in the costs. Bill of Quantities, which is a document breaking down the costs of construction for the client, relative to other types of more intransparent billing is far less common than for the non-certified sample. The dominant contract selection methods for both samples are 'Design and Build' and 'Selected Competition.' However, for the non-certified sample, 'Selected Competition' is used almost twice as often. ${ }^{19}$

The year of construction is comparable between the BREEAM-certified and noncertified samples. However, the BREEAM-certified sample has spikes in the number of projects in 2008 and 2010. This illustrates rapid growth in the population of BREEAMcertified buildings. The year 2008 is the highest year on record for BREEAM certifica-

\footnotetext{
${ }^{19}$ These contract selection methods say something about how the contract goes through the tender and procurement stage of construction. Within the data there are eight paths that a contract could take, which could impact the relative efficiency of the design and procurement of a building. Traditionally, 'Negotiated' contracts are the most expensive as they do not go through a bidding process and 'Design and Build' are the most efficient contracts as they do go through a bidding process and the design and construction of the building are streamlined together.
} 
Table 4.2: Comparison of BREEAM-certified and Non-certified Construction Samples

(a) BREEAM-certified Sample (107 Observations)

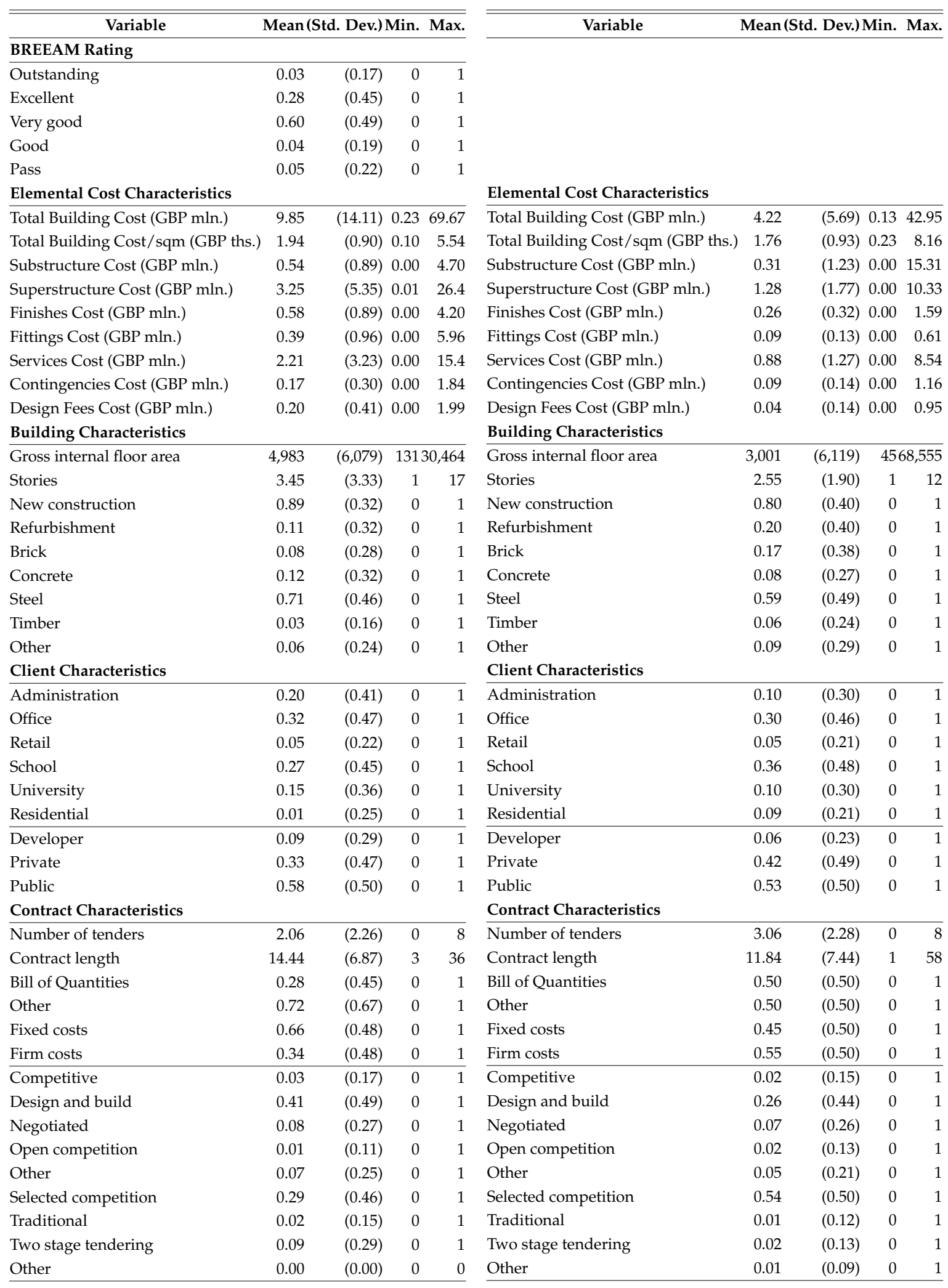

(b) Non-certified Sample (244 Observations) 
tion over the sample period 3. In addition, the sample is evenly spread across the UK, with only one-third of projects concentrated in London or Manchester.

When considering the maximum cost characteristics of the sample, the total building costs are greater for green buildings. However, the maximum cost per square meter is less by almost half. Substructure costs are less, but this may be due to refurbishments or subcontracts elsewhere. The maximum superstructure, finishing, fittings, services, contingencies and design fees are higher for green buildings. However, BREEAMcertified and non-certified buildings share the same number of maximum tenders, but the maximum contract length is half the required time for a BREEAM-certified building.

\subsection{Results}

\subsubsection{Green Innovation Costs}

Table 4.3 presents the results for the construction costs over the 2003 to 2012 period, relating the logarithm of construction costs per gross square meter to a set of elemental costs, building, client and contract characteristics with region and construction year fixed-effects. Importantly, the results are propensity-score-weighted without the interaction effect $Z_{i} \cdot X_{i}$. Figure 4.4 depicts the distribution of propensity score weights, where on the vertical scale presents the density of distribution, and the horizontal scale shows the applied weights. The dotted line depicts the non-certified buildings and the dashed line depicts the BREEAM-certified buildings. Economically, this suggests that both forms of construction do have areas of commonality, but distinct differences remain at the margins. ${ }^{20}$

The propensity-score-weighted specifications explain about 79 to 83 percent of the variation in the log construction cost per gross square meter. Region and time dummies are added to the specifications, each jointly statistically significant at the one percent level.

Column (1) reports the results of comparing the averages of the BREEAM-certified to the non-certified buildings, which is a direct comparison to the previous methods in the green construction literature. The results of this simple analysis show that BREEAM-certified buildings did not cost more.

Column (2) reports the propensity-score-weighted regression results, relating construction costs to their elemental sub costs, i.e., substructure, superstructure, finishes, fittings, services, contingencies and design fees. As expected, these results reflect that the economically largest and statistically most significant costs are the superstructure and services costs. As elasticities, these indicate that when superstructure or services'

\footnotetext{
${ }^{20}$ The region of common support is $[.04, .88]$, which is distributed amongst 5 blocks. The mean weight is 30 percent and the standard deviation is 14 percent.
} 
Figure 4.4: Propensity Score Distribution and Area of Common Support

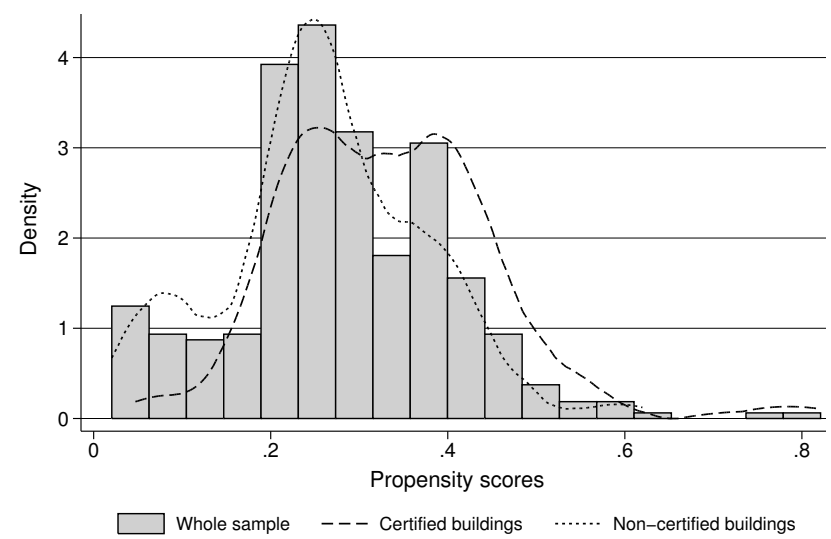

Notes: Figure 4.4 displays the distribution of propensity score weights for the whole sample, BREEAM certified and non-certified samples. The region of common support is [.04, .89], which is distributed amongst 5 blocks. The mean weight is 30 percent and the standard deviation is 14 percent. The propensity score density is positively skewed, with a measure of .59. In addition, the dashed and the dotted lines indicate the area of common support for the samples. The overlap indicates that there are BREEAM-certified and non-certified construction projects with similar weights.

costs increase by one percent, the total cost of the building increases by .31 and .16 percent on average, respectively.

Column (3) adds building and client characteristics, such as age, stories, and new buildings relative to refurbished buildings, main construction type, client type and type of construction. First, the BREEAM-certified coefficient remains statistically insignificant. Second, the elemental costs are modified by the addition of these features and increase with the additional filter of client characteristics. Although building characteristics are statistically insignificant, client characteristics are statistically significant across client type and type of construction. Relative to Administrative building functions, Office, Retail and University buildings are more expensive, with Retail buildings costing comparatively the most at 53 percent. This is likely due to the extensive finishes and necessary attention to detail for Retail structures. Private clients construct buildings at a discount relative to developers, at approximately 13 percent less. Lastly, the elemental costs for fittings and finishes increase marginally to .10 and .05 percent, respectively.

In column (4), contract characteristics are added to the specification. BREEAMcertified remains statistically insignificant. The elemental costs are further modified and decrease moderately with the addition of contract characteristics. Design fees are no longer statistically significant, which may be related to how design fees are agreed upon in the tendering of the contract. Client characteristics remain statistically significant. Offices relative to Administration and Retail spaces are cost 16.6 percent more, which three percent less when the contract characteristics are added. Again, Offices are more often built with a combined contract for design and construction. Moreover, the number of tenders, contract length, fixed costs and bill of quantities dummies mea- 
suring how contracts are established are statistically insignificant.

Table 4.3: Construction Costs for BREEAM-certified and Non-Certified Buildings (Dependent Variable: Logarithm of Construction Cost per gross square meter)

\begin{tabular}{|c|c|c|c|c|c|c|c|c|c|}
\hline & & (1) & (2) & (3) & (4) & (5) & (6) & (7) & (8) \\
\hline \multirow{12}{*}{ 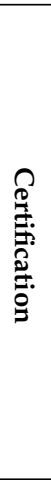 } & BREEAM Certified & 0.099 & 0.022 & 0.023 & 0.007 & & & & \\
\hline & & {$[0.066]$} & [0.035] & [0.037] & {$[0.038]$} & & & & \\
\hline & Outstanding & & & & & $0.274^{* * *}$ & 0.104 & $0.169^{*}$ & $0.167^{*}$ \\
\hline & & & & & & {$[0.096]$} & [0.113] & [0.093] & {$[0.088]$} \\
\hline & Excellent & & & & & $0.163^{*}$ & 0.082 & 0.060 & 0.035 \\
\hline & & & & & & [0.097] & [0.052] & {$[0.054]$} & {$[0.050]$} \\
\hline & Very good & & & & & 0.056 & -0.015 & -0.009 & -0.030 \\
\hline & & & & & & {$[0.091]$} & [0.051] & [0.049] & [0.053] \\
\hline & Good & & & & & 0.169 & -0.006 & 0.023 & 0.008 \\
\hline & & & & & & {$[0.166]$} & {$[0.091]$} & [0.125] & {$[0.100]$} \\
\hline & Pass & & & & & 0.041 & 0.070 & 0.077 & 0.079 \\
\hline & & & & & & [0.165] & {$[0.064]$} & {$[0.060]$} & {$[0.072]$} \\
\hline \multirow{14}{*}{ 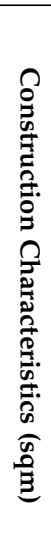 } & Log (Substructure cost) & & $0.058^{* * *}$ & $0.075^{* * *}$ & $0.069^{* * *}$ & & $0.059^{* * *}$ & $0.075^{* * *}$ & $0.071^{* * *}$ \\
\hline & & & {$[0.018]$} & {$[0.018]$} & {$[0.018]$} & & {$[0.019]$} & {$[0.018]$} & {$[0.018]$} \\
\hline & Log (Superstructure cost) & & $0.315^{* * *}$ & $0.313^{* * *}$ & $0.310^{* * *}$ & & $0.315^{* * *}$ & $0.311^{* * *}$ & $0.309^{* * *}$ \\
\hline & & & {$[0.075]$} & {$[0.077]$} & {$[0.076]$} & & {$[0.076]$} & [0.077] & {$[0.077]$} \\
\hline & Log (Finishes cost) & & $0.082^{* *}$ & $0.100^{* *}$ & $0.095^{* *}$ & & $0.080^{*}$ & $0.098^{* *}$ & $0.094^{* *}$ \\
\hline & & & {$[0.042]$} & {$[0.043]$} & {$[0.044]$} & & {$[0.042]$} & {$[0.043]$} & {$[0.044]$} \\
\hline & Log (Fittings cost) & & $0.033^{* *}$ & $0.049^{* * *}$ & $0.046^{* * *}$ & & $0.033^{* *}$ & $0.049^{* * *}$ & $0.047^{* * *}$ \\
\hline & & & {$[0.016]$} & {$[0.016]$} & {$[0.016]$} & & {$[0.017]$} & {$[0.017]$} & {$[0.016]$} \\
\hline & Log (Services cost) & & $0.160^{* * *}$ & $0.168^{* * *}$ & $0.168^{* * *}$ & & $0.158^{* * *}$ & $0.168^{* * *}$ & $0.166^{* * *}$ \\
\hline & & & {$[0.042]$} & {$[0.038]$} & [0.039] & & {$[0.043]$} & [0.039] & {$[0.039]$} \\
\hline & Log (Contingencies) & & $0.070^{* * *}$ & $0.071^{* * *}$ & $0.077^{* * *}$ & & $0.071^{* * *}$ & $0.072^{* * *}$ & $0.079^{* * *}$ \\
\hline & & & {$[0.014]$} & {$[0.014]$} & {$[0.015]$} & & {$[0.014]$} & {$[0.014]$} & {$[0.015]$} \\
\hline & Log (Design Fees) & & $0.022^{*}$ & $0.023^{*}$ & 0.017 & & 0.020 & 0.021 & 0.015 \\
\hline & & & [0.013] & [0.012] & [0.013] & & [0.013] & [0.013] & [0.013] \\
\hline \multirow{14}{*}{ 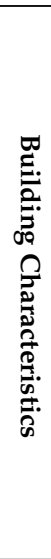 } & Age & & & -0.003 & -0.005 & & & -0.003 & -0.004 \\
\hline & & & & {$[0.016]$} & [0.015] & & & {$[0.016]$} & {$[0.015]$} \\
\hline & Stories & & & -0.016 & -0.015 & & & -0.015 & -0.016 \\
\hline & & & & {$[0.010]$} & {$[0.011]$} & & & [0.010] & {$[0.011]$} \\
\hline & New construction & & & -0.034 & -0.034 & & & -0.024 & -0.026 \\
\hline & & & & [0.073] & {$[0.072]$} & & & {$[0.075]$} & {$[0.074]$} \\
\hline & Brick & & & -0.014 & -0.023 & & & -0.017 & -0.029 \\
\hline & & & & [0.081] & [0.080] & & & [0.082] & [0.081] \\
\hline & Concrete & & & -0.051 & -0.030 & & & -0.048 & -0.029 \\
\hline & & & & [0.103] & [0.104] & & & [0.106] & [0.107] \\
\hline & Steel & & & -0.097 & -0.092 & & & -0.100 & -0.098 \\
\hline & & & & [0.080] & [0.082] & & & {$[0.082]$} & [0.083] \\
\hline & Timber & & & -0.014 & -0.020 & & & -0.020 & -0.032 \\
\hline & & & & [0.085] & {$[0.090]$} & & & {$[0.087]$} & [0.091] \\
\hline \multirow{12}{*}{ 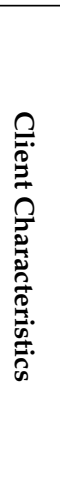 } & Office & & & $0.196^{* * * *}$ & $0.166^{* * *}$ & & & $0.192^{* * *}$ & $0.165^{* * *}$ \\
\hline & & & & {$[0.053]$} & [0.054] & & & {$[0.053]$} & {$[0.054]$} \\
\hline & Retail & & & $0.530^{* * *}$ & $0.538^{* * *}$ & & & $0.544^{* * *}$ & $0.547^{* * *}$ \\
\hline & & & & [0.140] & [0.139] & & & [0.142] & [0.140] \\
\hline & School & & & $0.126^{* *}$ & $0.106^{*}$ & & & $0.122^{* *}$ & $0.101^{*}$ \\
\hline & & & & [0.057] & [0.056] & & & [0.057] & [0.055] \\
\hline & University & & & $0.187^{* * *}$ & $0.184^{* * *}$ & & & $0.175^{* *}$ & $0.171^{* *}$ \\
\hline & & & & {$[0.072]$} & {$[0.070]$} & & & [0.070] & [0.068] \\
\hline & Private & & & $-0.132^{*}$ & $-0.141^{*}$ & & & $-0.141^{*}$ & $-0.146^{*}$ \\
\hline & & & & [0.078] & {$[0.074]$} & & & [0.080] & {$[0.076]$} \\
\hline & Public & & & -0.096 & -0.087 & & & -0.102 & -0.090 \\
\hline & & & & [0.086] & [0.085] & & & [0.087] & [0.086] \\
\hline
\end{tabular}


Table 4.3 - continued from previous page

\begin{tabular}{|c|c|c|c|c|c|c|c|c|c|}
\hline & & (1) & (2) & (3) & (4) & (5) & (6) & (7) & (8) \\
\hline \multirow{29}{*}{ 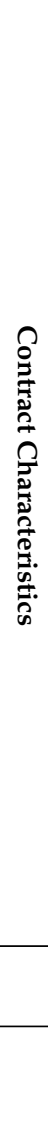 } & \multirow[t]{2}{*}{ Number of tenders } & & & & -0.003 & & & & -0.005 \\
\hline & & & & & {$[0.008]$} & & & & {$[0.008]$} \\
\hline & \multirow[t]{2}{*}{ Contract length } & & & & 0.006 & & & & 0.007 \\
\hline & & & & & [0.007] & & & & {$[0.007]$} \\
\hline & \multirow[t]{2}{*}{ Contract length ${ }^{2}$} & & & & -0.000 & & & & -0.000 \\
\hline & & & & & [0.000] & & & & {$[0.000]$} \\
\hline & \multirow[t]{2}{*}{ Fixed costs } & & & & -0.015 & & & & -0.013 \\
\hline & & & & & {$[0.031]$} & & & & [0.031] \\
\hline & \multirow[t]{2}{*}{ Bill of Quantities } & & & & -0.049 & & & & -0.044 \\
\hline & & & & & [0.047] & & & & {$[0.048]$} \\
\hline & \multirow[t]{2}{*}{ Competitive } & & & & -0.139 & & & & -0.129 \\
\hline & & & & & [0.129] & & & & {$[0.130]$} \\
\hline & \multirow[t]{2}{*}{ Design and build } & & & & -0.135 & & & & -0.127 \\
\hline & & & & & [0.083] & & & & [0.082] \\
\hline & \multirow[t]{2}{*}{ Negotiated } & & & & -0.001 & & & & -0.008 \\
\hline & & & & & [0.101] & & & & [0.104] \\
\hline & \multirow[t]{2}{*}{ Open competition } & & & & 0.110 & & & & 0.122 \\
\hline & & & & & {$[0.121]$} & & & & {$[0.120]$} \\
\hline & \multirow[t]{2}{*}{ Selected competition } & & & & -0.144 & & & & -0.136 \\
\hline & & & & & {$[0.088]$} & & & & [0.089] \\
\hline & \multirow[t]{2}{*}{ Traditional } & & & & -0.060 & & & & -0.047 \\
\hline & & & & & [0.145] & & & & [0.146] \\
\hline & \multirow[t]{2}{*}{ Two stage tendering } & & & & -0.148 & & & & -0.125 \\
\hline & & & & & [0.102] & & & & {$[0.104]$} \\
\hline & \multirow[t]{2}{*}{ Constant } & $7.308^{* * *}$ & $3.707^{* * *}$ & $3.566^{* * *}$ & $3.765^{* * *}$ & $7.308^{* * *}$ & $3.667^{* * *}$ & $3.553^{* * *}$ & $3.737^{* * *}$ \\
\hline & & {$[0.036]$} & {$[0.350]$} & {$[0.344]$} & {$[0.385]$} & {$[0.036]$} & {$[0.349]$} & {$[0.340]$} & {$[0.386]$} \\
\hline & Observations & 351 & 351 & 351 & 351 & 351 & 351 & 351 & 351 \\
\hline & R-squared & 0.007 & 0.792 & 0.823 & 0.834 & 0.010 & 0.794 & 0.825 & 0.835 \\
\hline & Adj R2 & 0.004 & 0.740 & 0.770 & 0.780 & 0.004 & 0.740 & 0.770 & 0.770 \\
\hline
\end{tabular}

Notes: Table 4.3 reports the results of equation (4.2) via OLS corrected for heteroskedasticity with robust standard errors (White, 1980). Dummies are relative to the following: New Construction(Renovation); Brick, Concrete, Steel and Timber(Other); Office, Retail, School and University (Administration and Resdiential); Fixed Costs (Firm Costs); Bill of Quantities (Other); Procurement Methods (Other).

Column (1) reports the results of comparing the averages of the BREEAM-certified to the non-certified buildings, which is a direct comparison to the previous methods in the green construction literature. The results of this simple analysis show that BREEAM-certified buildings did not cost more.

Column (2) reports the propensity-score-weighted regression results, relating construction costs to their elemental sub costs, i.e., substructure, superstructure, finishes, fittings, services, contingencies and design fees. As expected, these results reflect that the economically largest and statistically most significant costs are the superstructure and services costs. As elasticities, these indicate that when superstructure or services' costs increase by one percent, the total cost of the building increases by .31 and .16 percent on average, respectively.

Column (3) adds building and client characteristics, such as age, stories, and new buildings relative to refurbished buildings, main construction type, client type and type of construction. First, the BREEAM-certified coefficient remains statistically insignificant. Second, the elemental costs are modified by the addition of these features 
and increase with the additional filter of client characteristics. Although building characteristics are statistically insignificant, client characteristics are statistically significant across client type and type of construction. Relative to Administrative building functions, Office, Retail and University buildings are more expensive, with Retail buildings costing comparatively the most at 53 percent. This is likely due to the extensive finishes and necessary attention to detail for Retail structures. Private clients construct buildings at a discount relative to developers, at approximately 13 percent less. Lastly, the elemental costs for fittings and finishes increase marginally to .10 and .05 percent, respectively.

In column (4), contract characteristics are added to the specification. BREEAMcertified remains statistically insignificant. The elemental costs are further modified and decrease moderately with the addition of contract characteristics. Design fees are no longer statistically significant, which may be related to how design fees are agreed upon in the tendering of the contract. Client characteristics remain statistically significant. Offices relative to Administration and Retail spaces are cost 16.6 percent more, which three percent less when the contract characteristics are added. Again, Offices are more often built with a combined contract for design and construction. Moreover, the number of tenders, contract length, fixed costs and bill of quantities dummies measuring how contracts are established are statistically insignificant.

In columns (5) through (8), the BREEAM-certified designation is broken down to its BREEAM rating and columns (1) through (4) are re-estimated. Column (5) reports the results of comparing the averages of the BREEAM ratings to the non-certified buildings, where Outstanding and Excellent buildings cost 27.4 and 16.3 percent more than non-certified buildings. In column (6), the elemental sub costs are added to the specification, negating the BREEAM rating costs found in the previous specification. In column (7), Building and Client Characteristics are added to the specification. The coefficients on the control variables perform similarly. However, BREEAM Outstanding buildings are statistically significant and cost 16.9 percent more than non-certified buildings. In column (8), the final specification adds the contract characteristics. the BREEAM Outstanding marginal construction costs are modified slightly to 16.7 percent. There are three Outstanding buildings in the sample, which reflect a marginal cost increase of 16.7 percent over their non-certified peers.

On average, BREEAM-certified buildings over the 2003 to 2012 do not indicate increased construction costs relative to their non-certified peers. Thus, the variation in the construction cost per square meter does not seem to be due to an omission in measuring the certification status of a building, ceteris paribus. ${ }^{21}$

\footnotetext{
${ }^{21}$ For robustness, we ran the specifications of equation and (4.2), without the elemental construction cost characteristics. Results of the BREEAM-certified dummy do not differ nor do the results of the BREEAM-rating. Within the construction cost literature the ex-post measurement of cost is specified in two operationalized models Emsley, Lowe, Duff, Harding, and Hickson (2002); Lowe, Emsley, and
} 
Table 4.4: Marginal Construction Costs for BREEAM-certified and Non-certified Buildings (Dependent Variable: Logarithm of Construction Cost per gross square meter)

\begin{tabular}{|c|c|c|c|c|c|}
\hline & & (1) & (2) & (3) & (4) \\
\hline & BREEAM Certified & 0.238 & 0.248 & 0.281 & 0.209 \\
\hline & & [0.566] & {$[0.555]$} & [0.507] & [0.527] \\
\hline & Log (Substructure cost (sqm)) & $0.066^{* * *}$ & $0.083^{* * *}$ & $0.086^{* * *}$ & $0.082^{* * *}$ \\
\hline & & {$[0.020]$} & [0.021] & [0.019] & [0.019] \\
\hline & Log (Superstructure cost (sqm)) & $0.288^{* * *}$ & $0.305^{* * *}$ & $0.299^{* * *}$ & $0.293^{* * *}$ \\
\hline & & [0.093] & {$[0.101]$} & [0.094] & [0.096] \\
\hline & Log (Finishes cost (sqm)) & 0.041 & 0.046 & 0.073 & 0.070 \\
\hline & & [0.044] & [0.046] & [0.046] & [0.048] \\
\hline & Log (Fittings cost (sqm)) & 0.031 & $0.033^{*}$ & $0.049^{* * *}$ & $0.046^{* *}$ \\
\hline & & [0.019] & {$[0.018]$} & {$[0.018]$} & [0.018] \\
\hline & Log (Services cost (sqm)) & $0.247^{* * *}$ & $0.233^{* * * *}$ & $0.227^{* * *}$ & $0.223^{* * *}$ \\
\hline 8 & & {$[0.046]$} & {$[0.048]$} & {$[0.046]$} & [0.046] \\
\hline क & Log (Contingencies (sqm)) & $0.056^{* * *}$ & $0.051^{* * *}$ & $0.058^{* * *}$ & $0.064^{* * *}$ \\
\hline ह & & [0.015] & [0.015] & {$[0.015]$} & [0.016] \\
\hline ?. & Log (Design Fees (sqm)) & 0.015 & 0.015 & 0.020 & 0.018 \\
\hline 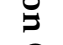 & & [0.017] & [0.016] & [0.015] & [0.016] \\
\hline $\mathcal{ح}$ & Certified ${ }^{*} \log$ (Substructure cost (sqm)) & -0.008 & -0.026 & -0.027 & -0.034 \\
\hline 苛 & & [0.034] & [0.033] & [0.030] & [0.031] \\
\hline$\frac{2}{0}$ & Certified*Log (Superstructure cost (sqm)) & 0.070 & 0.096 & 0.064 & 0.075 \\
\hline . & & [0.148] & [0.147] & [0.134] & [0.136] \\
\hline : & Certified ${ }^{*} \log ($ Finishes cost (sqm)) & 0.072 & 0.047 & 0.012 & 0.005 \\
\hline & & [0.098] & [0.098] & [0.090] & [0.095] \\
\hline & Certified*Log (Fittings cost (sqm)) & 0.017 & 0.018 & 0.008 & 0.008 \\
\hline & & [0.034] & [0.033] & [0.033] & [0.031] \\
\hline & Certified ${ }^{*} \log ($ Services cost (sqm)) & $-0.191^{* * *}$ & $-0.183^{* * *}$ & $-0.124^{* *}$ & $-0.115^{*}$ \\
\hline & & [0.061] & [0.062] & {$[0.061]$} & [0.059] \\
\hline & Certified*Log (Contingencies (sqm)) & 0.025 & 0.028 & 0.026 & 0.026 \\
\hline & & [0.030] & [0.028] & [0.028] & [0.027] \\
\hline & Certified*Log (Design Fees (sqm)) & 0.020 & 0.018 & 0.011 & 0.007 \\
\hline & & [0.024] & [0.023] & [0.022] & [0.021] \\
\hline & Building Characteristics & & Yes & Yes & Yes \\
\hline & Client Characteristics & & & Yes & Yes \\
\hline & Contract Characteristics & & & & Yes \\
\hline & Constant & $3.326^{* * *}$ & $3.478^{* * *}$ & $3.153^{* * *}$ & $3.711^{* * *}$ \\
\hline & & [0.348] & {$[0.354]$} & [0.347] & [0.471] \\
\hline & Observations & 351 & 351 & 351 & 351 \\
\hline & R-squared & 0.804 & 0.812 & 0.830 & 0.840 \\
\hline & Adj R2 & 0.75 & 0.76 & 0.78 & 0.78 \\
\hline & & & & & \\
\hline & BREEAM Certified Calculation & 0.03 & 0.06 & 0.03 & 0.00 \\
\hline
\end{tabular}

Notes: Table 4.4 reports the results of equation (4.2) with BREEAM-certified interacted with each elemental cost via OLS corrected for heteroskedasticity with robust standard errors (White, 1980). Dummies are relative to the following: New Construction(Renovation); Brick, Concrete, Steel and Timber(Other); Office, Retail, School and University (Administration and Residential); Fixed Costs (Firm Costs); Bill of Quantities (Other); Procurement Methods (Other). The conditional marginal effect with respect to certification is calculated as follows: $=\beta_{\text {Certified }}+\operatorname{Elemental\operatorname {Cost}}($ Mean $) *$ $\beta_{\text {Certified } * \text { ElementalCost. }}$. 


\subsection{Results}

The identification of certified green construction costs suggests that on average green buildings are not more expensive, but Figure 4.2 suggests that there are marginal cost elements of green construction cost that are on average more costly per square meter. According to Brambor, Clark, and Golder (2006), we can calculate the conditional marginal effects at the mean, even when individual coefficients are statistically insignificant using the following equation:

$$
\frac{\partial \log C_{i}}{\partial Z_{i}}=\phi+\gamma \cdot \text { ElementalCosts(CertifiedMean) }
$$

Thus, we re-estimate equation (4.2) with BREEAM-certified interacted with the elemental cost dependent variables. Similar to Table 4.3, we develop these results across the dependent variables to understand how the marginal cost of construction changes.

Table 4.4 reports the results of the conditional marginal effects analysis, which explains 80 to 84 percent of the variation in the logarithim in construction cost per gross square meter. In line with previous results, BREEAM certification does not have a statistically significant impact on construction cost. However, filtering the BREEAMcertified marginal effect from the control marginal effect indicates that there are some conditional marginal effects that explain the variation in construction costs, namely for service costs.

Thus despite their lack of statistical significance, at the mean, certified construction over the 2003 to 2012 period, costs at minimum zero percent more and at maximum six percent more than a non-certified project, conditional upon the specification. Importantly, the building, client and contract characteristics do play a modifying role in the economic significance and magnitude of the BREEAM-certified construction costs. ${ }^{22}$

\subsubsection{The Magnitude of Green Innovation Costs}

To assess the source of green innovation costs, we estimate equation (4.2) for the BREEAM certified sample. The results are reported in Table 4.5, which explains 69 to 73 percent of the variation in the logarithim of BREEAM-certified construction costs per gross square meter.

Column (1) reports the results of the hard and soft construction costs for BREEAMcertified construction, which suggests that the elasticity of superstructure costs is positive and significant where a one percent increase in the superstructure costs per square meter results in a .36 percent increase in in construction costs. Thus, hard costs that

Harding (2006) include the elemental costs in their construction cost specifications using BCIS data, whereas Wheaton and Simonton (2007) do not include these elemental costs, but use a US dataset that may not break down costs in this manner.

${ }^{22}$ The conditional marginal effect with respect to certification is calculated as follows: $=\beta_{\text {Certified }}+$ ElementalCost $($ Mean $) * \beta_{\text {Certified } * \text { ElementalCost }}$. 
drive the construction costs of BREEAM-certified buildings result in increased expenses from the walls, roof and interior insulation of the buildings. In addition, contingencies, or unplanned soft costs of BREEAM-certified construction are also positive where a one percent increase in the contingencies costs per square meter results in a 0.10 percent increase in construction costs.

Column (2) adds building characteristics to the specification. Building characteristics similar to the general specification do not explain the variation in construction costs. Moreover, they do not modify the elemental costs of construction for BREEAMcertified buildings. In column (3) client characteristics are added. In contrast to the general specification, client characteristics do not explain the cost of BREEAM-certified construction, nor do they have a modifying effect on the elemental costs.

Finally, in column (4) we add contract characteristics to the specification. Surprisingly, contracting features do not impact BREEAM-certified construction costs. The regression analysis depicts no significant premiums or discounts from competition in the market.

Table 4.5: Construction Costs for BREEAM-certified Projects (Dependent Variable: Logarithm of Construction Cost per gross square meter)

\begin{tabular}{|c|c|c|c|c|c|c|}
\hline & & $(1)$ & $(2)$ & (3) & $(4)$ & (5) \\
\hline \multirow{2}{*}{ 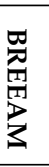 } & Outstanding & & & & & $\begin{array}{c}0.207 \\
{[0.390]}\end{array}$ \\
\hline & Excellent & & & & & $\begin{array}{c}0.027 \\
{[0.160]}\end{array}$ \\
\hline \multirow{8}{*}{ 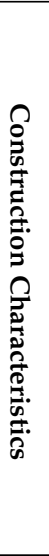 } & Log (Substructure cost (sqm)) & $\begin{array}{c}0.043 \\
{[0.035]}\end{array}$ & $\begin{array}{c}0.072 \\
{[0.049]}\end{array}$ & $\begin{array}{l}0.087^{* *} \\
{[0.042]}\end{array}$ & $\begin{array}{c}0.090 \\
{[0.063]}\end{array}$ & $\begin{array}{c}0.102 \\
{[0.075]}\end{array}$ \\
\hline & $\log$ (Superstructure cost (sqm)) & $0.360^{* *}$ & $0.358^{* *}$ & $0.300^{* *}$ & $0.277^{*}$ & 0.260 \\
\hline & Log (Finishes cost (sqm)) & $\begin{array}{c}{[0.164]} \\
0.123 \\
{[0.150]}\end{array}$ & $\begin{array}{c}{[0.163]} \\
0.120 \\
{[0.179]}\end{array}$ & $\begin{array}{c}{[0.146]} \\
-0.003 \\
{[0.150]}\end{array}$ & $\begin{array}{c}{[0.146]} \\
-0.031 \\
{[0.173]}\end{array}$ & $\begin{array}{c}{[0.155]} \\
0.020 \\
{[0.239]}\end{array}$ \\
\hline & Log (Fittings cost (sqm)) & $\begin{array}{c}0.020 \\
{[0.065]}\end{array}$ & $\begin{array}{c}0.013 \\
{[0.068]}\end{array}$ & $\begin{array}{c}0.032 \\
{[0.065]}\end{array}$ & $\begin{array}{c}-0.032 \\
{[0.114]}\end{array}$ & $\begin{array}{l}-0.025 \\
{[0.126]}\end{array}$ \\
\hline & Log (Services cost (sqm)) & $\begin{array}{c}0.067 \\
{[0.060]}\end{array}$ & $\begin{array}{c}0.042 \\
{[0.089]}\end{array}$ & $\begin{array}{l}0.275^{* *} \\
{[0.117]}\end{array}$ & $\begin{array}{c}0.299 \\
{[0.228]}\end{array}$ & $\begin{array}{c}0.265 \\
{[0.260]}\end{array}$ \\
\hline & $\log ($ Contingencies (sqm)) & $0.106^{* *}$ & $0.119^{* *}$ & $0.095^{* *}$ & 0.210 & 0.188 \\
\hline & & [0.049] & {$[0.046]$} & {$[0.045]$} & [0.144] & [0.179] \\
\hline & Log (Design Fees (sqm)) & $\begin{array}{c}0.034 \\
{[0.028]}\end{array}$ & $\begin{array}{c}0.042 \\
{[0.030]}\end{array}$ & $\begin{array}{c}0.026 \\
{[0.032]}\end{array}$ & $\begin{array}{c}0.040 \\
{[0.056]}\end{array}$ & $\begin{array}{c}0.038 \\
{[0.059]}\end{array}$ \\
\hline \multirow{7}{*}{ 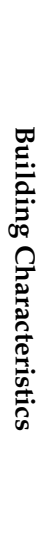 } & Age & & $\begin{array}{c}0.038 \\
{[0.106]}\end{array}$ & $\begin{array}{c}0.075 \\
{[0.097]}\end{array}$ & $\begin{array}{c}-0.056 \\
{[0.129]}\end{array}$ & $\begin{array}{l}-0.066 \\
{[0.125]}\end{array}$ \\
\hline & Stories & & 0.015 & -0.019 & 0.022 & 0.018 \\
\hline & New construction & & $\begin{array}{c}{[0.023]} \\
0.114 \\
{[0.268]}\end{array}$ & $\begin{array}{c}{[0.039]} \\
0.075 \\
{[0.225]}\end{array}$ & $\begin{array}{c}{[0.051]} \\
-0.244 \\
{[0.281]}\end{array}$ & $\begin{array}{c}{[0.051]} \\
-0.244 \\
{[0.289]}\end{array}$ \\
\hline & Brick & & $\begin{array}{c}-0.260 \\
{[0.333]}\end{array}$ & $\begin{array}{c}-0.038 \\
{[0.312]}\end{array}$ & $\begin{array}{c}0.054 \\
{[0.438]}\end{array}$ & $\begin{array}{c}0.036 \\
{[0.499}\end{array}$ \\
\hline & Concrete & & $\begin{array}{c}-0.120 \\
{[0.254]}\end{array}$ & $\begin{array}{c}0.192 \\
{[0.268]}\end{array}$ & $\begin{array}{c}0.205 \\
{[0.415]}\end{array}$ & $\begin{array}{c}0.162 \\
{[0.464]}\end{array}$ \\
\hline & Steel & & $\begin{array}{c}-0.340 \\
{[0.361]}\end{array}$ & $\begin{array}{l}-0.047 \\
{[0.329]}\end{array}$ & $\begin{array}{c}0.024 \\
{[0.437]}\end{array}$ & $\begin{array}{c}-0.014 \\
{[0.494]}\end{array}$ \\
\hline & Timber & & $\begin{array}{c}-0.177 \\
{[0.434]}\end{array}$ & $\begin{array}{c}0.276 \\
{[0.496]}\end{array}$ & $\begin{array}{c}0.301 \\
{[1.110]}\end{array}$ & $\begin{array}{c}0.185 \\
{[1.310]}\end{array}$ \\
\hline
\end{tabular}




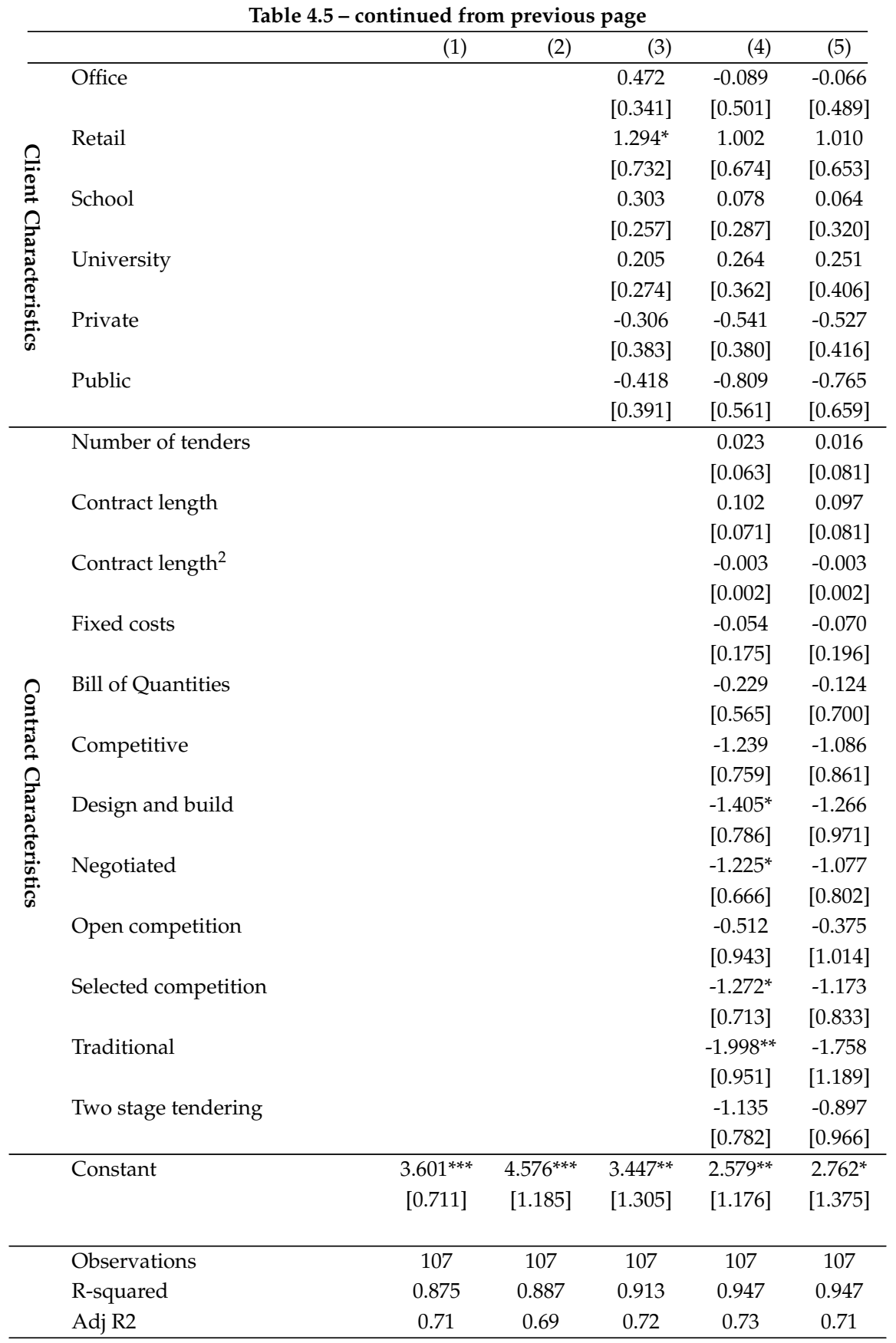

Notes: Table (4.5) reports the results of equation (4.2) for the BREEAM-certified sample alone (107 observations) via OLS corrected for heteroskedasticity with robust standard errors (White, 1980). Dummies are relative to the following: New Construction(Renovation); Brick, Concrete, Steel and Timber(Other); Office, Retail, School and University (Administration and Residential); Fixed Costs (Firm Costs); Bill of Quantities (Other); Procurement Methods (Unknown).

To further explore competition for contracts, we look at two aspects of the construction contract that might explain variation in construction costs across the two samples, contract length and number of tenders. Figure 4.5 explores the construction market's ability to supply green contracts. Panel 4.5 a depicts the relationship between contract length and construction cost per square meter. In the case of contract length, for both BREEAM-certified and non-certified samples, the slopes of the fitted lines appear slightly positive overall, but do not depict a relationship remarkably dis-similar 
from one another. Empirically, when the fitted lines have a more or less zero slope, we would not expect a significant relationship between the independent and dependent variables. ${ }^{23}$ Panel $4.5 \mathrm{~b}$ depicts the relationship between the number of tenders and construction cost. For both BREEAM-certified and non-certified buildings, the variation in cost is not impacted by the number of tenders that bid on the contract. ${ }^{24}$

Figure 4.5: Market Ability for BREEAM-certified Construction

(a) Contract Length by BREEAM-certified

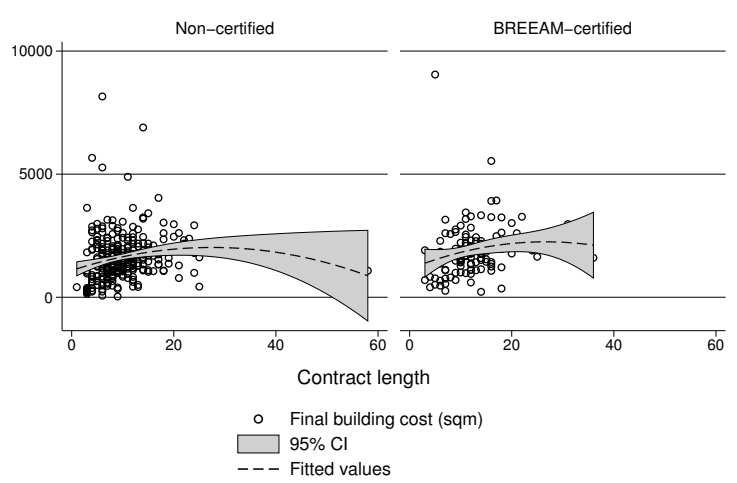

(b) Number of Tenders by BREEAM-certified

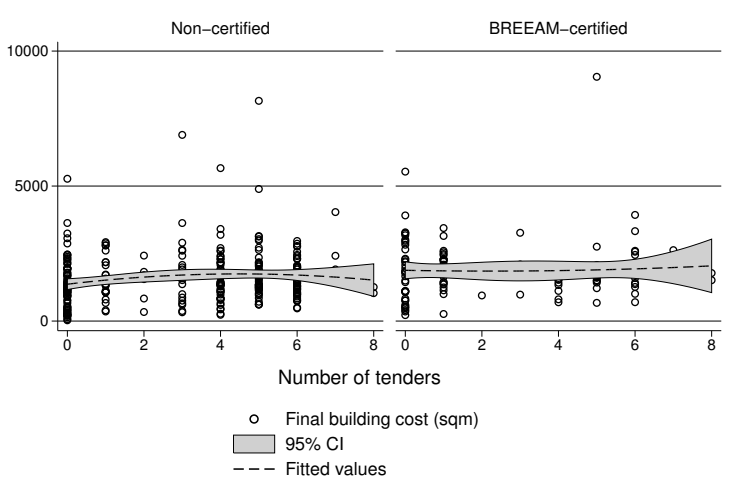

Notes: Figure 4.5 depicts the market's ability to handle BREEAM-certified construction in two sectors, by contract length and number of contractors bidding on contracts. Panel 4.5a displays the final building cost (per sqm) by a project's contract length. As expected, as construction periods increase construction cost increases. The variation between BREEAM-certified and non-certified projects is not distinct. Panel $4.5 \mathrm{~b}$ displays the final building cost (sqm) by the number of tenders bidding on a project. For both BREEAM-certified and non-certified, the fitted trend depicts no significant relationship between final construction costs as competition for building the project increases.

\subsubsection{The Dynamics of Green Innovation Costs}

To assess the dynamics of green innovation costs, we estimate equation (4.2) for the full sample across two sub-periods, 2003 to 2007 and 2008 to 2012. Table 4.6 reports the results across the two sample periods. The explanatory power is consistent across both periods, explaining about 88 percent of the variation in the logarithim of total construction costs per square meter.

Starting with the 2003 to 2007 period, column (1) shows that, in line with previous findings, BREEAM-certified construction costs are statistically insignificant. Elemental construction costs for substructure, finishes, services, contingencies and design fees

\footnotetext{
${ }^{23}$ We also test this relationship across the BREEAM ratings. Results are not remarkably dis-similar, but contract lengths for Excellent and Very Good buildings are the longest. Outstanding buildings have the shortest contract lengths. This is not an error and was check in the building prospectives of each of these buildings.

${ }^{24}$ We further looked at the tender bid spread, which further confirmed that there are not distinct differences between BREEAM-certified and non-certified buildings. Both types of projects exhibit similar tender bid spreads and the slopes of fitted lines through a BREEAM-certified and non-certified project are zero.
} 


\subsection{Results}

are positive and statistically significant. However, in contrast to previous findings superstructure costs are statistically insignificant. This finding is surprising, given the large, positive, statistically and economically significant costs for BREEAM-certified construction in 2003 found in Figure 4.2. However, the elemental costs filter differences in construction costs away and the averages dominate the outlier found in that sample period. In column (2), the BREEAM-rating is added to the specification and does not display a statistically significant cost component in this period.

Turning to the 2008 to 2012 period, in column (3) BREEAM-certified continues to be statistically insignificant and the elemental costs for substructure, superstructure, finishes, services and contingencies are significant in explaining the variation in the logarithim of construction costs per square meter in this period. In addition, client characteristics become statistically significant, where Retail and University buildings are positive and significant relative to Administrative buildings. Column (4) adds the BREEAM-rating label, which is statistically insignificant. Importantly, this sub-sample analysis is in contract to our earlier findings.

Table 4.6: Construction Costs for BREEAM-certified and Non-certified Buildings: Subperiod Analysis (Dependent Variable: Logarithm of Construction Cost per gross square meter)

\begin{tabular}{|c|c|c|c|c|c|}
\hline & & $(03-07)$ & $(03-07)$ & $(08-12)$ & $(08-12)$ \\
\hline \multirow{12}{*}{ 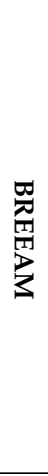 } & BREEAM Certified & -0.361 & & 0.119 & \\
\hline & & [1.929] & & [0.563] & \\
\hline & Outstanding & & 0.000 & & 0.148 \\
\hline & & & {$[0.000]$} & & {$[0.151]$} \\
\hline & Excellent & & -0.018 & & 0.070 \\
\hline & & & [0.112] & & [0.078] \\
\hline & Very good & & 0.001 & & 0.019 \\
\hline & & & [0.092] & & [0.073] \\
\hline & Good & & -0.134 & & 0.147 \\
\hline & & & {$[0.174]$} & & [0.168] \\
\hline & Pass & & -0.047 & & 0.055 \\
\hline & & & [0.171] & & [0.211] \\
\hline \multirow{14}{*}{ 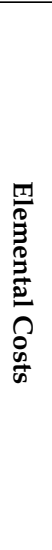 } & Log (Substructure cost (sqm)) & $0.085^{*}$ & $0.091^{* *}$ & $0.075^{* * *}$ & $0.063^{* *}$ \\
\hline & & [0.045] & [0.044] & {$[0.025]$} & {$[0.024]$} \\
\hline & Log (Superstructure cost (sqm)) & 0.191 & 0.185 & $0.327^{* * *}$ & $0.334^{* * *}$ \\
\hline & & [0.178] & [0.156] & {$[0.054]$} & [0.068] \\
\hline & Log (Finishes cost (sqm)) & $0.198^{*}$ & 0.158 & $0.123^{*}$ & $0.147^{* *}$ \\
\hline & & {$[0.114]$} & [0.108] & [0.067] & {$[0.065]$} \\
\hline & Log (Fittings cost (sqm)) & 0.024 & 0.034 & -0.012 & 0.008 \\
\hline & & {$[0.034]$} & {$[0.029]$} & {$[0.033]$} & [0.027] \\
\hline & Log (Services cost (sqm)) & $0.254^{* * *}$ & $0.258^{* * *}$ & $0.232^{* * *}$ & $0.164^{* * *}$ \\
\hline & & {$[0.074]$} & [0.069] & {$[0.053]$} & [0.039] \\
\hline & Log (Contingencies (sqm)) & $0.066^{* *}$ & $0.071^{* *}$ & $0.059^{* * *}$ & $0.092^{* * *}$ \\
\hline & & {$[0.032]$} & {$[0.028]$} & {$[0.020]$} & {$[0.023]$} \\
\hline & Log (Design Fees (sqm)) & $0.072^{*}$ & 0.033 & 0.025 & 0.030 \\
\hline & & [0.039] & [0.029] & {$[0.023]$} & [0.021] \\
\hline
\end{tabular}


Table 4.6 - continued from previous page

\begin{tabular}{|c|c|c|c|c|c|}
\hline & & $(03-07)$ & $(03-07)$ & $(08-12)$ & $(08-12)$ \\
\hline \multirow{14}{*}{ 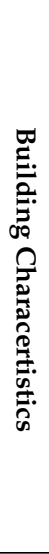 } & Age & 0.036 & 0.016 & 0.014 & 0.005 \\
\hline & & [0.059] & [0.062] & {$[0.062]$} & [0.054] \\
\hline & Stories & 0.001 & -0.002 & -0.012 & -0.014 \\
\hline & & {$[0.021]$} & [0.019] & [0.016] & [0.016] \\
\hline & New construction & 0.187 & 0.036 & -0.005 & -0.007 \\
\hline & & [0.381] & [0.395] & [0.121] & [0.112] \\
\hline & Brick & 0.079 & 0.120 & -0.088 & -0.092 \\
\hline & & [0.148] & [0.121] & [0.125] & [0.114] \\
\hline & Concrete & -0.023 & 0.078 & -0.095 & -0.063 \\
\hline & & [0.188] & [0.165] & [0.139] & [0.152] \\
\hline & Steel & 0.055 & 0.080 & -0.153 & -0.142 \\
\hline & & [0.197] & [0.147] & [0.106] & [0.103] \\
\hline & Timber & 0.317 & 0.201 & -0.057 & -0.053 \\
\hline & & [0.281] & [0.227] & [0.139] & [0.135] \\
\hline \multirow{12}{*}{ 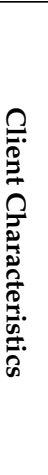 } & Office & 0.081 & 0.076 & 0.133 & $0.172^{* *}$ \\
\hline & & [0.110] & [0.110] & [0.085] & [0.084] \\
\hline & Retail & -0.126 & -0.156 & $0.681^{* * *}$ & $0.823^{* * *}$ \\
\hline & & [0.182] & [0.171] & [0.168] & [0.164] \\
\hline & School & -0.018 & -0.032 & 0.102 & $0.138^{*}$ \\
\hline & & [0.156] & [0.154] & {$[0.071]$} & {$[0.074]$} \\
\hline & University & 0.116 & 0.108 & $0.215^{* *}$ & $0.229^{* *}$ \\
\hline & & [0.199] & [0.197] & [0.097] & {$[0.090]$} \\
\hline & Private & -0.093 & -0.101 & -0.200 & -0.169 \\
\hline & & [0.139] & [0.113] & [0.157] & [0.138] \\
\hline & Public & 0.067 & 0.021 & -0.181 & -0.142 \\
\hline & & [0.213] & {$[0.145]$} & [0.193] & [0.166] \\
\hline \multirow{29}{*}{ 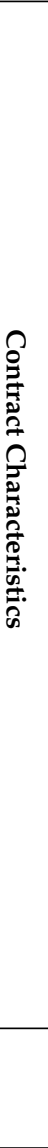 } & Number of tenders & -0.008 & -0.016 & -0.002 & -0.004 \\
\hline & & [0.015] & {$[0.014]$} & [0.017] & [0.017] \\
\hline & Contract length & -0.021 & -0.012 & 0.004 & 0.001 \\
\hline & & {$[0.028]$} & [0.023] & [0.013] & [0.014] \\
\hline & Contract length ${ }^{2}$ & 0.001 & 0.000 & -0.000 & -0.000 \\
\hline & & [0.001] & [0.001] & [0.000] & [0.000] \\
\hline & Fixed costs & -0.029 & 0.005 & -0.016 & -0.002 \\
\hline & & [0.065] & [0.052] & {$[0.058]$} & [0.057] \\
\hline & Bill of Quantities & -0.068 & -0.085 & -0.030 & -0.011 \\
\hline & & [0.107] & [0.098] & [0.089] & [0.083] \\
\hline & Competitive & 0.202 & 0.097 & -0.240 & -0.230 \\
\hline & & [0.265] & {$[0.271]$} & {$[0.181]$} & [0.178] \\
\hline & Design and build & 0.102 & 0.039 & $-0.318^{* *}$ & $-0.277^{*}$ \\
\hline & & [0.192] & [0.170] & {$[0.145]$} & [0.142] \\
\hline & Negotiated & 0.234 & 0.120 & -0.074 & -0.077 \\
\hline & & [0.213] & [0.188] & [0.181] & [0.174] \\
\hline & Open competition & 0.166 & 0.169 & 0.141 & 0.166 \\
\hline & & [0.271] & [0.243] & [0.238] & [0.207] \\
\hline & Selected competition & 0.054 & 0.037 & -0.157 & -0.165 \\
\hline & & [0.199] & [0.184] & [0.167] & [0.153] \\
\hline & Traditional & 0.172 & 0.047 & $-0.495^{* *}$ & -0.332 \\
\hline & & [0.282] & [0.247] & {$[0.224]$} & [0.208] \\
\hline & Two stage tendering & -0.075 & -0.050 & -0.289 & -0.207 \\
\hline & & [0.330] & [0.269] & [0.180] & [0.168] \\
\hline & Constant & $3.187^{* *}$ & $3.367^{* * *}$ & $3.253^{* * *}$ & $3.308^{* * *}$ \\
\hline & & [1.288] & {$[0.651]$} & {$[0.465]$} & [0.435] \\
\hline & Observations & 146 & 146 & 205 & 205 \\
\hline & R-squared & 0.882 & 0.879 & 0.886 & 0.882 \\
\hline & Adj R2 & 0.73 & 0.74 & 0.80 & 0.80 \\
\hline
\end{tabular}

Notes: Table 4.6 reports the results of equation (4.2) across two sub-periods 2003 to 2007 and 2008 to 2012 via OLS corrected for heteroskedasticity with robust standard errors (White, 1980). Dummies are relative to the following: New Construction(Renovation); Brick, Concrete, Steel and Timber(Other); Office, Retail, School and University (Administration and Resi- 
dential); Fixed Costs (Firm Costs); Bill of Quantities (Other); Procurement Methods (Unknown).

Overall, there is a difference between the BREEAM standards across the two specifications. In the early period, BREEAM standards require a maximum of 82 points. However, in the later period, there are two shifts in BREEAM standards, one in 2008 and one in 2011, which culminates in standards that require 110 points. Although the individual requirements for each BREEAM element does not increase substantially, the areas considered for BREEAM certification, especially Innovation credits, do expand over this period.

We can also visualize this cost pattern via an index. The aggregate BREEAMcertified and non-certified parameter estimates from equation (4.2) are re-estimated to interact $Z_{i} \cdot T_{t}$, which can be transformed into an ex-post construction cost index representing the marginal cost of green construction. Figure 4.6 depicts the marginal ex-post construction costs for the BREEAM-certified and non-certified samples over the 2004 to 2011 sample period. The left axis depicts index values, with 2004 as the base year and on the horizontal axis the year of construction.

Figure 4.6: Green Construction Cost Index

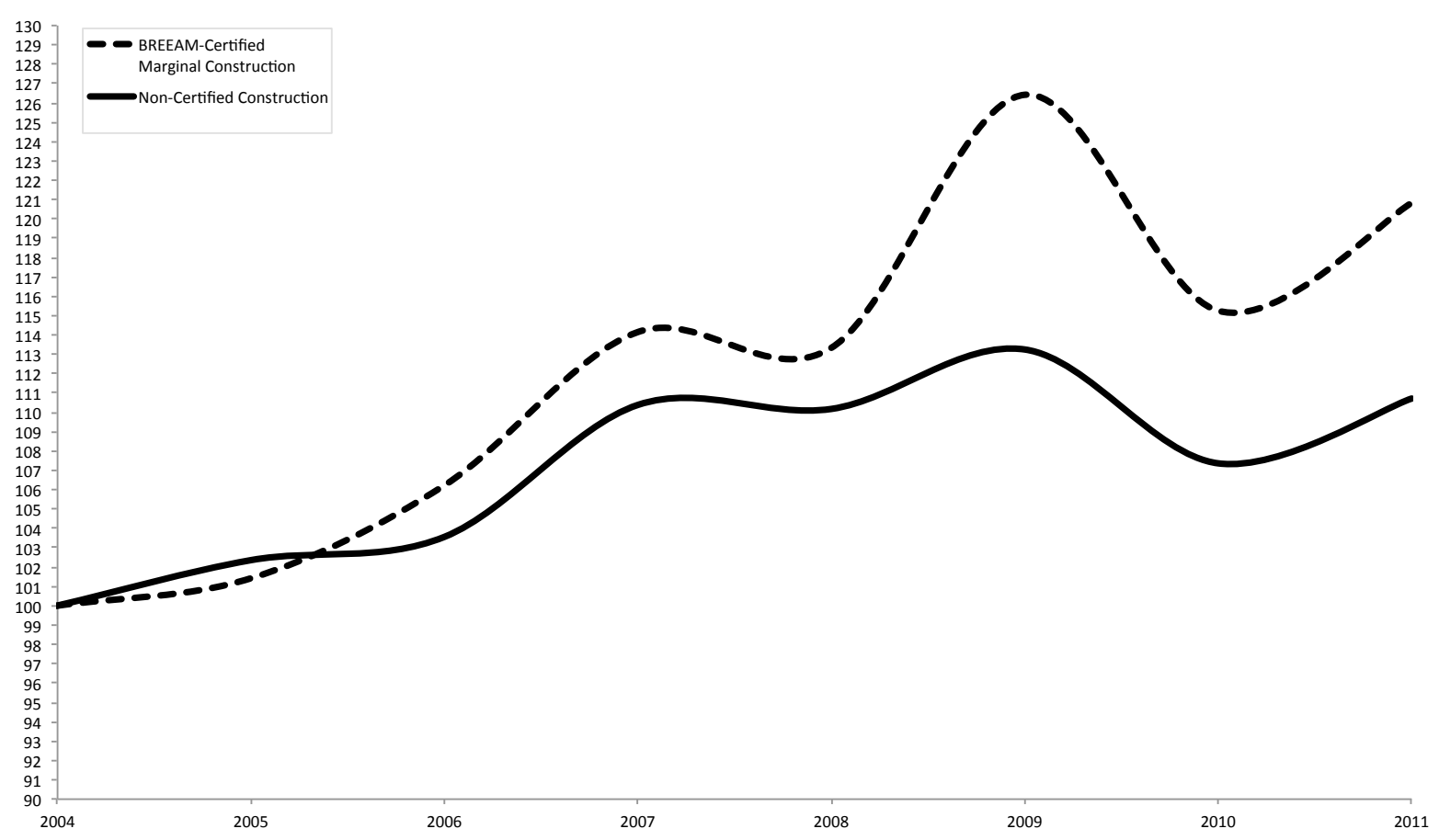

Notes: Figure 4.6 displays the BREEAM-certified and Non-certified sample construction cost indices over the 2004 to 2011 period. Index year 2004 is the base period. For the BREEAM-certified sample the peak is 2008 and the trough is in 2005. The indices cross in 2010, where the cost of BREEAM-certified construction costs less relative to non-certified sample.

From 2004 to 2009 there is an increase in the construction costs of BREEAM-certified buildings and starting in 2009 there is a year over year decline. For the non-certified sample, there is a year over year increase in construction costs; representing a nomi- 
nal increase of 32 percent in construction costs over the period. The analysis further confirms that there is an increase in the cost of green construction over the sample period. However, this cost begins to decrease starting in 2009. Over the 2004 to 2007 period, 20 percent of the sample is represented, whereas from 2008 to 2011, 80 percent of the sample is represented. Thus, the number of green observations in the sample substantially increases in the second period of the analysis. This could indicate that the cross-sectional analysis is dominated by observations in the second period. As the comparison of construction cost indices shows, this may also indicate why crosssectionally the variation in costs between the BREEAM-certified and the non-certified sample is very low, and suggesting limited evidence of higher green construction cost.

\subsection{Discussion and Conclusion}

In this chapter, we measure the ex-post cost of a systems innovation in the construction industry. The bundle of innovations is represented by a technical change in the materials, labor and capital used to construct buildings in an energy-efficient and sustainable manner, as measured by the BREEAM certification scheme for green buildings. We assess the marginal cost of BREEAM-certified commercial real estate and its magnitude and dynamic progression over the 2003 to 2012 period. In contrast to the previous literature, we utilize a two-stage matching procedure for BREEAM-certified and non-certified buildings, matching on their construction location, time and individual building characteristics.

In line with the innovation literature, we explore whether the effort cost for green construction projects is zero. We first address the question through a univariate set of statistics as employed by the nascent case studies on green construction costs. Overall, the univariate statistics on total construction costs do not provide evidence of economically or statistically significant cost differences. Further analysis at the annual level suggest that for this sample of BREEAM-certified buildings, 2003 and 2008 exhibited additional construction costs, and design fees were economically and statistically significantly higher across the sample period. However, after further analysis, these additional costs in 2003 and 2008 were attributed to single construction projects. Moreover, design fees are a marginal factor in the total cost of a building.

In contrast to US and European case studies, the results documented here do not support positive and statistically significant costs over the 2003 to 2012 sample period. By estimating a multi-variate regression of construction costs the conditional marginal effects of the green elemental costs, controlling for building, client, and contract characteristics as well as time and location fixed-effects, we further confirm that these findings are robust. However, when controlling for quality within the BREEAM-certified sample, the BREEAM-rated 'Outstanding' buildings cost on average 16.7 percent more per gross square meter. Yet, given the small samples of these innovative buildings, 
future studies may find different cost premiums.

Moreover, we investigate the magnitude of innovation costs, which for green buildings may stem from the type of innovation, differences in the hard costs in green materials, labor and capital and from differences in soft costs in green design and green contracting. Overall, the largest costs for green construction are derived from the hard costs or the services' elemental costs, which supplies the plumbing and disposal of water, heat sources, air treatments, electrical equipment, etc. The results are in line with the empirical literature on BREEAM-certified costs as increased attention to the energy-efficiency and $\mathrm{CO} 2$ emission reduction of a building could result in the use of more capital directed at innovation in capturing energy. In addition, soft costs like design fees and contingencies are a statistically significant factor in the construction process, but not a economically significant one. Annually, the average design fees account for zero to three percent of total costs of a building.

Furthermore, the results of our index and sub-sample analysis suggest that costs are indeed dynamic. The results of the so-called "Green Construction Cost Index" indicates that construction costs for BREEAM-certified buildings were on average higher prior to 2009, but began to decrease in 2009 and steadily decline until 2011. Results of this index should be looked at with caution as prior to 2008 the sample is quite small.

In line with the estimates from individual case studies, our analysis indicates a positive cost for BREEAM certification. However, the magnitude and timing of our estimates indicate that BREEAM construction costs are dynamic over time. This could be due to the type of innovation that a BREEAM-certified building undergoes, the timing of this innovation in the market or the potential increasing returns being realized in the construction market for green building products.

Consequently, the scaling up of BREEAM-certified inputs in the construction process is contingent upon the timing of implementation. The BREEAM certification process was dynamic over the study period, resulting in eight iterations of the BREEAM scheme, with the last iteration taking place in 2011. Thus, our analysis could be picking up a series of waves in innovation, where with each subsequent shift in the enhanced energy-efficiency and sustainability of buildings was leading to technological obsolesence in the previous 'green' construction process. Simcoe and Toffel (2012) find for the LEED scheme that this can lead to an ineffective implementation of the innovation, where first movers are unlikely to take up innovations without a stable base. Thus, investors are waiting for signals from the construction market and in turn, the construction market is waiting for a signal from investors. This 'inertia' is all too common in innovation, where establishing an effective bandwagon for everyone to get on is a part of the standardization process (Farrell and Saloner, 1985). Consequently, innovations costs will not begin to normalize until a 'standard' has been established.

Importantly in 2008, the UK government implemented the EU's Energy Perfor- 
mance Buildings Directive, mandating energy-efficiency in buildings. ${ }^{25}$ Formally, the UK government required Energy Performance Certificates (EPC) and Declaration of Energy Certificates (DEC) to be on display for large building's frequented by the public, and for public buildings in general. The declaration of energy performance would have an impact on 70 percent of our sample. When the mandate was enforced, the realized energy-performance, reflected in DECs, was on display in the main entry-ways of buildings for newly constructed and transacted buildings. For the first time, there was a visual association between energy-efficiency and a building. Given the increased transparency of energy-efficiency in buildings, there was a potential nudge towards adopting an energy-efficiency innovation process in buildings.

Furthermore, decreasing costs may have not been viable until there was a critical mass invested in the 'green' construction industry. As Katz and Shapiro (1985) indicate, there are increasing returns to innovation when more participants are able to gain access to the innovation. In this case, as the number of clients using the BREEAM certification process grows, the demand for 'green' materials, labor and capital increases. The transmission mechanisms for causality are unclear here. However, Abrahamson and Rosenkopf (1997) suggest that social networks could play a significant role in diffusing and dynamically changing the costs of innovations that have increasing returns to scale. Indeed, two aspects of the BREEAM certification network changed during this period, which may have influenced the increasing returns for BREEAM-certified projects and the decreasing costs post 2009. First, active attendance at Ecobuild, the 'green' building fare held annually in the UK has doubled annually since 2005, resulting in some 57,000 attendees and 1,500 exhibitors in 2012. ${ }^{26}$ Second, the number of BREEAM assessors has expanded substantially over the last decade, resulting in an average 10 assessors per county and 975 assessors in aggregate. ${ }^{27}$

Thus, the signals to investors to take on innovations like a BREEAM certification have been complex over the past ten years. It was not until 2008 that there was a government standardized scheme to enforce energy-efficiency mandates. In addition, it was not until June of 2008 that the BREEAM standard had reached a momentary steady state in the requirements for BREEAM innovation. Moreover, momentum in networks and the availability of human capital necessary for BREEAM assessment was limited. As a result, the costs suggested during the 2003 to 2009 period would be understandably high. However, these projects would not have gone forward without an anticipated positive net present value, which suggests that there were gains for "first movers" in this market offsetting the increased costs of construction (Abrahamson and

\footnotetext{
${ }^{25}$ Directive 2012/27/EU (2012).

${ }^{26}$ Ecobuild annually publishes there attendance figures for an example, please see: http://www. ecobuild.co.uk/uploads/ecobuild-13-post-show-brochure.pdf

${ }^{27}$ Using data from GreenBook Live, we geo-coded assessor location, and aggregated by county. BREEAM Assessor locations can be found at http://www.greenbooklive.com/search/ companysearch.$j$ spid=214\&sectionid=0\&companyName=\&partid=10001\&productName=\&countryId= 56\&postcode $=$ \&s cale $=-1$
} 
Rosenkopf, 1997). Thus, the early diffusion of the commercial product still required access to cost deferring capital, e.g., subsidies, or pecuniary rewards for investors who captured the demand of niche consumers.

Which brings us back to the nascent literature on green value in commercial real estate. A core component of any gross innovation value premium is the cost of innovation itself. Based on economic theory, we expected that the cost of green construction would nullify the premiums previously found. Evidence from this sample suggests that with the exception of Outstanding buildings the costs do not nullify the value premium. Although this finding may change with future empirical work ${ }^{28}$, the results reported here are an important information signal for future 'green' construction. The industry is facing regulatory mandates for an increase in 'green' buildings to attain zero-energy consumption, which suggests that the level of innovation for new and old buildings will change. Consequently, the market competition will shift from 'green' versus 'brown' forms of construction towards more incremental innovations in the quality of the 'green' construction in place. This study already provides evidence that at the frontier of 'green' construction innovation, it is more costly. Thus, there is a new race in innovation already underway, which could lead the construction industry towards becoming more resource efficient, which may have important implications for the environmental impact of the real estate sector for decades to come.

${ }^{28}$ To date, the value premium for Outstanding buildings has not yet been estimated. 



\section{Chapter 5}

\section{The Value of Real Estate Capital in the Digital Economy}

\subsection{Introduction}

Increasing demand for big data and the limited supply of suitable real estate have had a significant impact on the price of commercial real estate. In 2010, Google purchased 111 8th Avenue for $\$ 1.7 \mathrm{bln}$, making it the largest single-asset transaction in US commercial real estate history. Importantly, this transaction coincided with the US's worst commercial real estate crisis on record ${ }^{1}$ and involved an asset located in the Chelsea neighborhood, which is not a location in New York City that traditionally commands that kind of transaction price. The seller, Jamestown Properties, had originally purchased the property for $\$ 700 \mathrm{mln}$ in 2006; it thus earned its investors a gross return of 142 percent. $^{2}$ Today, 111 8th Avenue is a Class A office space, Google's East Coast headquarters and a major data center for the East Coast of the US. ${ }^{3}$

Although some of the premium paid by Google may reflect refurbishments to the building, a significant portion is likely to relate to Google's valuation of the building's

\footnotetext{
${ }^{1}$ See MIT Center for Real Estate - New York City Metro Area - Office Property Annual Indices. Commercial office property price levels for the calendar year index troughed in the third quarter of 2009 and at the time of the Google building's sale, in the fourth quarter of 2010, the index reflected the same average price levels as the fourth quarter of 2005. On average, property prices in 2005 do not reflect the peak of the market. In addition, at the time of the Google sale, equity and loan capital was in scarce supply. Thus, the transaction, in those market conditions, is likely an outlier for the New York metro office market in the Chelsea region.

${ }^{2}$ Taconic Investment Partners LLC bought the property initially in 1998. The exact price for the building at that time is not known as the purchase was a part of a portfolio sale including two other properties, for $\$ 387 \mathrm{mln}$. The buyer then invested $\$ 50 \mathrm{mln}$ in a capital improvement program and repositioning and leasing campaign, and upgraded the rent roll to include world class tenants (www.taconicinvestments.com/portfolio/118th_ave.html accessed March 25, 2013). In 2004, Digital Reality Trust purchased a 'Data Center Condo in the building for $\$ 250 \mathrm{mln}$, and in 2006, Jamestown Properties took the primary equity stake in the property.

${ }^{3}$ This information comes from the Investment publications of Taconic Investment Partners, LLC, Jamestown Properties and the Real Capital Analytics commercial property transaction database.
} 
potential for contributing to future growth. In light of the timing of the transaction and the location of the building, it may be that the building's potential is not limited to bricks and mortar but reflects the value of the innovation embedded in the building. To understand why that is the case, it is necessary to consider the importance of the Internet, digital content and their real telecommunications infrastructure in the form of data centers and fiber-optic cables.

Today, the Internet is pieced together by a mélange of copper and fiber-optic cables, which crisscross cities, sprawl across countries and rest on the ocean floor. These elemental strands of copper and glass connect the increasing bulk of US telecommunications infrastructure and the spiders dispersed across the Internet's web are the approximately 200,000 fiber-lit buildings, data centers and Internet Exchanges. ${ }^{4}$

In the era of big data, the telecommunications sector serves as an innovative way to support the movement of real goods and services through the digital telecommunications network of the Internet. Within this network, information is digitized and transferred electronically across the vast network of the Internet. In the 1990s, buildings were connected to the Internet through copper cables like phone lines. However, in the next decade, buildings began to be connected to the Internet through fiber-optic cables. ${ }^{5}$ The result is a fiber-lit building which is a commercial building connected to these fiber-optic cables with a T1 connection of at least 1.54 Megabits per second.

Moreover, this innovation in connectivity has created a demand for real estate capital infrastructure that can handle the intersections of fiber-optic connectivity and storage of an increasing amount of data. These buildings are known as data centers and they are used to house computer systems, e.g., routers, servers and telecommunications cables, as well as mission-critical systems like fire-protection systems, backup electricity generators and fuel tanks and cooling systems to support the digital movement and storage of information. Internet Service Providers, e.g. telecommunications carriers such as Vayo or Verizon, provide fiber-optic connectivity to Neutral carrier data centers. ${ }^{6}$ In order to serve as a data center, a building undergoes a significantly

\footnotetext{
${ }^{4}$ Estimates of the number of data centers vary widely, also depending on the definition, and it is not possible to establish a total with a high degree of confidence. The figure reported here reflects the number of 'fiber-lit buildings in the GeoTel database (http://www.geo-tel.com/products/ fiber-lit-buildings/). Emerson documents at least 500,000 data centers globally (http://www . emersonnetworkpower.com/en-US/About/NewsRoom/Pages/2011DataCenterState.aspx). However, International Data Corporation, a think tank specializing in data center knowledge, alleges that the number is closer to 2.94 million. This figure includes units from server closets to big box data centers and Internet Exchanges (http://www. idc. com/getdoc. j sp? containerId=prUS23724512\#. USkoCo5LpVx).

${ }^{5}$ In general, relative to copper cables, fiber-optic cables can carry a larger bandwidth of data, at faster speeds and without electrical current interruption. However, not all fiber-optic cables are created equal in terms of the amount of data that can be downloaded per second (bits per second). Fiber-optic cables range from a T1 connection at 1.544 Megabits per second to the fastest commercially available, the OC3072 at 159.2 Gigabits per second to cables that are used in scientific settings that approach the speed of light at 73.7 Terabits per second.)

${ }^{6}$ Non-neutral data centers are those in which a single service provider runs fiber-optic cables to the
} 
different design and construction process from a traditional factory or office building. Whether this is via new construction or the redevelopment of existing building space, data center construction requires the builders to utilize the traditional components of a building in a novel way. ${ }^{7}$

The main reason for the extensive reconfiguration of a building's features is that the demand for data centers is not driven by the local market's service or industrial sector employment, but by the bytes of data that travel across the digital fabric of the Internet. Thus, the occupants of data centers are data bytes, the demand for space is a 'digital demand' and that demand corresponds to the increasing global span of Internet connectivity and the exponentially growing amount of digital information.

One source of data growth is from the increasing number of computer systems and data centers connecting to the Internet. Zhang, Zhang, Yang, Cheng, and Zhou (2008) found in a study of the Internet's automated systems architecture that since 1991, the span of the Internet's network has grown exponentially every year to accommodate an increasing number of computer systems. As of 2013, the Internet's main content of web pages and e-mails comprises approximately 4.0 to 4.5 bln web pages and 52.5 quadrillion e-mails, sent by approximately 2.2 bln users. ${ }^{8}$ More recently, the source of growth in demand for digital space expanded to include not just new web pages and e-mail traffic but also a new universe of digitized communications. Hilbert and López (2011), who track 60 categories of ICT, find that as of 2007 the world was able to store 0.3 zetabytes $^{9}$ of digital information, communicate 2.0 zetabytes of digital information, and execute 6.4 exabytes of computational instructions per second. ${ }^{10}$ A more recent report from International Data Corporation (IDC) indicates that as of 2011, there were approximately 1.8 zetabytes of data created and replicated globally, and this number is predicted to double every two years. ${ }^{11}$

building, and neutral carrier data centers are those where multiple carriers can provide fiber-optic access to the building.

${ }^{7}$ For redevelopment purposes, data center buildings are reinforced with insulation and steel, the floors are raised and the ceiling is lowered to allow space for the cables to move through, elevators are converted into cable ducts, atriums are emptied, vast HVACs are plugged in, gas tanks are brought into the facility, backup generators are installed on roofs and in basements, windows are blocked off completely, and large vents and large fans are installed. For new construction, steel boxes with cooling systems are embedded into the ground with state-of-the-art electrical facilities and co-generation plants.

${ }^{8}$ The average number of web pages reported here represent Googles daily indexed web pages for the 2011 to 2013 period reported on this site (http: //www . worldwidewebsize. com/, accessed July 18, 2013). There are numerous reports of annual and daily e-mails sent. This site presents annual figures for emails (http://royal .pingdom. com/2013/01/16/Internet-2012-in-numbers/, accessed July 18,2003).

${ }^{9} \mathrm{~A}$ bit is a binomial measure of data representing one or zero and is the smallest unit of measure; $\mathrm{a}$ byte is eight bits.

${ }^{10}$ An exabyte is $10^{18}$ bytes or one quintillion bytes and a zetabyte is $10^{21}$ bytes or one sextillion bytes. Hilbert and López (2011) go on to contextualize by suggesting that this amount of data is approximately the same size as the bits stored in the DNA of a human adult.

${ }^{11} \mathrm{http}$ ://www .emc.com/collateral/demos/microsites/emc-digital-universe-2011/index.htm, accessed on July 25, 2013. 
To a large extent, the demand for digital space has become cumulative, where an increasing driver of data growth is the digitization of information from and by corporations, governments and individuals. IDC estimates that corporate industries alone account for approximately 14,000 data center operations. The US federal government has at least 2,000 data centers. ${ }^{12}$ And individuals increasingly leave a digital footprint on the Cloud, in Facebook and on YouTube. In addition, demand is further differentiated on the basis of the need for proximity versus storage. In some cases, space needs to be in close proximity to an exchange or 'meet-me room' on the Internet's network, whereas in other cases, space can be remote from the Internet's network when it is needed simply to store data. In turn, the growth and diversity of the digital demand has generated a growing commercial real estate sector dedicated to serving the internet and its users.

The distinctness of the data center commercial real estate product and the extent of the digital demand these buildings serve provides a glimpse into the innovation and value dynamics of the built environment itself. Real estate, like other forms of assets, can be subject to technical change and an innovation cycle (Slaughter, 1998). In the case of commercial real estate, in some instances the demand for new building products is derived from innovations in transportation and connectivity. Hoyt (1960) already documented the dynamics between systems of transportation, new economic geographies and value by tracing the land booms for cities that served mercantile trade through ships and friggats. Then he conceptualized value through other cities that served industrial production with steamships, then railroads and later with freight trucks. In one of his earlier works, Hoyt (1933) measured the sudden boom in land values along Chicago's Lake Michigan waterfront, the now infamous "Loop", when the steamship was first introduced and the Erie Canal opened. Using the same data on Chicago, Glaeser (2013) calculates the land-price gradient for the "Loop" on the Chicago waterfront and confirms Hoyt's findings that when the Erie Canal opened land values between 1830 and 1836 surged where prices doubled the closer the proximity to the waterfront.

In the 1830s, being the first to seize the rents associated with innovations in connectivity proved valuable to foresighted and innovative landlords. However, in the supply constrained commercial real estate markets of today, many innovations involve a new use for a structure, whereby existing building elements are reconfigured to be used in a novel way to serve a new demand. In the innovation literature, these types of innovations have been somewhat coincidentally named 'architectural innovations' (Henderson and Clark, 1990). These types of innovations are subtle and can be recognized when the core components of an existing product design are reconfigured to

\footnotetext{
${ }^{12} \mathrm{http}$ ://oversight.house.gov/wp-content/uploads/2013/07/McClure-Final.pdf, accessed July $25,2013$.
} 
make new products that resemble the old product, but serve a different demand. For real estate markets, what is important about these types of innovations is that wouldbe competitors are unable to capitalize on the new demand as either their skills, capital or institutional strategy does not implore them to seize the opportunity to innovate and serve the new demand. In turn, those firms/innovators that are able to re-configure the product are given some time on the market to be the sole provider.

To test the theory of innovation value in commercial real estate, this paper investigates two sources of value in technology in commercial real estate, fiber-optic connectivity and data center real estate. Glaeser (2013) documents that there are various changes in transportation technology that lead to new and re-developed sources of increased land values. To build on this evidence this paper first questions whether there is value for a building that has access to the flow of digital information via high-speed fiber-optic connectivity. Unlike previous transportation nodes, like harbors or railroad stations, the Internet's fiber-optic infrastructure is increasingly prevalent and dispersed throughout cities. Over the 2000s decade, high speed Internet connectivity more than tripled, connection points agglomerated into buildings and the mass of digital information expanded to require more space. In turn, buildings that were able to transform to serve a growing digital demand and the agglomeration of digital connectivity led to not only a new type of digital harbor, but a new commercial real estate product known today as data centers. However, data centers are a distinct building product requiring different design, location and functionality than traditional commercial real estate space. In turn, the digital demand requires a building reconfiguration that serves the digital rather than human demand, which may result in an innovative commercial real estate product that could allow investors to capture additional value.

Not all data centers have achieved the same level of digital agglomeration. As previously pointed out, there is a difference between Carrier neutral and Non-neutral carrier data center facilities. Data centers that are Neutral carrier may be in higher demand as they can provide occupiers with the benefits of being in a digital city through economies of scale, agglomeration and positive network externalities. Thus, telecommunications competition and increased connectivity could have a positive impact on the value of data centers.

This research links the financial performance of commercial real estate investments with the telecommunications infrastructure over the 2005 to 2012 period using Real Capital Analytics' commercial property transaction database as a source of property values over the period. For the telecommunications network, it links the transaction data to two informative sources for the Internets infrastructure: first, a proprietary data set of fiber-lit buildings and Internet service providers (carriers) from GeoTel Communications LLC (GeoTel), which enables a time-varying analysis of the necessary conditions for a building to become a data center; second, a combined data set of data centers 
from Real Capital Analytics, GeoTel and Data Center Map. Over the 2005 to 2012 period, there are 494 fiber-lit buildings and 50 data center transactions amongst a pool of 8,915 complete transactions for the New York Core Based Statistical Area (CBSA).

The results of the analysis demonstrate that over the sample period, fiber-lit buildings achieve higher transaction prices by 21.6 percent relative to a control sample of non-fiber-lit buildings in the New York CBSA. Moreover, data centers achieve transaction prices that are 23.5 percent higher relative to the control sample over the full sample period. However, when data centers are compared with other buildings that are fiber-lit, added-value is not present. Importantly, fiber-lit buildings transact at a premium across all specifications. Data centers do not do so: when an estimation accounts for a data center's link to the fiber-optic network, the value premium dissipates. The premium dissipates with one exception, data centers that facilitate digital agglomeration through Carrier neutral facilities demonstrate value, where Carrier neutral data center facilities transact for 11 percent more relative to Non-neutral data center facilities in the fiber-lit building environment.

The remainder of the paper is set out as follows. In section 5.2, an outline is given of data centers and fiber-lit buildings, innovation in commercial real estate and the type of innovation. Section 5.3 presents the data, identification strategy and summary statistics for the fiber-lit building, data center and control samples. In section 5.4, the estimation strategy for the hypothesis tests is outlined. Section 5.5 documents the results of the cross-sectional economic outcomes of fiber-lit building and data center innovations and the role of carrier competition. In section 5.6, there is a brief discussion of the results and section 4.6 provides concluding remarks on future research on innovation in commercial real estate.

\subsection{Information Technology and Commercial Real Estate}

\subsubsection{Getting Connected to the Information Superhighway}

On October 29, 1969 Leonard Kleinrock transmitted the letters "L" and "o" from a computer at UCLA's Network Measurement Center in Boetler Hall to Stanford University's Stanford Research Institute at the Menlo Park Campus. ${ }^{13}$ Although typing "Login" crashed the computer, it was at that moment that the Advanced Research Projects Agency Network, ARPANET, became the foundation of what would one day become the Internet.

\footnotetext{
${ }^{13} \mathrm{http}$ ://content.usatoday.com/communities/technologylive/post/2009/10/620000700/1\# .US4wpo5LpVw.
} 
In the 1970s and 1980s, digital transmissions between computers travelled through the phone lines on copper cables. ${ }^{14}$ From the mid-1990s, the US saw a growing number of fiber-optic cables laid into the ground. In the subsequent decade, the technology became more commercially viable for the US and in the 2010s fiber-optic cables can transfer data at increasingly faster rates. Fiber-optic cables range from a T1 connection at 1.544 Megabits per second to the fastest commercially available, the OC-3072 at 159.2 Gigabits per second to cables that are used in scientific settings that approach the speed of light at 73.7 Terabits per second. The vast majority of the country is still served by cable providers using older ethernet speeds at an average download speed of 10 Megabits per second. ${ }^{15}$

Figure 5.1 depicts the United States and New York CBSA fiber-optic network as of 2012, from GeoTel data. In Figure 5.1a, showing the US fiber-optic network, we observe a number of distinct telecommunications hubs including the Mid-Atlantic region, with New York and New Jersey serving as primary locations of connectivity to the Southern US, South America, Africa and Europe. There are seven Trans-Atlantic cables that serve the New York CBSA. A second notable connection point is the MiamiDade region in Florida. This area mainly connects to Central and South America, with seven transatlantic cables arriving onshore. In addition, the west coast provides Internet connectivity through Los Angeles, San Francisco, Portland and Seattle to serve the bulk of telecommunications to and from Asia. Moving to the figure's core, it is possible to detect approximately eight major nodes within the fiber-optic network, with about 12 to 13 minor nodes reaching other minor markets in the US. There are some surprising clusters of fiber-optics, including those in Iowa, Nebraska and Washington state. In states where towns have low population density there is a proliferation of fiber-optic connectivity. This is for no other reason than to serve the growing number of technology companies locating in the Mid-West and Northwest regions. In these locations, energy and land are at their cheapest, and they may be associated with more of a storage role for data centers.

Figure 5.1b depicts the fiber-optic network of the New York CBSA. The island of Manhattan is densely covered with fiber-optics south of Central Park. There are four main arteries to access downtown and midtown. Across the East River on Long Island there are distinct clusters of fiber-optic cables and vast stretches of long-haul fiber cables coming from the submarine landing stations (not shown at this scale). Across the Hudson River in New Jersey there is a vast fiber-optic network serving the outcrop of corporations from New York City.

\footnotetext{
${ }^{14}$ Fiber-optic cables with the potential for telecommunication were invented by Corning Glass Works in 1970.

${ }^{15}$ http: //www.fcc.gov/reports/eighth-broadband-progress-report, accessed July 19, 2013.
} 
Figure 5.1: United States and New York CBSA Land and Sea Fiber-Optic Routes

(a) United States

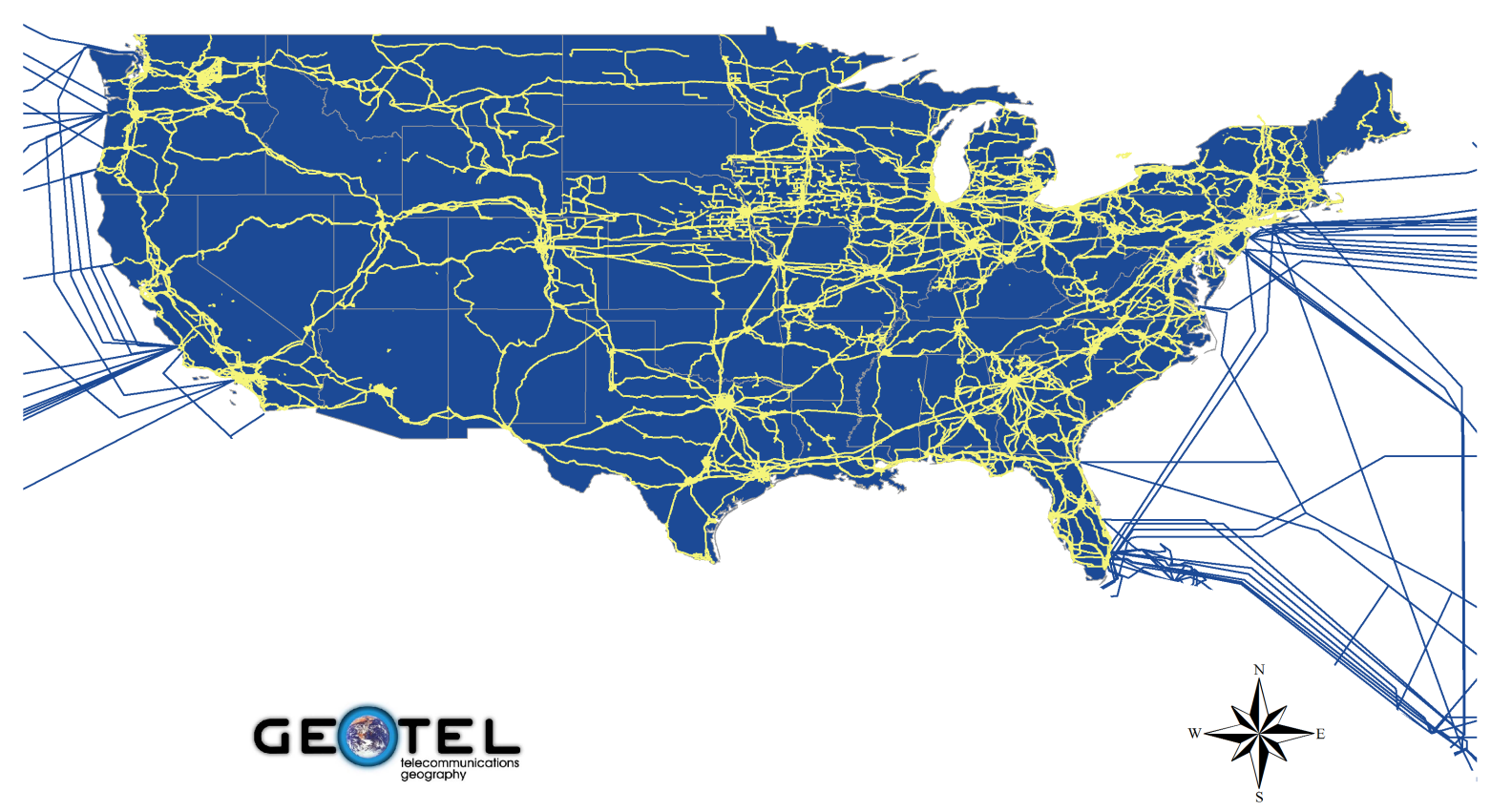

(b) New York CBSA

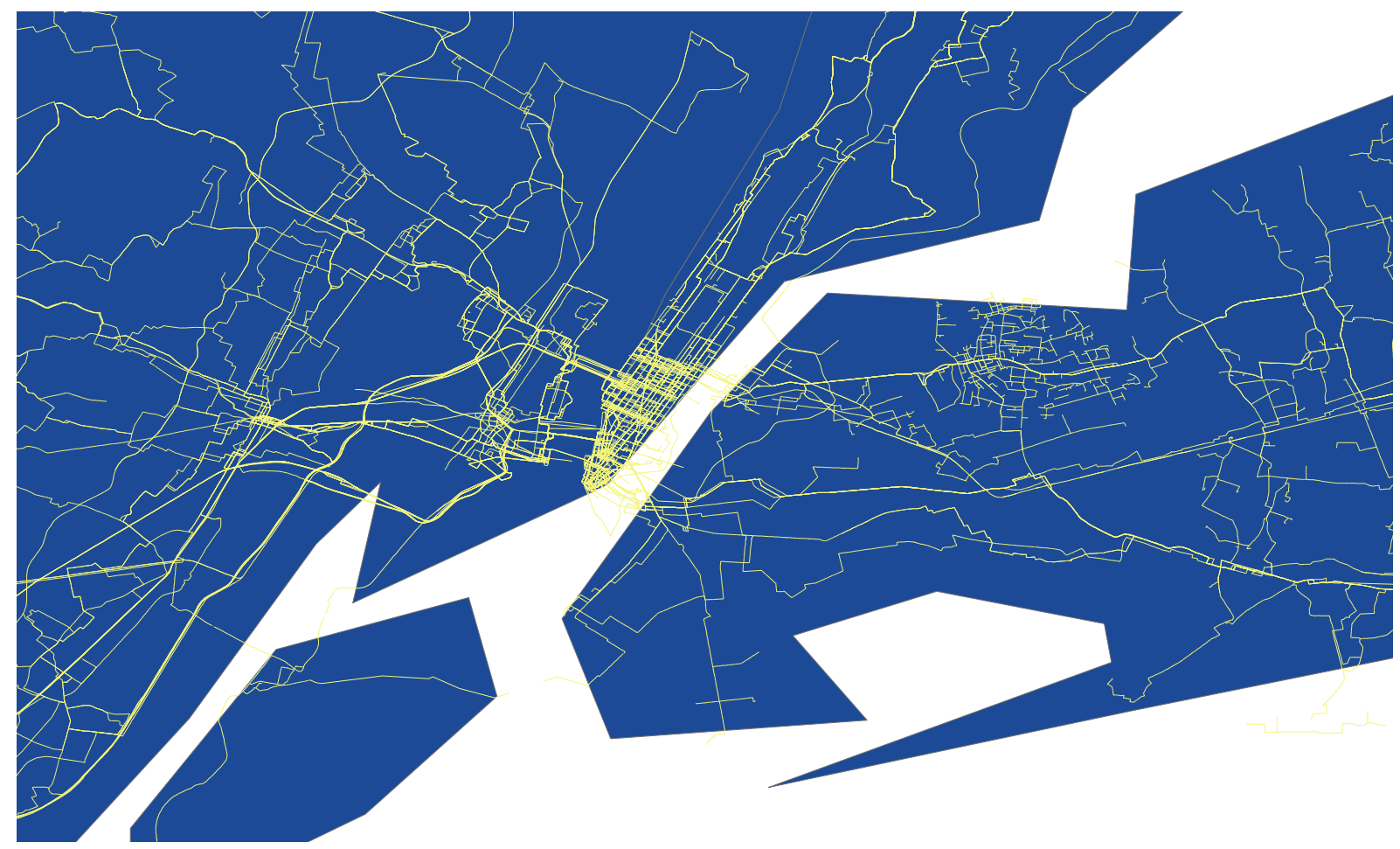

Notes: Figure 5.1 displays the distribution of the US and New York CBSA fiber-optic network as of 2012. Panel 5.1a highlights the US connectivity across states and submarine cable location and connectivity points. Panel $5.1 \mathrm{~b}$ highlights the fiber-optic cables for the New York CBSA. 
The New York CBSA is a densely populated area with high demand for fiber-optic connectivity. The area is home to many corporations, financial services firms, information technology firms and financial markets. The Eastern Sphere of the global telecommunications network connects to the New York CBSA in seven distinct locations. Glaeser (1998, p.150) already noted that "[D]espite having no pre-existing agglomeration in computer technology, New York City has recently become a major center for software, and has its own 'Silicon Alley'." New York City has grown to be a significant hub in the modern telecommunications sector. Pietz (2012) reports from Telegeography that New York City beats all other US metropolises on aggregate longhaul capacity, is capable of transmitting 12.3 terabits per second and ties only with San Franciso's 3.0 million square feet of multi-tenant data center space, the highest quantities for any city globally.

Fiber-optic routes connect to real estate via fiber-lit buildings. A conservative assessment suggests that just two to four percent of all commercial buildings are fiberlit. ${ }^{16}$ Figure 5.2 depicts the distribution of fiber-lit buildings across the US states and New York CBSA from GeoTel. Figure 5.2a displays the concentrations of fiber-lit buildings by state. The states with the highest concentrations, notably New York, California, Texas and Florida, also have the highest level of economic activity in the US. In addition, they are the most densely populated areas in the US. Two exceptions are Ohio and Virginia, where many large corporations and government facilities are located. Figure $5.2 \mathrm{~b}$ displays the fiber-lit buildings for the New York CBSA, where there are approximately 10,000 plus fiber-lit buildings as of 2012. This number has grown rapidly since 2005: the population of fiber-lit buildings has tripled in just eight years. Downtown Manhattan and midtown are the most dense fiber-lit building neighborhoods with approximately 60 percent of the total fiber in the region.

\subsubsection{Reconfiguring the Commercial Real Estate Stock}

It was not until the 1990s, however, that the growing demands of the Internet really penetrated the more liquid commercial real estate sector. In 1991, when the US Congress passed the High Performance Computing Act, the Internet was formally transformed from an academic and governmental research and development initiative to a private sector phenomenon. During the late 1990s, the World Wide Web expanded, and data centers took off as a means of expanding the Internet to more and more cities.

\footnotetext{
${ }^{16}$ According to the Commercial Building Inventory, there were approximately $8.5 \mathrm{mln}$. commercial buildings in the US as of 2011(http://www.commbuildings.com/, accessed March 25, 2013), but the Environmental Protection Agency cites a figure closer to $5.1 \mathrm{mln}$. At the same time, there were approximately 200,000 buildings with fiber optic connectivity in the US (Geotel, http://www.geo-tel.com/ products/fiber-lit-buildings/, accessed March 25, 2013).
} 
Figure 5.2: United States and New York CBSA Fiber-Lit Buildings

(a) United States
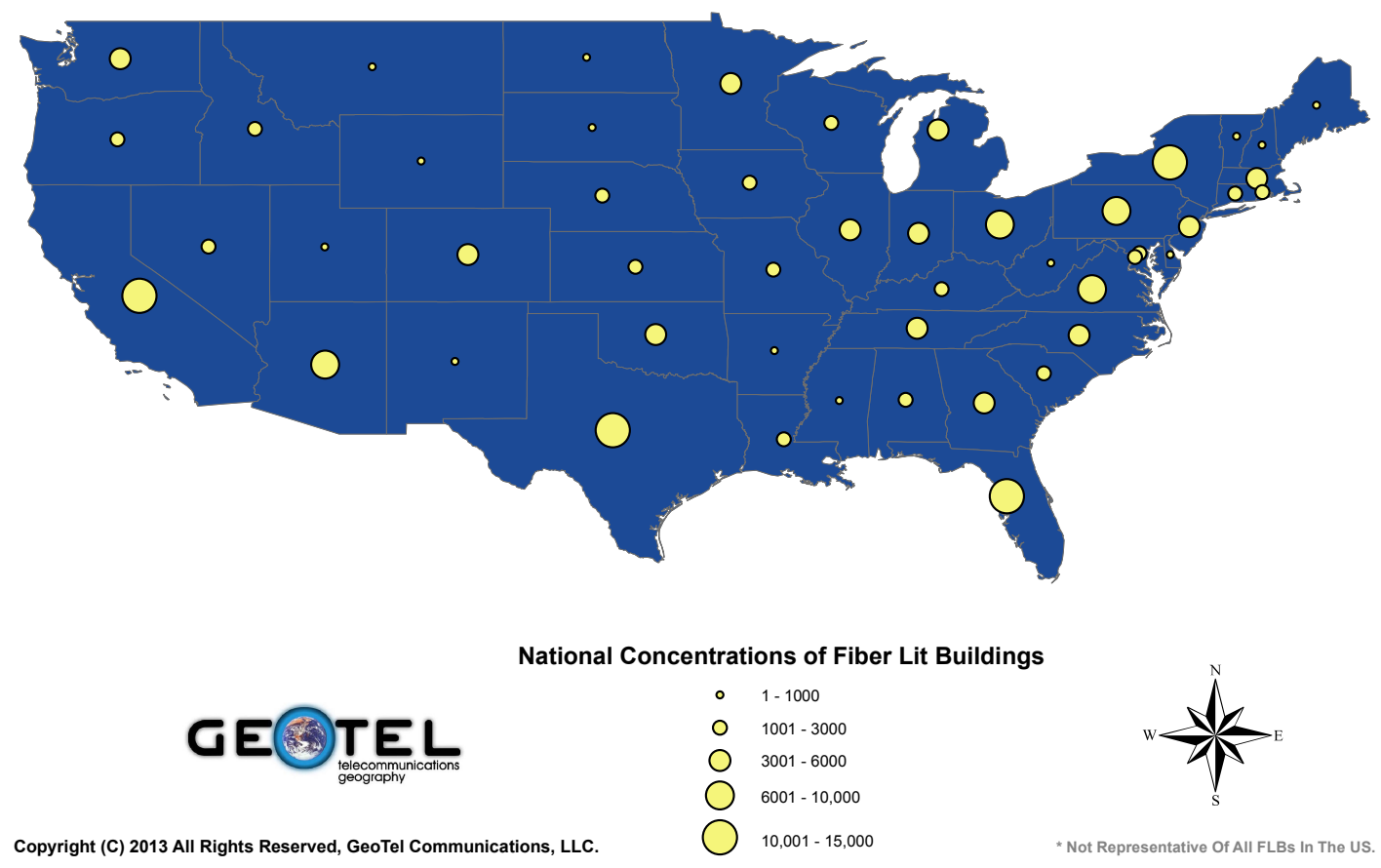

Copyright (C) 2013 All Rights Reserved, GeoTel Communications, LLC.

(b) New York CBSA

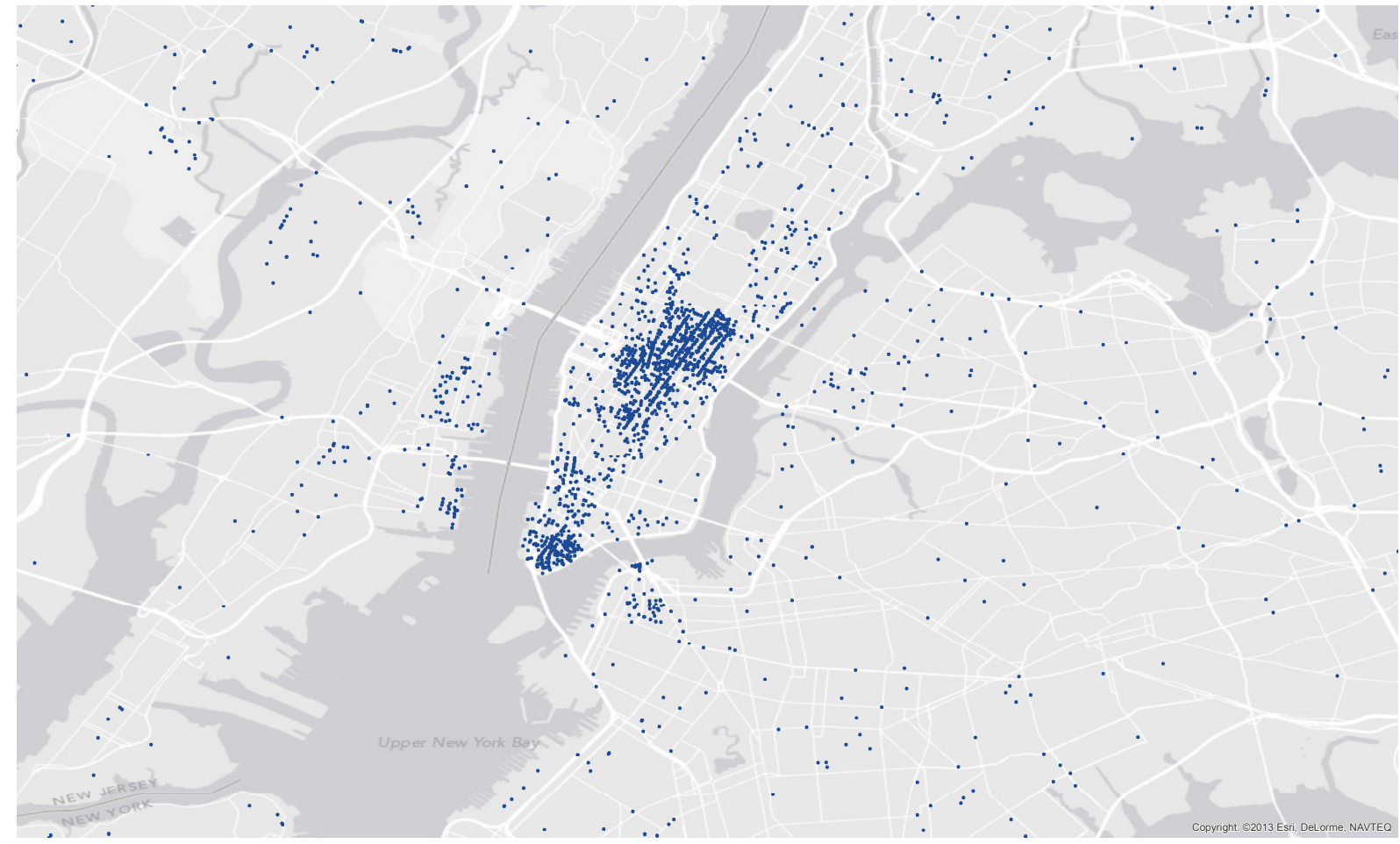

Notes: Figure 5.2 displays the distribution of the US and New York CBSA fiber-lit buildings as of 2012. Figure 5.2a highlights the US fiber-lit buildings by state across five concentrations. Figure 5.2b depicts the fiber-lit buildings for the New York CBSA. 
Initially, they were dubbed telecom hotels as they occupied abandoned downtown hotel facilities (Baginski and Malecki, 2013; Malecki, 2002). The dot-com bubble of that period eventually burst, leading to a drop in the burgeoning demand for data center buildings and a temporary flight from their occupancy and ownership. However, over the 2000s, as more tenants, institutions and corporates took up telecommunicationsbased business strategies, data centers took off once again. As technology shifted from phone lines to cable to broadband and then to fiber-optics, the cost of Internet access dropped and access to the World Wide Web increased rapidly.

A key development during this period was that computer science engineers, structural engineers, architects and civil engineers joined forces to create the physical infrastructure for the Internet as we know it today. After the dot-com bubble burst many of these individuals utilized their skills to diffuse these technologies into other sectors. In many instances, the CEOs of today's data center companies or data center brokerage firms are former information technology (IT) engineers. ${ }^{17}$

The transfer of human capital from one sector to another is an important aspect of capitalizing on synergies in the development of innovations. This can result from prior human capital development in relevant technologies being applied to new environments with unforeseen needs (Abernathy and Clark, 1985). Significantly, in the innovation literature, this transfer of human capital is typical in architectural innovations. These innovations involve the reconfiguration of an existing system to link together its individual components in a new way (Henderson and Clark, 1990). In line with this literature, an innovation does not have to be a radically new product in order to serve a niche demand. Abernathy and Clark (1985, p.7) state that the real power of architectural innovations is that they "... open up new linkages to the markets and users, which is characteristic of the creation of new industries as well as the reformation of old ones." For data centers, the installment of servers, routers and fiber-optic cables requires just such a reconfiguration of the core components of a standard commercial building. As a result, data centers are the poster child for architectural innovations in commercial real estate.

This may explain why the demand for data centers is vast, dynamic and complex. The market can be broken down into four primary user categories: Wholesale, Corporate, IT/Telecom and Government. Wholesale data providers lease space to any user requiring rack room. Niche institutional real estate investors own and operate space in this sector and serve demand from any and all users. The primary demand from

\footnotetext{
${ }^{17}$ For example, the president and CEO of Sabey Corportation, Dave Sabey started building data centers for corporations and the foundation of the Internet back in the 1990s. Sabey Corporation is a special purpose real estate investment trust dedicated to data centers (http://insidesabey. sabey.com/ dave_sabey, accessed July 25, 2013). Another example, is Wired RE, a commercial real estate brokerage firm and research group, where the CEO, Everett Thompson, formerly worked in the IT industry (http://wiredre.com/data-center-broker/leadership/, accessed July 25, 2013).
} 
corporate users is derived from Sarbanes Oxley (SOX) Provision 404, which pertains to the integrity of financial data. As part of data integrity controls and financial data security, data centers literally serve as the firewall between management and their financial data. Thus, over the late 2000s as compliance with SOX increased, so did the corporate data center supply. Finally, the government is a large user of data centers. Currently, the US General Services Administration reports that the federal government operates about 2,000 data centers nationwide. This figure has been growing steadily since 2001 . However, under the Federal Data Center Consolidation Initiative, approximately 40 percent of these government data centers will close by 2015. The implications for the growing trend from owner occupied data centers to a third-party data center model. Although today there is a considerable number of corporate, government and private institutions owning their data center, there is a growing segment of public and private specialized real estate.

\subsubsection{Architectural Innovations}

Physical reconfiguration is the manifestation of the architectural innovation that produces a data center. The building's floors and rooms that house vast server and router equipment are distinctly different from 'human' spaces. To serve the digital demand, engineers must determine the facility's topology design (space planning), decide on infrastructure design (mechanical systems such as cooling and electrical systems including power) and settle on technology infrastructure design (cable plant) for the server equipment. Moreover, there are different treatments for a building based on whether it is an existing structure undergoing redevelopment or a new construction. For redevelopment, data center buildings are first checked for solid steel construction and reinforced with insulation. Next, the floors are raised and the ceiling is lowered to create ventilation for the servers and space for the fiber-optic cables. In some cases, the elevators are converted into fiber-optic cable ducts. Building atriums are emptied and windows are blocked off completely to eliminate daylight that causes unnecessary warming. Vents, fans and HVACs are installed to keep the server equipment cool. Gas tanks are brought into the facility to link to back up generators, which are installed on roofs. For new construction, steel boxes with cooling systems are embedded in the ground, with state-of-the-art electrical facilities and co-generation plants. These facilities operate more like power plants and look more like building refridgerators.

Figure 5.3 depicts Google's East Coast headquarters in New York City, New York and data center facilities in Council Bluff, Iowa. Figure 5.3a shows some of the redeveloped data center features discussed above. The windows of the top floors are closed off in many cases, generators sit on roof ledges and large HVAC systems are clustered about on the roof. Although the building is used for data center operations, it is not 
listed by Google as such a facility. Digital Reality Trust, Telx, Equinix and many others operate in a 'Meet-Me Room' and data center space within the building. It is also a multi-tenant office and retail space. Google itself houses its New York City office here and leases space to the high-street tenants. Figure 5.3b depicts Google's newly constructed data center in Council Bluff, Iowa. In contrast to the redeveloped space in a city environment, this building is not a high rise, and its generators and HVAC facilities are relocated from the roof structures to the sides of the building. With more space and more energy possibilities available, this data center sources its energy from local wind farms.

A key goal in the design of data centers is to ensure that the buildings have zero downtime: minimising the risk of shutting down is an important determinant of data center value. Meerman (2011) indicates that there are multiple factors that are important when assessing risk for data centers, including highway access, flight patterns, flood plains, the proximity to nuclear power plants, railroad tracks access, crime levels and even the incidence of lightning strikes. ${ }^{18}$ In a recent example, Hurricane Sandy proved costly for traders when the data center for the New York Stock Exchange in Mahwah, New Jersey needed to close for two full days due to issues related to the storm. Several firms also experienced down time on their servers as the storm swept through. For these facilities, electrical redundancy in the case of power failures, fire protection systems and physical security are vital. In many cases, fuel capacity for backup generators must be put on site, involving protection against explosions. Large HVAC systems that can undergo 24 hour high capacity cooling to keep the servers cool are predominant.

In addition, what is striking about data centers is their need for access to large amounts of electrical power. Energy is the most important operational expenditure for data centers, as they need on average 2-5 MegaWatts (MW) of power. ${ }^{19}$ According to the Environmental Protection Agency, electricity use associated with the nations servers and data centers grew significantly from 2000 to 2006. As of 2006, electricity use attributable to the nations servers and data centers is estimated at about 61 billion kilowatt-hours (kWh), or 1.5 percent of total US electricity consumption (US DOE 2007a). This electricity usage has more than doubled since 2000 and involves about $\$ 4.5$ billion in annual electricity costs. It is equivalent to the electricity consumed by

\footnotetext{
${ }^{18}$ Data centers are beginning to be subject to standards for the risk assessments of their systems. The Uptime Institute certifies tiers of data centers based on their uptime capacity. There are four tiers, covering the size of the business, the uptime in the data center running, downtime, redundancy and power outage protection. A Tier Four data center is one that has complete redundancy within its own facility, and a complete duplicate facility. There are just 38 US data centers fully in line with the Uptime Institute's standards.

${ }^{19}$ MegaWatts is a unit of power, which means that the rate at which a data center facility transfers, uses, or transforms energy is two to five million Watts.
} 
Figure 5.3: Google Data Centers: Redevelopment and New Construction

(a) 111 8th Avenue

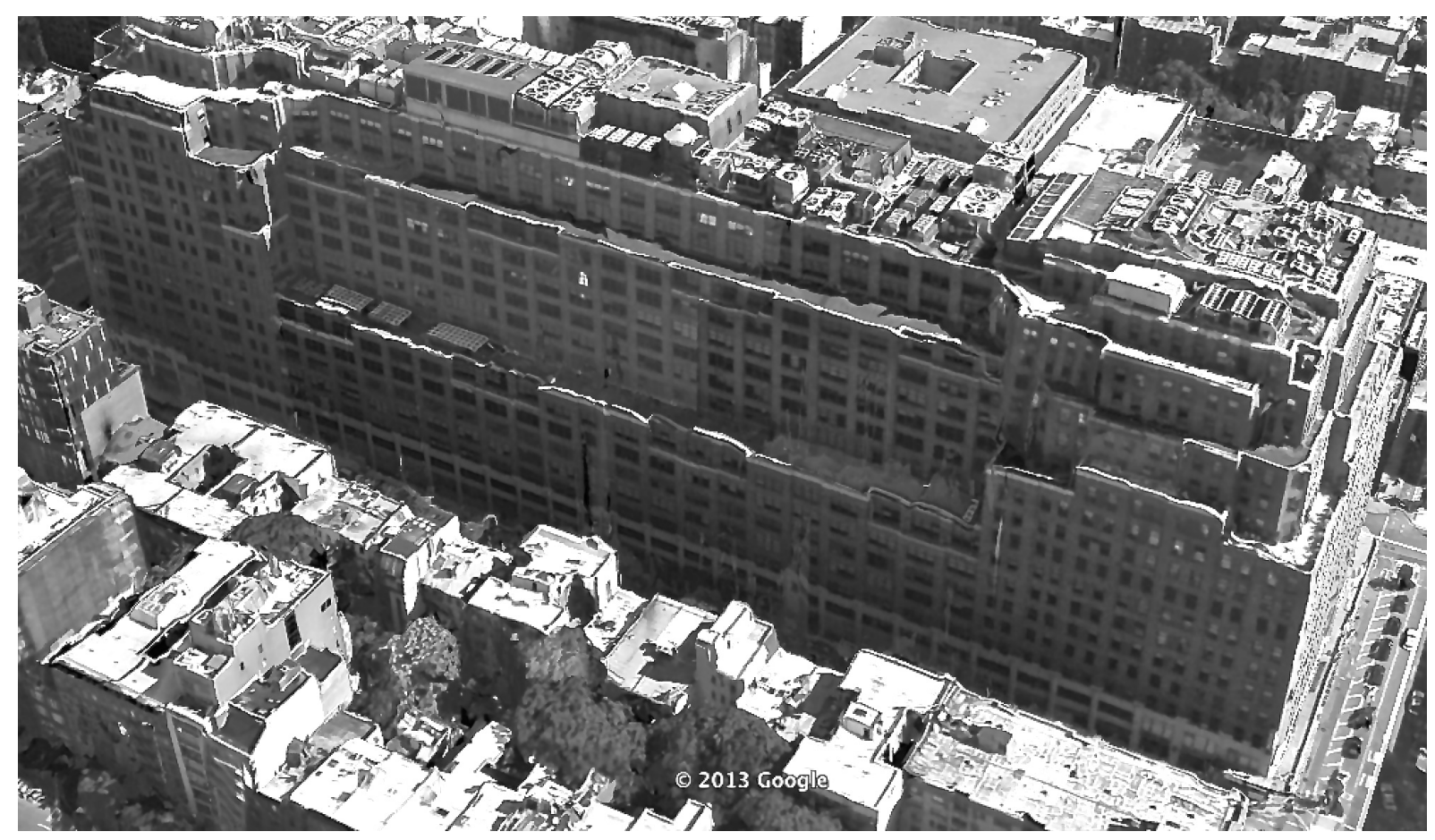

(b) 1435 Veterans Memorial Highway

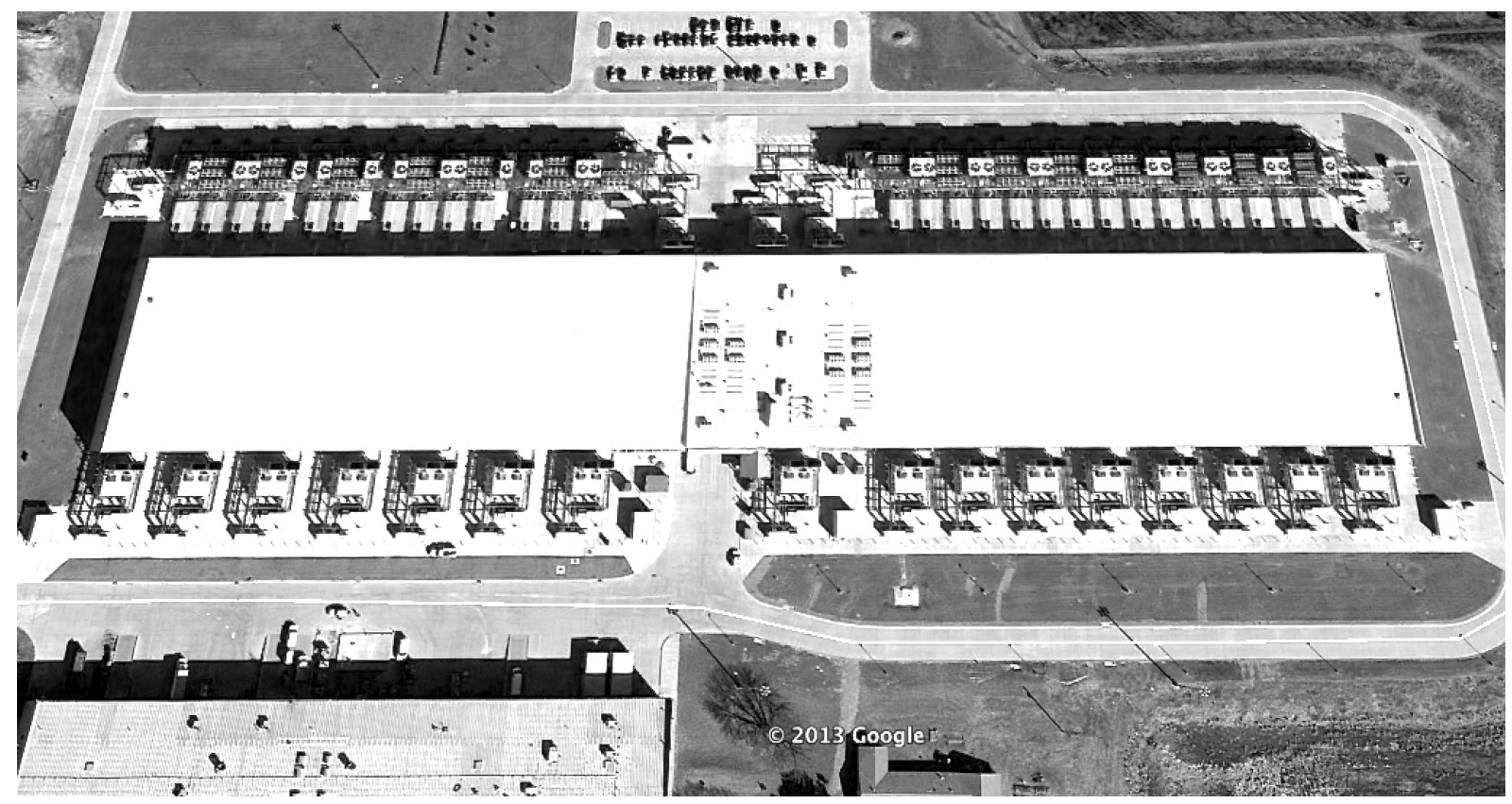

Notes: Figure 5.3 illustrates the data center building differences between redevelopment and new construction for the Google Coorporation. Figure 5.3a depicts 111 8th Avenue a 1932 Art Deco steel structure in the Chelsea district of Manhattan. Figure 5.3b depicts Google's Iowa data center in Council Bluff. 
5.8 million US households, which represent $5 \%$ of the US housing stock, and is similar to the amount of electricity used by the entire U.S transportation manufacturing industry, which includes the manufacture of automobiles, aircraft, trucks and ships (US Environmental Protection Agency Energy Star Program, 2007).

Figure 5.4 displays the distribution of data centers across the US and New York CBSA. Figure 5.4a highlights the fact that data centers cluster in the Mid-Atlantic and New England areas. However, there is also significant clustering in California, in Los Angeles and San Francisco. Most of these clusters mirror the fiber-optic cable clusters and submarine landing stations, which suggests that these markets capitalize on the agglomeration of fiber-optic connectivity in the major markets. However, path dependence also plays a role here, where the pathways of telecommunications, starting with the telegraph, were laid in these very same areas. Figure $5.4 \mathrm{~b}$ isolates the data centers located in the New York CBSA. There are clusters in New Jersey and a few on Long Island. However, the majority are clustered in Downtown Manhattan through Soho and on into Chelsea. Similar to the fiber-optic connectivity map of the New York CBSA, this map outlines where data centers are clustering in the city. Their path can be seen to follow the 'Hudson Street/9th Avenue' fiber-optic highway where many internet service providers lay their cables.

\subsection{Telecommunications Data}

To analyze the value of data centers and fiber-lit buildings, this research focuses on the New York-New Jersey-Pennsylvania Core Based Statistical Area ${ }^{20}$ (New York CBSA). For the principal and control variables in the analysis, it draws on several resources of proprietary and publicly available data. At the core of the analysis is a cross-section of transaction data from Real Capital Analytics, a commercial real estate transaction database that covers the New York CBSA from 2005 to present. ${ }^{21}$ Data on fiber-lit

\footnotetext{
${ }^{20}$ According to the 2010 US Census, this has a population of $22,085,649$ inhabitants in an area covering 1,865 square miles $\left(720 \mathrm{~km}^{2}\right)$.The CBSA comprises the following US counties: Kings County (Brooklyn), NY, Queens County, NY, New York County (Manhattan), NY, Bronx County, NY, Richmond County (Staten Island), NY, Westchester County, NY, Bergen County, NJ, Hudson County, NJ, Passaic County, NJ, Rockland County, NY, Putnam County, NY, Suffolk County, NY, Nassau County, NY, Middlesex County, NJ, Monmouth County, NJ, Ocean County, Somerset County NJ, Essex County, NJ, Union County, NJ, Morris County, NJ, Sussex County, NJ, Hunterdon County, NJ, Pike County, PA.

${ }^{21}$ Real Capital Analytics is a proprietary database of commercial property transactions. Data integrity controls ensure timely, accurate and completely objective data. Data is updated continuously, providing a nearly real-time view of investment activity and distressed property in the commercial real estate marketplace. Data base coverage is global, for markets outside the US, transactions greater than $\$ 10$ million and in the US, \$ 2.5 million. On average, market coverage of transaction events is about 90 percent. Property types covered are office, industrial, retail, multi-family, hotel and development sites.
} 
Figure 5.4: United States and New York CBSA Data Centers

(a) United States

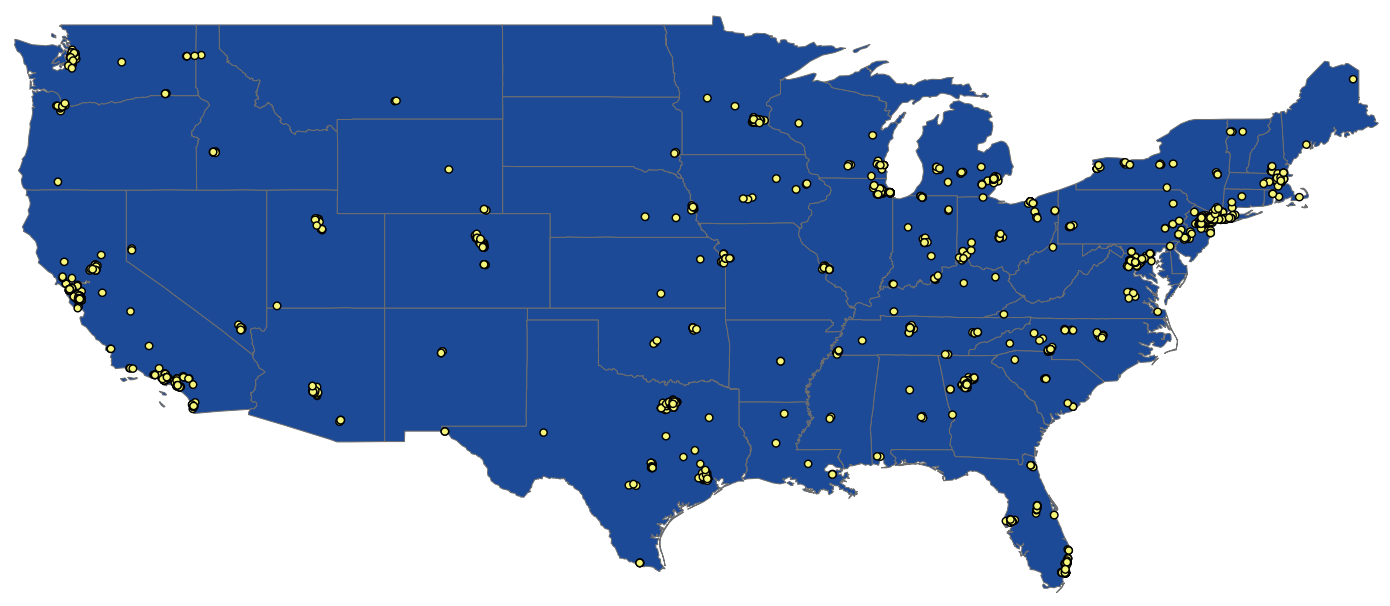

(b) New York CBSA

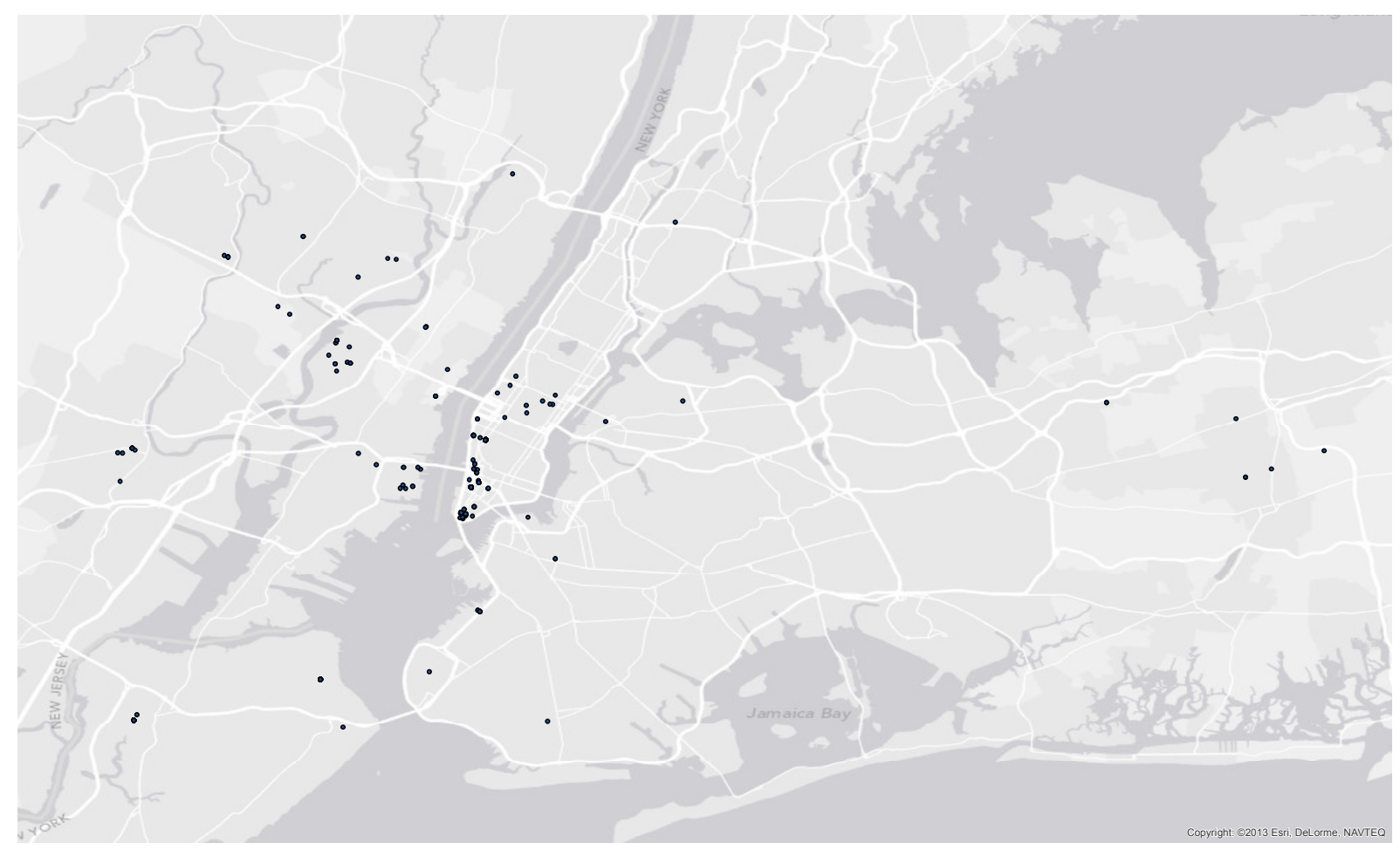

Notes: Figure 5.4 displays the distribution of the US and New York CBSA data centers as of 2012. Figure 5.4a highlights the US data centers by state. Figure 5.4b depicts the data centers for the New York CBSA. 
buildings and data centers are provided by GeoTel Communications, LLC. ${ }^{22}$ As a secondary source, Data Center Map provides data center locations. ${ }^{23}$

The identification strategy isolates fiber-lit buildings and data centers and their characteristics, and matches these buildings' address files to the property transaction database maintained by Real Capital Analytics over the period January 2005 to December 2012. To identify fiber-lit buildings at the time of sale, a panel dataset of fiber-optic connectivity is created using GeoTel's historic database. ${ }^{24}$ Next, Real Capital Analytics's transaction dataset is matched to the fiber-optic connectivity at the time of sale. A data center historic file is also created, by looking up dates of data center activity according to advertisements and building records. Finally, this transaction data is linked with the number of internet service providers (Carriers) who serve the building at the time of sale. As of 2012, there are a total of 144 observations in the Real Capital Analytics database that are related to current data centers, but only 50 have an observation for when they were transacted as a data center at the time of sale. Combining these records results in 494 fiber-lit building transactions, 50 data center transactions and 8,421 control sample transactions.

Ex-ante The following expectations of the control variables impact on value are posited in the research.

Building Characteristics, Location and Time: In line with the literature on commercial real estate valuation, transaction values are a function of their hedonic characteristics. Economically significant control variables include building size, stories, age, renovation status, date of renovation, building location and time of sale. These variables are included in the analysis to explain the core value of any transacted asset.

Telecommunications Carriers: The number of internet service providers (carriers) that serve a building determines the level of competition in fiber-optic connectivity for this building. Buildings with single carriers face higher connectivity charges and in turn higher operational costs. Data Centers with single carriers are called Non-neutral Car-

\footnotetext{
${ }^{22} \mathrm{GeoTel}$ Communications, LLC (GeoTel) is the leading provider of telecommunications infrastructure data for geographic information systems (GIS), which brings together the mapping of telecommunications fiber and other telecom infrastructure with GIS technologies. Available data sets are updated semi-annually. Data are available for carrier fiber networks, fiber routes, metro networks covering over 5,000 US Cities, location and building information on fiber-lit buildings and co-location centers, fiber proximity to wireless/cell sites and towers, tower and rooftop sites for cell towers, LATA and area code boundaries.

${ }^{23}$ Data Center Map is a free web service acting as the link between providers and clients in the data center industry, making it easier for clients to find potential providers matching their needs. The service focuses on co-location and IP transit, but also covers a number of other data center services such as wholesale space, dedicated servers, remote hands and internet exchanges. The data covers 2500 facilities from about 90 countries.

${ }^{24}$ It is assumed that once a building receives fiber-optic cabling it remains in place for the remainder of the sample. It is unlikely that such infrastructure would be removed from a building. However, it is possible that the fiber can go dark," i.e., the carrier turns off the line. In any event, the real infrastructure of fiber-optic connectivity is still in place.
} 
rier facilities as the tenant can only get service from one provider, while data centers with multiple carriers are Neutral Carrier facilities. Bringing in more carriers drives up competition and reduces operational costs. Pietz (2012) provides documentation showing that buildings with single carrier fiber-optic connectivity face a minimum of $\$ 3,000$ per month in connectivity charges, but when buildings increase their connectivity by adding multiple carriers, fees decrease. Thus, the number of carriers affects the financial performance of a building. In turn, this can be a source for increased demand for data centers. However, it may also be a source of agglomeration for firms as multiple carriers suggest increased 'meet-me' capacity across carriers. Firms that have access to direct transfers between firms may be able to take advantage of decreased connection costs.

Points of Connectivity: Blum (2012) highlights the nodes of the internet, Internet Exchanges, which round out the physical infrastructure and where carriers switch Internet traffic through to other networks. Although Internet Exchanges can also be used as data centers, their primary function is the routing of data, not its storage and retrieval. However, the proximity to Internet Exchanges may drive prices. Slavin (2011) describes algorithms designed by high frequency traders surrounding 60 Hudson Street, a significant Internet Exchange and data center in Manhattan. He explains how proprietors of high frequency algorithms like 'The Boston Shuffler' gut the buildings surrounding 60 Hudson Street to fill them with servers that operate algorithms that quote 2,000 to 7,500 trades per second, just so that they can execute trades five micro-seconds faster than those on Wall Street. ${ }^{25}$ Given the importance of financial services firms and the need for latency over the sample period, the study controls for Internet Exchange proximity by calculating the distance from all buildings to the nearest Internet Exchange. There are three Internet Exchanges in the New York CBSA.

Energy Optimization: Access to energy may be a moderating factor for data centers. In particular, data centers use between two and five MWs of power to supply energy to their servers, fans and cooling equipment. Thus, access to power supply is a critical factor for data centers, and these special energy demands can play a role in data center value. The distances for all observations to the nearest electrical transmission lines, power sub-stations and power plants are calculated using Platts data.

Investor and Seller Types: Descriptive variables detailing buyer and seller types are added to the analysis to control for financial incentives and risk preferences of different buyers and sellers as this can influence their return and risk preferences in the property market. Real Capital Analytics lists the buyers and sellers at the time of trans-

\footnotetext{
${ }^{25}$ At the time, the New York Stock Exchange had not created its own data center for trading. In 2011, the NYSE opened the Mahwah, NJ facility to execute high frequency trading volume. In addition, to resolve the distance factor for latency sensitive traders, all server cages have the same length of fiberoptic cabling to the NYSE's servers.
} 
action and places them in five distinct categories. On the Buyers side, these are Equity Funds, Institutional Investors (namely pension funds and sovereign wealth funds), Private companies, Public (real estate investment trusts), User (owner occupiers) and Unknown investors. On the Sellers side, they are Equity Funds, Institutional, Private and Public companies and properties sold from Commercial Mortgage Backed Security Portfolios.

Location Risk: Location risks are important due to their impact on the downtime of data centers. These risks may have been added to data center prices by building owners over the sample period. Thus, for all buildings, distances to data center risks are calculated: hazard roads, railroad tracks, interstate highways, major roads, subway stations, Amtrack stations and Airport perimeters. As previously discussed, data centers should not experience downtime. Thus, proximity to physical risks may play an important role in data center site selection and carve out distinct locations where data centers can operate with lower facility risk.

\subsubsection{Summary Statistics}

Table 5.1 documents the mean, standard deviation and frequency distribution of the price and building quality characteristics over the 2005 to 2012 period for the three samples: fiber-lit buildings, data centers, and the control sample. Fiber-lit buildings and data centers have higher prices on average, but with greater variation. However, these buildings are quite large. Data centers are on average more than five hundred thousand square feet, which is larger than the average fiber-lit building and much larger than the average control building. After controlling for size, data centers on average transact at sixty dollars less per square foot than the control sample. Fiber-lit buildings and data centers are three times as tall as the average building in the sample period, but with greater variation; a majority of the building population has more than 21 stories. On average, these buildings are younger than the remaining population, but only by about six years. In general, the New York CBSA building stock is relatively old. Approximately 44 and 46 percent respectively of fiber-lit building and data center stocks are renovated, compared with 28 percent for the control sample. In addition, the average number of years since a building had been renovated at the time of transaction is about five for all three samples, with slightly less variation for the data center sample.

In addition to prices and building characteristics, location and time of sale complete the core descriptive variables for a commercial real estate asset. To control for microlocation, the Real Capital Analytics sub-markets designation is used. This breaks the markets down into 25 regions. Within the sample's regions, the vast majority of data centers and fiber-lit buildings, approximately 65 percent, are located in Manhattan. 
Table 5.1: Transaction Prices and Building Characteristics

\begin{tabular}{|c|c|c|c|c|c|c|}
\hline \multirow[t]{2}{*}{ (a) Variable } & \multicolumn{2}{|c|}{ (b) Fiber-lit buildings } & \multicolumn{2}{|c|}{ (c) Data centers } & \multicolumn{2}{|c|}{ (d) Control sample } \\
\hline & Mean & (Std. Dev.) & Mean & (Std. Dev.) & Mean & (Std. Dev.) \\
\hline Price achieved (USD mln) & 177.40 & $(268.23)$ & 194.40 & $(325.23)$ & 19.17 & $(70.20)$ \\
\hline Log price achieved & 17.88 & $(1.65)$ & 18.03 & $(1.55)$ & 15.83 & $(1.04)$ \\
\hline Price per square foot (USD) & 532.94 & $(1100.44)$ & 343.39 & $(310.63)$ & 404.25 & $(701.71)$ \\
\hline Log price per square foot (USD) & 5.73 & $(0.99)$ & 5.39 & (1.05) & 5.44 & $(0.99)$ \\
\hline Size (sq. feet h.ths.) & 3.67 & $(4.09)$ & 5.26 & $(5.72)$ & 0.69 & $(1.44)$ \\
\hline Log size & 12.15 & $(1.33)$ & 12.64 & $(1.18)$ & 10.39 & (1.16) \\
\hline Stories & 15.76 & $(14.04)$ & 17.18 & (14.33) & 5.12 & $(5.60)$ \\
\hline Story $(<10, \%)$ & 0.45 & $(0.50)$ & 0.44 & $(0.50)$ & 0.93 & $(0.26)$ \\
\hline Story $(>11 \&<20, \%)$ & 0.25 & $(0.40)$ & 0.16 & $(0.30)$ & 0.05 & $(0.20)$ \\
\hline Story $(>21, \%)$ & 0.30 & $(0.46)$ & 0.40 & $(0.49)$ & 0.02 & $(0.14)$ \\
\hline Age (at purchase) & 52.08 & $(30.58)$ & 59.14 & $(29.00)$ & 68.81 & $(30.48)$ \\
\hline Age $(<10, \%)$ & 0.04 & $(0.20)$ & 0.04 & $(0.20)$ & 0.05 & $(0.22)$ \\
\hline Age $(>11 \&<20, \%)$ & 0.11 & $(0.31)$ & 0.06 & $(0.24)$ & 0.04 & $(0.19)$ \\
\hline Age $(>21 \&<30, \%)$ & 0.18 & $(0.38)$ & 0.12 & $(0.33)$ & 0.05 & $(0.22)$ \\
\hline Age $(>31 \&<40, \%)$ & 0.09 & $(0.28)$ & 0.16 & $(0.37)$ & 0.06 & $(0.23)$ \\
\hline Renovated $($ yes $=1)$ & 0.44 & $(0.50)$ & 0.46 & $(0.50)$ & 0.28 & $(0.45)$ \\
\hline Time since renovation (years) & 5.14 & $(8.65)$ & 5.28 & $(8.06)$ & 5.26 & $(10.55)$ \\
\hline Number of observations & \multicolumn{2}{|c|}{494} & \multicolumn{2}{|r|}{50} & \multicolumn{2}{|c|}{8,421} \\
\hline
\end{tabular}

Notes: Table 5.1 highlights the mean and variation of transaction price and building characteristics for the fiber-lit building, data center and control samples over the 2005 to 2012 period.

The three remaining New York City boroughs account for about 25 to 21 percent of these buildings. Sixty-five percent of data center transactions are concentrated in the 2009 to 2012 period, with the other 36 percent taking place in the 2005 to the 2008 period. This is similar for both the fiber-lit building and control samples. As expected, 2008 and 2009 had the lowest transaction volume over the sample period, corresponding with the trough in prices in the commercial real estate markets over this time period.

Table 5.2 identifies the telecommunications infrastructure for a building and its environment. The number of carriers for data centers is on average higher than for fiberlit buildings, with twice the variation. Since the data center business model is intended to aggregate fiber-optic connectivity into one building facility, then we would indeed expect that these buildings would have more carriers. However, this is contingent on whether data centers are Neutral or Non-Neutral carrier data center facilities. Sixty percent of the data centers in the sample are Neutral carrier facilities, indicating an agglomeration of carriers in the facility. Data centers are closer to Internet Exchanges than fiber-lit buildings and the control sample, but with comparable variation. However, data centers are also the closest to power sub stations, power plants and electricity transmission lines.

Table 5.3 outlines the buyers and sellers for the three samples. The majority of buyers of data centers are private buyers or companies and equity funds. This may 
Table 5.2: Telecommunication Environment

(a) Variable (b) Fiber-lit building

Number of carriers

Neutral carrier

Non-neutral carrier

Distance to Internet Exchange (mls)

Distance to power sub station (mls)

Distance to power plant (mls)

Distance to power lines (mls)

Number of observations

\begin{tabular}{|c|c|c|c|c|c|}
\hline Mean & (Std. Dev.) & Mean & (Std. Dev.) & Mean & (Std. Dev.) \\
\hline 2.28 & (3.71) & 4.00 & $(7.00)$ & 0.00 & $(0.00)$ \\
\hline 0.00 & $(0.00)$ & 0.60 & (0.02) & 0.00 & (0.00) \\
\hline 0.00 & $(0.00)$ & 0.40 & $(0.23)$ & 0.00 & $(0.00)$ \\
\hline 18.03 & (23.81) & 14.28 & (19.48) & 18.66 & (21.96) \\
\hline 1.69 & $(0.90)$ & 1.61 & $(0.95)$ & 2.07 & (1.41) \\
\hline 2.35 & (1.91) & 2.27 & (1.66) & 3.00 & (2.13) \\
\hline 0.85 & $(0.74)$ & 0.79 & (0.70) & 1.14 & (1.38) \\
\hline \multicolumn{2}{|r|}{494} & \multicolumn{2}{|r|}{50} & \multicolumn{2}{|c|}{8,421} \\
\hline
\end{tabular}

Notes: Table 5.2 highlights the number of carriers and distances to critical data center connectivity points, e.g., Internet Exchanges and electrical power, for the fiber-lit building, data center and control samples over the 2005 to 2012 period.

reflect the vast use of data centers by Fortune 500 companies and by the financial sector. In contrast, the largest sellers of fiber-lit buildings and data centers are institutional and public companies.

Table 5.3: Buyers and Sellers

\begin{tabular}{|c|c|c|c|c|c|c|}
\hline \multirow[t]{2}{*}{ (a) Variable } & \multicolumn{2}{|c|}{ (b) Fiber-lit building } & \multicolumn{2}{|c|}{ (c) Data center } & \multicolumn{2}{|c|}{ (d) Control sample } \\
\hline & Mean & (Std. Dev.) & Mean & (Std. Dev.) & Mean & (Std. Dev.) \\
\hline \multicolumn{7}{|l|}{ Buyers - in \% } \\
\hline Equity Fund & 0.14 & $(0.35)$ & 0.30 & $(0.46)$ & 0.06 & $(0.23)$ \\
\hline Institutional & 0.14 & $(0.35)$ & 0.12 & $(0.33)$ & 0.04 & $(0.19)$ \\
\hline Private & 0.46 & $(0.50)$ & 0.40 & (0.49) & 0.75 & (0.43) \\
\hline Public & 0.12 & $(0.32)$ & 0.10 & $(0.30)$ & 0.03 & $(0.18)$ \\
\hline Unknown & 0.01 & $(0.11)$ & 0.00 & $(0.00)$ & 0.05 & $(0.22)$ \\
\hline User/Other & 0.13 & $(0.34)$ & 0.08 & $(0.27)$ & 0.07 & $(0.25)$ \\
\hline \multicolumn{7}{|l|}{ Sellers - in \% } \\
\hline Equity Fund & 0.16 & $(0.37)$ & 0.18 & (0.39) & 0.04 & $(0.19)$ \\
\hline Institutional & 0.47 & $(0.50)$ & 0.42 & (0.50) & 0.77 & $(0.42)$ \\
\hline Private & 0.10 & $(0.30)$ & 0.08 & $(0.27)$ & 0.03 & $(0.16)$ \\
\hline Public & 0.12 & (0.33) & 0.24 & (0.43) & 0.09 & $(0.29)$ \\
\hline Unknown & 0.02 & $(0.13)$ & 0.00 & $(0.00)$ & 0.04 & $(0.20)$ \\
\hline Commercial Mortgage Backed Security & 0.12 & $(0.33)$ & 0.08 & $(0.27)$ & 0.03 & $(0.17)$ \\
\hline Number of observations & \multicolumn{2}{|r|}{494} & \multicolumn{2}{|r|}{50} & \multicolumn{2}{|c|}{8,421} \\
\hline
\end{tabular}

Notes: Table 5.3 highlights the number of carriers and distances to critical data center connectivity points, e.g., Internet Exchanges and electrical power, for the fiber-lit building, data center and control samples over the 2005 to 2012 period.

Lastly, Table 5.4 documents the distance to neighborhood risk sources for the three samples. Data centers are furthest from hazardous roads, by approximately seven miles, but are about as close to railroad tracks tracks as the fiber-lit buildings and the control sample. In addition, data centers are closest to the interstate and major roads, which could be because fiber-optic cables run under the interstate road and railroad track networks. Fiber-lit buildings and data centers are the furthest away from airports on average, which might relate to the risks associated with plane crashes - but this difference is small. Finally, data centers are closest to Amtrack stations. However, 
this may be because the number of Amtrack stations is limited and the most significant Amtrack station on the Eastern Seaboard is Penn Station. Thus, this could reflect the centrality of the data centers, as opposed to their proximity to Amtrack stations in general. However, it is worth bearing in mind that Penn Station is located quite close to the 'Hudson Street/9th Avenue' fiber-optic corridor.

Table 5.4: Data Center Location Risks

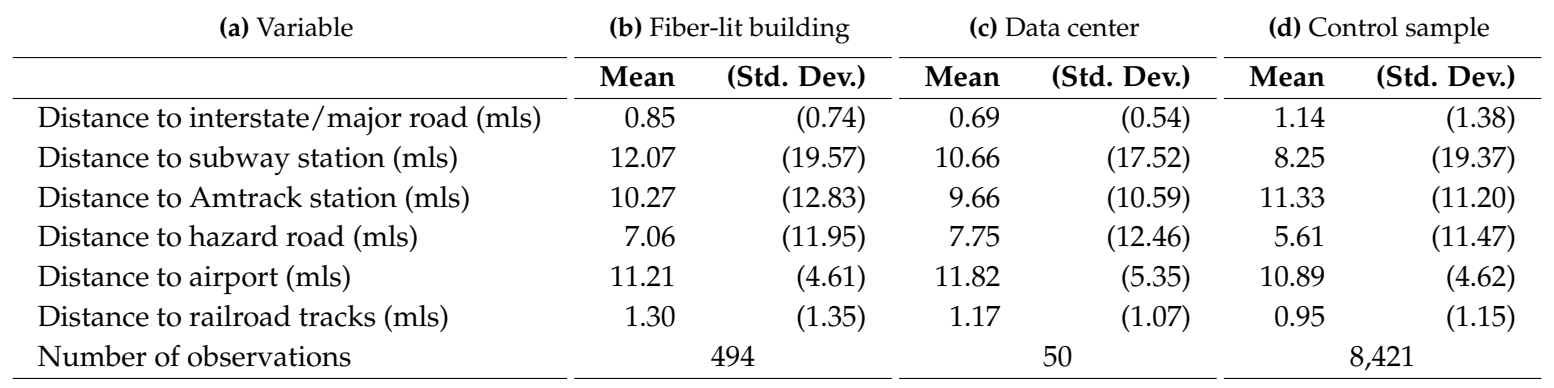

Notes: Table 5.4 highlights the distances to data center risks and general neighborhood connectivity features, for the fiber-lit building, data center and control samples over the 2005 to 2012 period.

\subsection{Methodology}

The standard hedonic framework as established by Rosen (1974) is applied here. Fisher, Geltner, and Webb (1994), are the first to apply the hedonic method in the commercial real estate context, and regress the log price per square foot on a vector of hedonic characteristics. Recently, Eichholtz, Kok, and Quigley (2010) apply the hedonic model to price a contemporary building innovation, "green buildings." In the green building context, the operationalized model regressed the log price per square foot on a certified green building dummy and a vector of hedonic characteristics. Within the context of testing fiber-lit building and data center value, the same method is employed. Thus, the standard hedonic framework is operationalized in this context as follows:

$$
\log P_{i}=\alpha+\beta X_{i}+\delta_{t} T_{i}+\gamma D_{i}+\epsilon_{i}
$$

where $P$ is the transaction price per square foot for transaction $i$; is a dummy equal to one when building $i$ is a fiber-lit building (data center) at the time of transaction and zero otherwise; $X$ is a vector of building and neighborhood characteristics for transaction $i$, building size (in logs), age, renovation status, year of renovation, investor type, seller type, and the distance to airports, subway stations, Amtrack stations, major 
roads, interstates, hazardous roads and railroads). It also includes location-fixed effects using Real Capital Analytics sub-market dummies; $T$ is a vector of of time dummies representing the transaction year for transaction $i ; \beta, \delta$ and $\gamma$ are parameter vectors; $\epsilon_{i}$ is the vector of regression disturbances.

Being fiber-lit by a telecommunications carrier is a necessary but not a sufficient condition for being a data center. Data centers require additional external and internal infrastructure changes. Thus, to estimate the value of data centers, equation (5.1) is re-estimated for the fiber-lit building sample alone.

Finally, the estimation procedure for equation (5.1) is OLS, corrected for heteroskedasticity with robust standard errors (White, 1980). In order to compare data centers to a control sample that has the same propensity of becoming a data center, equation (5.1) is estimated with propensity score weights and common support (Black and Smith, 2004; Rosenbaum and Rubin, 1983). This procedure is repeated when the operationalized regression directly compares data centers with fiber-lit buildings. The procedure eliminates differences between "treated" data centers and fiber-lit buildings and "non-treated" control buildings. I estimate the propensity score using a logit model, which includes non-discrete building characteristics, e.g. the size, number of stories, age, number of carriers at the time of sale, distance to nearest internet exchange point, distance to nearest electricity substation, transmission line and power plant, distance to hazardous roads, major roads, railroad tracks, subway stations and airports. The resulting probability weighting is applied as a weight in the regression of equation (5.1).

The influence of more telecommunications carriers in a building is investigated. Fiber-optic cables are a scarce resource. As previously discussed, not all buildings have this level of high speed connectivity. As a result, when a single carrier enters a building, it can offer its product at high prices, i.e., monopoly prices. However, as the number of carriers increases, the operational expenditures for tenants and owners will theoretically decrease. In turn, this is expected to increase the overall value of fiberlit buildings and data centers. However, to further distinguish between Neutral and Non-neutral carrier data center facilities, an additional control variable is employed to measure whether there is viable competition in the building.

The agglomeration effect is expected to be different for fiber-lit buildings and data centers. Fiber-lit buildings with more fiber-optic cables may have decreased operational expenditures, which is more valuable for tenants and owners. This can increase building demand, enhance occupancy and in turn increase value. However, data centers may see higher values for an additional reason. When an increasing number of carriers join a facility, the functionality of a data center changes from just a data storage facility to a data exchange facility. 


\subsection{Results}

\subsubsection{Innovation Value}

Table 5.5 presents the results for the New York CBSA transaction prices over the 2005 to 2012 period, relating the logarithm of transaction price per square foot to a set of building and neighborhood characteristics with location and time-fixed effects. These specifications explain about 69 percent of the variation in the log transaction price per square meter. Not reported are the year-fixed effects, which are statistically significant across specifications. The dummy coefficients, relative to 2005, are positive on a year-on-year basis, with the exception of 2008. This corresponds to the trends reported by the Moody's Real Capital Analytics New York Repeat Sales Index. In the direct comparison between data centers and fiber-lit buildings, the coefficient for 2008 is also negative. As expected, across both samples and all specifications, the Real Capital Analytics sub-region variables for Manhattan commercial properties in the Upper East Side, Midtown East, Midtown South, Midtown West and Downtown, relative to property on Staten Island, transact for almost twice as much.

Column (1) reports the results of the propensity score weighted specification of equation (5.1), relating transaction prices to hedonic characteristics, i.e., logsize, number of stories, age, age ${ }^{2}$, renovation status, time since renovation, amenities, investor and seller types. In addition, neighborhood controls are included, as measured by distances to Internet Exchanges, power substations, power plants, power transmission lines, Amtrack stations, subway stations, interstates and major roads, hazard roads, railroad tracks and airports.

Building characteristics, such as logsize, number of stories, age, age ${ }^{2}$, renovation status, time since renovation and amenities, all have a statistically significant impact on transaction prices. Transaction prices per square meter decrease by 0.37 percent as square footage increases by one percent. Similarly, when age increases by one year, transaction prices decrease by 1.2 percent. Renovation in general lifts prices by about 23 percent, but as the time since renovation increases by one year, prices decrease by 0.8 percent. Institutional and Public Real Estate Companies pay more for commercial real estate relative to Owner Occupiers. Public Real Estate companies pay about 55 percent more, while Private investors (both real estate and corporations) pay 6.4 percent more than Owner Occupiers. However, this factor could be picking up on the quality of real estate because institutional grade real estate is generally owned by institutional investors looking for stable cash returns, low vacancy and low turnover. Sellers, like Equity Funds and Private companies sell their properties for more than Commercial Mortgage Backed Securities companies. Private companies sell their properties for 21 percent more, and Equity Funds for 22 percent more, relative to Commercial Mortgage 


\section{Backed Securities}

Table 5.5: Transaction Prices for Fiber-lit Buildings and Data Centers (Dependent Variable: Logarithm of transaction price per square foot)

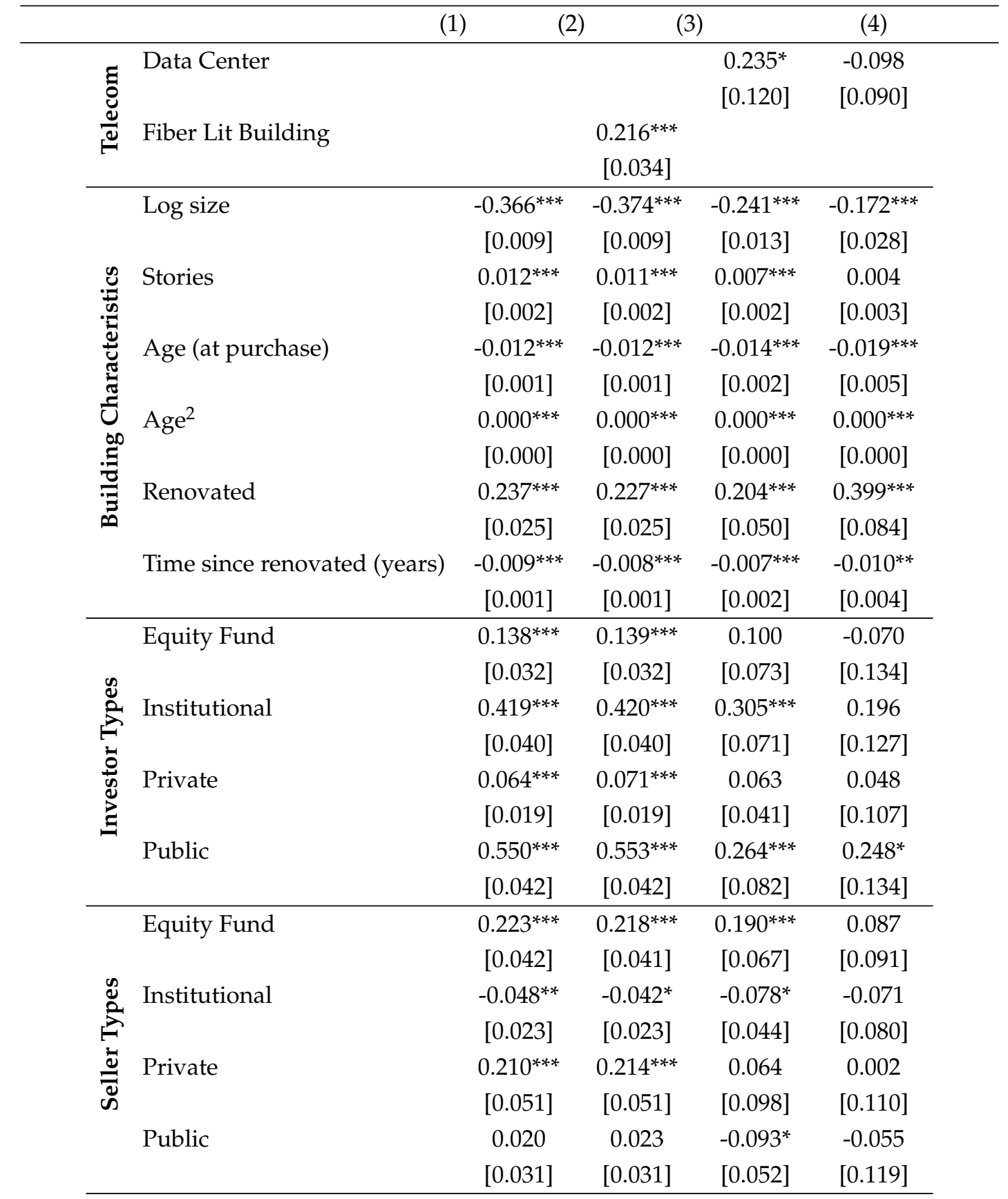


Table 5.5 - continued from previous page

\begin{tabular}{|c|c|c|c|c|c|}
\hline & & (1) & (2) & (3) & (4) \\
\hline \multirow{25}{*}{ 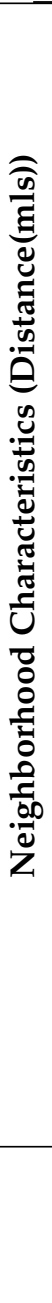 } & \multirow[t]{2}{*}{ To internet exchange point } & $-0.021^{* * *}$ & $-0.021^{* * *}$ & $-0.020^{* * *}$ & 0.019 \\
\hline & & {$[0.002]$} & {$[0.002]$} & {$[0.003]$} & {$[0.019]$} \\
\hline & \multirow[t]{2}{*}{ To power sub station } & 0.008 & 0.008 & $0.036^{* * *}$ & 0.058 \\
\hline & & {$[0.006]$} & [0.006] & {$[0.009]$} & {$[0.051]$} \\
\hline & \multirow[t]{2}{*}{ To power plant } & $0.011^{* * *}$ & $0.011^{* * *}$ & 0.007 & $0.056^{* * *}$ \\
\hline & & {$[0.004]$} & {$[0.004]$} & {$[0.006]$} & {$[0.020]$} \\
\hline & \multirow{2}{*}{ To power transmission lines } & 0.008 & 0.009 & $-0.018^{*}$ & 0.010 \\
\hline & & [0.006] & [0.006] & [0.010] & [0.057] \\
\hline & \multirow[t]{2}{*}{ To Amtrack station } & $-0.010^{* * *}$ & $-0.009^{* * *}$ & $-0.010^{* * *}$ & -0.002 \\
\hline & & {$[0.002]$} & {$[0.002]$} & {$[0.003]$} & [0.011] \\
\hline & \multirow{2}{*}{ To subway station } & $0.025^{* * *}$ & $0.024^{* * *}$ & $0.022^{* * *}$ & $-0.043^{* *}$ \\
\hline & & {$[0.002]$} & {$[0.002]$} & {$[0.004]$} & {$[0.022]$} \\
\hline & \multirow{2}{*}{ To interstate/major road } & 0.000 & 0.000 & 0.000 & 0.000 \\
\hline & & {$[0.000]$} & [0.000] & {$[0.000]$} & {$[0.000]$} \\
\hline & \multirow{2}{*}{ To hazard road } & $-0.004^{* *}$ & $-0.004^{*}$ & -0.002 & $0.021^{* *}$ \\
\hline & & {$[0.002]$} & [0.002] & [0.003] & {$[0.010]$} \\
\hline & \multirow[t]{2}{*}{ To railroad } & 0.010 & 0.008 & 0.005 & 0.042 \\
\hline & & {$[0.007]$} & {$[0.007]$} & {$[0.011]$} & {$[0.032]$} \\
\hline & \multirow[t]{2}{*}{ To airport } & $0.015^{* * *}$ & $0.015^{* * *}$ & $0.015^{* * *}$ & -0.002 \\
\hline & & {$[0.002]$} & {$[0.002]$} & {$[0.003]$} & [0.009] \\
\hline & \multirow[t]{2}{*}{ Constant } & $8.958^{* * *}$ & $9.009^{* * *}$ & $9.039^{* * *}$ & $6.836^{* * *}$ \\
\hline & & {$[0.188]$} & [0.187] & {$[0.381]$} & {$[0.561]$} \\
\hline & Observations & 8,915 & 8,915 & 8,915 & 490 \\
\hline & R-squared & 0.691 & 0.693 & 0.680 & 0.724 \\
\hline & Adj R2 & 0.690 & 0.690 & 0.680 & 0.690 \\
\hline
\end{tabular}

Notes: Robust standard errors in brackets, ${ }^{* * *} \mathrm{p}<0.01,{ }^{* *} \mathrm{p}<0.05,{ }^{*} \mathrm{p}<0.1$. This table reports the OLS estimates linking building telecommunications characteristics with transaction prices over the 2005 to 2012 period. Columns (1) and (2) report the results from equation (5.1) and Column (3) reports the results from equation (5.1) with probability weights and common support. Investor types are relative to Owner Occupiers and seller types are relative to Commercial Mortgage Backed Securities.

In Column (2), the fiber-lit building variable is added to the specification. The variable is positive and statistically significant, indicating that fiber-lit buildings transact for 21.6 percent more than their non-fiber-lit peers. When the dummy is added, the coefficients on the building characteristics, investor types, seller types and neighborhood characteristics remain constant.

In Column (3), the data center variable is added to the specification. The variable is positive and statistically significant, indicating that data centers transact for 23.5 percent more than conventional real estate. When the dummy is added, the logsize coefficients decrease, where when size increases by one percent transaction prices decrease by 0.25 percent. The coefficients on Buyers and Sellers are moderated, decreasing by 


\subsection{Results}

25 percent for Public Investors relative to Owners. Institutional and Public sellers both trade at a discount, of 7.8 and 9.3 percent respectively, compared with Commercial Mortgage Backed Securities

To assess whether values for data centers are related to their connectivity via the fiber-optic network, equation (5.1) is re-estimated with propensity score weights and common support resulting in a common support sample of 490 fiber-lit and data center transactions. This calculation explains the variation of transaction prices of fiber-lit buildings.

Column (4) reports the propensity score weighted specification. The coefficient on the data centers is statistically insignificant, indicating that relative to already being a fiber-lit building, there are no transaction premiums for data center buildings over the full sample period. Like the full sample specification, the fit for the model is approximately 69 percent. Size is negative and statistically significant, indicating that as size increases by one percent, transaction prices decrease by 0.18 percent, less than for the full sample. The effect of depreciation increases as age increases by one year where prices decrease by 2.3 percent. Renovated buildings transact for 37 percent more and depreciation on renovated buildings is comparable to that of the full sample. Public companies pay 24.8 percent more than Occupiers, which is in line with previous findings on the relative transaction prices of building owners (See Chapter 3 of this thesis).

\subsubsection{Telecommunications Competition and Neutral Carrier Facili- ties}

Table 5.6 presents the results for the New York CBSA transaction prices over the 2005 to 2012 period for equation (5.1), with controls for carrier competition and Netural carrier data center facilities. The table relates the logarithm of transaction price per square foot to a set of building and neighborhood characteristics with location and time-fixed effects. Column (1) adds carriers to the full sample specification in place of fiber-lit buildings and data centers. Carriers are positive and statistically significant, indicating that in general transaction prices per square foot increase by 2.4 percent with the number of fiber-optic cable providers serving the building. Carriers do not modify the coefficients or statistical significance of other control variables. In Column (2), the carriers and fiber-lit building variables are added to the full specification. The carrier variable becomes statistically insignificant. In addition, the fiber-lit building variable is modified slightly from 21.6 percent to 20.4 percent. Column (3) tests the impact of carriers on the data center variable. Here again, carriers are statistically insignificant, but have a modifying impact on the data center coefficient. The coefficient on data centers decreases by approximately the same amount as the fiber-lit building coefficient, from 23.5 to 22.2 percent. 
In Column (4) the carrier neutral variable is added to the specification. Within this specification, carrier neutral facilities do not have a statistically significant impact on price nor do they have a modifying impact on data center value more than controls for carriers in general.

To assess whether values for data centers are based on their connectivity via the fiber-optic network and their carrier competition characteristics, equation (5.1) is recalculated with propensity score weights and common support, resulting in a common support sample of 490 fiber-lit and data center transactions. Column (5) reports the coefficient on the data centers, which remains statistically insignificant and carriers do not play a significant role either. This indicates that relative to already being a fiberlit building, there are no transaction premiums for data center buildings over the full sample period. However, in Column (6) when the carrier neutral dummy is added to the specification, this produces positive and statistically significant impacts on fiberlit building transaction prices. This in turn indicates that for more competitive data centers, prices increase by 11 percent relative to fiber-lit builidings, ceteris paribus.

Table 5.6: Carrier Competition and Neutrality Impacts on Transaction Prices (Dependent Variable: Logarithm of transaction price per square foot)

\begin{tabular}{|c|c|c|c|c|c|c|c|}
\hline & & (1) & (2) & (3) & (4) & (5) & (6) \\
\hline \multirow{8}{*}{ 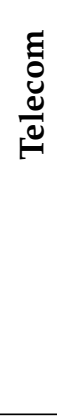 } & Carriers & $0.024^{* *}$ & 0.006 & 0.005 & & 0.005 & \\
\hline & & [0.011] & [0.007] & [0.008] & & [0.005] & \\
\hline & Fiber-lit building & & $0.204^{* * *}$ & & & & \\
\hline & & & [0.037] & & & & \\
\hline & Data center & & & $0.222^{*}$ & $0.220^{*}$ & -0.102 & -0.102 \\
\hline & & & & [0.124] & [0.127] & [0.091] & [0.091] \\
\hline & Carrier neutral & & & & 0.053 & & $0.110^{*}$ \\
\hline & & & & & [0.066] & & [0.067] \\
\hline \multirow{12}{*}{ 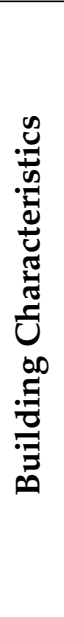 } & Log size & $-0.368^{* * *}$ & $-0.374^{* * *}$ & $-0.243^{* * *}$ & $-0.243^{* * *}$ & $-0.175^{* * *}$ & $-0.180^{* * *}$ \\
\hline & & [0.009] & [0.009] & [0.014] & [0.014] & [0.029] & [0.029] \\
\hline & Stories & $0.012^{* * *}$ & $0.011^{* * *}$ & $0.007^{* * *}$ & $0.007^{* * *}$ & 0.004 & 0.004 \\
\hline & & [0.002] & [0.002] & [0.002] & [0.002] & [0.003] & [0.003] \\
\hline & Age (at purchase) & $-0.012^{* * *}$ & $-0.012^{* * *}$ & $-0.014^{* * *}$ & $-0.014^{* * *}$ & $-0.019^{* * *}$ & $-0.018^{* * *}$ \\
\hline & & [0.001] & [0.001] & [0.002] & [0.002] & [0.005] & [0.005] \\
\hline & $\mathrm{Age}^{2}$ & $0.000^{* * *}$ & $0.000^{* * *}$ & $0.000^{* * *}$ & $0.000^{* * *}$ & $0.000^{* * *}$ & $0.000^{* * *}$ \\
\hline & & [0.000] & {$[0.000]$} & [0.000] & [0.000] & [0.000] & [0.000] \\
\hline & Renovated & $0.234^{* * *}$ & $0.227^{* * *}$ & $0.202^{* * *}$ & $0.200^{* * *}$ & $0.399^{* * *}$ & $0.387^{* * *}$ \\
\hline & & [0.025] & [0.025] & [0.051] & [0.050] & [0.084] & [0.085] \\
\hline & Time since renovated (Years) & $-0.009^{* * *}$ & $-0.008^{* * *}$ & $-0.007^{* * *}$ & $-0.007^{* * *}$ & $-0.010^{* *}$ & $-0.010^{* *}$ \\
\hline & & [0.001] & {$[0.001]$} & {$[0.002]$} & [0.002] & [0.004] & [0.004] \\
\hline
\end{tabular}


Table 5.6 - continued from previous page

\begin{tabular}{|c|c|c|c|c|c|c|c|}
\hline & & (1) & (2) & (3) & (4) & (5) & (6) \\
\hline \multirow{8}{*}{ 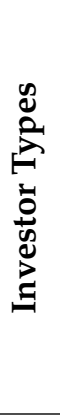 } & Equity Fund & $0.139^{* * *}$ & $0.139^{* * * *}$ & 0.098 & 0.091 & -0.064 & -0.071 \\
\hline & & [0.032] & [0.032] & [0.074] & [0.074] & [0.136] & [0.136] \\
\hline & Institutional & $0.420^{* * *}$ & $0.421^{* * *}$ & $0.306^{* * *}$ & $0.301^{* * *}$ & 0.205 & 0.196 \\
\hline & & [0.040] & [0.040] & {$[0.072]$} & {$[0.071]$} & [0.130] & [0.130] \\
\hline & Private & $0.067^{* * *}$ & $0.071^{* * *}$ & 0.062 & 0.061 & 0.052 & 0.045 \\
\hline & & [0.019] & [0.019] & [0.041] & [0.041] & [0.109] & [0.109] \\
\hline & Public & $0.551^{* * *}$ & $0.553^{* * *}$ & $0.265^{* * *}$ & $0.261^{* * *}$ & $0.254^{*}$ & $0.242^{*}$ \\
\hline & & [0.042] & [0.042] & [0.082] & [0.082] & [0.137] & [0.135] \\
\hline \multirow{8}{*}{ 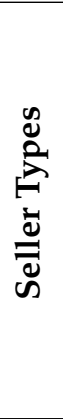 } & Equity Fund & $0.224^{* * *}$ & $0.219^{* * *}$ & $0.198^{* * *}$ & $0.198^{* * *}$ & 0.096 & 0.094 \\
\hline & & [0.041] & [0.041] & [0.065] & [0.064] & [0.090] & [0.091] \\
\hline & Institutional & $-0.046^{* *}$ & $-0.041^{*}$ & $-0.073^{*}$ & $-0.071^{*}$ & -0.068 & -0.062 \\
\hline & & {$[0.023]$} & [0.023] & [0.043] & [0.042] & [0.080] & [0.079] \\
\hline & Private & $0.214^{* * *}$ & $0.215^{* * *}$ & 0.072 & 0.076 & 0.006 & -0.001 \\
\hline & & [0.051] & {$[0.051]$} & [0.097] & [0.096] & [0.109] & [0.109] \\
\hline & Public & 0.022 & 0.023 & $-0.087^{*}$ & $-0.085^{*}$ & -0.048 & -0.061 \\
\hline & & [0.031] & [0.031] & [0.052] & [0.051] & [0.120] & [0.120] \\
\hline \multirow{25}{*}{ 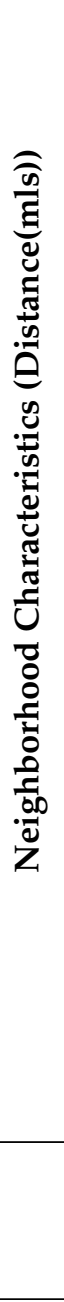 } & To internet exchange point & $-0.021^{* * *}$ & $-0.021^{* * *}$ & $-0.020^{* * *}$ & $-0.020^{* * *}$ & 0.021 & 0.020 \\
\hline & & {$[0.002]$} & {$[0.002]$} & [0.003] & {$[0.003]$} & [0.019] & [0.019] \\
\hline & To power sub station & 0.008 & 0.008 & $0.036^{* * *}$ & $0.035^{* * *}$ & 0.060 & 0.057 \\
\hline & & [0.006] & [0.006] & {$[0.009]$} & {$[0.009]$} & [0.052] & [0.052] \\
\hline & To power plant & $0.011^{* * *}$ & $0.011^{* * *}$ & 0.007 & 0.007 & $0.054^{* * *}$ & $0.056^{* * *}$ \\
\hline & & {$[0.004]$} & {$[0.004]$} & [0.006] & {$[0.006]$} & {$[0.021]$} & {$[0.020]$} \\
\hline & To power transmission lines & 0.008 & 0.009 & $-0.018^{*}$ & $-0.017^{*}$ & 0.009 & 0.000 \\
\hline & & {$[0.006]$} & {$[0.006]$} & {$[0.010]$} & {$[0.010]$} & {$[0.057]$} & {$[0.000]$} \\
\hline & To Amtrack station & $-0.010^{* * *}$ & $-0.009^{* * *}$ & $-0.010^{* * *}$ & $-0.010^{* * *}$ & -0.003 & -0.002 \\
\hline & & {$[0.002]$} & {$[0.002]$} & {$[0.003]$} & {$[0.003]$} & {$[0.011]$} & {$[0.011]$} \\
\hline & To subway station & $0.024^{* * *}$ & $0.024^{* * *}$ & $0.021^{* * *}$ & $0.022^{* * *}$ & $-0.044^{* *}$ & $-0.044^{* *}$ \\
\hline & & {$[0.002]$} & {$[0.002]$} & {$[0.004]$} & {$[0.004]$} & {$[0.022]$} & {$[0.022]$} \\
\hline & To interstate/major road & 0.000 & 0.000 & 0.000 & 0.000 & 0.000 & 0.014 \\
\hline & & {$[0.000]$} & {$[0.000]$} & {$[0.000]$} & {$[0.000]$} & {$[0.000]$} & [0.058] \\
\hline & To hazard road & $-0.004^{*}$ & $-0.004^{*}$ & -0.002 & -0.002 & $0.022^{* *}$ & $0.022^{* *}$ \\
\hline & & [0.002] & {$[0.002]$} & [0.003] & [0.003] & [0.010] & [0.010] \\
\hline & To railroad & 0.010 & 0.008 & 0.005 & 0.005 & 0.042 & 0.042 \\
\hline & & [0.007] & {$[0.007]$} & {$[0.011]$} & {$[0.011]$} & [0.032] & [0.032] \\
\hline & To airport & $0.015^{* * *}$ & $0.015^{* * *}$ & $0.015^{* * *}$ & $0.015^{* * *}$ & -0.003 & -0.003 \\
\hline & & {$[0.002]$} & {$[0.002]$} & {$[0.003]$} & {$[0.003]$} & [0.009] & [0.009] \\
\hline & Constant & $8.978^{* * *}$ & $9.011^{* * *}$ & $7.545^{* * *}$ & $7.542^{* * *}$ & $6.866^{* * *}$ & $6.899^{* * *}$ \\
\hline & & {$[0.188]$} & {$[0.187]$} & {$[0.297]$} & {$[0.297]$} & {$[0.567]$} & {$[0.559]$} \\
\hline & Observations & 8,915 & 8,915 & 8,915 & 8,915 & 490 & 490 \\
\hline & R-squared & 0.691 & 0.693 & 0.680 & 0.680 & 0.725 & 0.726 \\
\hline & Adj R2 & 0.690 & 0.690 & 0.680 & 0.680 & 0.690 & 0.690 \\
\hline
\end{tabular}

emphNotes: Robust standard errors in brackets, ${ }^{* * *} \mathrm{p}<0.01$, ${ }^{* *} \mathrm{p}<0.05,{ }^{*} \mathrm{p}<0.1$. This table reports the OLS estimates linking building telecommunications characteristics with transaction prices over 
the 2005 to 2012 period. Columns (1) and (2) report the results from equation (5.1) and Column (3) reports the results from equation (5.1) with probability weights and common support. Investor types are relative to Owner Occupiers and seller types are relative to Commercial Mortgage Backed Securities.

\subsection{Discussion and Conclusion}

We can trace the history of 111 8th Avenue (111) back to its construction in 1932. Originally, 111 was designed to be the inland union terminal, a cargo terminal, for the Port Authority of New York, in the middle of the port area of Chelsea. The facility included a vast distribution depot for physical goods and services and large freight elevators to carry trucks and cargo up and down the building floors. From 1932 to 1940, the building was bustling with the freight shipments coming in on the railroad tracks. However, as railroad tracks within Manhattan fell into decline, so too did the Chelsea district and High-line area. From 1940 to 1970, the Port Authority occupied the building as an office, but in 1970 the Authority moved to the former World Trade Center downtown. For the next 28 years, the building had no grand tenant or real economic purpose. In 1998, Taconic Investment Partners bought the building for approximately $\$ 300 \mathrm{mln}$ (\$103 per square foot) and invested a relatively large sum in capital expenditure, \$50 $\mathrm{mln}$. The main investment consisted of upgrading the structure from its physical obsolescence in order to attract new high street retail and Class A office tenants to the area. However, Taconic carried out one other significant upgrade in the building: fiber-optic cabling.

Users and investors value gaining access to the breadth and speed of information that fiber-optic connectivity represents and the imbedded architectural innovation from serving the digital demand. This paper has investigated the dynamic economic outcomes for the New York CBSA's telecommunications-based real estate capital stock by using ex post sales transactions achieved over the 2005 to 2012 period. The results indicate that buildings with fiber-optic connectivity in the commercial real estate market transact for 21.6 percent more than their non-fiber-lit peers, and data centers transact for 23.5 percent more than their conventional peers. Importantly, this effect is conditional on the building characteristics, investor and seller types, neighborhood characteristics and location and time fixed effects. However, when considering the new topography in location value for data centers, e.g. the price of data centers conditional upon being a fiber-lit building, the rents over the full period dissipate.

Over the sample period, the supply of fiber-lit buildings and data centers increased. For the greater US, there are approximately 200,000 fiber-lit buildings, data centers and internet exchanges. For the New York CBSA, the number of fiber-lit buildings grew by 70 percent, but still only accounts for roughly six percent of the commercial building 
stock. Data centers doubled over this time frame, but still are a mere decimal of the greater commercial real estate supply. Interestingly, given the premiums found here, it is surprising that more firms are not switching to the fiber-optic network, or that more firms that have fiber-lit buildings are not developing the asset like a data center. This is especially the case since other firms appear to have the infrastructure to do so.

Or maybe this is not always the case. An important caveat of the literature on architectural innovations developed by Abernathy and Clark (1985) and Henderson and Clark (1990), is that identifying the potential innovation within a building is a challenge for established property firms. Managing asset value in the data center environment is different from doing so in the conventional office environment. It is true that all buildings need power, but data centers need a whole city's worth per month. Certainly, all buildings need physical security, but data centers need cyber security as well. Thus, the mix of human capital that is able to seize the embedded potential of an innovation such as this in commercial real estate and turn it to something new is a subtle but important aspect of an architectural innovation.

Within the US, the New York CBSA is a unique and well-stocked area for fiberlit buildings and data centers. This is an important consideration for the future dynamics of data centers, and for fiber-lit buildings for that matter. The results of this analysis have shown that data centers occupy unique locations relative to their commercial real estate peers. Of course, fiber-optic connectivity is an important driver of location. However, electrical capacity, proximity to Internet Exchanges and locationspecific risks are other drivers. Consequently, data centers are only able to occupy limited vectors of space which are optimal for minimizing their risk and maximizing their performance. Moreover, this is important for a supply-constrained area like the New York CBSA, which demands that so many financial services firms, financial market locations (6 in this CBSA alone), corporate users, Internet Exchange points and submarine landing stations locate themselves in this area. Consequently, conditional on technical change in the server markets, future premiums in these markets may be driven by supply constraints.

Of course, the premiums reported here are conceivably not pure economic rents. CBRE estimates that the average new construction shell of a data center is about $\$ 150$ 300 per square foot, with about $\$ 12$ to $\$ 18 \mathrm{mln}$ dollars per MW of power in operating expenditures per year. ${ }^{26}$ Considering the original example of 1118 th Avenue, a $2.9 \mathrm{mln}$ square foot facility with the power of $13 \mathrm{MW}$ (M J per second) with energy consumed at operational capacity is $13,000 \mathrm{kWh}$, then the total cost of new construction for a stateof-the-art facility would be about $1.2 \mathrm{bln}$. 111 is not a brand-new facility. Nor have the capital expenditures of Jamestown Properties or their JV partners implied such

\footnotetext{
${ }^{26}$ http://www. cbre.us/services/office/critical-environment/Pages/cost-segregation. aspx, accessed March 25, 2013.
} 
expenditures. Consequently, some of this value may be attributable to the factors of prime connectivity on the fiber-optic network, garnering access to a world class 'Meet $\mathrm{Me}^{\prime}$ Room, the fiber-optic infrastructure running under the building and establishing ownership in the growing New York City Silicon Valley.

The results of this paper provide the first evidence on the economic outcomes of fiber-lit buildings and data centers in a commercial real estate context. It finds that fiber-optic connectivity commands a premium in the market place. As a result of the patent-free nature of fiber-optic connectivity, firms have increasingly easier access to state-of-the-art internet connectivity. Indeed, the premiums reported here reflect this aspect of innovation within the real estate market. Data centers and fiber-lit buildings are an input in today's information economy, and a growing source of efficiency and productivity for firms in the New York CBSA, where financial markets, internet exchange points, financial services firms, information technology firms, the Cloud and submarine connection points are all competing for space. From a policy perspective, these results therefore reinforce the importance of stimulating competition between telecommunications firms. The outcomes of the analysis in this paper suggest that it is indeed the within-building competition for services that is an important driver in how access to data centers diffuses. Finally, future research that is able to find longer times series or more transacted data centers may find modified results, but future outcomes are also contingent upon competition within the local telecommunications environment and the amount of fiber-lit building space coming online. 


\section{Chapter 6}

\section{Conclusion}

This thesis explores the empirical outcomes of innovative products in commercial real estate. The chapters in this thesis concentrate on green buildings and data centers, but the patterns they lay out can be expanded to explore other building innovations that deal with urban challenges and opportunities facing society. For instance, in Asia and Africa 'Extreme Urbanism,' caused by explosive population growth in cities, could drive increased demand for urban farms and skyscraper villages. In the US and Europe, the aging of the baby boomer generation may bring on new types of smart homes and aging-in-place facilities, where smart, connected and green technologies further integrate into buildings. These buildings are not conventional. They are product and process innovations that are capitalizing on an opportunity to meet a new space demand in the built environment.

However, throughout the innovation process there is an ubiquitous element of uncertainty; it is inherent. Although innovation can lead to economic growth and development, getting across the hurdles of uncertainty means moving through unpredictable phases of market uptake and commercial product diffusion. Within the commercial real estate sector, there is very limited empirical work in this domain, which leaves a gap in the knowledge of how building innovations develop. Yet, it is important to break down the uncertainty around innovation and shift it more towards a measurable risk. Indeed, the more experience there is from breaking down the systematic and idiosyncratic risks in real estate innovations, the better informed current performance, risk expectations, investment and regulation can become. Consider, for example, an investor or policy maker who wants a performance estimate for green buildings over the next ten years. By its nature, the performance of an innovation like a green building is difficult to predict; on its own, that is. However, we can see the green building innovation as a part of a larger picture of innovative products, and can take the financial performance patterns of multiple commercial real estate innovations to derive better analysis of future innovations. 
Importantly, by understanding the general characteristics that determine the property lifecycle of real estate innovations, their stock development and capital accumulation, we can use our knowledge of past innovations to help assess the financial performance of today's innovations, and - more generally - develop a dynamic assessment of an innovations long-run financial performance. The more products are mapped, tracked and assessed in this way, the better the long-run understanding of innovative product performance can become.

\subsection{Investigating Innovation in Commercial Real Estate}

\subsubsection{Measurement Matters}

At the core of this thesis is the development of real estate metrics that reflect the lifecycle performance of the real estate stock as reflected by a repeat-sales index. Index construction serves an important empirical purpose in measuring the aggregate structure value (both the land and building value at a site) of commercial real estate. Without establishing a valid benchmark, it is difficult to measure the extent to which the innovator has acquired any pecuniary rewards for taking a less than certain path. There are a few methods for establishing a valid benchmark, but an intuitive measure is one that links the realized return outcomes for an investor to the current period. This simple metric is realized in a repeat sales index.

Chapter 2 of this thesis develops a repeat-sales index for London, one of two mega cities in the institutional commercial real estate universe. It is not until recently that transaction-based data became available to support such an index, but the development of such metrics is important. The global development of reliable, timely and accurate measures of commercial property value trends is paramount for establishing a benchmark of property value. As a result it provides a simple, yet transparent measure of price information. This clear metric decreases asymmetric information and uncertainty in the pricing of the commercial real estate stock.

The results in this chapter have important implications for the global development of indices. For one, it adds to the pre-existing commercial property price indices developed for US markets. Since repeat sales indices are absent in the commercial real estate sector in Europe (Financial Stability Board and International Monetary Fund, 2010), there is added value in establishing these metrics for the second largest commercial real estate market in the world. In addition, there is a significant lack in timely yardsticks for commercial property markets, which makes managing a global real estate portfolio very difficult. This chapter also demonstrated that comparisons between two global markets like London and New York using a transaction based index is now viable and more importantly, the correlations between these two markets is less than 
was previously expected. The introduction of a repeat sales index for London serves both as a contribution to and as a blueprint for the future development of more repeat sales indices in other global markets, suitable as ex-post analysis tools for investors, regulators and academics alike.

\subsubsection{Supply Matters}

A source of value for the innovator is their unique ability to supply products that serve demand. within real estate, the scarcity of suitable sites and the stickiness of supply can help protect value. The history of London and New York is provides evidence of real estate titans, who acted at times like monopolists who were able to serve the space demands of the commercial sectors of their time. However, in the 21st century commercial real markets are less monopolistic: there are more than 1,000 distinct owners in the commercial real estate markets of London and New York. Consequently, the monopoly power of innovators today comes from brief time periods of illiquidity and supply constraints in the construction markets.

Chapter 3 looks at a modern innovation in commercial building markets by investigating the role of green building competition in financial performance of London's rapidly evolving environmentally-certified commercial building stock. The chapter documents that growth in green building supply has an economically significant impact on London's commercial real estate prices in general and on certified real estate in particular. From 2000 to 2009, stand-alone green building rents and transaction prices are higher relative to non-green buildings by 24.6 and 18.0 percent, respectively. Yet, when considering the competitive dynamics of an increasing supply and demand on rents and transaction prices for BREEAM-certified buildings value decreases. Thus, when buildings trade hands in a more concentrated green building neighborhood, rents and prices are 19.7 and 14.7 percent more, respectively, than their conventional neighbors. This moderate decrease in value is important as it provides some evidence for the dynamic effects that an increasing supply has on innovation value in the shortand long-run. When builders are able to respond and provide more stock, supply constraints drive down the value of the innovative product.

\subsubsection{Dynamics Matter}

A key element of any innovative process is its dynamic aspect: there are first movers, early adopters and there is learning involved. As a result, the gains from innovation are not constant over time. In the short-run limited supply of suitable sites and long construction periods can protect value. However, in the long-run these factors may not be able to offer the same protection. For the innovator, the supply of the innova- 
tive product in their market is an important factor in their value. Indeed, if the lessons from Chapters 3 and 4 are taken together, then the innovator's dilemma is clear: there is a fine line between product scarcity, for the sake of protecting value, and inviting competition to help drive down the costs of inputs in production. Chapter 3 would suggest that increased competition from neighboring buildings drives down value for an innovative product. Chapter 4 provides evidence that there is construction cost trends for green buildings that are responding to the dynamic inputs in the construction process. Thus, the value of the building is important, but understanding the role of building competition and construction market competition in assessing value in the commercial property markets is an important factor for future research.

\subsubsection{Meeting Demand Matters}

The progress and innovation capacity of society is moving at an exponential rate. So too is the growth of digitized information. The data center commercial real estate innovation discussed in Chapter 5 outlines how a reconfiguration of a traditional building space to meet the rapidly growing digital demand has value. In the case of the Internet, there is a new digital domain that innovators can capitalize on to identify or restore the physical, functional and economic use of sites.

Fiber-optic cables are like the rivers, railroads and highways that came before them. By dividing what is physical from what can be digital, they can be used to decrease transaction costs and increase support of the real economy. Data centers are the digital cities that enable the three benefits of central places: scale economies, agglomeration and positive network externalities. By co-locating in a digital city, firms are able to gain economies of scale from cheaper network access, potentially realize network synergies by offering new products and services and overall share in the costs of routing and storing the in 'cloud.' This expanding digital topology is embedded in the physical geography of the globe's already very central places. Thus, the value of data centers and fiber-optic connectivity is driven by their ability to further decrease transportation costs and increase scale economies.

Within the Chapter 5, 111 8th Avenue, which was previously an inland distribution facility for the New York/ New Jersey port area, is an example of a site where the physical, functional and economic use of the building was restored by serving the digital demand. As a site that sits on the 9th Avenue/ Hudson Street fiber-optic highway, the building is poised to take advantage of the high speed access of digital information. Moreover, as a building with a large 'Meet $\mathrm{Me}^{\prime}$ room and colocation facility, the building can serve as a digital city for its tenants. 


\subsubsection{Costs Matter}

Of course, the green premiums found in Chapter 3 and elsewhere in the literature may reflect increased construction or renovation costs stemming from the incorporation of innovative construction processes. Chapter 4 provides the first evidence on the cost of investments in energy-efficiency and sustainability for a large sample of construction projects. This chapter measures the ex-post cost of a systems innovation in the construction industry, assesses the marginal cost of BREEAM-certified commercial real estate and the magnitude and dynamic progression of BREEAM-certified construction costs over the 2003 to 2012 period.

In contrast to what has been reported in other studies, the results documented in this chapter do not support positive and statistically significant costs over the 2003 to 2012 sample period. From univariate statistics to a multi-regression analysis, the crosssectional evidence provides little room to support higher average costs for BREEAMcertified buildings. However, when moving further along the quality latter, BREEAMcertified buildings do demonstrate some statistically significant cost differences. Outstanding buildings, those buildings that have reached exceptional standards across all dimensions of energy-efficiency and sustainable design, cost on average 16.7 percent more than a conventional construction project. In addition, when digging deeper into the potential sources of green construction costs, the conditional marginal effects analysis suggests that the largest costs for green construction are derived from the hard costs or the services elemental costs of a building. Services costs are the labor and capital costs for installing utilities in a building. In line with the requirements for BREEAM-certified buildings, this result fits as increased attention to the energyefficiency and carbon emission reductions in buildings could result in the use of more innovative capital and labour for energy-efficiency, water and waste consumption.

Furthermore, the results of the 'Green Construction Cost Index' and sub-sample analysis suggest that costs are indeed dynamic. This could be due to the type of innovation that a BREEAM-certified building undergoes, the timing of this innovation in the market or the increasing returns from positive network externalities being realized in the construction market for green building products. What should be taken into consideration is that the signals to investors to take on innovations like a BREEAMcertified construction process have been complex over the past ten years. It was not until 2008 that there was a government standardized scheme to enforce energy-efficiency mandates. In addition, it was not until June of 2008 that the BREEAM standard had reached a momentary steady state in the requirements for BREEAM innovation. In the early 2000s, momentum in networks and the availability of human capital necessary for BREEAM assessment was limited. It was not until the late 2000s that a standardized sustainability label was accompanied by a green building network, regulation, human 
capital and materials within the UK economy.

With the exception of 'Outstanding' buildings, Chapter 4 teaches us that the costs of BREEAM-certified construction are not necessarily nullifying the value premium found in other studies, which may change with future empirical samples. This finding is important for the future of the 'green' construction industry as the coming regulatory mandates for an increase in 'green' buildings to attain zero-energy consumption suggests that the level of innovation for new and old buildings will change. Consequently, the market competition will shift from 'green' versus 'brown' forms of construction towards more incremental innovations in the quality of the 'green' construction in place.

\subsection{Future Research}

The real impact of this thesis is for developers, investors and policy makers to make more informed decisions regarding the innovation process in commercial real estate. Future research at the nexus of innovation and commercial real estate should develop in three key areas: the process of innovation diffusion in commercial real estate, models that look at the financial performance of commercial real estate over the property life cycle, and the aggregate impact of commercial real estate innovations.

An important first step is establishing a typology for innovation for commercial real estate. The innovation literature generally adopts the typology espoused by Abernathy and Clark (1985), and Slaughter (1998) demonstrates through her innovation typology for construction that it might be a useful application for developing standards in commercial real estate. However, a typology is only a first step in understanding supply and demand dynamics.

Once the property life cycle of innovations in real estate is determined, it is possible to link back to neighborhood succession theory and identify product innovations that reach the 'innovation', 'uptake', 'mainstream' and 'decay' phases. Some innovative building developments succeed and some fail and it is not clear why that is the case systematically. This is important as we want to be more efficient in developing sites as builders, allocating capital as investors or even providing stimulus as policy makers.

Finally, it is important to look not just at individual innovations, but rather focus on innovation patterns. By combining all innovations identified so far, it is possible to improve commercial real estate price indexes, taking into account not only individual innovation life cycles, but also innovation waves, the correlations among innovation returns and the diversification gains offered by real estate innovations. In sum, we can benchmark investments in innovative real estate against common real estate, and make better investment decisions. 


\section{References}

ABERNATHY, W. J., AND K. B. CLARK (1985): “Innovation: Mapping the winds of creative destruction," Research policy, 14(1), 3-22.

AbrahAMSON, E., AND L. ROSENKOPF (1997): "Social network effects on the extent of innovation diffusion: A computer simulation," Organization science, 8(3), 289-309.

Aghion, P., AND R. GRIFFITH (2005): Competition and Growth: Reconciling Theory and Evidence (Zeuthen Lectures). Cambridge: MIT Press.

AKERLOF, G. A. (1970): "The market for "lemons": Quality uncertainty and the market mechanism," The Quarterly Journal of Economics, 84(4), 488-500.

AtKINSON, J. (2010): “Capital Cost Sustaiable Offices," Discussion paper, Halcrow Yolles,South West of England Regional Development Agency, Davis Langdon LLP and Cyril Sweett.

BAgINSKI, J., AND E. J. MALECKI (2013): "The Oxford Handbook of the Digital Economy, edited by Martin Peitz and Joel Waldfogel," Journal of Regional Science, 53(1), 205-206.

Bailey, M. J., R. F. Muth, AND H. O. Nourse (1963): “A Regression Method for Real Estate Price Index Construction," Journal of the American Statistical Association, 58(304), 933-942.

Baltagi, B. H., AND J. M. GRIfFin (1988): “A General Index of Technical Change," The Journal of Political Economy, 96(1), 20-41.

BCIS (2012): “Elemental Standard Form of Cost Analysis," Report, Royal Institute of Chartered Surveryors, London, UK.

BLACK, D. A., AND J. A. SMITH (2004): "How robust is the evidence on the effects of college quality? Evidence from matching," Journal of Econometrics, 121(1), 99-124.

Blum, A. (2012): Tubes: A Journey to the Center of the Internet. Ecco/HarperCollins, New York, NY.

BoKhari, S., AND D. Geltner (2011): "Loss Aversion and Anchoring in Commercial Real Estate Pricing: Empirical Evidence and Price Index Implications," Real Estate Economics, pp. no-no.

BOKHARI, S., AND D. GELTNER (2012): “Estimating real estate price movements for high frequency tradable indexes in a scarce data environment," The Journal of Real Estate Finance and Economics, 45(2), 522-543.

BONDE, M., AND H.-S. SONG (2013): “Does greater energy performance have an impact on real estate revenues?," Discussion paper, KTH Royal Institute of Technology, Stockholm, Sweden. 
BRAMbOR, T., W. R. CLARK, AND M. GOLDER (2006): “Understanding Interaction Models: Improving Empirical Analyses," Political Analysis, 14(1), 63-82.

BROUNEN, D., AND N. KOK (2011): “On the economics of energy labels in the housing market," Journal of Environmental Economics and Management, 62(2), 166-179.

BRYAN, T., AND P. Colwell (1982): “Housing Price Indices,” Research in Real Estate, 2, 57-84.

Burrows, E., AND M. WAllace (1999): Gotham: A History of New York City to 1898 (The History of New York City). Oxford University Press, New York, NY.

BUTLER, T., AND L. LEES (2006): "Super-gentrification in Barnsbury, London: globalization and gentrifying global elites at the neighbourhood level," Transactions of the Institute of British Geographers, 31(4), $467-487$.

CASE, B., AND J. Quigley (1991): "The Dynamics of Real Estate Prices," Review of Economics and Statistics, 79(1), 50-58.

CASE, K., AND R. SHILler (1987): "Prices of single family homes since 1970: New indexes for four cities," New England Economic Review, Sep, 46-56.

(1989): “The Efficiency of the Market for Single Family Homes," American Economic Review, 79(1), $125-137$.

CBRE (2010): “Locational Preferences of Central London Occupiers," Discussion paper, CBRE Research, London, UK.

CBRE (2011): “CBRE 4th Quarter 2011 Research Report,” Discussion paper, CBRE Research, London, UK.

Cerin, P., L. G. Hassel, And N. Semenova (2012): “Energy Performance and Housing Prices," UMEA University Mimeo.

Chau, K., S. WONG, C. YiU, AND H. Leung (2005): “Real Estate Price Indices in Hong Kong," Journal of Real Estate Literature, 13(3), 337-356.

Chegut, A., P. EichHoltz, AND N. KoK (2013): "Supply, Demand, and the Value of Green Buildings," Urban Studies, forthcoming.

Chegut, A., AND N. KOK (2011): “A global perspective on 'green' value in commercial property," in Sustainable Investment in Real Estate, ed. by P. McNamara, chap. 2, pp. 21-30. PEI, Sycamore Street London EC1Y 0SG United Kingdom.

Cheshire, P., AND C. Hilber (2008): “Office Space Supply Restrictions in Britain: The Political Economy of Market Revenge*," The Economic Journal, 118(529), F185-F221.

Clapp, J., AND C. Giaccotto (1992): “Repeat Sales Methodology for Price Trend Estimation: An Evaluation of Sample Selectivity," Journal of Real Estate Finance and Economics, 5(4), 357-374.

CLARK, G. L. (2002): “London in the European financial services industry: locational advantage and product complementarities," Journal of Economic Geography, 2(4), 433-453.

CoE, N., AND A. JONES (2010): The Economic Geography of the UK. Sage Publications, London, UK. 
Colwell, P. F., H. J. Munneke, AND J. W. TRefZger (1998): “Chicago's Office Market: Price Indices, Location and Time," Real Estate Economics, 26(1), 83-106.

Crawford, J., M. Dubin, S. Kaplan, P. Knops, R. Leigh, L. F. Matthiessen, J. Rios, M. Rudin, A. SPARKO, AND R. UnGER (2009): "Cost of Green in NYC," Discussion paper, Urban Green and U.S. Green Building Council, http://www.davislangdon.com/upload/images/publications/USA/ Cost_Study_NYC_10.02.09.pdf.

Debrezion, G., E. Pels, AND P. Rietveld (2007): “The Impact of Railway Stations on Residential and Commercial Property Value: A Meta-analysis," The Journal of Real Estate Finance and Economics, 35(2), $161-180$.

DeNG, Y., Z. LI, AND J. M. QuigLEY (2012): “Economic returns to energy-efficient investments in the housing market: Evidence from Singapore," Regional Science and Urban Economics, 42(3), 506-515.

Devaney, S., AND R. M. DiAZ (2011): “Transaction based indices for the UK commercial real estate market: an exploration using IPD transaction data," Journal of Property Research, 28(4), 269-289.

DiRECTIVE 2012 / 27 /EU (2012): “DIRECTIVE 2012/27/EU OF THE EUROPEAN PARLIAMENT AND OF THE COUNCIL of 25 October 2012 on energy efficiency, amending Directives 2009/125/EC and 2010/30/EU and repealing Directives 2004/8/EC and 2006/32/EC," Official Journal of the European Union, L(315), 1-55.

DORSEY, R., H. HU, W. MAYER, AND H. WANG (2010): “Hedonic versus repeat-sales housing price indexes for measuring the recent boom-bust cycle," Journal of Housing Economics, 19(2), 75-93.

EICHHoltz, P. (1997): “A long run house price index: the Herengracht index, 1628-1973," Real Estate Economics, 25(2), 175-192 1540-6229.

EichHoltz, P., N. KoK, AND J. Quigley (2010): “Doing Well by Doing Good? Green Office Buildings," American Economic Review, 100(5), 2492-2509.

EIchHoltz, P., N. KoK, AND J. Quigley (2011): “Who Rents Green? Ecological Responsiveness and Corporate Real Estate," PROGRAM ON HOUSING AND URBAN POLICY WORKING PAPER SERIES W09-004, UC Berkeley.

EichHoltz, P., N. KOK, AND J. M. Quigley (2013): “The economics of green building," Review of Economics and Statistics, 95(1), 50-63.

Emsley, M., D. Lowe, A. Duff, A. Harding, AND A. Hickson (2002): “Data modelling and the application of a neural network approach to the prediction of total construction costs," Construction Management \& Economics, 20(6), 465-472.

ENKvist, P., T. NAUCler, AND J. Rosander (2007): “A Cost Curve for Greenhouse Gas Reduction.," The McKinsey Quarterley, 1, 35-45.

FAbozzI, F. J., R. J. SHILler, AND R. S. TunARU (2010): “Property Derivatives for Managing European Real-Estate Risk," European Financial Management, 16(1), 8-26.

FARRell, J., AND G. SALONER (1985): “Standardization, compatibility, and innovation," The RAND Journal of Economics, pp. 70-83. 
FinANCIAl Stability BoARD AND International Monetary Fund (2010): The Financial Crisis and Information Gaps, Progress ReportIMF Staff and FSB Secretariat, Washington, DC.

Fisher, J., D. Gatzlaff, D. Geltner, AND D. HAurin (2003): “Controlling for the Impact of Variable Liquidity in Commercial Real Estate Price Indices," Real Estate Economics, 31(2), 269-303.

Fisher, J., D. GeltNer, AND H. POLLAKOWSKI (2007): “A Quarterly Transactions-based Index of Institutional Real Estate Investment Performance and Movements in Supply and Demand," The Journal of Real Estate Finance and Economics, 34(1), 5-33.

Fisher, J. D., D. M. GeltneR, AND R. B. WebB (1994): “Value indices of commercial real estate: a comparison of index construction methods," The journal of real estate finance and economics, 9(2), 137164 .

Fisher, L., AND W. BradshaW (2010): “Green Building and the Organization of Development," in 46th Annual AREUEA Conference Paper.

FrANCKE, M. (2010): “Repeat Sales Index for Thin Markets," The Journal of Real Estate Finance and Economics, 41(1), 24-52.

Fuerst, F., AND P. MCAllister (2011a): “Green noise or green value? Measuring the effects of environmental certification on office values," Real Estate Economics, 39(1), 45-69.

(2011b): “The impact of Energy Performance Certificates on the rental and capital values of commercial property assets," Energy Policy, 39(10), 6608-6614.

GATZlafF, D., AND D. GeltNeR (1998): “A transaction-based index of commercial property and its comparison to the NCREIF index," Real Estate Finance, Spring(15), 7-22.

Geltner, D. M., AND S. BOKHARI (2008): “A Technical Note on Index Methodology Enhancement by Two-stage Regression Estimation," Supplement 1 to: A Set of Indexes for Trading Commercial Real Estate Based on the Real Capital Analytics Transaction Prices Database.

GeltNer, D. M., AND J. FisheR (2007): "Pricing and index considerations in commercial real estate derivatives," The Journal of Portfolio Management, 33(5), 99-118.

Geltner, D. M., N. G. Miller, J. Clayton, AND P. EichHoltz (2013): Commerical Real Estate: Analysis and Investments. OnCourseLearning, Mason (OH).

GlAeser, E. L. (1998): “Are cities dying?,” The Journal of Economic Perspectives, 12(2), 139-160.

(2013): "A Nation of Gamblers: Real Estate Speculation and American History," Discussion Paper 18825, NBER Working Paper.

GoetZmanN, W. (1992): "The accuracy of real estate indices: Repeat sale estimators," The Journal of Real Estate Finance and Economics, 5(1), 5-53.

Hendershott, P., C. M. Lizieri, AND B. MACGregor (2010): “Asymmetric Adjustment in the City of London Office Market," The Journal of Real Estate Finance and Economics, 41(1), 80-101, 10.1007/s11146009-9199-6.

Hendershott, P. H., C. M. Lizieri, AND G. A. Matysiak (1999): “The Workings of the London Office Market," Real Estate Economics, 27(2), 365-387. 
Henderson, R., AND K. CLARK (1990): “Architectural innovation: The reconfiguration of existing product technologies and the failure of established firms," Administrative science quarterly, 35(1), 9-30.

Hilbert, M., AND P. LÓPEZ (2011): “The world's technological capacity to store, communicate, and compute information," Science, 332(6025), 60-65.

Hobhouse, H. (ed.) (1994): "The West India Docks: Introduction," Survey of London: volumes 43 and 44: Poplar, Blackwall and Isle of Dogs. British History Online, http://www.britishhistory.ac.uk/report.aspx?compid=46493.

Holly, S., M. HAshem Pesaran, AND T. YAmagata (2011): “The spatial and temporal diffusion of house prices in the UK," Journal of Urban Economics, 69(1), 2-23.

HoOver, E. M., AND R. VERnON (1962): Anatomy of a Metropolis: The changing distribution of people and jobs within the New York metropolitan region. Anchor/Doubleday, New York.

Hoyt, H. (1933): One Hundred Years of Land Values in Chicago: The Relationship of the Growth of Chicago to the Rise in Its Land Values, 1830-i 933. University of Chicago Press, Chicago.

(1960): “Changing patterns of land values," Land Economics, XXXVI(May), 109-117.

HYLAND, M., R. LyONS, AND S. LyONS (2012): “The value of domestic building energy efficiencyevidence from Ireland," University of Oxford Department of Economics Working Paper, 614.

Jones LANG LASALle (2011): “The Performance Measurement Challenge,” in ECOBUILD, 2011 London.

KATS, G. (2003): “The Costs and Financial Benefits of Green Buildings," Discussion paper, A Report to California's Sustainable Building Task Force, http://www.calrecycle.ca.gov/greenbuilding/ design/costbenefit/report.pdf.

KATZ, M. L., AND C. ShapiRo (1985): “Network externalities, competition, and compatibility," The American Economic Review, 75(3), 424-440.

KNOX-HAYES, J. (2009): “The developing carbon financial service industry: expertise, adaptation and complementarity in London and New York," Journal of Economic Geography, 9(6), 749-777.

KOK, N., R. BAUER, AND P. EICHHOltz (2011): “GRESB Research Report,” Discussion paper, GRESB, Maastricht, the Netherlands.

KOK, N., AND M. JENNEN (2012): “The impact of energy labels and accessibility on office rents," Energy Policy, forthcoming.

KOK, N., M. MCGRAW, AND J. M. Quigley (2011): “The Diffusion of Energy Efficiency in Building," American Economic Review, 101(3), 77-82.

LANGDON, D. (2004): “Costing Green: A Comprehensive Cost Database and Budgeting Methodology," Lisa Fay Matthiesen and Peter Morris. July.

LEE, S., C. LIZIERI, AND C. WARD (2000): “The time series performance of UK real estate indices," RERI report, 31(2), 140-387.

LIZIERI, C., A. BAUM, AND P. SCOTT (2000): “Ownership, occupation and risk: a view of the City of London office market," Urban Studies, 37(7), 1109-1129. 
LOWE, D., M. EMSLEY, AND A. HARDiNG (2006): "Predicting construction cost using multiple regression techniques," Journal of construction engineering and management, 132(7), 750-758.

MALECKI, E. (2002): “The Economic Geography of the Internet's Infrastructure*," Economic geography, $78(4), 399-424$.

Mapp, C., M. Nobe, AND B. Dunbar (2011): "The Cost of LEED—An Analysis of the Construction Costs of LEED and Non-LEED Banks," The Journal of Sustainable Real Estate, 3(1), 254-273.

MARGOLIS, J. D., AND J. P. WALSH (2003): "Misery Loves Companies: Rethinking Social Initiatives by Business," Administrative Science Quarterly, 48(2), 268-305.

MCCAFFer, R., M. MCCAFFrey, AND A. Thorpe (1984): "Predicting the tender price of buildings during early design: method and validation," Journal of the Operational Research Society, pp. 415-424.

MeErman, M. (2011): “Money \& Speed: Inside the Black Box," Documentary film by Tegenlicht (VPRO, Netherlands).

Miles, M., D. Hartzell, D. GuilKey, AND D. Shears (1991): “A transactions-based real estate index: is it possible?," Journal of Property Research, 8(3), 203-217.

Miller, N., J. Spivey, AND A. FlorAnCE (2008): “Does green pay off?,” Journal of Real Estate Portfolio Management, 14(4), 385-400.

Nelson, A., AND A. RAKAu (2010): “Green Buildings: A Niche Becomes Mainstream,” Discussion paper, Deutsche Bank Research, Frankfurt, Germany.

Philipp, T., K. Fagan, AND N. Levidy (2012): “US CMBS: Moody's to Publish State-of-the-Art Commercial Property Price Indices," Special report, Moody's Investors Service.

PietZ, J. (2012): “How Chicago became of the nation's most digital cities," Crain's Chicago Business.

Quigley, J. M. (1995): “A Simple Hybrid Model for Estimating Real Estate Price Indexes," Journal of Housing Economics, 4(1), 1-12.

RaO, D. P., C. J. O’Donnell, G. E. BAtTese, AND T. J. Coelli (2005): An introduction to efficiency and productivity analysis. Springer.

Rosen, S. (1974): "Hedonic Prices and Implicit Markets: Product Differentiation in Pure Competition," Journal of Political Economy, 82(1), 34-55.

Rosenbaum, P. R., AND D. B. Rubin (1983): "The central role of the propensity score in observational studies for causal effects," Biometrika, 70(1), 41-55.

Runeson, G. (2010): "Modern Construction Economics: Theory and Application," in Modern Construction Economics: New Developments in Theory, ed. by G. de Valence. Taylor \& Francis.

SASSEN, S. (2001): The Global City: New York, London, Tokyo. Princeton University Press, 2 edn.

SHORTO, R. (2005): The Island at the Center of the World: The Epic Story of Dutch Manhattan and the Forgotten Colony That Shaped America. Random House, New York. 
Simcoe, T., AND M. W. Toffel (2012): "Public Procurement and the Private Supply of Green Buildings," Discussion paper, National Bureau of Economic Research.

SLAUGHTER, E. S. (1998): “Models of construction innovation," Journal of Construction Engineering and management, 124(3), 226-231.

SLAVIN, K. (2011): “How algorithms shape our world," TED Global, http://www.ted.com/talks/ kevin_slavin_how_algorithms_shape_our_world.html, last accessed March 8, 2013.

TATARI, O., AND M. KUCUKVAR (2011): “Cost premium prediction of certified green buildings: A neural network approach," Building and Environment, 46(5), 1081 - 1086.

TIROLE, J. (1988): The Theory of Industrial Organization. MIT press, Cambridge.

Turban, D. B., AND D. W. Greening (1997): “Corporate Social Performance And Organizational Attractiveness To Prospective Employees," Academy of Management Journal, 40(3), 658-672.

US Environmental Protection Agency Energy Star Program (2007): “Report to Congress on Server and Data Center Energy Efficiency Public Law 109-431," Discussion paper, U.S. Environmental Protection Agency, http://www.energystar.gov/ia/partners/prod_development/downloads/ EPA_Datacenter_Report_Congress_Final1.pdf?2efe-0457.

WheAton, W., R. TORTO, AND P. Evans (1997): “The Cyclic Behavior of the Greater London Office Market," The Journal of Real Estate Finance and Economics, 15(1), 77-92.

Wheaton, W. C., M. S. Baranski, And C. A. Templeton (2009): "100 Years of Commercial Real Estate Prices in Manhattan," Real Estate Economics, 37(1), 69-83.

Wheaton, W. C., AND W. E. SimOnton (2007): "The secular and cyclic behavior of "True" construction costs," Journal of Real Estate Research, 29(1), 1-26.

White, H. (1980): “A Heteroskedasticity-Consistent Covariance Matrix Estimator and a Direct Test for Heteroskedasticity," Econometrica, 48(4), 817-38.

Yoshida, J., AND A. SugiURA (2010): "Which “Greenness" is Valued? Evidence from Green Condominiums in Tokyo," MPRA Paper 23124, University Library of Munich, Germany.

Yoshida, J., AND A. Sugiura (2011): “Which Greenness is Valued? Evidence From Green Condominiums in Tokyo," Discussion paper, 46th Annual AREUEA Conference Paper, Denver.

Zahedien, N. (2010): The Capital and the Colonies: London and the Atlantic Economy 1660-1700. Cambridge University Press, Cambridge, UK, 1st edn.

ZHANG, G.-Q., G.-Q. ZHANG, Q.-F. YANG, S.-Q. CHENG, AND T. ZHOU (2008): “Evolution of the Internet and its cores," New Journal of Physics, 10(12), 123027. 



\section{English summary}

This thesis investigates the financial performance of three types of innovations in commercial real estate, driven by different demands in the economies of contemporary London and New York City.

The first innovation this thesis explores is an innovation in market information. Within the academic literature and the commercial real estate sector, there is a demand for benchmarking techniques to assess the financial performance over time of properties. Chapter two of this thesis contributes by applying the repeat sales construction technique espoused by Bokhari and Geltner (2012) for the London commercial property market. This is important, because up until recently transaction data on commercial property in London did not enable this type of analysis. To assess the performance of the innovation, we contrast the repeat sales index performance with that of traditional appraisal-based techniques. The repeat sales index for London outperforms the appraisal-based based index on the key metric of turning points. The peaks and troughs in the market are reflected earlier by the repeat sales index. Moreover, this chapter contributes to the growing literature on index construction by looking at recent performance trends in London and New York City. Interestingly, this is the first time such a comparison could be made in the academic literature. The results suggest that London's commercial property market peaked and crashed with the financial crisis before that of New York City. The main lesson from this comparison is that there is no single correct real estate index. Each type of index serves its purpose in the market place.

The second innovation this thesis explores is green commercial buildings in the London office market. London is a relatively early adopter of energy-efficiency and sustainability in commercial property. This is due to an early establishment of the BRE group, who develop methods for measuring energy-efficiency and sustainability. These methods are now known as BREEAM. Chapter three of this thesis looks at the financial performance of BREEAM-certified properties in London and the role of increasing competition from the growth of these types of properties. The results suggest that BREEAM-certified buildings transact and rent for more than their non-certified peers. Moreover, these buildings are growing in numbers. This has a positive impact on neighborhood values in general, leading to a gentrification effect. However, as 
these buildings begin to cluster, their relative financial performance begins to decrease. Ultimately, this competition effect of more green buildings takes away the value premium (rents) of green buildings. Over time, as the supply of green buildings increases further, innovation or quality improvements on these buildings will require more and more attention to energy-efficiency and sustainability.

The third innovation this thesis explores is data centers. Data centers are the corner stones of a nascent building innovation that serves the rising digital demand of the computing age. These buildings are a new type of warehouse that stores the vast amounts of digital information accumulating in the real economy. However, these building are unlike traditional commercial real estate infrastructures. They do not hold people, but mainly computing hardware like servers. They constitute an innovation in construction and commercial real estate, a so-called 'architectural innovation'. Chapter five of this thesis investigates the financial performance of this building product, as well as the fiber-optic connectivity necessary for becoming a data center. The results suggest that relative to traditional commercial real estate infrastructures, there is value in being linked to high-speed fiber-optic connectivity, but there is also value in being a data center: a place where fiber-optic connectivity agglomerates.

Lastly, this thesis explores the cost of innovation through green building construction. By connecting BREEAM-certified buildings to a database of building construction costs, chapter four of this thesis aims to investigate the building costs of green buildings relative to their conventional peers. The results of the analysis suggest that, for this sample, green buildings do not necessarily cost more on average. However, there are some construction components like building design or specific building treatments like electrical, heating and cooling systems that do cost more. Nevertheless, on aggregate this increase is economically marginal and does not suggest that the cost of green buildings is a deterrent for the uptake and diffusion of more energy-efficient and sustainable construction.

This thesis contributes to our understanding of the creation and valuation of innovations in the built environment, by focusing on the financial performance of innovations in commercial real estate. As properties go through a natural cycle of value and move through the stages of economic, functional and physical obsolescence, there are opportunities for innovators in commercial real estate to capitalize on a site's economic potential. Neighborhoods and cities undergo phases of growth and decline in the long run, and properties within those cities have their own lifecycle too. Some of those dynamics of growth and decline may be explained by the supply and demand of innovative new products. After all, the pecuniary rewards to innovation serve as the carrots to investors. This thesis explores whether those carrots really exist, and to what extent they are different across innovations and over time.

For future research, the key contribution of this thesis may lay in outlining the in- 
centives for diffusion for innovators in the built environment. By looking at the trends and value developments of innovative properties in the modern era, the understanding of value dynamics over the property cycle may be enhanced. Thus, the more innovations we can document, track and map trends for, the more we can understand the pricing and diffusion patterns of innovation in the built environment. 



\section{Nederlandse samenvatting}

In dit proefschrift bestudeer ik de financiële prestaties van drie soorten innovaties in commercieel vastgoed, gedreven door de economische behoeften van het huidige Londen en New York.

The eerste innovatie die in dit proefschrift onderzocht wordt, is een innovatie in markt informatie. Binnen de academische literatuur en de commerciële vastgoedsector is een toenemende vraag naar vergelijkende statistieken voor de financiële prestaties van vastgoed. Hoofdstuk twee van dit proefschrift komt tegemoet aan die vraag door een reprise verkoop techniek ontwikkeld door Bokhari and Geltner (2012) toe te passen op de commerciële vastgoed market van Londen. Een dergelijke toepassing is belangrijk, omdat tot voor kort geen cijfers voor een vergelijkende analyse op basis van transactie data beschikbaar waren. Om te onderzoeken hoe belangrijk een dergelijke innovatie is, vergelijken we in het hoofdstuk de reprise verkoop index met een traditionele indexen, gebaseerd op taxatie waardes. Voor Londen is de reprise index is vooral beter dan een traditionele index wanneer het gaat om zogeheten keerpunten: momenten waarop de markt een piek of dal bereikt. In dit hoofdstuk vergelijken we tevens voor het eerst de commerciële vastgoed ontwikkelingen in Londen en New York. Onze resultaten laten zien dat de markt in Londen piekte en ineenstortte voordat hetzelfde in New York gebeurde. De voornaamste les die in dit hoofdstuk wordt getrokken, is verschillende vastgoedindexen een variëteit aan informatie over ontwikkelingen in de markt weergeven.

De tweede innovatie in dit proefschrift betreft groen commercieel vastgoed in Londen. In Londen heeft men al vroeg energie efficiënt en duurzaam vastgoed ontwikkelt. Met de oprichting van de BRE groep ontstonden door de markt overgenomen methodes voor het meten van energie efficiëntie en duurzaamheid, nu bekend als BREEAM. In hoofdstuk drie van dit proefschrift kijken we naar de financiële prestaties van door BREEAM gecertificeerd vastgoed in Londen, en de invloed van een sterkte toename van dit type vastgoed. De resultaten van onze analyse laten zien dat groen vastgoed een positief gentrificatie effect, resulterend in een toename in de waarde van het vastgoed. Echter, zodra er in bepaalde buurten clusters van dit type gebouwen ontstaan, daalt de vergroeningsbonus. Zolang deze trend doorgaat is een verder innovatie impuls nodig om deze gebouwen te laten blijven renderen. 
De derde innovatie die in dit proefschrift geanalyseerd wordt is een data center. Data centers zijn de hoekstenen van een ontluikende innovatie in vastgoed die voldoet aan de toenemende digitale vraag in onze gecomputeriseerde maatschappij. Deze gebouwen zijn een nieuw type opslagplaatsen, waar de gigantische hoeveelheid digitale informatie die onze reële economie ondersteunt wordt bewaard. Toch zijn deze gebouwen erg verschillend van hun meer traditionele tegenhangers: in plaats van mensen, bevatten ze vooral servers. Ze vormen innovatie in de bouw en commercieel vastgoed, een zogeheten 'architectonische innovatie. Hoofdstuk vijf van dit proefschrift onderzoekt de financiële prestaties van dit type vastgoed en het belang van de snelle bekabeling die vereist is voor het goed functioneren van data centers. In vergelijking met traditioneel commercieel vastgoed, zorgt een snelle verbinding met de digitale snelweg voor een premie, evenals de innovatie tot data center.

Tot slot onderzoekt dit proefschrift de kosten van innovatie, middels een analyse van de constructiekosten van groene gebouwen. Door BREEAM gecertificeerde gebouwen te koppelen aan een database met constructiekosten, slagen we er in hoofdstuk vier van dit proefschrift in om de kosten van een groen gebouw te vergelijken met die van een traditioneel gebouw. De resultaten van onze analyse suggereren dat de groene gebouwen in onze dataset niet duurder zijn om te bouwen dan hun traditionele evenknieën, hoewel sommige elementen, zoals het ontwerp en de klimaatbeheersing, duurder zijn. Deze analyse suggereert dan ook dat de constructiekosten van groene gebouwen een verdere ontwikkeling van de markt voor energie efficiënt en duurzaam vastgoed niet in de weg zal staan. Dit proefschrift draagt bij aan ons begrip van de creatie en waardering van innovaties in de gebouwde omgeving, middels een analyse van de financiële prestaties van innovaties in commercieel vastgoed. Tegen het einde van de levenscyclus van gebouwen zijn deze vak economisch, functioneel en fysiek sterk verouderd. Op dat moment zijn er mogelijkheden voor innovators in commercieel vastgoed om een nieuw economisch potentieel te realiseren, eventueel resulteren in een nieuwe levenscyclus. De dynamiek van groei en afname in steden is dus deels het gevolg van de vraag naar en het aanbod van innovatieve gebouwen. De financiële rendementen op deze gebouwen zijn de beloning die innovators aantrekt. Dit proefschrift onderzoekt of die beloning werkelijk bestaat, en in welke mate zijn verschilt naarmate de karakteristieken van innovaties verschillen.

Dit proefschrift legt hiermee de basis voor toekomstig onderzoek naar de prikkels voor innovators in vastgoed. Door een beter begrip van de waardering en dynamiek van innovatieve gebouwen, kunnen we de vastgoed cyclus in moderne steden beter begrijpen. Des te meer innovaties we analyseren, volgen en in kaart brengen, des te beter zijn we in staat om de prijsontwikkeling en verspreiding van vastgoedinnovaties te begrijpen. 


\section{Curriculum Vitae}

Andrea Chegut was born in Boonton, NJ. She earned her BS and BA in Economics and Philosophy, respectively, from the College of Charleston, Charleston SC, US. During this period, Andrea studied for a semester at Georgetown University and did research at the Mercatus Center. After graduation, Andrea spent three years in the US capital markets with Sherman Capital Markets. In 2009, she earned her MSc in Economics and Law from Utrecht University focusing on finance and sustainability.

In 2009, Andrea joined the Finance Department of Maastricht University as a PhD Candidate. As a teacher, she was the Academic Advisor to students for the Cornell International Real Estate Case Competition, and taught courses on Real Estate Finance and Economics, Finance, Entrepreneurial Finance and Banking. In addition to her dissertation, Andrea managed the finance component of the EU 7th Framework Project, Demonstration of Energy Efficiency through Retrofitting of Buildings - BEEM-Up. This four-year project will result in 332 retrofitted social housing units in France, Sweden and the Netherlands.

In 2013, Andrea joined the MIT Center for Real Estate as a Visiting PhD Candidate under the tutelage of Professor David Geltner. While there she conducted research, took courses and presented her research at seminars for the SENSEable City Lab, MIT Center for Real Estate and for various MIT industry partners.

Andrea's research papers have been published in the Journal of Real Estate Finance and Economics, Urban Studies and Journal for Sustainable Development. She has presented her academic research at the Allied Social Sciences Association (ASSA) meetings, the European Central Bank, Columbia University, University of Florida, American Real Estate and Urban Economics Association meetings, ReCapNet meetings, and Principal for Responsible Investing meetings.

Andrea Chegut is a research affiliate of the MIT Center for Real Estate, the European Center for Corporate Engagement, the European Property Research Institute, Social Investment Research Platform and the American Real Estate and Urban Economics Association.

Financial support for this research was provided by the European Center for Corporate Engagement. 


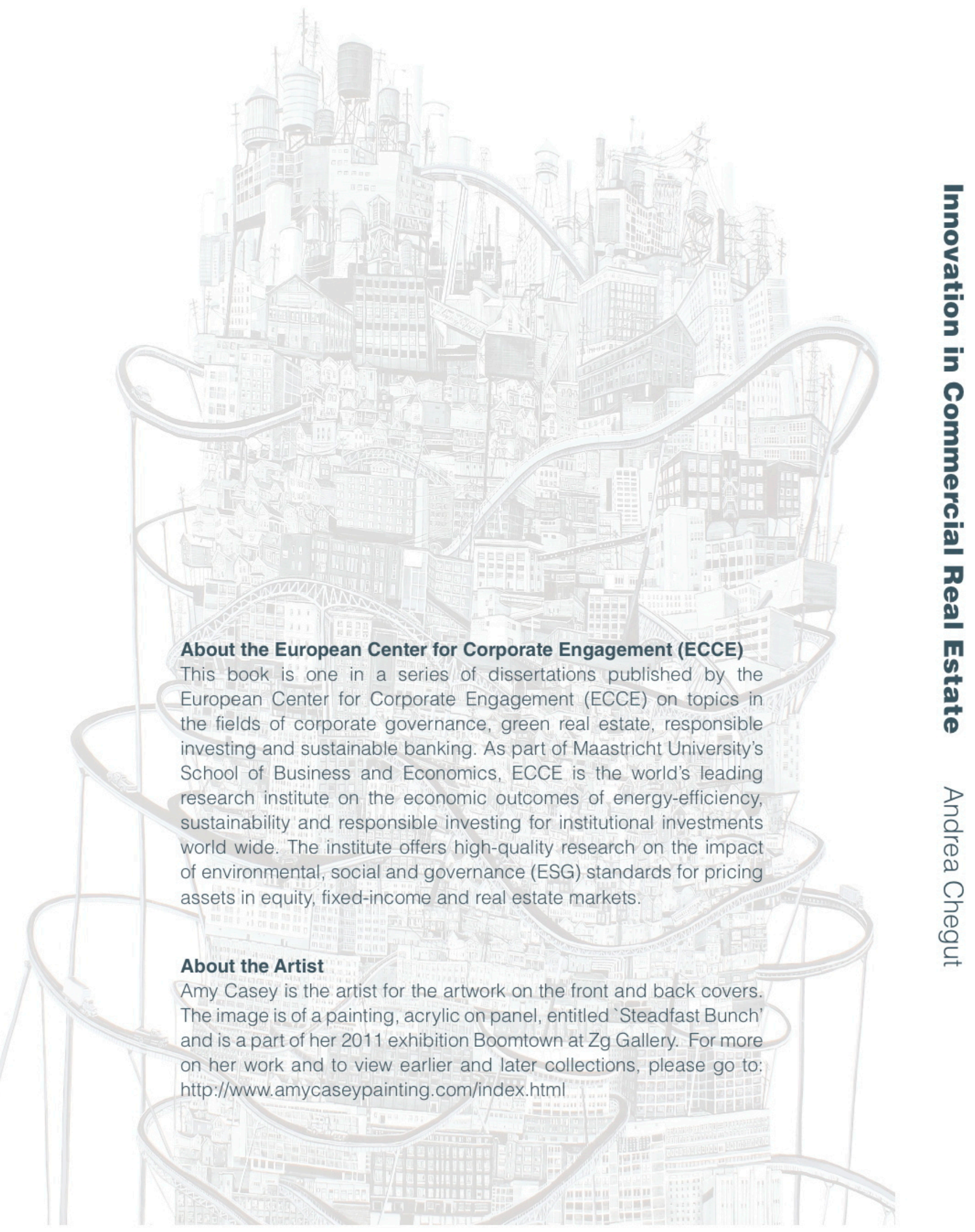

